\title{
POLITICS OF ENVIRONMENTAL MANAGEMENT AND POLICY: A CASE STUDY OF GHANA
}

\author{
by \\ Vivienne Torpey
}

A Thesis Submitted to Faculty of Graduate Studies and Postdoctoral Affairs in partial fulfillment of the requirement for the degree of

Doctor of Philosophy

In

Political Science

Carleton University

Ottawa, Canada

(C) 2012

Vivienne Torpey 
Library and Archives

Canada

Published Heritage

Branch

395 Wellington Street

Ottawa ON K1A ON4

Canada
Bibliothèque et

Archives Canada

Direction du

Patrimoine de l'édition

395 , rue Wellington

Ottawa ON K1A ON4

Canada
Your file Votre référence

ISBN: 978-0-494-89309-8

Our file Notre référence

ISBN: 978-0-494-89309-8

\section{NOTICE:}

The author has granted a nonexclusive license allowing Library and Archives Canada to reproduce, publish, archive, preserve, conserve, communicate to the public by telecommunication or on the Internet, loan, distrbute and sell theses worldwide, for commercial or noncommercial purposes, in microform, paper, electronic and/or any other formats.

The author retains copyright ownership and moral rights in this thesis. Neither the thesis nor substantial extracts from it may be printed or otherwise reproduced without the author's permission.
AVIS:

L'auteur a accordé une licence non exclusive permettant à la Bibliothèque et Archives Canada de reproduire, publier, archiver, sauvegarder, conserver, transmettre au public par télécommunication ou par l'Internet, prêter, distribuer et vendre des thèses partout dans le monde, à des fins commerciales ou autres, sur support microforme, papier, électronique et/ou autres formats.

L'auteur conserve la propriété du droit d'auteur et des droits moraux qui protege cette thèse. $\mathrm{Ni}$ la thèse ni des extraits substantiels de celle-ci ne doivent être imprimés ou autrement reproduits sans son autorisation.
In compliance with the Canadian Privacy Act some supporting forms may have been removed from this thesis.

While these forms may be included in the document page count, their removal does not represent any loss of content from the thesis.
Conformément à la loi canadienne sur la protection de la vie privée, quelques formulaires secondaires ont été enlevés de cette thèse.

Bien que ces formulaires aient inclus dans la pagination, il n'y aura aucun contenu manquant. 


\begin{abstract}
Environmental problems abound in today's world, and few societies remain unaffected by it. While not absent in developed countries, these problems present themselves in much greater dimensions in developing parts of the world including sub-Saharan Africa. Although the rapid deterioration of the environment is alarming, it has helped open up for debate, questions surrounding the efficacy (or otherwise) of structures, systems and actors traditionally associated with the management and protection of the environment. There is, in particular, increasing emphasis being drawn to the direct (intended) and indirect (unintended) impacts of environmental management efforts on the part of key actors and stakeholders in any given context. This makes even more pertinent, the need for research to understand how these actors within society; exercise strategic choices that can impact the distribution and attainment of outcomes - in this case, environmental goals. To this effect, this study explores the role of political actors - specifically elites in environmental management. Using evidentiary support from the specific case of Ghana, a developing country with grave environmental problems that have portentous implications on the social-economic and general well-being of its citizenry, it argues that the governing elite's perception of the environmental problem continues to be one that lacks urgency and immediacy. This in turn has given way to the adoption of a top-down, centralized and exclusionary decision-making and problem-solving approach towards the management of Ghana's environmental problems. What this implies is that there is little or no room for any meaningful contribution or participation by a wider section of the
\end{abstract}


general populace. This is a grave cause for concern, given that environmental problems are wide-encompassing in nature and, as such, necessitate all-inclusive and participatory approaches. Against this background, questions can therefore be raised as to whether Ghana is really a model of success in good governance practices, democratic reform, socio-economic and political progress within the sub-region as asserted by some observers, particularly within the international community. 


\section{ACKNOWLEDGEMENTS}

l owe a debt of gratitude to a number of individuals for the completion of my work and it is my hope that the words expressed here may in some way help convey that gratitude. My thanks and appreciation goes to members of my thesis committee, Dr. Daniel OsabuKle, Dr Blair Rutherford and Dr Scott Bennett who guided, supported and encouraged me through this study. I appreciate their immense contribution and assistance. A special thank you to my thesis supervisor, Dr Daniel Osabu-Kle, who not only believed in me, but also encouraged me to believe that this study was worthwhile doing. Without his insightful intellectual contributions, encouragement and support, this study would not have been successfully completed. I also wish to express my deepest gratitude to my loving husband, Kofi for his spiritual, emotional and financial support and his constant "You have come this far, the worst is over, you have to finish this" and his encouragement that saw me through to the end of the study. I am grateful for my adorable daughter, Adjoa Adoma who although born in the very latter stages of my work, became a continuous source of inspiration for me. I also wish to thank my mother, Victoria and all my siblings Nana Kwasi, Tina, Cynthia and Paa, all of whom pointed out to me at various stages in the study that I had the innate ability to do successfully

complete it. My late father, John Antwi-Agyei who always believed in me, would also have been so proud of my accomplishment.

Finally and above all, a big thank you to the Almighty God for giving me the strength, energy, health, spiritual well-being and wisdom to complete this work. To Him be the glory. 


\section{TABLE OF CONTENTS}

\section{Contents}

ABSTRACT

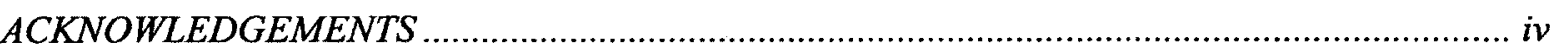

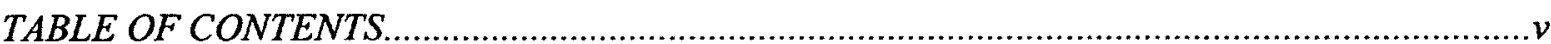

LIST OF FIGURES

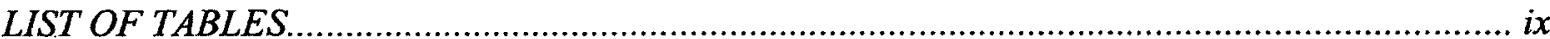

Chapter ONE (1): ENVIRONMENTAL (Mis?) MANAGEMENT IN GHANA......................... 1

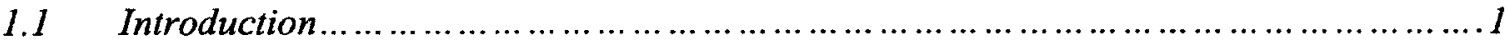

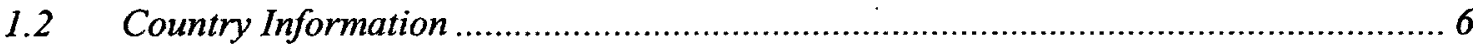

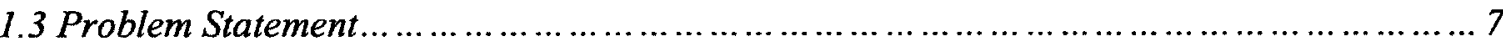

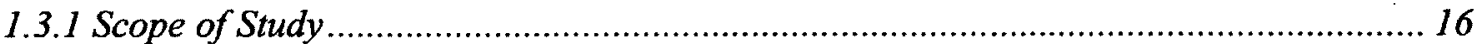

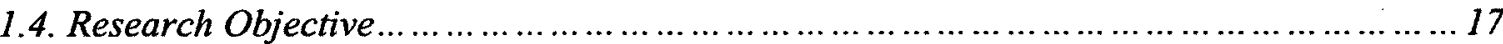

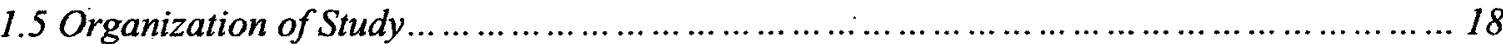

1.6 Effective Leadership: A Necessary precondition for Environmental management ...........19

1.6.1 Modern and Traditional elites in Ghana ..................................................................... 23

1.7. Perception of the environmental problem in Ghana ...................................... 30

1.8. The State of the Environment in Ghana ....................................................................... 36

1.8.1. Environmental Management Approaches .............................................................. 45

1.8.2. The Structure of Environmental Management in Ghana ........................................... 53

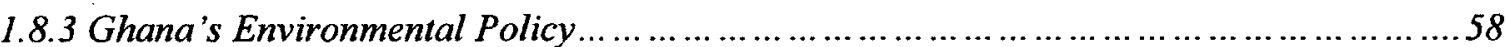

1.9 Summing up

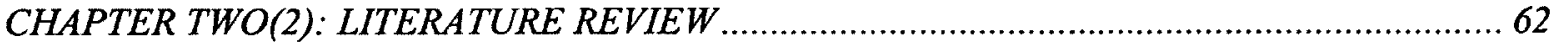

2.0. Power Distribution and Democracy: The Theoretical Debate ........................... 62

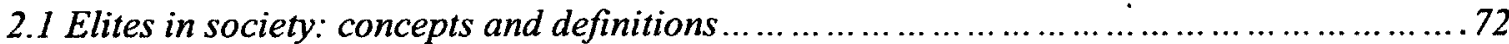

2.2. The Scope of Elite power: Challenges for Environmental management .................. 81

2.3. Conceptualizing Elite Governance: Propositions and Theories .........................83

2.4. Environmental Policy making in Ghana: Through the Elite Framework of analysis........92

2.5 The International Power Elite and Environmental Planning in Ghana ..................95

2.6. Explaining Elite Governance Failure: A historical perspective on Authoritative Management. 
2.7 Summing up .99

CHAPTER THREE (3): CITIZEN INVOLVEMENT:EVOLVING TRENDS IN ENVIRONMENTAL GOVERNANCE 103

3.0 Managing Public Business with the 'Public'........................................................... 103

3.1 Lessons from the Canadian Case .............................................................................. 106

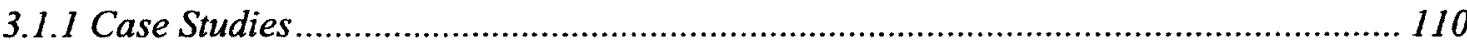

3.2 Civic Engagement and Participation and Environmental Protection in Ghana .......... 118

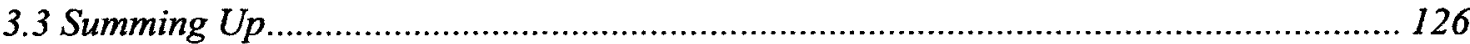

CHAPTER FOUR (4): THE METHODOLOGICAL APPROACH .................................... 128

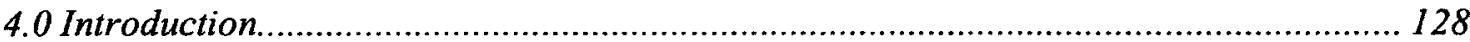

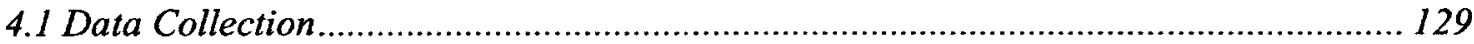

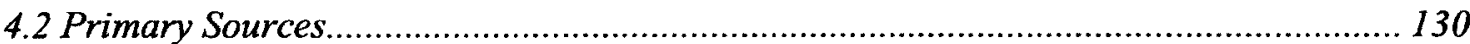

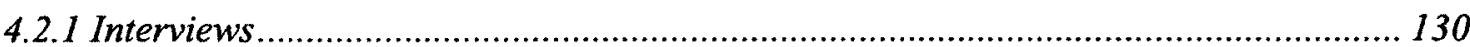

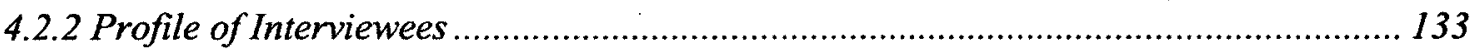

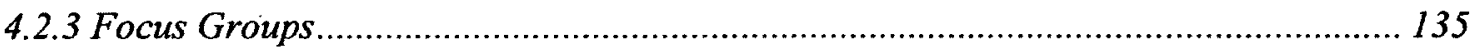

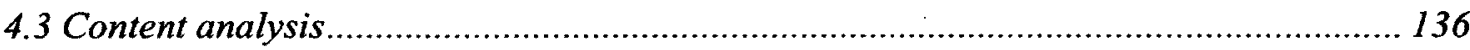

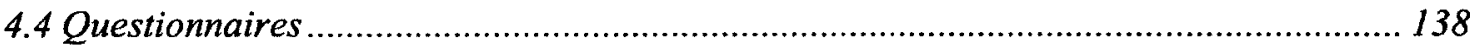

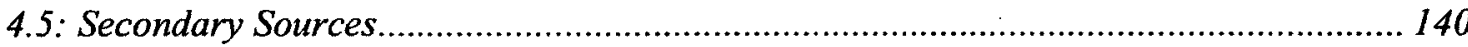

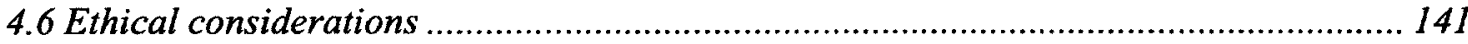

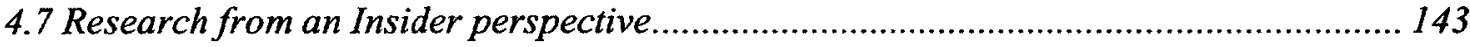

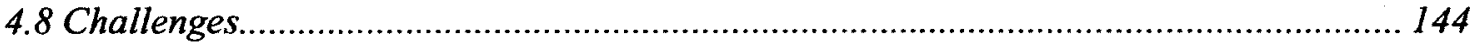

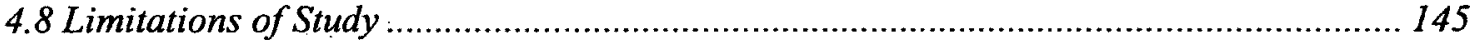

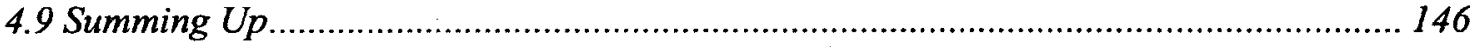

CHAPTER FIVE (5): DATA ANALYSIS AND INTERPRETATION ........................................ 147

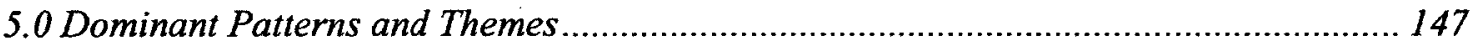

5.1 Centralization and Formalization in Environmental Decision-making ....................... 147

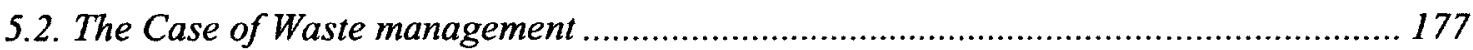

5.3 Environmental (Mis?)Communication in Ghana: the role of elites............................... 192

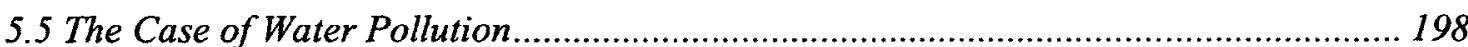

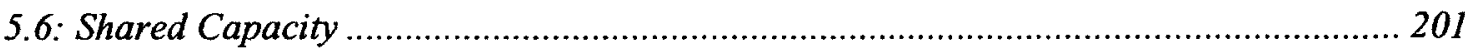

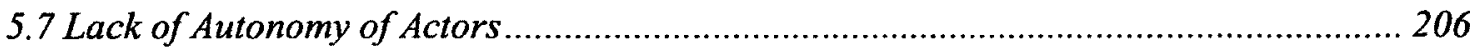

5.8 Citizen attitudes and responses to environmental problems ...................................... 219

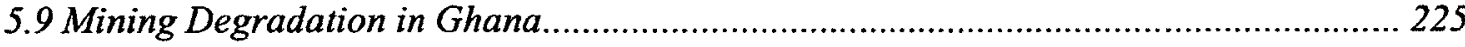


5.10: Perception of environmental issues vis-à-vis issues of economic development.

5.11. Summing Up

CHAPTER SLX (6) SUMMARY, CONCLUSION S AND RECOMMENDATIONS..................... 236

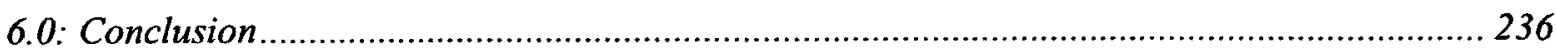

6.1 Restatement of Thesis and Research Questions ...................................................... 237

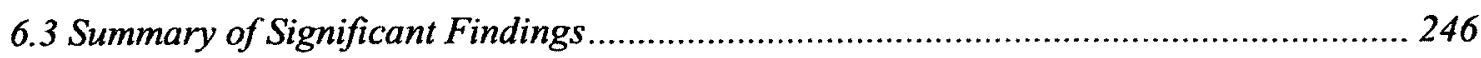

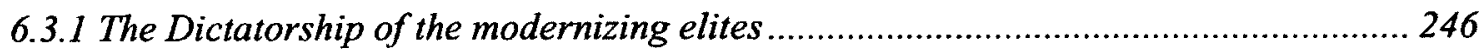

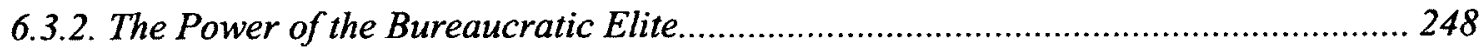

6.3.3 The State as the dominant actor in environmental governance arrangements ......... 249

6.3.4 The disengagement of Non-state Actors..................................................................... 252

6.4 Recommendations: Bridging the Gap for Sustainable Environmental

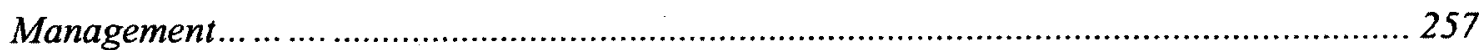

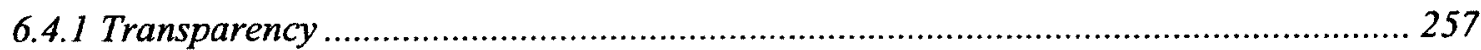

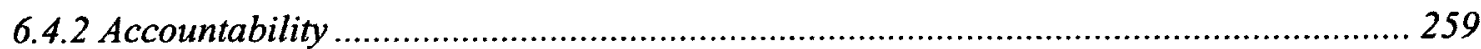

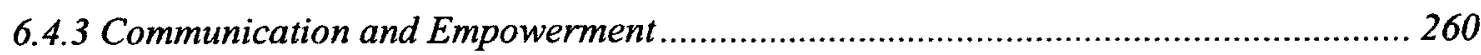

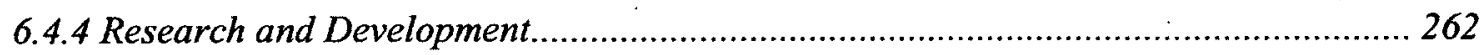

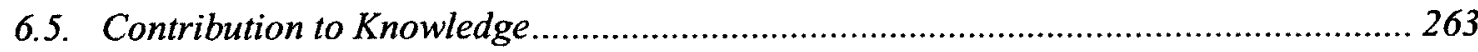

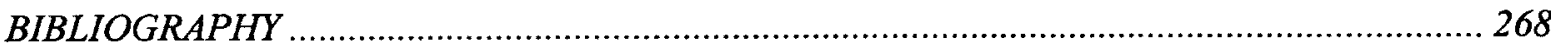

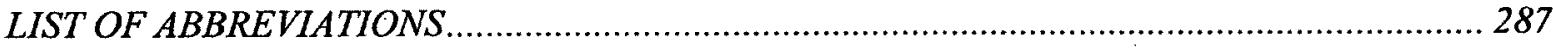

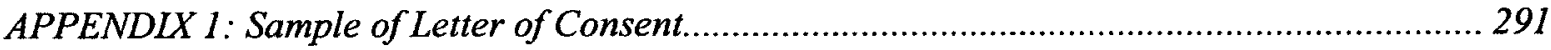

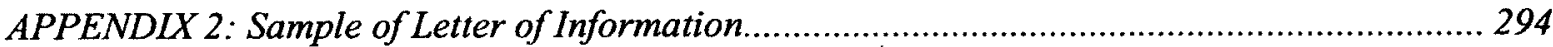

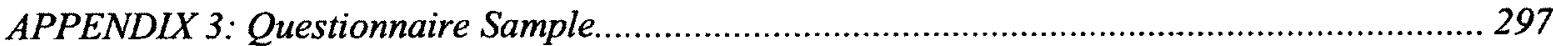

APPENDIX 4: Interview and Focus Group Discussion Guide ............................................... 300 


\section{LIST OF FIGURES}

Figure $1:$ Map of Ghana, showing administrative regions............................................

Figure 2: Institutional Structure of Environmental Management in Ghana ..................58

Figure 3:Environmental Policy and Implementing Institutions.........................................93

Figure 4:Arnstein's ladder of citizen participation ....................................................... 108

Figure 5:Respondents' perception of government performance on waste management -

Nima.

Figure 6:Respondents' perception of level of public participation in policy making regarding waste management -Nima

Figure 7:Respondents' perception of overall government performance on the environment- Nima

Figure 8: Respondents' perception of level of public participation in policy making and implementation regarding waste management - Ashiaman Figure 9: Respondents' response as to whether the environmental problem was perceived as a national priority by government- Ashiaman

Figure 10: Respondents' knowledge or awareness about governmental policies or programs on the environment

Figure 11: Generalised process flow sheet of the EIA process .....................................212

Figure 12: Respondents' perception of the environmental problem. .221

Figure 13: Respondents' responsibility and commitment to finding solutions for these problems. 


\section{LIST OF TABLES}

Table 1: Ghana's Post-Colonial Governments (1957-To Date) ................................... 12

Table 2: Ghana's Environmental Problems: Sources and Effects ............................... 42

Table 3: Demographic characteristics of respondents ........................................... 139

Table 4 : Respondents' perception of government performance on waste management-

Nima

Table 5: Respondents' perception of level of public participation in policy making regarding waste management -Nima

Table 6: Respondents' perception of overall government performance on the environment

-Nima 186

Table 7: Respondents' perception of level of public participation in policy making and implementation regarding waste management - Ashiaman....

Table 8: Respondents' response as to whether the environmental problem was perceived

as a national priority by government -Ashiaman

Table 9: Sources of Environmental data in Ghana 193

Table 10: Environmental effects of major factories in the industrial area of Accra-Tema

Table 11: Citizens' ranking of environmental problems in Ghana 220 


\section{Chapter ONE (1): ENVIRONMENTAL (Mis?) MANAGEMENT IN GHANA}

\subsection{Introduction}

Environmental problems such as air and water pollution, deforestation, desertification, soil erosion and land degradation have been on the rise in the past few decades. ${ }^{1}$ These problems, not surprisingly, have prompted some concerns about an impending global environmental crisis, with unprecedented and insurmountable effects. The mere mention of crisis implies that things are not in a normal state, but in one that is in dangerous disequilibrium. Much of the concern about an environmental crisis therefore stems from the perception of an increasing imbalance or disequilibrium in the natural environment which has surrounded and supported humans for as long as they have lived on this earth. Admittedly, the man-nature relationship has always been ambiguous and contentious. One cannot deny, for instance, the impact of the agricultural revolution on the natural environment years ago. ${ }^{2}$ But it is also true that there was, at that time, a remarkable harmony between man and nature.

The same cannot be said about the relationship between man and nature today. Indeed, as the United Nations Environmental Plan (UNEP)'s 2007 Global Environmental Outlook (GEO-4) points out, "global climate change, declining fish stocks; loss of fertile lands

\footnotetext{
${ }^{1}$ According to the 2005 Millennium Assessment Report, there has been over the past fifty years, a substantial and irreparable loss of the earth diversity, due to problems such as pollution and deforestation.

${ }^{2}$ The intensification of agriculture meant that farmers were capable of producing higher yields using less labor. But with intensification came an increase in environmental impacts such as the degradation of water and soil resources.
} 
through degradation, unsustainable pressure on resources", are indicators of an ongoing threat to the environment that "could pass the point of no return" (GEO, 2007: xvi).

In effect, the rapid deterioration of the environment both globally and nationally has therefore helped open up a new debate about the efficacy (or otherwise) of existing structures, systems and levels of public engagement towards the development and delivery of relevant policies for sustainable environmental and resources management. This debate is rather pertinent to countries in the Third World which not only represent an interesting mix of political structures and systems, but are also associated with grave environmental problems which have debilitating effects that threaten the very livelihood of vast populations.

Parts of sub-Saharan Africa, for example, suffer from widespread land degradation - a problem that has contributed to huge losses in livelihoods as well as a decline in per capita food production. ${ }^{3}$ Another example worthy of mention is the continued use of rivers and streams as open sewers and garbage dumps which have seen an alarming rise in water - and filth-borne diseases and illnesses and, in some cases, even death. The World Health Organization (WHO), for its part, attributes about 4-8 percent of all disease burden in Africa and developing countries in South-East Asia to unsafe water and poor sanitary conditions. ${ }^{4}$ Yet another example is the issue of soil erosion which negatively affects the agricultural productivity of developing countries, leading to annual losses in

\footnotetext{
${ }^{3}$ See UNEP (2009) Global Environmental Outlook, (GEO-4), Geneva, Switzerland

${ }^{4}$ See World Health Organization (2002), Reducing Risks, Promoting Healthy Life, World Health Report, Geneva
} 
Gross Domestic Products (GDP) ranging from 1 percent to 15 percent..$^{5}$ Equally alarming is the increasing incidence of deforestation which has led to severe flora and fauna damage, gene pool loss and also reduced carbon sequestration rates. ${ }^{6}$

The list of problems is endless. With each of these problems, however, comes the promise of a solution(s) which when fulfilled can bring about long-lasting changes and societal well-being. But the complexities of these problems and their far-reaching societal effects coupled with the demands of modern governance mean that governments alone cannot, by themselves, realize prescribed goals of environmental protection and management. Rather they need the help of other actors - including environmental interest groups and associations, and citizens - to bring about transformational changes. This brings to the fore the notion of collaborative action, which in the context of this study refers to any attempt to achieve common goals by working across boundaries and in multi-sector and multi-actor relationships (O’Leary, Gazley, MacGuire and Bingham, 2009). By embracing notions of shared responsibility and collaboration, governments are placed in a better position to develop meaningful and long-lasting solutions to complex environmental issues.

Collaborative partnerships by their very nature therefore offer important mechanisms through which public and social problems can be effectively addressed. Through collaborative action, all affected stakeholders are able to share the responsibility and authority to establish common goals and develop road maps or blue prints for achieving

\footnotetext{
${ }^{5}$ See Barbier, E. (1998) "Economics of Soil Erosion: Theories, Methodology and Examples" in The Economics of Environment and Development, (ed) E. Barbier, London, Edward Elgar ${ }^{6}$ Carbon sequestration is the process whereby atmospheric carbon dioxide is absorbed by trees, grasses and other plants through the process of photosynthesis and then stored as carbon in trunks, roots, foliage, etc.
} 
those goals. Simply put, collaborative action helps to change the balance of power and, by so doing, makes room for new power bases. This, for all intents and purposes, leads to a more communicative democracy. ${ }^{7}$ In addition, collaborative action helps to avoid a 'one policy fits all' approach to complex problem solving, and instead tailors solutions to fit specific contexts and circumstances. It does seem to be the case, however, that collaborative partnerships yield practical and long-lasting results when accompanied by clear and decisive leadership that can bring about transformative change. For without leaders who are prepared to 'take charge of affairs', progress will be sluggish and motivation will be low. To this effect, this study examines the dynamics of government leadership and collaborative partnerships and how the latter impacts environmental outcomes. In this study, focus is placed on Ghana, a sub-Saharan African country which continues to receive international acclaim for its political and economic progress and yet in reality, is grappling with serious developmental problems, including environmental ones that have not been met with sustainable and practical solutions.

In the case of Ghana, significant barriers to addressing environmental problems such as poverty, illiteracy still exist and must not be overlooked. Nevertheless, the actions and behavior of the governing elite warrant even greater scrutiny, given the key positions the latter occupy and the important role they play in the governance of all sectors of society. As this study argues, the governing elite ${ }^{8}$ in Ghana have over the years presided over an

\footnotetext{
${ }^{7}$ Iris Marion Young's idea of communicative democracy is one in which different kinds of voices and ways of communication can easily enter the arena of democratic discussion. He argues decisions are better informed as more viewpoints are heard.

${ }^{8}$ In this study, less emphasis is placed on the conception of elites as being "selfish people in power bent on protecting their interests ... willing to manipulate opinions, rig elections and use force if necessary to retain power..." (Kuper and Kuper, 1985: 243) Instead, elites are considered to be " the incumbents: those who are collectively the influential figures in the governance of any sector of society, institutional structure, any geographic locality or trans-local community" ( Ibid: 243)
} 
era under which collaborative action on environmental protection and management has been the exception rather than the rule. A good case in point is the lack of coordination or articulation between the country's modern and traditional elite which, to a great extent, negatively affects the ability of the latter to have a meaningful and lasting impact on the sound management of the environment. By examining the processes and practices of environmental policy and planning in Ghana through the lens of the elite theoretical framework, this study draws attention to issues of leadership, power relations and its very dynamics, and how the latter have led to, or exacerbated the challenges and problems associated with environmental protection and management.

The choice of Ghana as a case study for this research project is informed by several considerations. First and foremost, the country has, over the past few decades, been somewhat of an activist on the environmental front particularly within the sub-Saharan region. Active also on global front, she is a signatory to important international agreements on the environment such as the 1992 Convention on Biological Diversity $(\mathrm{CBD})^{9}$ and the United Nations Framework on Climate Change (UNFCC). ${ }^{10}$ Also to enable it participate effectively internationally, there has been set up a special ministry the Ministry of Environment, Science \& Technology- responsible for the management and protection of the environment. The question, however, is whether or not these actions have translated into positive outcomes as far as realization of sound and long-lasting

\footnotetext{
${ }^{9}$ The CBD is a global, comprehensive agreement, put together at the 1992 Earth Summit in Rio to address all aspects of biological diversity: genetic resources, species, and ecosystems.

${ }^{10}$ This is an international treaty put in place with the idea of addressing the problem of global warming and considering what could be to tackle its inherent causes. The Montreal and Kyoto protocols are some of the arrangements that have arisen out of this treaty.
} 
environmental management goals is concerned. The study seeks to provide answers to such questions and related issues.

\subsection{Country Information}

The West-African country of Ghana-formerly known as the Gold Coast- shares borders with three French speaking countries, Burkina Faso in the north, Togo in the east and Ivory Coast in the west. It covers an area of about 239,460 square kilometres and its geography places it within the equatorial forest belt of Africa. With a recent discovery of economic quantities of gas and oil in its offshore waters, Ghana also stands the chance of becoming an important producer and exporter of oil in the near future. But, as a country, its history includes over three hundred years of slavery followed by a hundred years of British indirect rule colonialism which transformed it into a weak economy vulnerable to fluctuations in the price of primary products such as cocoa and gold. ${ }^{11}$ Ghana is fortunate that though it is a multi-ethnic society, multi-ethnic tensions, are on the whole, so low and so localized that, unlike the historical experience of Nigeria, Sierra Leone, Somalia and Rwanda, they have not been able to significantly affect the political fabric of the country after independence. Its population of about four million at the time of independence in 1957 has increased to almost twenty three million in 2009 (GSS, 2009). Unfortunately, the increase in the country's population has also been accompanied by a rapid decrease in the capacity of the environment to sustain human activities. ${ }^{12}$ In this

\footnotetext{
${ }^{11}$ Ghana, like other African countries, has no control over the terms of trade in the international market, making it impossible for her to earn enough to develop its economy. She is a price-taker, not price-setter of her products.

${ }^{12}$ This is not true for countries such Singapore that have effectively tackled their environmental challenges despite increasing population and development pressures.
} 
respect, due reference can be made to energy-intensive activities such as roads, dams, power plant construction, industrial and agricultural production all of which have over the years, led to severe cases of atmospheric and water pollution and widespread land degradation. The construction of Akosombo hydroelectric dam, for example, led to serious cases of deforestation and erosion, and to the displacement of a large number of people (Girmay, 2006). There is, therefore an urgent need for sound environmental management under the umbrella of transformational leadership and good governance.

\section{Figure 1 : Map of Ghana showing administrative regions}

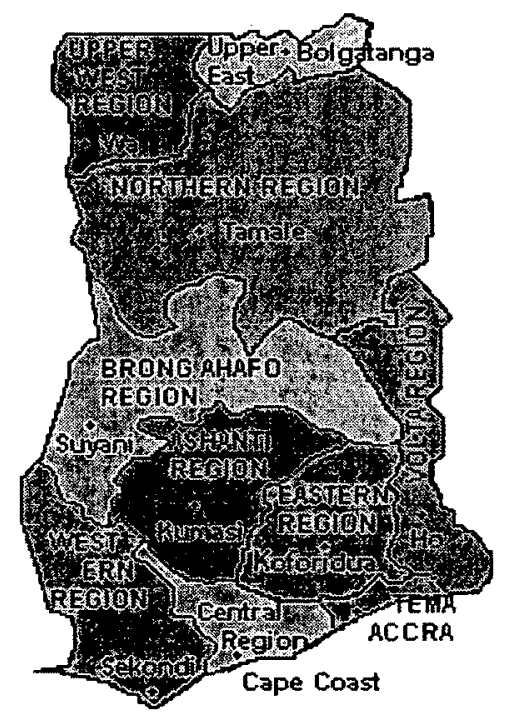

\subsection{Problem Statement}

Ghana gained its political independence from the British under the leadership of its first president, Dr Kwame Nkrumah. Giving his speech to mark the end of colonial rule and to celebrate the dawn of a new beginning, Dr Nkrumah affirmed the importance of independence, and underscored the commitment of his government to do all in its power 
to bring prosperity and progress to the people of Ghana - a promise of good governance. ${ }^{13}$ The country, in the ensuing years, has undergone some political, economic, social changes that have earned it considerable recognition and acclaim, particularly within international circles. Yet, this Star of Africa (as it is often described) has over the years also been plagued by many problems including environmental ones.

To this effect, questions arise about the efficacy of structures, systems and actors traditionally associated with the management and protection of the environment. For exploratory purposes, however, this study limits itself to the actor-oriented perspectives on this debate while recognizing the role of structural and systemic factors. In the author's view, there is a need for more research to understand how key actors within society exercise strategic choices that can impact the distribution and attainment of outcomes - in this case, environmental goals. Emphasis is on the role of political actors in environmental management - specifically elites - in the specific case of Ghana. The country's environmental problems are a great cause for concern, first and foremost, because of their portentous implications on the health and general well-being of its citizenry. ${ }^{14}$ For example, between the period of 2001 and 2006 alone, over eight major cases were documented in which wide-spread contamination of rivers and other water bodies, resulting from the operations of mining companies, led to serious related diseases and illnesses and, in some instances, death in several parts of the country. ${ }^{15}$

\footnotetext{
${ }^{13}$ See Dr Kwame Nkrumah's midnight speech on the day of Ghana's independence, $6^{\text {th }}$ March, 1957.

${ }^{14}$ Human wellbeing is the extent to which individuals have the ability and opportunity to live the kind of lives they value.

${ }^{15}$ See chapter five for a detailed discussion
} 
Poor sanitation and unsafe drinking water has also been identified as one of the root causes of mortality especially among infants. ${ }^{16}$ In addition, given the huge amount of jobs that are tied to the fisheries, forests and agriculture sector, the environment creates numerous opportunities for employment. For example, the agricultural industry accounts for fifty percent of Ghana's employment and up to 26 percent of the national GDP (Aryittey and Boateng, 2007). Over-exploitation and degradation of the environment therefore does not only threaten individual livelihoods specifically with regard to their cash earning opportunities, but also impacts adversely on the national economy as well. Emissions from point sources - including vehicles, industries - are also on the rise. This problem, has over the years been worsened by the alarming loss of forest cover (estimated to be about 70,000 per annum) ${ }^{17}$ which would ordinarily serve such important functions as carbon sinks. ${ }^{18}$ No extensive study is available as yet, but several pilot projects ${ }^{19}$ have been undertaken that draw linkages between atmospheric pollutants, and respiratory and cardiovascular diseases which have become rampant in recent years in Ghana. Also of concern here is the linkage between the environment and poverty. For example, the impact of forest loss and the ongoing dissemination of valuable biodiversity present a grave problem, particularly, for rural farming communities which depend on the latter for their main source of livelihood. Yet, another problem is desertification which has been rather devastating to the Ghanaian ecosystem, particularly in the Northern parts

\footnotetext{
${ }^{16}$ Speaking at the launch of Ghana's Sixth National Food Safety Week in July, 2008, the Health Minister General Courage Quarsigah, disclosed that inadequate sanitation was the cause of eight deaths in the country every hour, pushing it to the very top of the list of all causes of mortality.

${ }^{17}$ EPA's State of the Environment Report, 2004

${ }^{18}$ Forests play an important role in the regulation of the earth's temperature mainly through their ability to store large quantities of water and carbon.

${ }^{19}$ From November 2004 to May 2006, a group of scientists in Ghana, in collaboration with the US Environmental Protection Agency (EPA) with funding from the United States Agency for International Development (USAID) embarked on a series of projects concerned with basic air quality monitoring systems and standards for monitoring air quality.
} 
of the country where it continues to negatively affect the soils of the area, resulting in increased soil erosion, reduced soil fertility and low crop yields. Ghana is said to be losing five percent per annum of agricultural Gross Domestic Product (GDP) as a direct result of the latter (Dogbevi, 2009). This has resulted in food insecurity, human migration and in some cases environmental conflicts. ${ }^{20}$

The main argument of this study is that the current state of the environment, in Ghana as characterised by problems including deforestation, water pollution, and waste mismanagement, signals a gross failure on the part of those who have been in charge of the environment - the political elite - to effectively engage all affected stakeholders to achieve practical and sustainable environmental goals. While the governing elite continue to demonstrate an appreciable level of environmental awareness, this awareness has not translated into concrete and meaningful action on the environment. This, the author argues, is largely due to the governing elite's perception of the environmental problem as a non-pressing one that can be minimized or played down, without losing the favour or support of the people. The result, as this study shows, is the adoption of a top down, centralized and exclusionary decision-making and problem-solving approach by the governing elites towards the management of Ghana's environmental problems. What this implies is that there is little or no room for any meaningful contribution or participation by a wider section of the general populace. This presents a serious setback, given that environmental problems are wide-encompassing in nature and, as such, necessitate all-inclusive and participatory approaches. Against this background, questions

\footnotetext{
${ }^{20}$ This is of particular concem in Northern parts of Ghana where competition over the use of scare land has been a source of violent conflict between Fulani herdsmen and local farmers.
} 
can therefore be raised as to whether Ghana is really a model of success in good governance practices, democratic reform, socio-economic and political progress within the sub-region as asserted by some observers particularly within the international community. For, what is 'good' about a governance system in which broad and open citizen participation in important decisions is the exception rather than the rule? In whose benefit are policies and decisions made, and to what effect? How is this system democratic? In addressing these questions, the author argues that, the notion of political renewal has to be understood in the specific context within which it is being considered.

It is worthy to note that, there is in Ghana, a lasting preoccupation with identifying and establishing governance arrangements under which available resources could be best harnessed for the attainment of common national and societal goals. There has, for instance, been a wide-spread embrace of liberal democratic politics which supposedly opens the door to meaningful and effective participation of its citizens in important decision-making processes. ${ }^{21}$ It therefore comes as no surprise then that the country's post-independence history commenced with a popularly elected democratic government and has since then made other major attempts at establishing democratic regimes in 1969, 1981 , 1996, and finally in 2000 (Boafo-Arthur, 2007 ). Over this same time period, however, the country gained some notoriety for its often violent military upheavals which overthrew democratically elected governments over claims of political, economic and social mismanagement. Simply put, the political environment and its principal actors have undergone frequent changes ${ }^{22}$ (see Table 1 below). This may appear to be - an

\footnotetext{
${ }^{21}$ See literature review in Chapter two for a detailed discussion.

${ }^{22}$ This to some may be seen as efforts or attempts to foster political renewal
} 
indictment of the leadership qualities of the governing elite, particularly with respect to their abilities to keep a united and stable front.

Table 1: Ghana's Post-Colonial Governments (1957-To Date)

\begin{tabular}{|c|c|c|}
\hline YEAR & HEAD OF STATE & REGIME TYPE \\
\hline $1957-66$ & Dr Kwame Nkrumah & Constitutional Rule \\
\hline $1966-69$ & $\begin{array}{l}\text { General Ankrah/General } \\
\text { Afrifah }\end{array}$ & Military Rule \\
\hline $1969-72$ & Dr K.A Busia & Constitutional Rule \\
\hline $1972-79$ & $\begin{array}{l}\text { General Acheampong/General } \\
\text { Akuffo }\end{array}$ & Military Rule \\
\hline $1979-80$ & Flt. Lt Jerry Rawlings & Military Rule \\
\hline $1980-81$ & Dr Hilla Limann & Constitutional Rule \\
\hline $1981-92$ & Flt. Lt Jerry Rawlings & Military Rule \\
\hline $1992-96$ & Flt. Lt Jerry Rawlings & Military Rule \\
\hline $1996-2000$ & Flt. Lt Jerry Rawlings & Constitutional Rule \\
\hline $2000-2004$ & Mr J.A. Kuffour & Constitutional Rule \\
\hline $2004-2008$ & Mr J.A. Kuffour & Constitutional Rule \\
\hline 2008-To date & Prof. John Atta-Mills & Constitutional Rule \\
\hline
\end{tabular}

Source: Field Survey, 2008

The decline in the state of Ghana's environment admittedly is alarming, but it also provides an entry point for further inquiry into how existing modes of governance can be improved and realigned, in order to make them more suitable and effective for the 
realization of environmental management objectives and goals. But, any such inquiry must be embarked upon with an overview of some of the ideas and worldviews that have shaped ongoing discussions on governance particularly within the context of sub-Saharan Africa. To this effect, it is important to point out that, there is increasing emphasis on quality in terms of governance, as expressed through its varied elements and dimensions. This stems from the crucial role the latter plays in ongoing development strategies and efforts for countries such as Ghana. A good case in point is the World Bank's endorsement of good governance as a key component of its development agenda for the continent.

Through its promotion of wide-sweeping economic and institutional reforms, the Bank has sought to limit what it sees as the state's monopolisation of political power and the economy. This stems from its view that statism, corruption and mismanagement by African governments have together created a poor climate inimical to the attainment of development goals and societal well-being. In this sense, the concept of governance refers to "the manner in which power is exercised in the management of a country's economic and social resources for development" (World Bank, 1992: 1). It can also refer to the "traditions and institutions by which authority is exercised" (Kaufmann et al, 2002).

The notion of good governance was first introduced in the 1989 World Bank's report on sub-Saharan Africa, which presented the socio-economic and political crisis in the region as a 'crisis of governance' (World Bank, 1989). This marked the beginning of the Bank's 
campaign towards the promotion of an appropriate institutional and political framework within which to situate and promote its development agenda. Thus, in dealing with the issue of governance, the Bank questions the ability, capacity and willingness of political authorities to govern effectively in the common interest of all. To this effect, it places sharp emphasis on the fact that a country's governance system is a key determinant of its ability to pursue economic and social development. To quote the Bank:

Underlying the litany of Africa's development problems is a crisis of good governance. Because countervailing power has been lacking, state officials in many countries have served their own interest without fear of being called to account. In self-defence, individuals have built up personal networks of influence rather than hold the all-powerful state accountable for its systematic failure. In this way, politics become personalised and patronage becomes essential to maintain power. The leadership assumes broad discretionary authority and loses its legitimacy, information is controlled, and voluntary associations are co-opted or dis-banded. The environment cannot support a dynamic economy (World Bank, 1989: 61).

It makes further note of the fact that "efforts to create an enabling environment and to build capacities will be wasted if the political context is not favourable... ultimately, better governance requires political renewal" (Ibid: 70). Taking the same path as that of the World Bank, other donor agencies (bilateral and multi-lateral) have enthusiastically embraced the concept of governance and incorporated it into their aid policies and 
development cooperation agenda for Africa. These include the Organization for Economic Cooperation and Development (OECD) and other private agencies including the Ford Foundation. On a broader platform, organizations like the Commonwealth and the United Nations (UN) have also begun to emphasize and promote issues of good governance in their activities. For example, the Commonwealth, charted a new course for itself, by resolving at its 1991 Harare Summit to promote the principles of democracy, respect for human rights and good governance (Adejumobi, 1995). The New Partnership for Africa's Development (NEPAD), for its part, also identifies good governance as "a basic requirement for peace, security and sustainable political and socio-economic development (NEPAD, 2001: 7).

The good governance agenda for Africa, although rather broad in terms of its specification, in the context of this study, is examined in terms of its prescription of political liberalization as a necessary condition of development. Here, the major assumption is that political liberalization will 'open the gates' for political renewal which will consequently lead to and establish better modes and arrangements of governance. In this sense, given the massive wave of democratization ${ }^{23}$ that has hit most countries in sub-Saharan Africa, questions arise as to what type of renewal has the political landscape undergone over the years? The question is whether this is practical and sustainable enough to help foster fundamental changes in governance or is merely superficial and ad hoc in nature? It is also important to note that, the notion of political renewal, which

\footnotetext{
${ }^{23}$ Michael Bratton and Nicholas van de Walle explore in further detail, Africa's wave of democratization. As they point out, between 1990 and 1994 alone, 29 out of the 47 states organized their first multi-party elections.
} 
appears to be the driving force behind the good governance agenda, has to be understood in the specific context within which it is being considered. In this respect, Ghana presents itself as an interesting case study because of the 'drastic' political transformation it has undergone over the past three decades. The country has been widely acclaimed for the rapid evolution of its political regime from a military dictatorship in the early 1980s into its current democratic state, and, in fact, has been applauded especially in the international community as a shining example for other developing countries. But questions still remain as to how far Ghana has gone in terms of achieving a style or mode of governance that is open and inclusive in nature and can at best be described as effective and transformative.

\subsubsection{Scope of Study}

This study is exploratory in nature. To this effect, it concentrates, on evidence based on environmental management processes and practices in Ghana embarked upon by successive governments since the $1980 \mathrm{~s}^{24}$ to date in support of the argument that, despite the so-called advances that have been made in respect of 'political liberalisation,' the style of governance that has prevailed over the years is one that is exclusionary, centrist and top-down. In this sense therefore, governance can be described as being elitist in nature. This is rather troubling, considering the negative impact the latter has on the attainment of national and developmental goals. By examining some of the salient governance challenges that plague the management of societal issues - in this case the environmental problem- relevant recommendations are offered towards the quest for lasting solutions.

${ }^{24}$ It was in 1988 that the then PNDC government began to formally address issues of environmental degradation at the national level. 


\subsection{Reseurch Objective}

The influence of politics on the processes and functions pertaining to environmental management and its impact is what this research work sets out to examine. It is being suggested here that in the context of the Ghanaian society, it is the political elite, who wield power and make important decisions and policies.

Consequently this study poses the following research question:

How have the actions (or inactions) of the political elites, who are leaders of the Ghanaian society, shaped, or determined the realization of environmental management goals?

The above question is further broken into the following sub-questions:

(1) Has environmental management been on the decline over the years?

(2) To what extent can we attribute this to the nature and dynamics of the elite leadership within the specified time frame?

(3) What has been the level of political commitment towards the protection and management of the environment vis-à-vis economic development goals - Has environmental management been a priority for the political leaders and what is the level of priority given to these issues of the environment?

(4) What is the level of public participation or civic engagement in environmental policy and decision-making processes in Ghana?

(5) To what extent are ordinary citizens encouraged or allowed to take ownership of the environmental problems that plague the communities in which they live in and do these people feel a sense of engagement in environmental decision-making processes? 
One way of determining this is to study policies and programmes that have been put in place by governments within the specific time frame that deal with problems of deforestation, land degradation, desertification, and waste and water pollution with the hope that they tell the story about the larger political environment in which they were shaped.

\subsection{Organization of Study:}

This study is organized into six chapters and the details are as follows:

Chapter one, the introduction, discusses the general background to the study, the research problem, and study objectives. It also provides an overview of the rationale and scope of the study as well as the outline of the study. Then it takes a further look at the issue of leadership and how the latter impacts on the realization of prescribed public and national goals and offers an analytical overview of the structure of elites (modern and traditional) in Ghana. Following up on that is a general overview of the environmental problem in Ghana. The chapter ends with a review of the contending paradigms on environmental management and how the latter have influenced environmental management practices, structures and policy in Ghana.

Chapter two builds a theoretical foundation that forms the basis of the study: first it develops an in-depth discussion and review of the existing literature and research on the debate about power distribution and democracy. This includes a through and detailed account of the concepts and definitions dominant in elite theory and follows up with an analysis of the scope of elite power and how the latter presents challenges for environmental management. Propositions and theories of elite governance are also 
discussed. The chapter also takes a further look at elites as makers and implementers of policy including environmental policy and their relevant linkages to the international power elites and also presents a historical perspective on elite governance failure.

Chapter three describes evolving trends in environmental governance and draws on Canadian examples to illustrate how citizens can be involved and engaged in environmental decision-making processes. Following up on that is a thorough discussion of citizen involvement and civic engagement in environmental governance as pertaining to the specific case of Ghana.

Chapter four starts with a general overview of the main research methods employed in the collection of available data for this study and include as well a detailed description of the data collection processes involved in the study.

In chapter five, the data collected is analysed and the general patterns observed and conclusions drawn are discussed.

The sixth and concluding chapter begins with a summary of the main points of the study, makes some recommendations towards the improvement in environmental management in Ghana and concludes with a review of the study's contribution to existing scholarship.

\subsection{Effective Leadership: A Necessary precondition for Environmental management}

Leaders are elites and as a concept, leadership can be perceived in several ways. Leaders are so often conceived of in terms of larger-than-life individuals. Cases in point include Gandhi and Ghana's own Kwame Nkrumah who, through exemplary leadership led non- 
violent resistance to drive out the British colonialists. One could also argue that it was the strong leadership qualities of Winston Churchill that spurred Britain to continue to fight the war in 1940, in spite of seemingly insurmountable difficulties and circumstances. As Burns (1978) argues, understanding leadership styles or types is a first step towards developing leadership potential. Leadership, he notes, falls into two main types transaction leaders and transformation leaders.

Transactional leaders, for the most part, accept the status quo, but motivate their followers by appealing mainly to where their own self-interests and the interests of their followers are fused and focus on the accomplishment of tasks and attainment of objectives in exchange for some rewards of some kind. A good example of the latter is the politician who exchanges favours for votes. Transformational leaders on the other hand, are those leaders who have a profound sense of vision for change and who seek to influence their followers with a high level of commitment to that vision. Transformation leaders may aim at rejection and overhaul of the status quo with a view of totally transforming it and establishing a new system that conforms to their vision. In doing so, they may go to extremes which might yield negative or extreme positive results with attendant unintended consequences in the short, medium or long terms.

Adolph Hitler's recruitment of a mass following to annihilate all 'aliens' in the Aryan state refers to a more negative or extreme example of transformational leadership. The excesses of Robespierre's reign of terror in France and Stalin's destruction of the kulaks and operation of gulags in the former Soviet Union are examples how extremely 
dangerous some transformational leaders can be. On the other hand, the transformational leadership of Abraham Lincoln and his stance and adherence to democratic principles and rights had a far reaching and positive impact not only in the United States of America, but also in many parts of the globe. Ronald Regan's style of leadership can also be essentially described as being transformational given the extent to which he rallied support for conservative economic policy goals such as privatization and government down-sizing. Leadership, as thus conceptualized, implies two things: that there exists, on the part of a leader, not only a deep commitment to a mission or a vision, but also an ability on the part of a leader to persuade or manipulate his followers to accept or 'buy into' this commitment ( Cartwright, 1983). Leadership can also be said to refer to the ability to engender a compromise or consensus out of a multiplicity of diverse interests. An example is Mackenzie King's ability to avert a French-English split in Canada over the issue of conscription during World War II.

Suffice is to say, however, that leadership, on the whole, entails the ability and willingness to act rather than sit back and do nothing. Dixon (1976) puts forward several possible explanations that could account for effective leadership. First of all, effective leaders, at any given time, are themselves concerned about the efficient use of public resources - including money, people, and materials. This, by itself, he argues, is most likely to have a positive impact on those around them who, as a result, are steered into thinking along similar lines. Effective leaders shun fundamental conservatism and a stubborn affinity for outworn traditions. For leaders, the danger of being fixated on the past and on the past way of doing things is that people become ill-equipped for changing 
with the times and are not able to open themselves up to new ideas and problem-solving approaches.

According to Dixon, so long as leaders are not immersed in their own undertaking and are not self-involved and convinced of their own intelligence, they will be able to see and assess problems - the scope and dimensions for what problems really are. It is also important that leaders avoid overestimating or underestimating their inherent capabilities and wisdom to deal with such problems. Moreover, effective leaders are those who are well prepared personally, intellectually and professionally to deal with complex problems as and when they come up so as to amass the necessary resources for the ultimate solutions of those problems. An effective leader is also one who encourages critical thinking on the part of those he rules and does not feel threatened by constructive criticisms or feedback.

Effective leadership, as Dixon points out, calls for firmness and decisiveness in time of crisis. Leaders are effective when they do not flounder when problems arise, but are able, as it were, to stand their ground and rally those around them to meet challenges when things go wrong. A good leader is also one who, at any given time, avoids looking for 'scape-goats' or conspiracies whenever things do not seem to be going in the right direction. As he notes, leadership at the superficial level is believed to include such factors as voice, stature and appearance, an impression of omniscience, trustworthiness, sincerity and bravery. But, at a deeper and rather more important level, it depends upon a proper understanding of the needs and opinions of those one hopes to lead. In much more specific terms, Cartwright(1983) sees leadership as involving an action on behalf of the 
leader which, for the most part, stimulates some sort of reaction (positive for the most part) on behalf of the followers.

What one surmises from the latter is that, persons who possess power - whether by virtue of the positions they occupy and the roles associated with these positions - may not necessarily exhibit or demonstrate leadership abilities. In other words, not all leaders are effective or transformational. Leadership, therefore, may not necessarily be restricted to occupants of positions or roles of power within any given society. Indeed effective actions on behalf of a person, hitherto considered as ordinary, can make him/her a leader. Such indirect leadership may potentially be channeled into solving environmental problems.

\subsubsection{Modern and Traditional elites in Ghana}

As public awareness continues to grow about the impact of environmental problems on human health and the overall quality of life worldwide, there is also a growing demand for transformational leadership on the part of government and other stakeholders. Like any other kind of leadership, environmental leadership connotes the ability to influence and direct the performance of an individual or group towards the attainment of common environmental goals. In societies such as Ghana, where strong organizational groups are few and relatively weak and sometimes ad hoc, it is appropriate to refer to the few who 
manage the affairs of the masses and these groups as elites. ${ }^{25}$ It is an analysis of the structures and roles of these elites that will be examined next. The argument made here is that elites may not necessarily possess the leadership qualities as earlier discussed.

Modern elites refer to the class that has, in modern times, emerged out of the struggle for pre-eminence concerning wealth, status, authority and control over the means of directing human activities or wills, and decisions about who gets what and when. The organized winners of this struggle become the modern ruling class while the losers and the apathetic become the ruled. As classical elite theorist Gaetano Mosca points out, contrary to basic democratic theory that would have it that majorities rule minorities, in practice, it is organized minorities who rule majorities. The ruling class, however, does not govern by brute force. Rather, they legitimize their rule by political formulas that are accepted by the ruled. As he puts it "there is always a ruling minority, but such minorities never stop at the brute force of holding power. They justify their rule by theories or principles which are, in turn, based on the beliefs or ethical systems which are accepted by those who are ruled" (Mosca, 1939: 34). In today's world, electoral legitimization is widely accepted as the best means through which political leadership accedes to power. But, this legitimization as one sees in the case of Ghana, does not always have to be democratic. The country has seen five military take-overs since independence. Ghana's political history shows that military governments have, in some cases, arrived at some 'political formulas' that have endeared them to the people even if on a temporary basis. For instance, the 1975 military government of Colonel Acheampong, although authoritarian,

\footnotetext{
${ }^{25}$ Ghana - is a leader driven society with the legacies of Kwame Nkrumah, the country's first president, the 'Big Six' that led the fight that brought independence, some of the worthy examples.. To understand its politics therefore, it is only appropriate that a leadership perspective is used.
} 
through its initiation of some popular action-plans, succeeded in winning the hearts of the masses to legitimize itself - albeit for a short period. ${ }^{26}$

Characteristically known for its precision, rigid adherence to systems and procedures, discipline, regularity of life, there is really no question about the potential for the military to exude transformational leadership. Indeed, there is the view that these "military values, skills and ideologies ensure that military politicians in the Third World, make the most thorough and perhaps the only reliable managers of social change" (Olatunde, 1982: 5). In the case of Ghana, however, military leadership has been transactional in nature and as Shils puts it, is limited to "suppressing attempted putsches, clearing up streets, removing beggars from the center of the main towns, prosecuting the beneficiaries of previous regimes and preventing the spread of rumors of corruption about its own regime" (Shils, 1962: 34). Suffice it to say then that these regimes have placed very little or no emphasis on the need to empower citizens to make meaningful contributions towards the advancement of national goals and objectives. This type of leadership, it is safe to argue, has produced very little or no gains in the area of environmental protection or natural resource management.

Despite the existence of the modern elites of which the military is a part, traditional rule continues to exist in Ghana in parallel with the legal-rational modern democratic or modern elite system. Military rule in Ghana did not kill traditional rule, preferring rather to cooperate with it. Essentially, therefore, there exists in Ghana at least two main and parallel political systems- modern and traditional. The existence of two parallel systems,

\footnotetext{
${ }^{26}$ A good case in point is the so called 'Operation Feed Yourself', a programme introduced by Colonel Acheampong's government aimed at promoting principles of self-reliance in agriculture.
} 
traditional and modern, could in the case of Ghana be explained in several ways. On a broader note, it is an affirmation of the inability of the modernizing elite to completely obliterate structures and institutions that were considered as traditional and, hence, by implication backward, primitive and archaic. The survival of the traditional elite, in spite of the seemingly inherent contradictions between them and their modern counterparts, had to do with the key role (albeit unofficial) they played, and continue to play in society particularly in the rural areas. With the traditional rulers playing multiple roles of judges, administrators and law makers mostly in rural areas, the modern elites are enabled to focus whatever limited resources is available on meeting the needs of citizens in the urban areas of the country. This articulation of the modern and traditional in Ghana, if nothing at all, negates the contention of proponents of the modernization paradigm such as W. Rostow ,that it is only when societies transform themselves from 'traditional' into 'modern' ones, that they can cross into the threshold of 'development'(Rostow, 1982).

With respect to the cultural underpinnings of the traditional system of rule, there exists in Ghana, for example, some forty different ethnic or tribal communities each of which seeks to attain economic, social and political objectives by means of its own unique blend of language, customs, and cultural attributes as embodied in traditional structures of authority. Traditional authorities in Ghana comprise chiefs, queen mothers, linguists, heads of "Asafo" ${ }^{27}$ companies, clan heads, heads of extended families, and priests and priestesses all of whom either on a collective or individual basis "command lots of influence in urban and rural areas because they are considered as people with customary legitimacy in their areas of jurisdiction..." (Prof Bekoe quoted in Ghanaian Chronicle,

\footnotetext{
${ }^{27}$ The word 'Asafo' which translates to 'people of war' is derived from 'sa' (meaning war) and 'fo' (meaning people).
} 
March 2007). The latter, however powerful and vibrant, nevertheless all accept and recognize the existence of an over-arching political authority vested with constitutional powers that require them to yield certain rights and responsibilities to the modern state apparatus. It means that, while legitimacy(political or otherwise) can be attained from what Weber describes as traditional or charismatic sources of authority, the overarching or predominant form of authority in the particular case of Ghana is, indeed, rational-legal in nature.

This current state of affairs can be traced to the period of colonial rule during which the establishment and affirmation of control and influence was achieved mainly through the super-imposition of centralized and 'modern' political structures on existing traditional ones. Traditional authorities in pre-colonial times - the institution of chieftaincy in particular - exercised some real political power either though raising of armies, or raising of revenues or adjudicating in civil and criminal cases affecting its citizenry. But policies of indirect rule - ${ }^{28}$ under the colonial dispensation combined with numerous attempts by successive governments in the post-colonial era to 'strangle' the life out of traditional authorities have - may have served as constraints on the ability of the latter to have a meaningful and lasting impact on the sound management of public affairs. Thus, while traditional authorities in Ghana continue to wield some cultural, economic and quasipolitical powers over the people, their potential for transformational leadership remain grossly under-exercised.

\footnotetext{
${ }^{28}$ Indirect rule involved the use of local chiefs to implement colonial policies. Chiefs appointed as Native Authorities were empowered to collect tax revenue within their jurisdictions for expenditure by the colonial Administrators or on their advice. Policies of assimilation
} 
The articulation between these two parallel systems is described to some extent in the literature as the syncratic model (Organski 1965, Bertsch et.al, 1986: 444-448). Its character may be reinforcing or adversarial. In the case of Ghana, elite alliances, in some instances, have been forged between elements of the two parallel systems to constitute ruling elite coalitions. A case in point is the appointment of Nana Kwame Akuako Sarpong II, the paramount chief of the Agogo Traditional area as a Minister of government under the Provisional National Defence Council (PNDC) headed by John Rawlings. It is within this context that successive governments of Ghana may be regarded as shifting coalitions of elites. This should not be interpreted to mean that the existence of an elite coalition necessarily implies the demise of the tension between the two parallel systems. Indeed, failure to bring the existence of such tension under control may rather spell the demise of a ruling elite coalition.

One origin of such tension concerns cases of land management where legislations exist to allow the state to acquire and hold land in public interest or for public purposes. Worthy of mention here is the 1962 Administration of Land (Act 123) which provides for the state to approve the disposition of stool lands for valuable considerations and, includes as well, the power of summary expropriation and appropriation of land in the public interest. The Act also gives the state the power to grant stool- related concessions and empowers the President to intervene in land litigation cases. Also of interest here is the 1994 Land Commission Act (Act 483) which established the Land Commission to manage on the government's behalf, all public lands and any other land vested in the President as well as the 1994 Office of the Administrator of Stool Lands (Act 481) which established the 
Office of the Administrator of Stool Lands, mandated to collect all revenues accruing from stool lands and allocate it in accordance with constitutionally enacted provision. In real terms, however, eighty percent of land is held under customary law which essentially make provision for customary land arrangements that allow traditional institutions such as stools, skins, clans and families to hold allodial (absolute ownership) of titles to land on behalf of their people. This makes traditional rulers important stakeholders in the administration of land.

With land ownership overwhelmingly remaining in the hands of traditional rulers and its management in the hands of government, it is easy to see how tensions and difficulties are bound to arise. For example, though land is under the control of the traditional rulers, their input is often not sought in the exercise of town planning. The resulting tension is reflected in the often non-compliance with the town planning directives by the local communities. Thus, in the Greater Accra Metropolitan Area (GAMA) of Ghana, this tension has undermined water distribution projects, and houses have been built within proposed roads leading to much congestion. Other problems include unplanned expansions and unauthorized development, all of which impact negatively on sound environmental practices. Such confusion is indicative of lack of effective leadership. It also sends the message that the articulation between the traditional elite and the modern elite leaves much to be desired including discipline on both sides of the parallel.

It should not be forgotten that the neo-colonial structure of Ghana's economic and political spheres implies that these successive coalition of elites often include the 
international power elite with whom some of the modern elite of Ghana (the compradors) may be aligned, making the tension more complex. Although not comprehensive by any means, the above-mentioned indicators of effective leadership is a good starting point for the analysis of successive coalitions of government in Ghana, all of whom have been coalitions of elites. As surmised from the above, both modern and traditional elites, for varied reasons, have so far failed to demonstrate the requisite transformational leadership qualities which would otherwise have made them effective drivers of change. This leadership crisis has, as this study shows in the ensuing section, on many fronts adversely impacted the environmental sector and the search for sustainable solutions.

\subsection{Perception of the environmental problem in Ghana}

That Ghana continues to grapple with environmental problems is a reality that is not in dispute. To this effect, questions pertaining to problem perception become pertinent and must be addressed. How, for example, is the environmental problem perceived or defined in the specific case of Ghana, and who defines it? This is a rather important exercise, given that there are important linkages between how a problem is defined and the choices that are made towards its management or solution. As Dunn points out, “...problem structuring is a central guidance system or steering mechanism that affects the success of all subsequent phases of policy analysis" (2004: 72). To illustrate, Hirschman (1963) in his discussion on policy problems, makes a distinction between what he calls 'chosen problems' and 'pressing problems'. As he explains, a chosen problem is that policy problem about which a government can choose to take action or not without incurring the 
displeasure or losing the favour of the people. A pressing problem on the other hand is one which is tied in with critical issues, economic melt-down or electoral defeat.

To a large extent, the environmental problem - at least in the context of this study - for all intents and purposes must be seen as a pressing one. This is especially the case for a developing country such as Ghana where mention can be made of immediate and dire consequences of the national environmental decline particularly in economic terms. For. instance, the degradation of land and forests might have been a key contributory factor to agricultural productivity declines and crop losses. This spells major problems for Ghana, considering that the agricultural sector accounts for about one-third of the Gross Domestic Product (GDP) and employs more than half of the country's workforce (Aryittey and Boateng, 2007). Coastal zone degradation and the destruction of other natural support systems including wetlands and coral reefs translate into losses in tourism value and potential revenue. The pollution of water bodies and the depletion of groundwater and freshwater resources, among other things, lead to increases in water pumping costs as well as physical damages to structures and utility lines. Monetary costs associated with the adverse impacts of environmental problems on human health and safety are also worthy of mention. The latter include expenses incurred from hospital care, cost of drugs as well as the costs for doctors and other medical personnel. Also worthy of mention here are indirect costs such as productivity losses accrued as a result of absenteeism associated with environmental related illnesses, and expenditures associated with preventative actions aimed at environmental-related diseases. 
The significant linkages between the environment and the economy notwithstanding, a close look at the development plans and economic documents of successive governments suggest that the environmental problem in the case of Ghana is yet to be taken as a pressing one. For example, Ghana's Economic Recovery Program (ERP) introduced in 1983 under the auspices of the World Bank and the International Monetary Fund (IMF) focused on the improvement of Ghana's economic performance through the implementation of several measures geared towards the revitalisation of agriculture, manufacturing and mining industries. ${ }^{29}$ The latter was to be achieved through deflationary, devaluation, privatisation measures and liberalized trade regimes (Saris et al 1991). The ERP had two phases. Phase I: $1983-86$ was aimed at halting economic decline and stabilization, while Phase II: 1987-90, sought to consolidate the gains of Phase I. Although, performance in the fiscal area, at least until the early 1990 s, were generally impressive ${ }^{30}$, the environmental impacts of these activities, potential or real, cannot be ignored.

Noteworthy here are the environmental effects of economic development which, not surprisingly, appear to be a subject of wide debate in the relevant literature. One popular argument with respect to the latter is the delinking hypothesis which assumes that the initial stages of a country's economic growth is necessarily rife with high levels of environmental degradation, given that environmentally-friendly technologies are either

\footnotetext{
${ }^{29}$ Ghana's economy is largely resource-dependent

${ }^{30}$ Until 1992 performance in the fiscal sector was generally impressive, taking into account, Ghana s economic history. Government revenue rose from 5.3 percent to 14.4 percent in 1986 and averaged 14.5 percent before declining to 12 percent in 1992 (Green, 1991). This facilitated a strong recovery of real expenditure which rose from about 7 percent of Gross Domestic Product (GDP) in 1983 to an average of 14 percent between 1987 and 1991, before increasing to almost 17 percent in 1992. At the same time, the persistent deficits in the recurrent budget turned into a small surplus from 1986.
} 
unaffordable or unavailable. The levels of environmental degradation, according to this theory, persists or increases up until a certain point beyond which increases in income (and by implication accessibility to advanced environmentally friendly-technology) finally produces increases or sustained improvement in environmental quality. This argument as mostly represented by an inverted U-shaped curve - often referred to as the Environmental Kuznets Curve (EKC) - therefore allows for an improvement in environmental quality as countries diversify and advance in terms of technology, better education and so on. ${ }^{31}$ In this sense, Ghana, like all other developing countries can be located on the low-income tail end of the curve, given the high level of environmental degradation and the relatively low levels of income.

In many ways therefore the structure of economic growth is a key determinant of environmental degradation. Essentially, an economic system can be said to be environmentally sustainable only when it is "...physically in a dynamic steady-state, i.e. the amount of resources utilized to generate welfare is permanently restricted to a size that does not over exploit the sources or over-burden the sinks provided by the eco-sphere .." (Stagl, 1999: 2).

Based on available data from the period of intense adjustment, 1985-9, it is clear that Ghana's economic growth was largely resource-intensive in nature. For instance, cocoa, which has traditionally been a major source of export earnings, rose to $\$ 495$ million in

\footnotetext{
${ }^{31}$ See Shafik N., and Bandyopadhyay S. (1992) in "Economic Growth and Environmental Quality: Time Series and Cross Country Evidence", Policy Research Working Paper, No.WPS 904, World Bank, Washington, for a detailed discussion.
} 
1987 from $\$ 425$ million in the previous year. Even more significant was the steady rise in export earnings from the mineral sector which, in the same period, rose through 1985 and peaking at some 48 percent in 1994 (Ndulu, 2008). In the particular case of the mining sector, the fore-mentioned gains can be said to be largely as a result of the implementation of market-driven reforms which saw, among other things, increases in foreign direct investment in mining activities. It is interesting to note, however, that Ghana's major action plan on the environment, the Environment Action Plan (EAP) was initiated in 1988, a time during which economic reform and growth was most paramount among the interests of government. Prepared by officials from the EPA and other governmental departments, the Environmental Action Plan (EAP) lacked a clear direction as to how to curb the environmental consequences of the ongoing ERP in areas such as agriculture, forestry, mining and manufacturing. It is not surprising, therefore, that the total cost of environmental degradation on the Ghanaian economy in 1988 alone was estimated to be 4 per cent of GDP (Convery and Tutu, 1990).

Other cases in point are development plans such as the Ghana-Vision $2020^{32}$ and the Ghana Poverty Reduction Strategy I (GPRS) ${ }^{33}$ both of which appear to affirm the significance of the country's natural resources and yet place very little emphasis on the need for sustainable conservation and preservation of these resources. On the issue of land degradation, for example, the Vision 2020 document only goes so far as to mention

\footnotetext{
32 This document as prepared in 1999 by government officials in collaboration with the World Bank and the IMF aims at fostering economic growth and improvement in the living standards of Ghanaians.

${ }^{33}$ This is a document that gives a projection of how Ghana intends to achieve the goals of poverty reduction and economic growth through the use of numerous social, structural and macroeconomic policies.
} 
the intention of government to " initiate a number of collaborative pilot ${ }^{34}$ management schemes in the high forests and the savannah woodlands involving individual farmers and entrepreneurs, families, school children and communities" (Vision 2020, section C:37). Similarly, the GPRS I on its part, while acknowledging the environmental consequences of mining activities, appear to place more emphasis on the revenue that the country stands to make from the industry. ${ }^{35}$ Equally lackadaisical, is the commitment of government towards resource allocation for environmental protection. It is therefore not surprising that government funding for the environment sector has actually reduced in recent years, going from 10.4 percent of the 2003 budget to just 8.5 percent in 2006 (Morgan, Ghanaian Statesman, 2007).

The failure of the major Ghanaian political parties to adequately address the environmental problem in their campaign manifestoes and platforms is yet another indicator of how environmental issues have been downplayed at the expense of the economy. For instance, the New Patriotic Party (NPP) which first came into power in 2000 , subsequently sought re-election in 2008 on a campaign platform that paid a lot of lip service to environmental protection. The party's 2008 manifesto, apart from reiterating its commitment to the "protection of the environment against degradation of all forms" (NPP Manifesto; 2008, section 2.3.8) is very sketchy on how it intends to achieve this. In fact, it devotes the least amount of attention to the issue of the environment, than it does to any other issue. The environmental position of the ruling New Democratic Congress (NDC) in its 2008 manifesto decries what it calls "...the rapid

\footnotetext{
${ }^{34}$ Emphasis added

${ }^{35}$ It should be pointed out however, that GPRS II addresses the issue of the environment in more depth.
} 
exploitation of our forests..." and the "deregulation of the mining industry" (NDC Manifesto, 2008; .5). But, it is equally non-committal. For instance, the manifesto goes to great extent to extol the economic benefits of Ghana's recent crude oil discovery, and yet it is silent about the measures it will adopt to curb the environmental consequences of oil production. As earlier noted, the perception of a policy problem is a determinant of the approaches that are adopted towards its solution and, in the case of Ghana; the choices made in terms of environmental management appear to be ones that have not inspired positive change.

\subsection{The State of the Environment in Ghana}

Ghana is plagued with environmental problems including atmospheric and water pollution, deforestation, desertification and land degradation, as well as poor waste management and sanitation in all parts of the country (EPA, 2004).

\section{Deforestation}

The exploitation of forest resources mainly for commercial purposes has been a stable feature of Ghana's economic history even before independence, but the beginnings of the 1980s saw a sudden increase in the rate of deforestation, estimated to be around 70000 hectares per annum (EPA, 2004). Ghana's forest cover which at the turn of the $20^{\text {th }}$ century was estimated to be about 8.2 million hectares, by the end of the 1980 s had been drastically reduced to 2.1 million hectares (Ibid, 2004). Data from the Forestry Commission of Ghana also show that between the 2001 and 2005 alone, Ghana lost on an average basis, about 115,000 hectares of land every year (FCG, 2007). Of notable interest here is the rise in timber exports which, since the introduction of the Economic 
Recovery Program in 1983, has increased both in volume and in revenue making it the third major foreign exchange earner. But, as evidence suggests, this rapid expansion in timber trade ${ }^{36}$, combined with the failure of major logging companies to invest in reforestation programs, might have significantly contributed to the increase in the deforestation rate. Urban and industrial expansion - and the growing demand for forest products, road and railway construction, illegal chain saw activities, surface and deep mining - might have also resulted in a huge loss of the country's forest cover. This brings to over ninety percent the portions of Ghana's forests reserves that have been currently been logged and puts the rate of forest change to about two percent per annum (EPA, 2000). This is indeed a serious cause of concern given that forests are important sources of valuable biodiversity. As explained earlier, they also serve as carbon sinks, windbreaks and are providers of economic activities to local communities and repositories of culture and tradition.

\section{Water pollution}

Yet another growing cause for concern is the pollution of the country's ground and surface water resources. The Volta Basin System, the South-western Basin system and the Coastal Basin system which together consists of rivers such as the Black Volta, the Pra and the Densu, have become highly susceptible to pollution as a result of industrial and mining activities, agricultural development as well as domestic and rapid population growth. Best evidence of this is Korle Lagoon - an erstwhile pristine lagoon and source of fish in the capital city of Accra - which has been negatively impacted by the increased

\footnotetext{
${ }^{36}$ Ghana's timber exports and other wood products in the first three quarters of 2008 brought in an estimated EUR 144.42 million, up from about EUR 135.55 million in the previous year
} 
levels of industrial activity and consumption by the urban population. This has earned it the most unenviable label of being one of the most polluted water bodies worldwide (Owusu Boadi and Kuittunen, 2002). Also worthy of mention here are major multinational mining companies including Newmont Ghana Ltd, AngloGold Ashanti Obuasi mine, Golden Star Resources (Bogoso and Prestea Mines) who have been responsible for the release of large quantities of cyanide into rivers in numerous mining communities. ${ }^{37}$ A related problem, although minimal in comparison to the latter, is the contamination of ground water resources from industrial and manufacturing activities.

\section{Atmospheric pollution}

Although Ghana, like other African countries produce negligible amounts of air pollutants and greenhouse gases in comparison to other parts of the world, emissions from point sources including vehicles, industries, have become a cause of concern in recent years. The introduction of economic reforms in 1983 has, for instance, seen a marginal growth in the manufacturing and construction industry which the EPA (2002) cites as one of the major sources of pollutants. In Ghana, the latter has been directly linked to the increase in emission of various air pollutants including oxides of Nitrogen (NOx), Sulphur Dioxides (SOx), and particulate matter. ${ }^{38}$ On the other hand, the high density of second hand automobiles with an estimated growth rate of about $6000-8000$ vehicles per annum has led to an increase in atmospheric lead emissions and other dangerous substances particularly in the urban parts of the country. ${ }^{39}$ For example,

\footnotetext{
${ }^{37}$ See a detailed discussion of this in chapter five

${ }^{38}$ Boah, I.J.K., "Air Pollution in Ghana: Issues, Trends and Challenges" National Nuclear Research Institute, Accra Ghana

${ }^{39}$ Ibid
} 
Kumasi, one of Ghana's big cities, saw an increase in vehicular emissions from $682 \mathrm{Gg}$ in 2000 to $883.5 \mathrm{Gg}$ in 2005 . $^{40}$ The implications of urban vehicular emissions on local air quality and human health and the ecosystem are debilitating, to say the least. Also, vehicular emissions, as the EPA points out, are also a major source of greenhouse gases such as carbon dioxide (EPA, 2000).

\section{Desertification and land degradation}

Desertification, according to the UN Convention to Combat Desertification (UNCCD) is the degradation of land in arid, semi-arid, and sub-humid areas brought about by variations in climate as well as human activities (UNCCD; 2000a). In Ghana, deforestation, and periodic droughts have resulted in desertification particularly in the Northern parts of the country comprising the Northern, Upper East and Upper West regions ${ }^{41}$ where it continues to negatively affect the soils of the area, resulting in increased soil erosion, reduced soil fertility and low crop yields. Ghana is said to be losing five percent per annum of agricultural Gross Domestic Product (GDP) as a direct result of the latter (Dogbevi, 2009). The degradation of land through sheet and gully erosion is also a growing cause of concern in other parts of the country such as the Afram Plains in the Eastern region of Ghana.

\section{Coastal and Wetland Degradation}

Ghana has a wide array of coastal and marine resources including lagoons, mangroves, marshes and estuarine swamps, beaches and cliffs which, among other things, provide

\footnotetext{
${ }^{40}$ Agyeman Bonsu, K.W. Dontwi, I.K., Tutu Benefoh, D., Bentil, D.E., Boateng, O.G., Asuobonteng K., Agyeman W, (2010) "Traffic-driven modelling of vehicular Emission using COPERT III in Ghana: a Case study of Kumasi, American Journal of Scientific and Industrial Research, Vol. No. 1

${ }^{41}$ Together this area constitutes about thirty percent of the total land area of the country and is mostly savannah land.
} 
supply spawning and nursing grounds for numerous species ${ }^{42}$ including migratory birds. They also serve as significant tourism potential and are considered a major source of livelihood for numerous communities. These resources are however currently being negatively impacted by natural threats including the rise in sea levels, and also by human settlement, domestic and industrial water releases, sand and gravel winning, excessive fishing and so on. It is estimated for instance that by 2020 , as many as 16 of Ghana's 21 coastal districts will have 'high' and even 'extreme' levels of pollution from domestic sources alone ( UNEP, 2007 ). It is also important to note, that the recent oil discovery off the coast of Cape Three Point of the Western Region of Ghana, if not well managed, also has the potential of exacerbating the pollution and degradation of the already fragile coastal and marine ecosystem. ${ }^{43}$

\section{Poor Waste Management and Sanitation}

One of the major environmental problems in Ghana today is the inefficient management of waste and poor sanitary conditions. There is an acute shortage in waste disposal systems and facilities. These not surprisingly have resulted in the indiscriminate dumping of industrial and domestic waste. At the domestic level, households without access to solid waste disposal facilities have turned their owned backyards into dump sites resulting in unhygienic and insanitary conditions (AMA, 2008). Data provided by the Waste Management Division (WMD) of the Accra Metropolitan Authority show that although an estimated 2000 metric tons of solid waste is generated in the capital city of

\footnotetext{
${ }^{42}$ There are also about 15 species of fish, 42 species of water birds, 3 species of the marine turtle, and the West African manatee that make the inland and coastal marine resources their roasting grounds or habitats.

${ }^{43}$ Environmental issues associated with oil and gas production range from acoustic emissions, and accidental chemical spills to waste disposal as well as water pollution.
} 
Accra, only 1200 metric tonnes of this waste is collected on a daily basis. The remaining amount continues to be improperly disposed in the city's drains, streams, beaches, canals, resulting in unsanitary conditions. The EPA also projects daily waste generation in Accra to rise to about 4000 metric tons by the year 2025 . One third of Ghana's population, according to the 2000 National Population and Housing Census, use public toilets commonly known as the Kumasi ventilated Improvised Pits (KVIPs) most of which are offered on a user-fee basis. This, needless to say, encourages dumping of faecal waste in surface waters and drains and creates a pressing sanitation problem with dire consequences.

The 2005 Ghana Living Standard Statistical Survey (GSS, 2005) estimates that more than forty percent of Ghanaians in rural, urban and peri-urban areas die each year from diseases related to unsafe water and poor hygiene. The increase in the usage of plastic products - mainly plastic bottles, sachets, wrappers, bags, combined with failure of authorities to initiate or encourage recycling programs has helped to create a plastic waste problem or crisis with most of the used plastic ending up as waste on the streets. For their part, manufacturing and construction industries have in recent years made some efforts to introduce waste recycling technologies ${ }^{44}$, but the effects of the latter are far outweighed by the large volumes of industrial waste that is dumped in drains, surface water and landfills. Ghana, in recent years, has also seen a rapid increase in the importation and trade of second-hand electronics such as computers, televisions, refrigerators and phones, many of which have been deemed obsolete in their countries of origin and therefore serve very

\footnotetext{
${ }^{44}$ Guinness Ghana Ltd derives some revenue though the sale of spent yeast and grain as animal feed to livestock farmers.
} 
limited purposes to their new owners. The disposal of the latter has also become a growing cause of concern. Another related problem is the disposal of electronic waste originating from developed countries in Ghanaian dumpsites which has left relevant authorities scrambling for solutions, given the non-biodegradable nature and toxicity of these materials. The table below attempts to paint a better picture of the sources and effects of Ghana's environmental problems.

Table 2: Ghana's Environmental Problems: Sources and Effects

\begin{tabular}{|c|c|c|}
\hline $\begin{array}{l}\text { Environmental } \\
\text { Problems }\end{array}$ & Sources & Effects \\
\hline Deforestation & $\begin{array}{l}\text { Unsustainable timber harvesting, } \\
\text { construction of buildings and } \\
\text { other infrastructure, land grazing }\end{array}$ & $\begin{array}{l}\text { Erosion of soil, disruption } \\
\text { of water cycles, } \\
\text { loss of biodiversity and } \\
\text { wildlife, flooding and } \\
\text { drought }\end{array}$ \\
\hline Water Pollution & $\begin{array}{l}\text { Direct Sources: Factories, refineries, } \\
\text { waste treatment plants, } \\
\text { Indirect sources include contaminants } \\
\text { from soil and ground water systems } \\
\text { and from the atmosphere }\end{array}$ & $\begin{array}{l}\text { Poisonous drinking water, } \\
\text { poisoned food and } \\
\text { animals, } \\
\text { unbalanced river and } \\
\text { lake ecosystems } \\
\text { incapable of supporting } \\
\text { life, } \\
\text { deforestation from acid } \\
\text { rain, } \\
\text { human health }\end{array}$ \\
\hline $\begin{array}{l}\text { Atmospheric } \\
\text { Pollution }\end{array}$ & Industries, traffic and agriculture & $\begin{array}{l}\text { Smog, Acid deposition, } \\
\text { erosion of buildings and } \\
\text { other infrastructure. }\end{array}$ \\
\hline $\begin{array}{l}\text { Desertification } \\
\text { and Land }\end{array}$ & $\begin{array}{l}\text { Overgrazing, loss of forest and } \\
\text { vegetation cover }\end{array}$ & $\begin{array}{l}\text { Flooding, drought, } \\
\text { food scarcity, }\end{array}$ \\
\hline
\end{tabular}




\begin{tabular}{|l|l|l|}
\hline Degradation & & environmental conflicts \\
\hline $\begin{array}{l}\text { Coastal and } \\
\text { Marine } \\
\text { Degradation }\end{array}$ & $\begin{array}{l}\text { Rapid urbanization and over fishing, } \\
\text { sea- level rises, industrial and } \\
\text { shipping activities }\end{array}$ & $\begin{array}{l}\text { Loss of coastal and } \\
\text { marine ecosystems, } \\
\text { loss of tourism revenue, } \\
\text { loss of livelihood }\end{array}$ \\
\hline $\begin{array}{l}\text { Solid and Liquid } \\
\text { Waste } \\
\text { management }\end{array}$ & $\begin{array}{l}\text { Industrial, domestic and trade } \\
\text { activities }\end{array}$ & $\begin{array}{l}\text { Health and aesthetic } \\
\text { impacts, } \\
\text { Pollution of streams and } \\
\text { water ways }\end{array}$ \\
\hline
\end{tabular}

Source: Field Survey, 2008

It must be noted however, that the steady decline of the environment in Ghana has not taken place within a policy vacuum. Rather, mention can be made of several initiatives and actions put in place by successive governments which promise to deal with problems at the national, regional and local level. For instance, on the international level, the country is signatory to important international agreements such as the 1992 Convention on Biological Diversity (CBD) ${ }^{45}$, the United Nations Framework on Climate Change (UNFCC), ${ }^{46}$, the Convention on International Trade in Endangered Species ${ }^{47}$, the Ramsar Convention on Wetlands ${ }^{48}$, and the Basel Convention on the Control of Trans-

\footnotetext{
${ }^{45}$ The CBD is a global, comprehensive agreement, put together at the 1992 Earth Summit in Rio to address all aspects of biological diversity: genetic resources, species, and ecosystems.

${ }^{46}$ This is an international treaty that seeks to addresses the problem of global warming and what could be done to tackle its inherent causes. The Montreal, Kyoto protocols are some of the measures that have arisen out of this treaty.

${ }^{47}$ An international treaty that aims to ensure that international trade in specimens of wild animals and plants does not negatively affect their survival.

${ }_{48}$ This is an intergovernmental treaty that commits its members to the protection and maintenance of their wetlands of international importance and to the sustainable use of all their wetlands.
} 
boundary movement of Hazardous Waste and their Disposal. ${ }^{49}$ Also Ghana was one of the first of the developing countries to set up an environmental institution. The Environmental Protection Council (EPC) was established in 1974 by National Redemption Council Decree 23 under the supervision of the Ministry of Finance and Economic Planning with the mandate of coordinating the activities of all bodies concerned with environmental matters and advising the government on all matters related to the environment.

The passage of the Environment Protection Act (Act 490) in 1994 saw the transformation of the EPA into a regulatory body charged with the implementation of government environmental policies and programs. The Ministry of Environment and Science and Technology was also created in 1993, charged with managerial and oversight responsibilities within the environmental sector. In many respects, therefore, Ghana appears to be a torchbearer in the sub-Saharan region in the 'battle' against environmental degradation and natural resource exploitation. Hence, one would presume that that some significant progress might have been made gradually towards the amelioration of these problems. This, as evidence presented in support of this study suggests, is far from the truth.

Effective or transformational leaders, as earlier argued, are those who do not fold their arms and do nothing. The dismal state of Ghana's environment, in effect, raises several efficacy issues about the ability of successive coalitions of elites to harness the requisite

\footnotetext{
${ }^{49}$ This is a treaty aimed at the protection of human and environmental health against the adverse results of the generation, management and trans-boundary movement and disposal of hazardous waste.
} 
resources to direct and influence individuals and groups towards the attainment of national, regional and local environmental goals. Modern elites, for their part, have been exposed to major environmental approaches as outlined in the literature, and yet have so far failed to customize these approaches, as and when necessary, to fit and solve prevailing environmental problems in the country. Assessing the performance of elite coalitions entails further examination of some of these management approaches.

\subsubsection{Environmental Management Approaches}

The fact that environmental problems of huge proportions exist particularly in developing countries such as Ghana, is undisputable. There is still no consensus, however, about how issues of the environment, particularly its management, should be approached. For some scholars, researchers and academics, environmental problems are economic in nature (Freeman et al, 1973). This is evident in the literature that analyzes environmental problems using economic concepts, models and frameworks. As some economists contend, production or economic activities are innate to human society. The main argument contended here is two-fold: that there is little to distinguish human kind from the millions of other species that exist on the planet; and that humans like all other organisms survive and grow by extracting material and energy from the ecosystems of which they form a part. This they point out, is not a problem by itself. Rather, the problem is that, economic and production activities are often conceived of and undertaken without meaningful regard to the need to reduce waste and resource expense. Production can go on so long as markets function effectively to ensure that externalities are factored into the policy decision-making processes, that those who are responsible for 
harming the environment pay (Weizsacker et al, 1997). But, when the market system fails in accounting for the costs of negative externalities, environmental problems begin to arise.

To economists, environmental degradation results mainly from the failure of the market system to "efficiently allocate environmental resources among their alternative uses" (Freeman et al, 1973; v). Clearly, this view minimizes the role that natural conditions play in environmental degradation. For economists, therefore, environmental problems occur because markets for environmental goods and services do not exist or when the markets do exist, market prices underestimate social costs - externalities including environmental consequences for producing those goods traded in the markets. The profit motive is what drives private enterprise to have no concern for the public good. If government fails to make business pay for the social cost of externalities with the view of repairing the damage, the environment continues to suffer. Even if government makes business pay, but diverts the amount collected to other activities it considers of higher priority, it is the environment that suffers. Hence, it is not only the profit motive that might menace the environment, but also government policy, especially policy as the course of inaction.

The tragedy of the commons is another factor which market-based solutions do not address adequately. For environmental resources such as clean air, water in river and springs, oceans and atmosphere, property rights are not well-defined. Markets can exist and function efficiently only when property rights on goods and services exchanged are 
well defined and transaction costs of exchange are small. ${ }^{50}$ Garrett Hardin's classic allegory of The Tragedy of the Commons forms the basis of this prescription. Common property regimes, as Hardin argued in his 1968 classic, are associated with 'inevitable' resource degradation. Policy options for internalizing negative externalities popular among economists centred on the use of economic or market-based instruments. The argument here is that market-based instruments, when properly designed and implemented, provide incentives for businesses and individuals to act in ways that further not only their own financial goals, but also environmental goals as well.

Economic instruments, economists argue, have more intrinsic values and are more effective than conventional approaches which, in most instances, are costly, static and limited in scope. Questions, however, remain about the efficacy or practicality of economic solutions to environmental problems. It has been pointed out, for instance, that increased flexibility associated with market-based instruments does lower the overall level of environmental protection. Then, there are others who believe that market mechanisms condone the right to pollute whereas conventional government instrument including command and control mechanisms have more superior moral virtue (Stavins and Whitehead, 1997).

As a close look at the literature reveals, most environmental management approaches are rationally-based technical endeavours. This is not surprising considering the fact that, in

\footnotetext{
${ }^{50}$ This thought can be traced to Garret Hardin's allegory of the Tragedy of the Commons in which he makes the argument that when land tenures are insecure, there is little incentive for tenants to prevent land degradation.
} 
modern industrial capitalist societies from where initiatives for environmental management solutions have emanated, decisions and actions are guided by reasons of efficiency and calculability rather than by emotional or traditional ones. As Oakeshott points out, modern rationalism stands for "independence of mind on all occasions" and "thought free from any obligation to any authority save the authority of reason..." (cited in Mckevitt and Lawton, 1994: 4). Thus, the assumption of the 'sovereignty of reason' which underlines this approach to problem-solving is one which implies the 'sovereignty of technique'. A good case in point is the preventive management paradigm which contends that prevailing environmental threats, as they persist in the world today, are simple manifestations of the failure of the human-centered or anthropocentric model. Anthropocentrism is that world view that promotes the idea that humans are over and above all other earthly creatures and therefore decisions should be made to maximise the value of total net benefits to humans. The solution is to effect worthy, sustainable and long-lasting changes through the introduction of preventive strategies and policies. ${ }^{51}$ The problem with this approach is how to define the "sustainable" and the "long-lasting" taking into consideration uncertainties such as unintended consequences arising from the short term and medium term which might extend into the long term. To emphasize the vagueness or ambiguity of the long term and to point to the need to define it more precisely, some even argue jovially that in the long run we are all dead.

\footnotetext{
${ }^{51}$ Measures such as regulatory standards and limits, cleaner production techniques have suggested and in many cases adopted to help combat problems such as air and water pollution.
} 
Also related to these strategies is the reactive or punitive paradigm that aims mainly at controlling the potential deleterious impacts of human activities on the environment. Thus, the emphasis here is control, not the eradication or prevention. Popular particularly among economists, the punitive or reactive paradigm, argues that the problem is not so much with production or economic activities that are an innate part of the human economy. Rather, the problem is that, economic and production activities are often conceived of and undertaken without much regard to the need to reduce waste and resource. Here, emphasis is placed on the application of criminal and administrative penalties and mechanisms to ensure compliance and, thus, control human behaviour. Another popular world view - compensatory management paradigm - is very much similar to the reactive or punitive management paradigm considering that it seeks to modify the latter, rather than seek alternatives to the anthropocentric or human centered world view of the environment. The goal here is attempting to prevent the slow decline of environmental quality and help mitigate adverse environmental impacts through the use of relevant measures and policies (Barrow, 2003).

Successive governments in Ghana, since the late 1980s, appear to have pushed for some form of action as far as management of the environmental and natural resources is concerned. But, it does seem to be the case that a great deal of what is being done is, however, at the direct behest of foreign donors and institutions. This is a clear indication of weak or ineffective leadership on the part of the modern elites. For instance, it was at the 1992 United Nations Conference on Environment and Development (UNCED) in 
Rio, Brazil, that Ghana agreed to mainstream environmental protection into the economic growth agenda, as this was crucial to sustainable development. This has seen a burgeoning of sustainable development-related policies in the country and on the subSaharan continent as a whole. Prominent among the latter is the adoption by most African countries of Agenda 21 described as a "comprehensive plan of action to be taken by all governments... in every area of human life that impact the environment" (UN, 2004: 1).

The commemoration of the tenth anniversary of the 1992 Earth Summit in South Africa goes to show how 'seriously' the notion of sustainable development is being taken by African governments and policy makers alike. This in itself is not entirely a bad thing. What is disconcerting, however, is the assumption common to management paradigms (such as the ones discussed above) that environmental problems are technical problems that can be solved through rational means. Such an assumption, for one thing, minimizes or treats as insignificant the underlying power dynamics of any given society and how the latter affects and shapes processes of choice and action, including the technical in any given setting. Technical or rational approaches to environmental management also erroneously take as a constant for all cases, the larger political and cultural context within which these initiatives are implemented. It is not surprising then that proponents are left scrambling for answers when these approaches and paradigms fail to realize any of their prescribed goals as is the case for most developing countries including Ghana.

Ghana's approach to environmental management is a fusion of the anthropocentric and rational approaches. On the one hand, it panders towards a preventative and sustainable 
philosophy that promotes socio-economic development while recognizing the need for adherence to environmental standards. On the other hand, there is some reliance on the application of rational tools such as the Environmental Impact Assessments (EIAs) which are supposed to guide authorities in assessing the suitability or otherwise of proposed development plans. The country has also developed a sustainability framework and a number of sustainable development indicators all of which are meant to guide national efforts in attaining the relevant goals. Given the fragile nature of its economy and the numerous socio-economic problems, the country's preference for this approach is not a mere coincidence.

The reality is that the management of public issues - in this case the environment- takes place within a larger context and is shaped by several conditions, some of which are political in nature. Consequently, the latter can be linked to several norms or values all of which are, in essence, normative underpinnings of the democratic political theory. Of notable interest here is the issue of citizen rights and how they can potentially be impacted upon or compromised by governmental actions (Harmon and Mayer, 1986). It is important to note that normative prescriptions of individual rights are rooted in constitutional democratic theory which links the rights of individual and groups to the process of governing itself. Consequently, principles have been developed to "provide protection to the individual and the group on one hand, and redress for violations of those protections on the other" (Ibid; 45). 
Difficulties, however, arise in instances where leaders are reluctant or unable to uphold and enforce these principles. In Ghana, citizens adversely affected by the environmental and social impacts resulting from the construction of a hydro-electric dam at Akosombo, had very limited recourse for action when government after government demonstrated little or no political commitment towards the resolution of these matters. This, of course, brings to the fore, issues of representation and raises questions about how much control the citizenry actually have over the workings of its government and its agents. This is well illustrated in Arnstein's 'ladder of citizen participation' which depicts a range, from non-participation, tokenism all the way to citizen power. As she points out,

"Citizen participation is a categorical term for citizen power. It is the redistribution of power that enables the have-nots citizens, presently excluded from the political and economic processes to be deliberately included in the future. It is the strategy by which the have-nots join in determining how information, goals and policies are shared..." $(1969 ; 216-24)$

Yet another perspective on citizen participation is provided by the Organization for Economic Cooperation and Development (OECD) that for its part argues that there are three major ways in which governments can improve and strengthen their citizens, i.e. information, consultation and active participation. Suffice it to say then that, encouraging citizen involvement undoubtedly provides a way of strengthening the legitimacy of the political process. It is a viable and almost foolproof means of promoting the public 
interest and confidence in public affairs. In philosophical terms, the argument could be made that all individuals in democratic societies do not only have the right to be informed and consulted, but to be allowed to possess or be part of the decision-making authority structures on matters that impact or affect them. However, structures may be both enabling and constraining. In the particular case of Ghana, therefore, an analysis of the environmental institutions and structures and their effects is deemed appropriate in this research. It is recognized that agency and leadership are both possible within such structures, but the same structures might constrain, as well.

\subsubsection{The Structure of Environmental Management in Ghana}

The structure of environmental management in Ghana consists of a set of institutions, administrative structures, combined with a set of policies, laws and guidelines which together form the basis of the country's environmental management processes and practices. At the helm of environmental affairs is the Ministry of Environment; Science and Technology which is responsible for the formulation of policy on environment and science. The Ministry has several supporting agencies including the Environmental Protection Agency (EPA), the Council for Scientific Research (CSIR), the Town and Country Planning Department (TCPD) and the Ghana Atomic Energy Commission (GAEC). The EPA was created under the 1994 Environmental Protection Act, Act 490, and is backed by the Environmental Assessment Regulation LI 1652 as the main enforcing agency with regards to issues of the environment. With offices in all the districts in Ghana, the EPA is responsible for ensuring that the activities of organizations and individuals and the general public are in compliance with existing standards on the 
environment. To a large extent, however, the agency has proven to be rather ineffective with respect to the latter. For example, Ghana has regulations and standards including the Minerals and Mining Law, 1986, Mining Regulations, 1970, Small-scale Gold Mining Law, 1986 and yet the EPA has not done a good job of holding mining companies up to these existing standards and regulations. This has resulted, among other things, in the wanton contamination and degradation of water bodies in mining areas such as Obuasi and Tarkwa. ${ }^{52}$

It must be noted, however, that some measures have been undertaken at the national level that have seen some incremental changes and additions to the environmental management structure. Of notable interest here are the attempts in recent years to extend power from the central government to regional and local units. The most comprehensive attempt dates back to 1988 when the then military government of John Rawlings, as part of its decentralization program, created a total of one hundred and ten (110) District Assemblies (DAs) as "legislative, executive, planning authorities" (Ofei-Aboagye, 2000, 2). The overall objective was to improve existing practices of governance by first and foremost bringing government closer to the people, and even more importantly allowing for more responsive and participatory development processes. Two-thirds of its DA members are elected by universal suffrage with the other third of its members being appointed by the government in consultation with traditional authorities and other interest groups.

\footnotetext{
52 The operations of mining companies, in these mining towns have also led to acute degradation of farm lands which serve as the main source of livelihood for the local people. Other related problems include air, noise pollution, as well as pollution-related diseases.
} 
As provided under the 1992 constitution of Ghana, DAs are headed by District Chief Executives (DCEs) who are nominated by the president and endorsed by the assembly. The assembly, as a group, meets three or four times in a year and for the rest of the year functions through committee-based systems. This includes an executive committee that is in charge of formulating and implementing relevant policies for the districts, and five sub-committees that support the work of the main committee. In addition, assemblies are mandated to establish more sub-committees to deal with other outstanding issues as and when they become necessary. Worthy of mention here are District Environmental Management Committees (DEMCs) which are responsible, among other things, for formulating local policies, programmes and enacting bye-laws on the environment. Also supporting the work of the assemblies are "corps of civil servants, headed by a district coordinating director whose mandate it is to provide the needed administrative and technical input" (Ibid; 2), as well as traditional authority members some of whom can be appointed to the DAs. There are also, at the regional level, Regional Coordinating Councils, (RCCs) headed by regional ministers who mainly have supervisory responsibilities for all the activities of the various districts within their respective regions, including environmental ones.

It is viewed that political, administrative and institutional decentralization, when well implemented, have the potential to redistribute authority and responsibility particularly at the local level. But in Ghana, the problem of elite capture still exists. For instance, it is the President who nominates the DCEs with DA members only endorsing them. In reality 
therefore, it is difficult, if not impossible, for the assembly to reject the nominations of the President. Also it is the government in power that appoints one-third of the assembly members. This makes rejection of the nominations of the President even more difficult. There is little doubt, therefore, that the government in power is always in control of the DAs. Added to the latter is the fact that the country still lacks clear constitutional principles as well as legislative and regulatory frameworks which are necessary for effective and transparent devolution of power. The latter has led to the current state of affairs where conventional models of governance that rely on a top-down and centralized approach to policy execution are the norm rather than the exception.

A good case in point is the adoption by the EPA of four different levels of desertification control. At the national level is the National Desertification Committee (NDC). The rest include Regional Environmental Management Committees (REMC), District Environmental Management Committees (DEMC) and Community Environmental Management Committees (CEMC), (EPA, 2002). Representation of the wider section of the general public in these committees is lacking. A good demonstration of this lack of representation is the structure of membership of the DEMCs which consists only of the Regional Programme Officer of the EPA, selected members of the District Assemblies (DA), representatives of environmental NGOs as well as other representatives of other governmental institutions (EPA, 1998).

Decentralization demands the prior existence of adequate capacity at the lower levels and the ability of the central government to coordinate activities to ensure a compatible 
balance between centralization and decentralization. It implies that the government must have the resources to train and build capacity at the lower levels of government as well as resources to support coordination from the centre. Thus, while the creation of District Assemblies (DA) may be seen by some as a step towards empowering the various districts to take ownership of their developmental agenda, there is still more work to be done on the part of the centralized government to cede genuine autonomy to decentralized levels of government to manage their own affairs (Aryee, 1998; Mohan, 1996).

Apart from governmental structures, there are Non-Governmental Organizations, Community Based organisations (CBOs) and Civil Society bodies that continue to engage in the environmental sector. The latter (see Figure 2, below) which include NGOs, such as the Friends of the Earth (FOE), Third World Network (TWN), CARE, and CBOs such as Wassa Association of Communities Affected by Mining (WACAM) form an integral part of the environmental management structure (albeit informal), given their engagement in environmental activities such as awareness creation, campaigning and advocacy and capacity building. But salient challenges, exists that continue to hamper the work of these non-state actors. These include a persistent lack of funding, difficulties of land tenure for women and communities to undertake sustainable practices, and low levels of trust and working relationships and partnerships between governmental agencies on the one hand and the NGOs and CBOs/CSOs on the other. To a great degree, therefore, the current environmental management structure in Ghana is highly 
centralized, and characterized by a lack of coordination between the relevant actors and institutions.

\section{Figure 2: Institutional Structure of Environmental Management in Ghana}

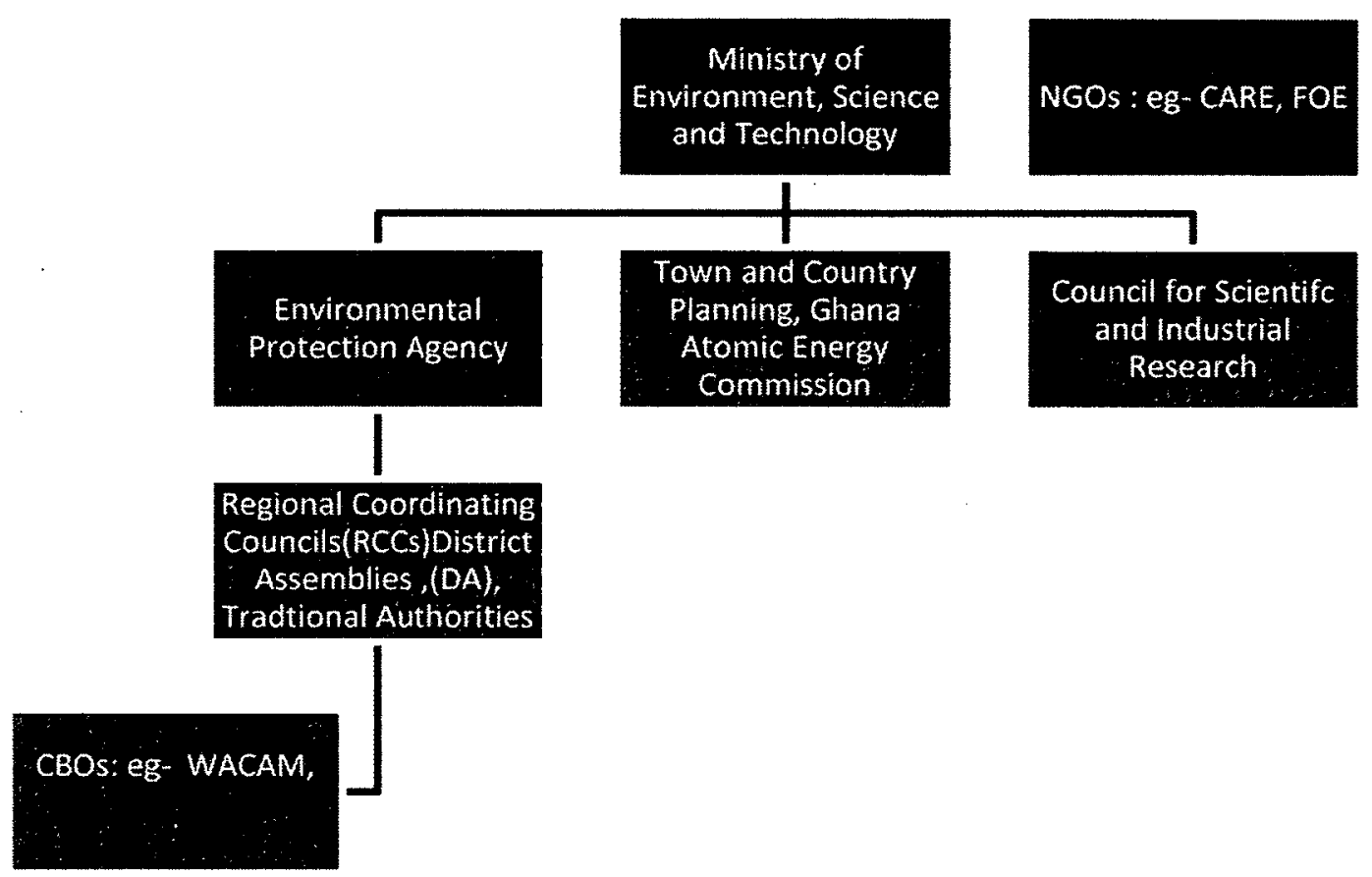

Source: Field Survey, 2008

\subsubsection{Ghana's Environmental Policy}

The adoption of the National Environmental Policy (NEP) in 1991 marked the beginning of efforts to prioritise environmental issues and create national awareness about the need for environmental protection (EPA, 1994). Seen as a culmination of actions initiated by the government in response to issues of sustainable development as identified by the 1987 Bruntland Report, Our Common Future, the NEP provides a broad framework for 
the implementation of plans and programmes that are aimed towards sound environmental management and promotes the integration of environmental issues into national development actions and processes. To a large extent, the policy reiterates the need for the maintenance of all ecological and ecosystem processes essential for the functioning of the biosphere as well as the protection of humans, animals, plants and their habitats. It also calls for the adoption of healthy environmental practices in the national development efforts and encourages the integration of environmental considerations in sectoral, structural, and socio-economic planning at all levels and promotes, as well, the need for common solutions to environmental problems in West Africa and the world.

Emerging from the NEP are specific policies and plans including the 1991 National Environmental Action Plan (NEAP) which takes an in-depth look at the key determinants of environmental sustainability such as land and water management, mining, human settlement and provides a framework for the management of these issues. Also worthy of mention are the 1994 Forest and Wildlife Policy, which promotes forest and wildlife conservation, the 1999 Environmental Sanitation Policy which outlines the principles for better environmental sanitation and environmental health, the 1999 National Land Policy and the 2004 National Action Programme to Combat Drought and Desertification which address issues of land management and land degradation respectively. Others include the 1998 Soil Fertility Management Plan which, as the name suggests, promotes the judicious use of land, and the 2006 Ghana Minerals and Mining Act which governs and regulates the activities of mining companies. 


\subsection{Summing up}

Ghana continues to be considered as a success story for political and socio-economic progress, particularly in international circles. Yet, the country continues to grapple with environmental problems including desertification, deforestation, coastal and marine degradation, water, pollution and poor waste management. These problems are on the ascendency and continue to impose further constraints on the socio-economic well-being and the quality of life of the Ghanaian society at large. To this effect, questions arise about the efficacy of actors traditionally associated with the management and protection of the environment. This chapter has drawn attention to the failure of the country's elites to demonstrate that transformational leadership skills needed to influence and direct individual and group behaviour towards attaining practical and sustainable environmental goals. That there is a pervasive lack of leadership on the part of the governing elite is exemplified, first and foremost, by the paucity of collaborative partnerships between the governing elites and other affected stakeholders. This might be the product of the centralized nature of existing governance arrangements. Another indicator is the lack of articulation or cooperation within the governing elite themselves and the resulting tension which has impacted negatively on the environment. This, for a country reputed to be a success in good governance practices and democratic reforms, is a cause for concern. To gain a better understanding of the current state of affairs, attention is turned in the next chapter to some of the major theories that have shaped or informed the modern elites in 
the country's preoccupation with the view of identifying and establishing governance arrangements best suited for the attainment of common national and societal goals. 


\section{CHAPTER TWO (2): LITERATURE REVIEW}

\subsection{Power Distribution and Democracy: The Theoretical Debate}

The preceding chapter has described how failure on the part of Ghana's political elites to open or make existing processes and practices of environmental management to include non-state actors has led to the current dismal state of the environment in Ghana. Given the country's embracement of liberal democratic politics and a concerted effort at facilitating the creation and establishment of democratic institutions (and by implication better governance), it is important that the conceptual underpinnings of democracy itself are further examined in this chapter. The debate surrounding the meaning of democracy is a highly contested one. In its pluralist sense, democracy is seen as a system that is built on and thrives on the equitable distribution and use of power and recognizes the existence of diverse interests within society.

These two main concepts, power and diversity, are ones that all democratic theorists seek to address, albeit in different ways. To help situate the different ways in which the concept of democracy is conceptualized in the literature, Dahl's idea of democracy is used here as the main point of reference. Western democracy, according to Dahl, can be described as a polyarchy or a system of government characterised by sub-system autonomy and organizational pluralism (Dahl, 1971). His basic assumption, as later taken up by the likes of Truman is that, organized groups form the basis of power in every western society. 
According to this view therefore, the level of efficacy and performance of groups within any western society, to a large extent, determines and shapes the successes and failures of that society. Dahl's idea of a democracy -a polyarchy - is one that necessitates three essential conditions. These include meaningful and extensive competition among organized groups including political parties bearing equal power. Dahl notes that, there must also be a high level of political participation in the selection of leaders through regular, free and fair elections. Thirdly, civil and political liberties should be attained by all. All of these, he argues are necessary to protect what he considers to be the two main pillars of democracy: inclusiveness and competiveness (Dahl, 1971). The latter, according to pluralist theorists are the key determinants of effective governance.

The notion of pluralism, however, has come under criticisms for several reasons. On the part of statist theorists or institutionalists such as Huntington, effective governance is realized not through the wide spread distribution of power, but rather through its aggregation at the centre (Huntington, 1997). He argues, the extent to which a country's resources and power is centralized to a large extent shapes and contributes to its political development, (and by implication better governance). This is an argument that has been taken up further by other state theorists including Joel Migdal, who goes as far to attribute the failure of Third World countries in attaining national and developmental goals to an inherent "lack of political centralization" (1977: 245).

The need for centralization is not the only criticism. The two themes of centralization (of statism) and inclusiveness (of pluralism) may not be mutually reinforcing. Also, one 
might be realized at the expense of the other. The possibility of asymmetry in the distribution of power coupled with the possibility of the dictatorship on the majority over the minority in a supposed democracy is yet another problem. In The Federalist, for example, James Madison and the other founding fathers wrote of their disapproval of societies in which one faction has an unfair advantage over others to the extent that it imposes its will over the rest. It was as a direct result of their criticisms over asymmetries in power relations that they designed for the United States of America, an elaborate system of checks and balances. This was to ensure the division and limitation of governmental power and the prevention of tyrannical majority rule. The logic behind the pluralist idea of democracy as far as structure and agency is concerned, is rather simple. All and not some of the citizenry have the potential to influence and shape the structures and processes of governance. Within any given society, power must therefore be equitably dispersed among all organized members of society. This opportunity, at least as far as Dahl is concerned, is best presented by political parties (Dahl, 1971).

Partisan politics, in the view of pluralists, necessarily engender effective and better governance. Unfortunately, not all members of society belong to organized groups and it is never mandatory that all members of society belong to some organized group or groups. Hence, not all the people have the potential to shape the structures and processes of governance through organized groups. Moreover, the assertion that power can necessarily be equitably distributed among organized groups, is theoretically admirable, but impossible to achieve considering the power of big business, and the weakness of 
disadvantaged and vulnerable groups such as immigrant communities and the physically disabled.

Other group theorists, such as Robert Putnam, while moving away from the emphasis of partisan politics in the enhancement of democracy (and by implication democratic governance), still lay a lot of emphasis on the fair distribution of power. In his book, Making Democracy Work, Putnam comes to the conclusion that good governance depends on a virtuous and public spirited citizenry (Putnam, 1993). The latter, he notes, serves as an effective system of checks and balances on their rulers and allow them to hold the rulers accountable and responsible for their actions. Consequently, civic norms and networks enhance the quality of public life. Even more importantly, they also contribute positively towards the efficacy of political actors and institutions. Associational life, he argues, thus forms the basis of a democratic society which, in turn, leads to efficiency and progress in the quest for national goals. It is fair to argue - based on the discussion so far - that pluralists including Dahl and Putnam attest to some inherent value judgement about democracy.

It is rather evident that pluralists see liberal democracy as a necessary precursor to political development and by implication better governance. Does this mean that undemocratic societies (as defined in the pluralist sense) can never develop or have effective governance arrangements? History abounds with examples of some dictatorships, authoritarian regimes and totalitarian regimes such as the former Soviet Union under Stalin developing faster than democratic regimes. Interestingly, the emphasis on competiveness, inclusiveness and civic engagement is one that has, in recent 
times, been incorporated into the externally-driven development agenda for Africa. ${ }^{53}$ The latter assertion, it must be pointed out, does represent a significant shift in the policy orientation of Africa's external partners as far as governance issues are concerned. Indeed, the linking of governance to development, as evidence shows, is a fairly recent occurrence.

Despite democratic grooming before the grant of independence, during the immediate post-independence era, 'development' plans for newly emerging independent African countries were characterised by an almost unanimous consensus about the need for a centralized and bureaucratized state (Haggard and Kaufman, 1992). The latter, was deemed necessary for the transformation of these societies into industrial and modern ones. Interestingly, very little was said about issues of political legitimacy and equity in the distribution of power. Not surprisingly, this was an era when one-party regimes, military and authoritarian rule were accepted and prescribed as essential pre-requisites to the developmental process in Africa, and in the drive to contain communism.

Against this background, one therefore sees how the ascription of a minimalist role of the state in development within the neo-liberal development paradigm marks a sharp departure from earlier thinking. Increasingly faced with a failure of its market-reform based economic programs for sub-Saharan Africa, International Financial Institutions (IFIs) notably the World Bank sought to tie the success(or otherwise) of the development agenda to existing governance systems. But, some critics have questioned why IFIs felt compelled to blame the failure of its programs on something external to itself without any

\footnotetext{
${ }^{53}$ See Claude Ake,(1996) Democracy and Development in Africa, Brookings Institute, Washington, , for a more detailed discussion on this.
} 
consideration whatsoever of the appropriateness of its own programs and policies within the developing country context. ${ }^{54}$ In identifying bad governance as the key reason behind the failure of its market based reforms for sub-Saharan Africa, the case for political renewal was made and the basis for the introduction of political reforms established.

A look at the literature indicates that there is indeed a wide array of governance issues that currently occupies centre stage in the debate over Africa's lack of development. This is especially so for the agenda of IFIs and other bilateral and multi-lateral organizations working in Africa. At the core of this debate is the confident assertion that good governance and democracy are not only desirable, but essential conditions for all societies. Taken together, 'democratic good governance' generally refers to a political regime based on a liberal-democratic model.

The liberal-democratic model, elevates to the fore the importance of partisan politics which supposedly lends itself to inclusivity and competition within any given society. Interestingly Africa's democratization processes have, in part, received positive reviews by liberal democracy advocates within the African continent itself. One such review comes from the New Partnership for Africa's Development (NEPAD) which, in its preamble, declares that, "there has been an increase in Africa of democratic regimes that are committed to people-centred development" (NEPAD, 2001: 7). Because NEPAD is

\footnotetext{
${ }^{54}$ In his article, "The Politics of One-Sided Adjustment in Africa" Osabu Kle argues that while Western countries continue to enjoy welfare benefits such as food stamps and welfare cheques, IFIs continue to compel African governments to implement structural adjustment that bring untold hardships to African populations. See the Osabu-Kle(2000) Journal of Black Studies, Vol. 30, No.4, for full article
} 
ostensibly supposed to be the brainchild of Africans themselves, this glowing review is accorded a lot of credence particularly in the international community.

But one would question how NEPAD could possibly be a reflection of the different spectrum of ideas and opinions when it's very formulation excluded civil groups and organizations that broadly represent the African society. The drafting process of NEPAD's main document involved selected elites mainly from the West including heads of Transnational Corporations (TNCs), economists and World Bank officials (Bond, 2002, Taylor and Nel, 2002). Obviously, the consultation with civil society and other social forces in this supposedly inclusive document was not considered to be a priority. It is within this context that NEPAD is not African- owned.

Affirmed pluralist like Dahl may want to believe that their 'vision' of democracy is one that affords everyone equal opportunities of competition and inclusion. As explained earlier, one flaw in the pluralist approach is that not all members of society belong to organized groups; also some groups including business are more powerful than others. The elite theory of democracy, for its part, has a different story to tell. A central premise of the elite theory of democracy is that in every society, it is an organized minority who makes and unmakes decisions. How this happens, however, is explained differently by different theorists. Robert Michel's elite theory of democracy is one that centres on the organizational dimensions of societal groups, specifically political parties. The size of the modern political party, he says, makes it impossible for all members to participate in decision-making. Also the complexity of party functions call for the delegation of authority. This, he notes, leads democracy in the direction of oligarchy (Michels, 1962). 
In short, partisan politics, Michels argues does not necessarily lend itself to democracy, at least in the sense that pluralists including Dahl conceptualize it. Here, the notion of political representation, inclusiveness and political equality becomes a myth. Elites in reality may be unaccountable and unresponsive to the masses. Geddes (1995), on the other hand, presents a pessimistic view of the significance of civil society in the democratic process. Using a rational choice analysis, the author explains how elites rarely make decisions in response to demands made by the masses. Instead, they base all their actions on their rational calculations, and seek to advance their own interests. Civil society, the author also points out, is usually fragmented, passive, apathetic and powerless. This notion that masses might actually influence the decisions and actions of their leaders is deemed as an unthinkable one (Ibid, 1995). Interestingly, pluralist democratic theorists like Dahl (1986), in more recent times, have come to acknowledge as rather simplistic, the assumption that everyone has a fair chance at competition and inclusion in any society. As he notes, gross economic inequalities within capitalist societies also contribute to asymmetrical power relations between groups and individuals. Also not all members of society belong to organized groups. There is indeed, an asymmetrical relation among organized groups with big business wielding disproportionate power. ${ }^{55}$

In its minimalist conception, democracy is viewed more as a means to an end and not an end in itself. Reference can be made here to theorists like Przeworski who believe that democracy is not an ultimate political or socio-economic panacea. Rather, it is the most

\footnotetext{
${ }^{55}$ It must be pointed out however that there have been instances in which the masses in Ghana have forced some changes in laws such as the Value Added Tax (VAT). This certainly attests to the potential for people power
} 
favourable political arrangement that can respond to societal demands in ways that preclude or discourage violence. He defines democracy as a system in which "political parties lose elections" (1991:10). Unlike theorists who make intrinsic values about democracy, Preworski maintains that democracy is useful because it ensures a level and equal playing ground to all parties and groups involved. The latter, unfortunately, does not hold to be true in the case of Africa which has seen a lot of elections-related violence, the most recent of which occurred in 2008 in Kenya. The adoption of competitive multiparty elections beginning in the early 1990 s, in sub-Saharan Africa, according to some Western scholars has opened up new prospects for further development for the African people. To some, the continent has experienced a second liberation. Yet the inherent competitiveness associated with multi-party politics alienates further the multi-plural and heterogeneous divisions that abound in Africa societies. This happens when people take sides with parties that appeal to their social, economic and political aspirations. As often noted, political leaders and strategists, also resort to all kinds of underhanded tactics to win more support and votes.

Pre-elections campaigns, characterised by bitter and sometimes dangerous rivalry between political parties are usually the norm in Africa. Tensions escalate to dangerous heights when those dissatisfied with the results, take to the streets, (with the tacit support of their party leaders) to vent their anger and wreak havoc on their 'enemies'. Even if one ascribes to the intrinsic values that democracy is said to bring, one must recognize the cultural, historical, socio-economic characteristics within the context in which it is being applied. So long as the latter is understated, the preoccupation with finding appropriate democratic governance will continue to be a misplaced one. Osabu-Kle in his book 
Compatible Cultural Democracy, reiterates this point when he notes that "only a democracy compatible with the African cultural environment is capable of achieving the political conditions for successful development in Africa" (Osabu-Kle, 2000: 9).

As far back as one can remember, the allocation of values and resources in any given society has been determined by its inherent power dynamics and by implication its political structure. Easton described the latter rather aptly, when he encapsulated the "authoritative allocation of values" in one word: politics. Politics as Lasswell also points out, is the study of "who gets what, when and how" (1965: 3). But in order to better understand, who gets what, how and when, we must know the entity that decides and its power or authority to do so. Consequently, the focus in this study is on the elite model of power distribution. The choice of the elite approach is not by any means arbitrary: rather it is the most apt choice considering the inappropriateness of other theories of power distribution to the specific case of Ghana. The attrition rate of interest groups in Ghana is so high that it may be described as volatile and ad hoc. Class-consciousness is too low to justify class analysis. However, it cannot be denied that there are both within the traditional ethnic society and modern sector of society, elites that are engaged in the act of ruling in various ways. The masses of Ghanaian society are aware that there is some organized few that rule and are responsible for making and implementing the policies that affect them.

Elite analysis is also compatible with group or pluralist theory when it is considered that it is elites that lead or manage the various groups and engage in negotiations in their interests. This view bodes well with Michel's iron law of oligarchy "whoever says organization says oligarchy" (Michel, 1962). Finally, it is compatible with actor-oriented 
institutionalism which holds that actors operate within institutional constraints to make and implement policies. They can make and shape these institutions in much the same way that institutions can shape their actions. This particularly applies in the Ghanaian context where the elite created institutions after independence which, in turn, shapes their actions even as they continue to shape those institutions. Indeed, as Ghana's former Prime Minister and sociologist, Dr Kofi Abrefa Busia argued, there exists a minority of the Ghanaian population who have pre-eminence over the rest of the population in terms of the influence they have over the allocation of societal values (Busia, 1956).

\subsection{Elites in society: concepts and definitions}

The role of elites in politics continues to be a focus of debate among political scientists as well as sociologists and political theorists. They all emphasize, albeit from different perspectives, how elites shape the effectiveness or otherwise of any given political system or society. Those who lay emphasis on the decision-making role of elites in society, for the most part, address themselves to notions of power and how the latter is wielded by the elites with little or no control from the rest of society. Then there are those whose interest in elites lie in the perceived ability of the latter to 'hold' or unite the society in which they can be found. Negative conceptions of elites also abound in literature: there is, for instance, that school of thought which perceives elites as being a major threat to the survival of democracy. Such views, while contradictory, are useful in as much as they demonstrate the very multifaceted nature of the elite concept. Indeed, as shown in relevant literature, studies on thematic areas ranging from political institutions, political behaviour, political ideology and political power all in one form or the other encompass the debate surrounding elites (Parry, 1969). This interest in the role of 
managers and leaders and the limits or otherwise of the power they possess in society is not new. Indeed, it was as far back as the sixteenth century when Machiavelli in The Prince laid out guidelines on the exercise of power by societal rulers. But it was not until the latter part of the nineteenth century (and the early twentieth century) that scholarship on elites was formally 'born.' As the state began to spread its influence into new areas of society, scholars such as Vilfredo Pareto and Gaetano Mosca, began to look into the functions and roles of leaders and the power wielded by the latter over society.

These classical theorists and others such as Michels and C. Wright Mills were all united in the view that, in any given society there exist a small minority of people, who possess the power to make all the major decisions that affect society as a whole. These decisions were political in nature because of their far reaching implications although classical theorists were quick to note that power, in most cases, extended beyond the realm of politicians or members of government. In other words, elites existed in society who, while not being politicians themselves, wielded a lot of political clout. Moving beyond the central thesis of elitism, however, classical theorists differed as to the how elites came to be who they were in society. For Michels, the biggest contributory factor for elite position and control is organizational capacity. Expounding on his now popular edict, "who says organizations, says oligarchy" Robert Michels (1962), explains how the very structure of an organized society leads inevitably to the formation of an elite class. As he argues, any organization, irrespective of its size, requires some sort of management and leadership to survive. Although these managers and leaders, he explains, may be elected by other members of the organization, the complex nature of the activities of the 
organization inevitably lead to situations in which group members cede control to their managers or leaders perceived to be best placed to manage mostly because of their skills and expertise.

For his part, Pareto (1935) identifies as the key factor for elite domination and control, elementary biological and psychological factors or human residues. The latter, he notes can be categorized into two major types: Class I residues which represents the imaginative or entrepreneurial ability of a minority in society to put together constructive ideas and Class II residues which represents the tendency of elites to consolidate their positions once acquired. The distribution of these residues within any given society determines its governance. While Class I residue are given expression in people who are more innovative and are willing to take risks, those with Class II residues, display tendencies of stability, loyalty and patriotism. Political life, he argues is best served when there is a circulation or dynamic changes in the mix of these elites. To wit: any given society is controlled either by a risk-taking or innovative elite at different times (Pareto, 1935). Gaetano Mosca has a lot in common with Pareto, although he gives greater emphasis than Pareto to the role of organisational superiority as the main source of elite power. C. Wright Mills (1956), on the other hand, explains the status and composition of elites in any given society in terms of its economic and social structure. As he points out in his study of Power elites in the United States, power, and by implication, elitism cannot be attributed to class or psychological attributes, but rather to institutional composition of any given society. In his view therefore, elites can be described not in 
terms of their actual power, but rather the potential power they stand to exercise by virtue of their control over these major institutions in society.

Conceptually the term elite as used in the context of this study refers to that minority who control important symbolic, material and political resources within any given society. The latter possess power not by virtue of who they are or what they have, but by virtue of the positions they occupy and the influence they wield. As C. W. Mills explains, elites are those "....in positions to make decisions having major consequences...and in command of hierarchies and organizations of modern society" (1959: 4). Also as Larry Diamond notes, the source of elite power can be traced to the "strategic locations" they occupy within existing structures in society (1987: 577). These positions in the context of Ghana encompass both traditional and modern ones. The common threads of Ghana's traditional structure includes the custodians of ancestral and community land. Others are the custodians of culture, customary laws, traditional history and initiators and champions of development activities in their respective areas of jurisdiction. For their part, modern elites, in general terms, are that group that has in modern times, emerged out of the struggle for pre-eminence concerning wealth, status, authority and control over the means of directing human activities or wills, and decisions about who gets what and when.

In Ghana, the source of elite power, to a large extent, is institutional in nature: key institutions vest certain positions and the individuals. who occupy these positions with the authority to make decisions about how and when to utilize resources controlled by these institutions. In other words, power is imputed to certain individuals by virtue of the fact 
that they occupy key positions that allocate and control wealth, status, force and knowledge in a given society. Suffice it to say therefore that, elites, by virtue of the positions they occupy and the influence they wield are vested with the power needed to mobilize the necessary resources for action on policy problems. Nevertheless, there are, in reality, multiplicity of factors that, in essence, determine whether or not this power will actually be effectively used to the advantage of society as a whole. It should be noted at this point that, the underlying concern of this study is neither the source nor justification of elite power. Rather the issues addressed here have to do with how elites have actually utilized power they possess and to whose advantage? Elitism goes beyond intelligence, or the genetic disposition of those in control. It is an issue of leadership, and willingness of those in charge to provide visionary leadership.

This brings to the fore the notion of the transformative use of power. The latter in the context of this study describes a leader's use of power to empower others or engender favourable political outcomes. As Waternburg notes,

In a transformative use of power, a dominant agent also exercises power over a subordinate agent for the latter's benefit. In doing so, however, the dominant agent's aim is not simply to act for the benefit of the subordinate agent; rather the dominant agent attempts to exercise power in such a way that the subordinate agent learns certain skills that undercut the power differentials between him/her and the dominant agent (1990: 222). 
To illustrate this further, this study presents the elite analysis in terms of their potential power vis-a-vis their actual exercise of power. This is rather necessary especially when one considers that there are several variables which help in determining whether or not elites (using the power they possess, and by implication the resources they control) can affect or determine the successful realization of relevant goals. Indeed, as power theorists including Eztioni (1968), Dahl (1957), Nagel (1975), have pointed out, one way to assess whether or not power is effectively utilized is through looking at its effects on behaviour or events. In this study, however, this notion of power will be expanded to include its effects on policy outcomes and societal goals as well. The significance of the latter is that, it does not only allow one to actually predict the outcomes of power use, but perhaps, even more importantly, the key variables that shape or determine exactly what these outcomes will be.

For instance, there are some democratic theorists who point to the degree of consensus among elites as one of the key determinants of progress in a state (Gould and Szomolanyi, 1997). The process of democratization is threatened whenever elites fail to agree on the very meaning of democracy and its associated norms and institution to the extent that some elites may prefer to rule through non-democratic means rather than forgoing their hold on power. Elite consensus, in this sense, refers not only to the extent to which the latter share similar ideas and views, but even more importantly the degree of access to crucial decision-making. Reference is made, for instance, to a strongly united elite who, as opposed to the divided or dis-unified elites, share common ideas about the 
rules and codes of political conduct as well as a reliable "access to each other and the most central decision-makers" (Boafo-Arthur, 2007:132).

It is rather obvious, as the above discussion shows, that elite pact, or degree of elite unity, does shape political or social outcomes. But as this study seeks to point out, the success or otherwise of political outcomes may not be necessarily limited to the unity or otherwise among elites. Indeed, the nature, of elite relationships with respect to their nonelites constituencies does determine to a large extent the transformative use of power. As Bernard Crick (1962) posits in his book, In Defense of Politics, the essence of politics is freedom of action. In other words, freedom of interaction is the pivotal wheel upon which political relationships thrive. Given that interaction is impossible without communication, an attempt is made in this study to conceptualize communication as an important aspect of political relationships. Indeed as John Dewey philosophises,

To learn to be human is to develop through a give-and-take approach of communication, an effective sense of being an individually distinctive member of a community; one who understands and appreciates its beliefs, desires and methods, and who contributes to a further conversion of organic powers into human resources and values... (1946: 332).

In a similar vein, Habermas (1979), in his theory of communicative action, affirms the importance of a public sphere in which citizens are able to actively participate in important political processes. Suffice it to say that, situations, in which distorted 
communication or silence is the rule rather the exception, immediately become a great source of concern. This, unfortunately, seems to be the case, within the specific context of Ghana, where the relationship between elites and their non-elites constituencies is one that is dominated by a culture of distorted communication and silence, domination and subordination. ${ }^{56}$

There is a lot to be said about the significance of communication in the effective running of any organization, institution or political system. Dewey, for instance, in The Public and its Problems, observes that "What is needed today is the perfecting of the means of communication of meanings, so that genuinely shared interest in the consequences of interdependent activities may inform desire and effort and thereby direct action.." (Dewey,1946: 332). As further mentioned, situations in which distorted communication or silence is the rule rather the exception are clearly a great source of concern. In Ghana's case, the government's communication approach is one that relies mainly on information dissemination and persuasion. A good case in point is the EPA's communication strategy which instead of a two- way communication model, employs a one-way approach with focus on radio and television broadcasts, pamphlet distributions, and newspaper publications to convey its messages to the public. This, the author argues, only serves to further widen the already existing gaps between the governing elite and non-elite constituencies.

Understanding the latter - the style of communication adopted by governing elites - also demands a closer look at the relationship between knowledge and power and how the

${ }^{56}$ Supporting evidence is presented in chapter five. 
latter influences the communication choices. As Barker has observed, there is, in addition to value-rational and democratic legitimacy, another form of legitimacy that is "to be found in the belief in the superior knowledge or skills of rulers... a belief which could take many forms, from a rational appraisal of technical ability to a deferential attribution of superiority"(Barker, 1990 :54). Of particular relevance to this study therefore, is the role science plays in the development of environmental policy in the specific case of Ghana. Broadly speaking, the reliance on scientific capacities for the development of policy positions can be traced to the colonial era during which "scientific expertise provided the legitimating authority for a range of interventions..." (Keeley and Scoones, 2003: 9). In some cases, 'expert' warnings about 'savannisation of forests' ${ }^{, 57}$. was, for instance, used as a basis upon which British administration reserved large amounts of forests. The latter was done ostensibly to protect the sanctity of the forests for the ultimate benefit of the public although the flagrant manner in which these forests were exploited for the lucrative timber trade belies this claim (Arce and Long, 1999). Ironically, patterns of technocratic policy making as Keeley and Scoones rightly point out, have "in recent decades been reinforced with the rise of involvement of aid donors" who, through the provision of "scientific expertise in the form of technical assistance", shape, to a great degree, policy development in all areas (2003:9).

As earlier discussed in chapter one, Ghana's environmental management structure is one that is characterised by a great deal of centralization and formalization with formulation, implementation and evaluation of environmental policies and programs left at the

\footnotetext{
${ }^{57}$ See Anthropology, Development and Modernities: exploring discourses, countertendencies, and violence, Arce Alberto and Long Norman (eds) (2000), Routlegde, London for an in-depth analysis.
} 
doorsteps of politicians and bureaucrats. At the risk of generalizing, the relationship between governing elites, and their non-elite constituencies could therefore be described as being paternalistic in nature. This has a direct bearing on the quality of governance which, in turn, impacts negatively on the achievements of outcomes.

\subsection{The Scope of Elite power: Challenges for Environmental management}

The scope of elite power, all things being equal, determines the extent to which they can shape or influence the outcomes of policy processes. Attention here is focused on Ghana's modern elite who, by virtue of the positions they occupy, control and allocate state resources. In this respect, it might be safe to argue then that both politicians and bureaucrats, by virtue of the positions they occupy, are key actors whose actions (or inactions) impact policy outcomes. ${ }^{58}$ Nevertheless, the exact scope of power and the relationships between members of the executive and bureaucracy has long been a subject of intense scrutiny and debate. Early scholars of public administration, for instance, saw a dichotomy between politics and administration. Bureaucrats, seen as mere executers of policies, were generally conceived to be apolitical in nature.

Politicians or elected officials, on the other hand, were seen as the ones who wielded considerable political power and, hence, controlled and shaped policy processes. In reality, however, bureaucrats by virtue of the positions they occupy and the very nature of their functions most often than not also tend to wield considerable amount of power which allows them to shape and influence policy processes. Bureaucrats, for example,

\footnotetext{
${ }^{58}$ In the case of Ghana, the impact of traditional elites on policy outcomes is minimal.
} 
exercise a lot of discretion in the implementation and execution of policies. As Heeger notes, the "complexities of issues of the modern state and bureaucratic expertise or superior access to expertise seems to necessitate a greater role for the bureaucracy in the initiation of policy" (Heeger, 1973: 601). As far as developing countries are concerned, there are those who see the bureaucracy as one of, if not the most important political institution (Smith, 2003). Not surprisingly, the concept of bureaucratic oligarchy or bureaucratic authoritarianism has been rather common with post-colonial state theorists who seek to draw attention to the powerful role played by appointed officials of the state. In Ghana, bureaucrats often have monopoly over expertise and knowledge which allows them significant leverage over policymaking in general.

All of this notwithstanding, the fact still remains that the bureaucratic apparatus continues to grapple with several challenges which severely limit the extent to which this power is used in its transformative sense. Prominent among these is the extreme politicization and erosion of bureaucratic norms and values. This problem has its genesis in the immediate post-independence era when the Nkrumah administration (first president of Ghana) introduced postcolonial reforms, which, among other things, sought to strengthen its political control over the public service. As Subramanian points out, the latter included the appointments of certain individuals to key positions within the bureaucracy (Subramanian, 1990). In recent times, however, the politicization of the bureaucracy have, to a greater extent, been achieved through processes of managerial reform particularly those informed by the New Public Management (NPM) paradigm. A good case in point: the Ghana Civil Service which assists government in the formulation and 
implementation of its policies has undergone several changes at the structural level. Not much has, however, changed in terms of how governmental actors - both political and administrative elites- mobilize human and material resources to attain environmental goals. Governance in other words still remains very elitist in nature.

\subsection{Conceptualizing Elite Governance: Propositions and Theories}

Several conceptual frameworks and perspectives have been developed to offer deeper insight into the complexities and intricacies associated with African politics - which are adaptable to the specific case of Ghana. Within the 'old' institutionalist school of thought, for instance, focus was for the most part placed on formal operations of key political institutions and, by implication, the factors that accounted for their successes and failures within African society. Then, there are historical perspectives propounded by the likes of Basil Davidson which attempted to link the inherent peculiarities of African politics to its long and often troubled history (Davidson, 1992). But the inadequacies of these early models led scholars and researchers to search for other conceptual frameworks that could offer deeper understanding as to why things were the way they were.

Modernization theory which held sway in the 1950 s and 1960 s, for its part, sought to give its interpretation of African politics on the basis of a fundamental assumption that there existed a gap between the so-called 'traditional' (and backward) societies of Africa and the 'modern' ones of the West. For instance, Binder in Crises and Sequences in Political Development, argues that the potential of any society to develop or advance, lies in its 
ability to resolve the various crises of identity, legitimacy, participation, equality and distribution that occurs as it attempts to 'cross'. the threshold from a 'traditional' to a 'modern' one (Binder, 1971). The 'underdevelopment' model, on the other hand, adopts a framework of analysis that explains the specific conditions and problems of African countries within the context of exploitation and asymmetrical power relations. A good case in point is Walter Rodney who in his book, How Europe Underdeveloped Africa, sees Africa's underdevelopment to be a result of imperialist and capitalist exploitation carried out by the Europeans who 'siphoned' off Africa's wealth and gave nothing back in return.

The debate about African politics has in recent times been centred mainly on the trend and patterns of democratization that has 'hit' the continent beginning in the 1990s. In the good governance discourse for sub-Saharan Africa, for instance, democracy is often presented as the necessary political framework for the attainment of national developmental goals. As has been repeatedly pointed out by the main proponents of this discourse, authoritarian and totalitarian governments have not only been assessed to be grossly inefficient, but also unable to execute national agenda as efficiently as democratic governments. The latter assertion is rather significant in as much as it brings to the fore the notion of regime type, its associated mode of governance and outcomes.

In the literature, the criteria for classifying regime types ranges broadly from policy orientation, ideology, through leadership styles and the degrees of competition, participation and control. On the whole, however, and at least as far as sub-Saharan 
Africa is concerned, the conceptual emphasis has been either on the style of leadership associated with a particular regime or the degree to which regimes either control or foster participation or competition. Placed on one extreme end of the continuum are regimes associated with an autocratic and coercive style of leadership and underpinned by a culture of control and exclusivity. On the other extreme are those regimes that are mobilizing and conciliatory in nature in terms of leadership and also foster competition and participation. By casting regime types in positive or negative terms, the case is then made for political renewal and regime change which, as advocates are quick to point out, is attainable through political liberalization and democratization. To be democratized is to move towards a more egalitarian society which is devoid of "autocratic authority structures" (Keller, 1996:204). Liberal democratic regimes are touted as the ideal form of democracy based on principles of rule of law, free and fair elections and popular participation in political processes. It is envisaged that with democratization comes fundamental changes in existing modes of governance. This, specifically, in policy terms, would connote changes in the processes of policy formulation and implementation. But with the state still dominating policy and decision-making processes in Ghana, participation by non-state actors can at best be described as transient and peripheral. Suffice it to say, therefore, that government is still the dominant agent of governance.

In his discussion of governance theory, Stoker (1998) underlines several propositions or principles which, in his view, form the bedrock of any inquiry into issues pertaining to governance. Some of these propositions - are discussed here, not only because of their 
theoretical implications, but more importantly the practical connotations they bring to bear on the analysis of elite governance.

Governance: an embodiment of institutions and actors from within and beyond government

The turn in governance studies in recent decades has been dominated by network theorists who advocate for a movement towards political entities that are conceptualized in terms of their 'fluidity' and 'multiple modes of authority' (Rosamond, 2000). The concept of multi-level governance which has, for instance, become immensely popular in European Union (EU) literature, is one that presents structures within the EU as consisting of "overlapping authorities and competing competencies" (Aalberts, 2004 : 23). The fundamental assumptions as they underpin network analyses can be traced, in very broad terms, to pluralist conceptions of society. The pluralist tradition is, indeed, popular for its 'minimization' of the significance of the role and influence of the state and its institutions. There is much emphasis on the activities of interest groups in society and how they shape politics as a whole. The notion of interest group pluralism, when subjected to closer scrutiny does, however, reveal several fundamental weaknesses. For one thing, empirical studies have revealed that "relationships are far more closed than pluralists had suggested" (Pal, 2006:.243). Hugh Heclo's depiction of American policymaking as being dominated by iron triangles, for instance, seeks to show how the circle of influence is limited to only a few groups within the American society (Heclo, 1978). The fundamental assumptions as they underpin interest group politics exhibit even more 
shortcomings when looked at within the context of Ghanaian politics, where political and bureaucratic elites essentially 'run the show'.

In the specific case of Ghana, policy-making and decision-making (in this case, as it pertains to the management of the environment) have in the past been unde 12 rtaken in a top-down and purely elitist manner. A good case in point: administrative and bureaucratic centralism have been justified and fomented on several grounds. One such justification often advanced by bureaucrats and politicians is that, centralism ensures that minimal natural resources are used optimally in accordance with national development priorities (Molebatsi :1994). Advocates of the administrative technocracy discourse also point out that decisions are best when carried out in a top down manner by experts and elites who are presumed to have a better grasp of the issues (Owakwah and Aswani, 2009).

The model of governance is more or less premised on the belief that government alone had sufficient resources to ameliorate social problems and steer society towards the realization of all its common goals. But it is this very model of governance which, as the literature suggests, has, in recent decades, come under attack from critics who have advocated for reform based on reasons varying from the growing ungovernability of modern society (Kooiman 1993); sheer inefficiencies and wastages associated with this model of governance (Osborne and Gaebler); or obsessiveness with rules and regulations (J. Wilson 1989; Barzelay 1992; Dilulio 1994). There are others who have called for a 'rethinking of government' based on what they describe as dysfunctions emanating from the permanent nature of government both for individual employment and public 
organizations (Walters 1992a and Kaufman 1976). Calls for administrative reform have also been made citing reasons varying from the overly hierarchical structure of the traditional model of governance to its non-deliberative, exclusionary and even sometimes undemocratic nature (Kernaghan 1992; Koven 1992a).

These calls for reform have been discussed and presented under various names: participatory management, street-level bureaucracy, discursive democracy and communitarianism. But there seems to be some unanimity among advocates of these approaches about the need for more participation and involvement within or beyond public organizations. As Koven (1992a) points out, advocates of communitarianism for their part, attempt to move beyond the idea that bureaucracies are the most important entities when it comes to the delivery of public services. Rather, the search for means of co-production and the increased involvement of the public is encouraged so as to make government work better. Within the communitarian model of governance, one therefore sees an emphasis on the significance of other non-state actors, (for example non-profit or third sector organizations existing outside of the public sector) to the long-lasting and practical solutions to many of societal problems.

Where governmental organizations have failed, these non-profit, non-governmental organizations, once 'infused' or inculcated with desirable communitarian values will more or less steer society towards the eventual realization of its ultimate goals. It is therefore not surprising that the literature on the "third sector' ${ }^{59}$ and its relevance to the

\footnotetext{
${ }^{59}$ This, in the context of this study, refers to all those groups, organizations, and individuals whose role are central to the well-being and progress of society
} 
success of public sector management has burgeoned in recent years. Of particular interest are those that focus on developing countries where recurrent instances of state failure and state mismanagement (perceived or real) have made activities of the "third sector' appear more attractive and perhaps more productive in the eyes of many. As mentioned earlier, environmental problems including desertification, deforestation, and water pollution continue to persist in Ghana. Such problems, threaten the very livelihood of the majority of affected citizens. This ironically is the case, in spite of efforts by past governments to tackle these problems at the national, regional and local levels. The inability of government to manage these problems stems mostly from its unwillingness or incapacity to engage non-state actors in policy and decision making processes.

Governance: acknowledgement of power dependence involved in relationships between institutions for collective action.

In recent decades, traditional models of governance have increasingly come under attack and several alternatives have been suggested. This includes the differentiated-polity model that underscores, among other things, the importance of "...institutional specialization and fragmentation of politics and policy" (Rhodes, 1997:3). The argument here is that, there is a limit to how any actor can dominate the agenda. Rather each actor, in order to attain expected goals, relies on the compliance and cooperation of other actors. Power is thus balanced to the extent that these different actors rely on each other for the attainment of identified goals. It could be argued then that the quality of governance can be determined, to a large degree, by the extent to which government relies or depends on non-state actors in the attainment of its policy objectives. Realistically speaking, 
however, the nature of power dependence for the most part tends to be asymmetrical. While governments depend on other actors for resources, these groups depend even more on government due to the latter's control and easy access to factors including tax-raising powers, legislations, and resources. (Richard and Smith, 2002). This appears to be the case particularly in developing countries such as Ghana where powerful non-state actors that can 'boost' of considerable influence over government still remain in the minority.

\section{Governance is about autonomous self-governing networks of actors}

Addressing the issue of autonomy as presented in the governance debate requires an understanding of the fundamental nature of the state. For the purpose of this study, the state is conceptualized as that central public domain, comprising "all individuals who occupy offices that authorize them and them alone to make and apply decisions that are binding upon any and all segments of society" ( Nordlinger, 1981: 11). The notion of sovereignty of rule is one that, in recent times, has increasingly come under fire particularly from governance advocates who call for a distribution and extension of this authority to include other relevant stakeholders. This contention is best captured in the New Public Management school of thought who advocates the introduction of public sector reforms aimed at changing the government's role from an interventionist one to a facilitative one. Osborne and Gaebler make this suggestion in their book Reinventing Government, in which they reiterate the need for governments to "steer rather than row". This, according to the authors can be done through empowering communities to solve their own problems and hence arrive at some level of autonomy from the government (Osborne and Gaebler, 1992). 
The state's envisaged role is to "govern ... by involving a plethora of ...intermediary groups (citizen groups, voluntary associations...) in the governing of society through the construction of self-regulating networks of responsible actors" (Torfing, 2005:307). The latter, however, is easier said than done. This is especially the case within the context of developing countries including Ghana where structural inequalities ${ }^{60}$ are some of the mitigating factors that prevent or discourage the creation of a level playing field where all or some can aspire to be independent and autonomous from the state.

Governance recognizes the capacity to get things done which does not rest in the power of the government to command or use its authority.

The concept of shared capacity as used in the governance literature refers to the ability of all relevant stakeholders to effectively introduce and successfully execute the necessary interventions towards the attainment of specific policy goals without intervention from a higher authority. Here the state is conceived of as being a part of the emergent network, but also seen as being dependent on other non-state actors to the same extent that the latter is dependent on them (Rhodes, 1988). In the specific case of Ghana, the establishment of a National Committee for the Implementation of Agenda $21^{61}$ (NACIA, 21) to help streamline environmental concerns into development programmes at the national, regional and local levels can be described as a step towards the adoption of the shared capacity concept. But, there is still a lot of work to be done in involving and coordinating the activities, not only of the relevant governmental and non-governmental

\footnotetext{
${ }^{60}$ This involves unequal relations between the state actors and other stakeholders.

${ }^{61}$ This is a global partnership created at the 1992 Earth Summit in Rio which commits all member countries to engage in continuous and constructive dialogue in support of issues of sustainable development.
} 
organizations, but also those of the communities for whom this problem is a daily reality. This might be realized when some effort is made to move away from traditional models of governance that rely on a top-down, centralized approach to policy execution.

\subsection{Environmental Policy making in Ghana: Through the Elite Framework of analysis}

Policy-making in the conventional sense is oft described in linear terms in which the relevant policy actors make rational decisions for particular policy areas. The linear rational model is useful in as much as it simplifies the rather nuanced and complex processes associated with policy making. But, it does to a greater extent fail to underscore the fact that policy making process is not only a rational or analytical one, but a political one as well. This perhaps explains the gradual shift of attention to a process-based view of policy making that lays more emphasis on the complex nuances underlying policy making. As pointed out by Dye and Zeigler, public policy in any given society, is not a fair reflection of the demands and aspirations of the 'people', but rather the "preferences, interests and values of the few who participate in the policy making process."(2003: 439) This holds true in the context of Ghana where environmental management processes point to elites being the central actors. ${ }^{62}$ For example, environmental planning processes, as shown in the diagram below, involve the relevant sectoral ministries and related organizations, regional, local and national authorities. There are several external actors including United Nations (UN) agencies and other bilateral donors who shape and influence planning processes.

${ }^{62}$ It important to point out that elites being the central actors is not a problem by itself. Rather, the issue is how they use this power to affect societal outcomes. 
Figure 3: Environmental Policy and Implementing Institutions

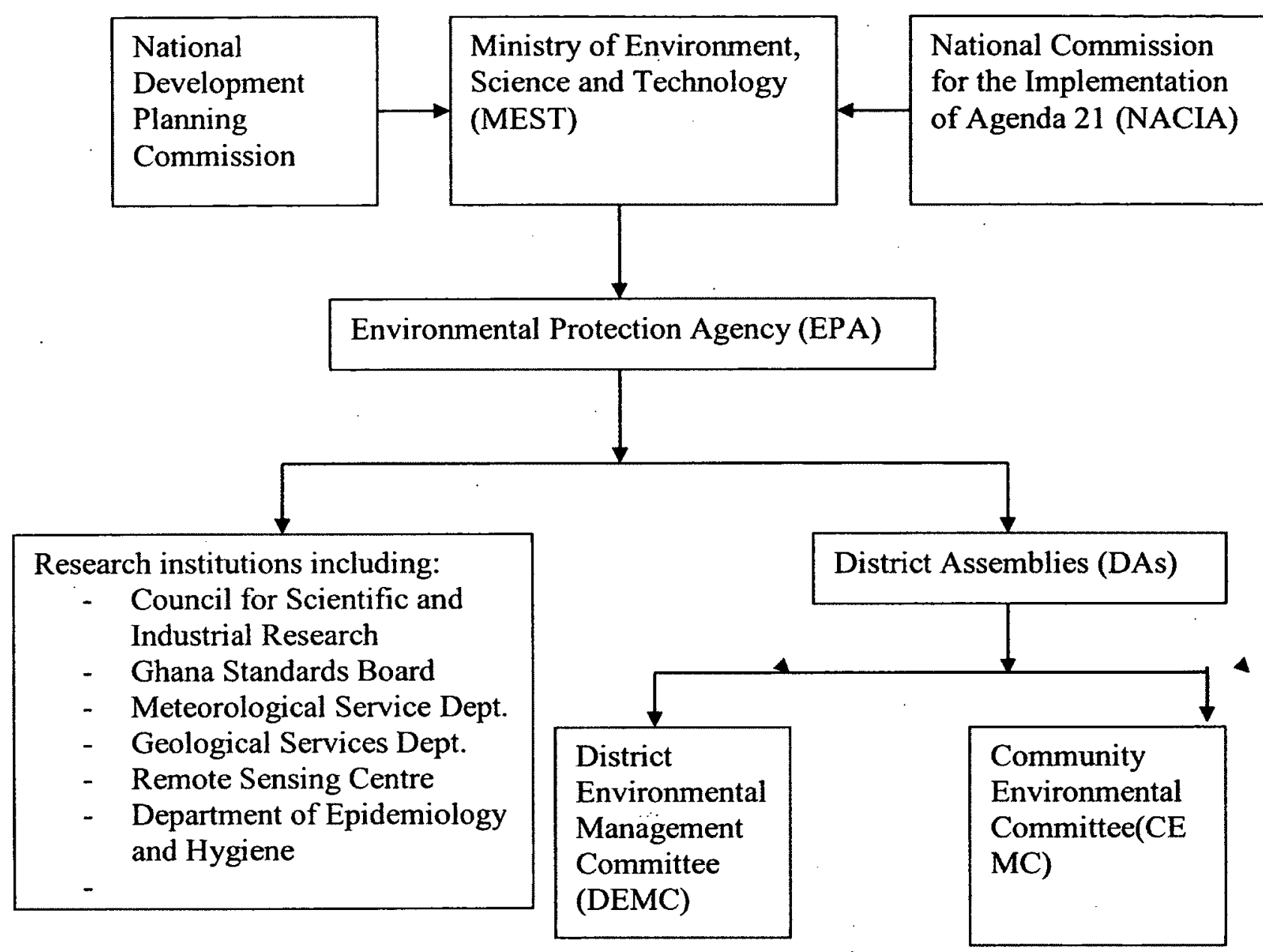

Source: Adapted from Boon E., K., and Hens L., ( 1999) "Institutional, Legal and Economic Instruments in Ghana's Environmental policy," Environmental Management, Vol 24, No.3

Underpinning these planning processes, in general, is the notion of rational planning which, for the most part, is being touted as the most effective and efficient means of attaining favourable policy outcomes. As noted by Marcussen, "the concept of planning is based on the idea of rationality whereby reality can be structured and controlled, changed at will ... and the outcome predicted" (2003: 2). In this sense, it could also be argued that all plans are driven by several goals, the key of which is to have some bearing on the achievement of positive outcomes. It becomes inevitable, then, for plans to reflect 
and express power struggles as they exist within any given society. In this sense, therefore, planning can be seized on as an instrument that provides for solidifying already existing power bases. It is perhaps in relation to this that advocates of communicative planning have, in recent years, called for a 'bottom up' approach that offers marginalized groups the opportunity to become involved so as to "create new powerful societal forces" (2003: 4). A look at the state of environmental planning does seem to suggest that there still remains a lot of work to be done particularly in the area of inclusive participation. For example, framers of the Ghana's Tropical Forestry Action Plan introduced in 1987 under the auspices of the Food and Agricultural Organization (FAO) from the very beginning reiterated the need for the close involvement and support of farmers and village communities as well as local and national NGOS, so as to ensure its success (FAO, 1987). But some twenty odd years later, the Plan has failed to achieve its major objective of combating the rise in the rate of deforestation. Part of the problem, Winterbottom (1990) and Cort (1991) explain, had to do with the fact that the contribution of grassroots organizations such as local NGOs to the development and implementation of the Tropical Action Forest Plan was minimal. The manner, in which the plan was drafted and implemented, in short, could at best be described as technocratic and top-down in nature.

In general, the historical experiences of developing countries such as Ghana relating to the planning and formulation action plans on the environment, reveals a consistent lack of stakeholder involvement (UNDP: 1995). Much of this, it must be noted, has to do with the fact that environmental information, as required and applied in these planning 
processes, in general, tend to be of a complex nature that is not easily understood by majority of stakeholders and also not readily available to the latter (Nath et al,1998).Yet another indication of the elitist nature of environmental planning is the role of the international power elite which, in the context of this study, refers to officials of the World Bank, International Monetary Fund(IMF) and other bilateral and donor organisations who, by virtue of their positions and associated power, are able to make decisions which have a far reaching effect on the majority of the Ghanaian society. Though the Bank is making efforts to improve consultation with developing countries, this process sometimes borders on tokenism since the concerns of developing countries is not reflected in final policy decisions.

\subsection{The International Pover Elite and Environmental Planning in Ghana}

The concept of good governance as promoted for sub-Saharan Africa by international donor communities is seen as encompassing three main dimensions: the state, civil society and the private sector. But as Farazmand (2004) points out, this triad interaction ignores perhaps the most important factor affecting governance in developing and lessdeveloped nations - the globalizing state power and the transnational elites. The international power elite has for the past century or so played a dominant role in the politics and economics of the Third World. A good indicator of this is found in environmental planning which has, in the past few decades, been on the ascendancy in developing countries such as Ghana. 
It is not a coincidence, however, that these plans have either been directly initiated or generously supported by donor countries and other international organizations. The World Bank, for instance, by the early 1980s, in response to the ever-worsening balance of payment problems in sub-Saharan countries including Ghana, began to devote a lot of attention to program aid. It is not surprising, therefore, that a lot more of responsibility was taken on by organizations such as the World Bank in the planning and preparation of what were considered to be relevant programs to combat sub-Sahara Africa's environmental problems (Devarajan et al : 2001). Donor countries also developed interest in environmental management on the realization that the consequences of environmental management are not limited to the developing countries alone, but are global in nature. Hence their direct initiatives in environmental management in developing countries and apparent generosity might not be all that altruistic after all, as their associates or agents would make as believe.

A good case in point on the part of the World Bank is the National Environmental Action Plan (NEAP) the introduction of which was made as one of the many conditionalities, required and necessary to be in place before any developing country could access the much needed funds being offered by the Bank. In the specific case of Ghana, the NEAP was introduced in 1988 during the negotiation processes of second phase of Structural Adjustment Program (SAP II). Given the number of stakeholders including various NonGovernmental Organizations that were involved, the entire process appeared to be participatory. Realistically speaking, however, it was the Bank that spearheaded the entire process. Adopted in 1991, the NEAP became the country's major "strategy through 
which key issues to the protection of the environment and better management of renewable resources was to be pursued" (UN Country paper, 2005: 2). This plan, among other things, was supposed to bring about significant improvement in major areas such as land management, forestry and wildlife, and water management. Unfortunately very little has been achieved to date.

Decades after the introduction of the NEAP, immense challenges persist in the area of environmental management and protection. For example, the EPA in its 2004 State of the Environment Report estimates that:

(1) About 64.97 percent of total land area of Ghana is under the threat of desertification

(2) The country is losing its forest cover at an annual rate of about 70,000 hectares per annum

(3) Most of the country's rivers are dying as a result of industrial and domestic pollution

(4) Less than 40 percent of urban residents have access to solid waste collection services, while less than 30 percent are served by "an acceptable household toilet facility" (2004:5).

These, may be seen as indicators of leadership failure, which, in turn, raises questions about the existing arrangements of governance. It is also an example of what is likely to 
happen when policies are not nationally or locally owed, but crafted and imposed from outside.

\subsection{Explaining Elite Governance Failure: A historical perspective on} Authoritative Management

Warren Uphoff and Norman Ilchman, in their seminal work, The Political Economy of Change, lament about the "failure of scholars in non-economic social sciences to transcend typologies and ex-post facto analysis and fasten their attention on the achievement and improvement of public purposes" (1969 : vi-vii). In their view, "macroanalytical approaches which view society in global terms cannot handle choices made by statesmen and other political activists" (Ibid, 8). This searing critique, as Higgot notes, was essentially a direct attack on modernisation theorists whose policy prescriptions for the' Third World (developed during the 1950s and 1960s) were perceived as being inadequate and unrealistic because of their failure to draw attention to " the process of choice or the ramifications of concrete political activity"(1983:25). That this perception became widespread is buttressed by the amount of literature that began to be produced, starting in the $1960 \mathrm{~s}$, that sought to draw attention to the effects of political choices on society as whole. Prominent among the latter, were works that looked specifically at the "economic effects of political choices" (Higgot, 1983: 25). This approach, it must be pointed out, is of crucial relevance in as much as it helps one move beyond macropolitics as based on generalisations and grand theories, to delve into politics on a contextual or case by case basis. 
This study, for its part, considers that structures of power (despite the actions of the political actors themselves) cannot be ignored as part of the determinants of major political outcomes. The inherent ability of certain key political actors to sustain, manipulate and even transform existing structures is also recognized. Hence, in a modest attempt at overcoming the 'agent-structure' problem, 'structure' is taken to refer to that which "simultaneously enables action by providing tools actors use to pursue their political projects and constrain action by delimiting the range of possible projects"( Mahoney and Snyder, 1999: 6 ). This helps to draw attention to political and bureaucratic factors within the Ghanaian polity and how the latter have, over the years, impacted state capacity and, by implication, the quality of governance.

The demand for the involvement of the citizenry in the choice of their leaders (as constitutes the critical core of political democracy) is not a new phenomenon in subSaharan Africa. The anti-colonial project emerged and was legitimized on this basis. Indigenous politics of pre-colonial African societies may have been given very little credence over the years, but it is important to note that these political systems were essentially democratic (Osabu-Kle, 2000). Pre-colonial political systems were characterised by diverse states, extensive kinship ties, age sets and acephalous societies. In sharp contrast, the colonial state was for all intents and purposes, exclusive, alien and essentially non-democratic. Best evidence of this, in the particular case of Ghana, can be seen in the dictatorial colonial administrative structure imposed on the colonies which had, as its head, the governor who took orders directly from the British government and was not accountable in any way to the citizens of the colonies. The independence and 
liberation struggles for self-determination, beginning in the post-world war period, were essentially, therefore, struggles for political emancipation from that dictatorial political structure.

With independence, Ghana, like most African countries, inherited a hybrid system where 'modern' governance and public administration systems were superimposed on traditional institutions and management systems. In reality, however, the public's sense of dedication, identity and accountability still remained centred around local ties to ethnic group, village and family. In other words, traditional authorities and institutions still held a lot of sway and a considerable amount of influence over the people. Recognizing the insecure nature of their hold on power and the inherent lack of legitimacy, the country's political leaders became more and more persuaded of the need to ensure the primacy of the state over civil society so as to strengthen their continued reign. But the challenge here was that they could not resort to the 'rule of conquerors' approach that had worked very well for the former colonial powers. Rather, their claim to rule, for the purposes of legitimacy, had to be grounded in some form of representation, not in conquest. Thus, on the political side, the modern elite used the single party system as tool of legitimacy with which to attract the goodwill of the people.

The one-party rule, which had nothing in common with the non-partisan African political culture in which the political party did not exist, was presented as a trade-off between political freedom and development. On the economic side, the concept of a strong central government was strongly upheld solely on the grounds that it was needed to ensure control over the economy with equity and fairness for all. In the absence of countervailing checks and balances from the legislature, judiciary and even civil society, 
this stronghold on the economy was sometimes used to build ethnic based support and establish clientelism as substitutes to moral and political legitimacy. As scholars like Throup (1993) contend, there are many cases where supporters of the party or government in power are rewarded and bought with resources from state-controlled coffers. However, it is also important to note that the interventionist nature of these governments were essentially a continuing legacy from the colonial era during which power was centralized and highly bureaucratized. In other words, colonial experiences had a profound impact upon the post-independence performance of Ghanaian governments. Allen (1995) identifies the roots of centralization in two elements of the decolonization process. Firstly, independence constitutions concentrated power in the executive branch of government to ensure order. Secondly, hastily organized elections encouraged the development of support through ethnic and regional networks which so frequently characterised post-independence Ghanaian political parties. Politics consequently became a 'winner takes all' game where leaders cling to power and clientelism provides a mechanism for mobilizing support and controlling the citizenry.

\subsection{Summing up}

This chapter discussed the theoretical perspective that best explains existing arrangements of governance within the specific case of Ghana. As it argued, there are enough grounds to focus on the elite model of analysis, given the inappropriateness of other theories of power distribution to Ghana. It has shown that within the context of Ghanaian politics where political and bureaucratic elites (with the not-so tacit support of international elite) essentially 'run the show', governance is really elitist in nature and not democratic as some would like to believe. This implies, among other things, that public 
affairs (in this case environmental ones) are being managed without adequate input and participation of a wider section of the Ghanaian populace. It is therefore not surprising that the quest for sustainable and practical solutions have so far come up with very little results. Consequently, the next chapter is devoted to a discussion of emerging models that can be effectively be utilized in engendering and facilitating citizen participation/ involvement in environmental management. 


\section{CHAPTER THREE (3): CITIZEN INVOLVEMENT: EVOLVING TRENDS IN ENVIRONMENTAL GOVERNANCE}

\subsection{Managing Public Business with the "Public"}

Chapter two explained that with the Ghanaian political and bureaucratic elites (with the tacit support of international elite) essentially 'running the show', governance is really elitist in nature and not democratic or open as some would like to believe. This means, that, citizen participation in decision-making is the exception rather than the rule. This chapter highlights, using selected cases, how citizens can be effectively engaged, in public affairs management. Public sector management has and continues to be one of, if not the most important, function of any given political system. Health care, safety regulation, industrial support and economic promotion, public education and environmental protection are all functions of public affairs, the direct administration of which has traditionally fallen under the responsibilities and purview of a plethora of governmental agencies, departments, or ministries.

It must be noted, however, that the traditional or old public administration, as Robert Denhardt and Janet V. Denhardt point out, are characterized among other things by “ programs that are implemented through top-down mechanisms" and bureaucratic structures that "seek to be closed systems to the extent possible, thus limiting citizen involvement" (2000: 551-552). That public administration needs to be transformed so as to make it more suitable for modern day societal demands cannot and should not be understated. 
But strategies, techniques or mechanisms for reform can also necessarily emanate from within the public sector itself. This chapter, therefore, seeks to explain that there are sources or ideas imbued with potential transformative power that are an innate part of the public sector itself. Given the right conditions, these sources may contribute to the ultimate rejuvenation and revitalization of the public sector - a feat which may be of immense benefit to society as a whole. To do this, the author draws on specific cases of citizen initiatives particularly as they pertain to Canada, but which might be adaptable to Ghana, to illustrate how a combination of exemplary leadership skills (on the part of public managers) and - dedication to delivery of quality public services (on the part of the public and public managers) can together lead to the effective utilization of such transformative ideas for the realization of desired goals and objectives.

As earlier noted, there is an urgent need to transform public administration to make it more suitable for modern day societal demands. It is possible, contrary to what critics and opponents believe, to locate and identify ideas and strategies capable of attaining this objective right within the public sector itself. On a much broader level, the debate on administrative reform has, for the most part, been "dominated by and directed towards a questioning of the role of government and perceived entrenched interests of public servants"(Shields and Evans, 1998: 8). This way of thinking is, to a larger degree, epitomized in what has become known as the managerial movement. Proponents of 
managerialism surfaced in the United States, U.K and Australia, during the early $1980 \mathrm{~s}$. They have argued, among other things, that obstacles which stand in the way of the successful realization of public administration goals emanate from within bureaucratic structures themselves. Hence, before any progress can be made, these structures need to be 'reinvented' (Osborne and Gaebler, 1993). This implies reforming the public sector through such means as privatization, financial management reform, procedural and structural reform as well as through initiatives aimed at improving service delivery (Pollit and Bouckaert, 2000; Osborne and Plastrik, 1997).

In respect of the latter, for instance, management practices such as Total Quality Management (TQM), Process Re-engineering, Strategic Management and Planning, are being pushed forward as the 'best' way to carry out public business. Interestingly, however, these ideas and practices are being imported from the private sector for use in the public sector under the rather erroneous assumption that existing differences, between the private and public sector are negligible and can be easily overlooked or ignored. The implication is that, little or nothing is said about the applicability of these practices to the public sector (Shields and Evans, 1998). It is no wonder therefore, that proponents of the New Public Management orthodoxy are left bemused and floundering when these practices, that have on one hand enjoyed tremendous successes in the private sector, fail to make any meaningful impact when applied to the management of public services. In the face of this, it does make some sense to look within the public sector itself for possible and practical solutions. 


\subsection{Lessons from the Canadian Case}

In a study carried out on administrative innovations in Canadian governments, Gow (1994) argues that public servants and the central agencies are the primary agents for innovative change. This contention by and large can be subjected to closer scrutiny. For instance, public managers in Canada are increasingly moving from the hierarchical and centralized models, and are experimenting with flatter structures and more participatory ways of organizing decision-making processes. This development forms part of an overall orientation towards a policy management culture which is said to be postbureaucratic in nature (Kernaghan, 2000). Of particular concern here are efforts being made in recent years to reform existing forms of public participation in the management of public affairs. This undoubtedly stems from the acknowledgement on the part of public managers that the input of the beneficiaries for whom services are being delivered do count and, hence, need to be recognized and adequately utilized as such.

This is not to suggest, however, that the idea of involving citizens in the management of public affairs is a novel one. Indeed, ideas and concepts such as the latter have been an "an integral part of the mission of public institutions" (Denhardt, 2000: 270). Reference can be made to two common methods - public meetings and surveys - both of which have been used in the past to "determine citizen's problems and inputs" (Desario and Langton, 1987: 30). It is important to note at this point that these methods have not been 
without problems. ${ }^{63}$ Thus there are enough grounds to argue that citizen involvement in any form can only be said to be worthwhile, not only when the views and opinion of the public are sought, but when these views are in some form, incorporated or reflected in policy practices and processes.

Encouraging citizen involvement, among other things, provides a way of strengthening the legitimacy of the political process. But for this to happen, it is important that public managers on their part possess and demonstrate exemplary leadership qualities that will enable them 'devolve' some of their decision-making powers to others both within and out of their organizations without threat to the security of their positions. In addition, there must also be some dedication on the part of public servants to the efficient delivery of relevant services for the ultimate benefits of citizens who, in turn, must be committed to the realization of desired societal goals.

Different taxonomies are employed in the literature to investigate the rather vast and complex field that citizen involvement encapsulates. As Dorcey and MacDaniels (2000), explain, the three most common taxonomies that are used derive from an emphasis on democratic theory, power relationships and tools respectively. For their part, proponents of democratic theory, tend to lay emphasis on the positive role (or otherwise) of citizen involvement in the democratic process. For instance, the 'managerial perspective', entrust elected representatives with the role of identifying and pursuing the common good of society as a whole. Thus, it is only natural that it sees citizen involvement or the direct

\footnotetext{
${ }^{63}$ Public meetings are often poorly attended or even worse they are sometimes hijacked by a 'few dissidents who do not represent the community" (Desario and Langton, 30). Good surveys can also be relatively expensive
} 
involvement of the public in decision-making as an obstacle to the realization of this common good. The 'pluralist perspective' lays emphasis not on elected representatives, but on organized interest groups who by deliberating and negotiating among themselves help in realizing the common good. The emphasis on organized groups spells the doomor death of liberalism - the right of the individual is replaced with the right of the organized group. Thus, liberal democracy is transformed into group democracy in which the voice of the individual no longer matters, but the right of the group. The 'popular perspective', on the other hand, calls for the direct involvement of citizens rather than their representatives or groups in decision making. Thus, while the pluralist perspective kills liberalism, the popular perspective resurrects it. In a 1969 seminal paper, Arnstein powerfully illustrates what has now become known as the 'power perspective'. Her ladder of citizen participation, as reproduced in the figure below, depicts a range of participation from: non-participation, tokenism, all the way to citizen power.

\section{Figure 4: Arnstein's ladder of citizen participation}

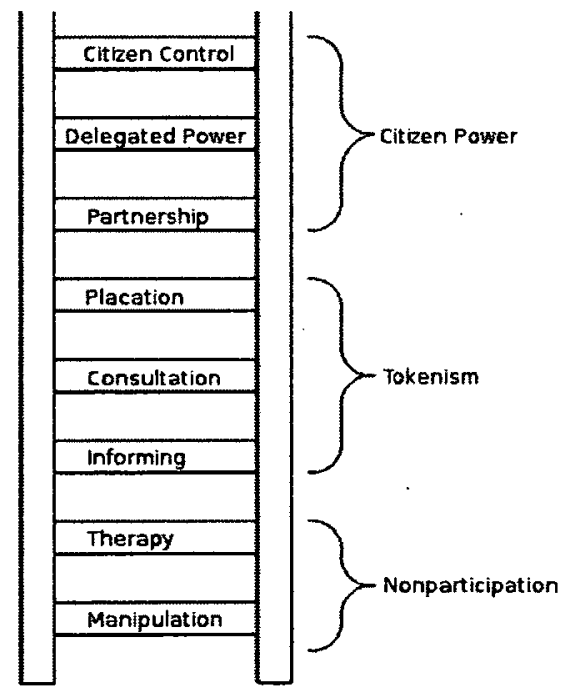

Arnstein, S. R., (1969) " A Ladder of Citizen participation" Journal of American Institute of Planners, Vol. 35, No. 4 
At the bottom of the ladder in the above figure is the situation where citizens have no voice or input and are merely manipulated by those who hold the levers of political power. At the top of the ladder is the situation where citizens have much voice or input that they are practically in control of their own affairs or decisions that affect them-the people are really sovereign.

While calls for citizen participation may be described by critics as being nothing more than mere rhetoric and by implication impracticable (Dorcey and Macdaniels, 2001), this might be far from the truth. The position of this author is that public management processes that limit citizen involvement may turn out to be options not worthy of consideration, if successes are to be chalked in the ongoing quest for sustainable solutions to prevailing public problems.

As earlier noted, there is ample demonstration of efforts made on the part of Canadian government to embrace principles of civic participation. Citizen initiatives, - specifically as they relate to environmental governance in Canada, but which might be adaptable to Ghana, are ample illustrations of this. In the author's view, the successes chalked by Canada in experimenting with participatory public management processes are significant because they are based on the democratic belief that solution of public problems is possible only when those experiencing the problems are involved in the search for viable options. To this effect, it will be useful to present examples of participatory environmental governance processes in a developed country such as Canada with the expectation that important lessons learnt can serve as the basis upon which similar processes can be developed to fit the specific context of Ghana. These lessons, it is 
important to point out, are particularly significant, given that Canada like Ghana has significant portions of its economy dependent on extractive based industries such as mining and forestry (White and Watson, 1996).

Environmental protection in Canada has gradually emerged as one of the most important domains in public policy. This stems from the fact that the country has a largely resourcedependent economy and a predominant urban population, thereby making problems such as water and air pollution, biodiversity loss and climatic change rather common. For instance, in 1997, Canada's emission of greenhouse gases (GHG) was 682 million tonnes (Mt) - a thirteen percent increase over that of 1990 (Parson, 2001). By 2008, country's per capita GHG emissions had seen an increase of 3.2 percent with the total GHG emissions growing by twenty four percent (Conference Board of Canada, 2011). The complex and widespread nature of these problems have made imperative, the design and successful adoption of innovative and ground-breaking problem-solving approaches other than those offered under traditional models of governance. In response, efforts have been made, in the recent past, to move towards a more inclusive approach to environmental problem solving through such mechanisms as citizen involvement and participation. Discussed below are case studies of citizen involvement initiatives.

\subsubsection{Case Studies}

Environmental Quality Monitoring in Ontario

As the most populated province in Canada, Ontario has, since the 1980 s, been engaged in an ongoing battle against the degradation of its air and water resources. The decline in air and water quality, although alarming, has provided an entry point for collaborative 
initiatives between government and citizens. These initiatives are significant in as much as they "retain government responsibility while building community authority, knowledge and power to improve local environmental quality" (Savan et al, 2003). This, perhaps, is most amply illustrated in the burgeoning relationship between the Ontario Ministry of Environment (MOE) and the Citizens Environmental Watch (CEW), which has seen the latter - a Toronto-based grassroots non-governmental organization, play a much productive role in the monitoring of environmental quality in Ontario. With a commitment to environmental education and monitoring, the CEW aims at helping citizens "establish and apply the connections between science, policy and action" so as to improve environmental conditions."(Ibid: 612). The latter is accomplished in several ways. There has been, for example, a concerted effort on the part of this organization to provide citizen and student groups with water and air quality monitoring communitybased protocols. All of the latter have been developed in consultation with the Toronto Region Conservation Authority (TRCA) and the federal government.

The CEW also commits some of its resources to working with educational institutions particularly high schools to gather scientific data on wildlife and plant life in Ontario communities. It also dedicates its resources and time at imparting knowledge and factual information on testing techniques, quality control and quality-assurance to community college students who then pass on this knowledge to high school students in a number of areas in Ontario. The $\mathrm{CEW}$, in its ability to create partnerships with educational institutions and foster extensive participation is succeeding in "engaging both citizens 
and governments without placing an onus on citizens to perform what it deems the responsibilities of government" (Savan et al, 2003, 611).

\section{Long-Term Management of Used Nuclear Fuel}

Another illustrative example concerns the long-term management of nuclear fuel. Canada's energy supply has changed over time; moving from a reliance on wood and coal to today's reliance on oil, gas, hydroelectricity and nuclear power. But how these resources are managed determine the quality of life both now and in the future. The major challenge here, therefore, is to provide a secure, safe and efficient mix of energy options. Canada's nuclear industry represents a clear example of this challenge. Nuclear energy offers some significant economic and environmental benefits. For example, the nuclear power sector makes a major contribution to the economy; it is a $\$ 6$ billion a year industry that employs about 70,000 directly and indirectly. (Canadian Energy Research Institute, 2008). Nonetheless, potential dangers ${ }^{64}$ associated with used nuclear fuel continue to present challenges particularly in terms of its long-term management and disposal. By its introduction of the Nuclear Fuel Waste Act in 2002, the federal government of Canada sought to provide effective over sight for the long-term management of radioactive waste in a "comprehensive, integrated and economically sound manner" (Bill C-27, 2002: 1). One of the direct results of this Act was the establishment of a Nuclear Waste Management Organization (NWMO) in 2002 whose mandate was to recommend a nuclear management strategy to the Canadian government. By the end of 2009, the NWMO had held numerous deliberative exercises that allowed it

\footnotetext{
${ }^{64}$ Used nuclear fuel is highly radioactive, - particularly within a few years of its discharge from the reactor core.
} 
to draw on the views of members of the general public regarding the values they deemed appropriate to underpin the long-term management strategy.

These exercises were carried out on a nation-wide basis. The latter included citizen dialogue sessions that drew upon the views of citizens randomly selected from the different provinces and territories. Workshops and roundtable discussions organized under the auspices of the NWMO brought together community groups, municipal associations, NGOs, researchers with diverse perspectives and experiences all crucial to the NWMO's mandate. A three-year study carried out between 2002 and 2005 sought the views and opinions of some 18, 000 Canadians on viable long-term options for nuclear waste management respondents, after which it came out with its Adaptive Phased management recommendation. (NWMO, 2007). With respect to the site selection processes, for instance, the NWMO invites Aboriginal organizations and groups in Saskatchewan, Ontario, Quebec, New Brunswick to “collaboratively design, develop and coordinate a series of information and dialogue sessions on proposed selection sites" (NWMO, 2009: 25)

The consensus among the participants of these deliberative exercises was two-fold;

- That the inclusion of citizens in policy decisions regarding the use disposal of nuclear fuels was both a necessary and sufficient condition for effective fuel management; 
- That values such as responsibility, accountability and transparency were necessary prerequisites for a sound and long-lasting management strategy on the used nuclear fuel.

The significance of this case study lies in the efforts that was made by the NWMO to draw on and incorporate the input of citizens at 'each decision point' through the use of a combination of other citizen engagement techniques such as focus groups, public opinion polls, surveys and public information sessions (Turnbull and Aucoin: 2006). It is safe to argue from the afore-mentioned that the recommendations that were submitted by the NWMO to the federal government in 2005 reflected not only the views and opinions of a selected group of 'experts' and technocrats', but also those of a wide cross-section of 'ordinary' Canadians as well. Indeed when the federal government finally succeeds in storing all of Canada's spent nuclear fuel in one deep underground location; one could confidently attribute a major part of this success to greater citizen involvement.

Co-managing Canada Natural Resources: The Mackenzie Valley Environmental Review Board

Yet another illustrative case study is found in the eco-management of certain natural resources of Canada. Oil and gas have long been a part of the economy of the Canadian Arctic. But it was not until the 1970s that an interest in the large-scale production of these resources reached its peak. This burgeoning interest of course was largely as a result of the 1973 Organization of Petroleum Exporting Countries (OPEC) oil embargo which peaked widespread interest in pipelines and saw several Canadian companies scrambling 
to build pipelines projects in this oil and gas-rich region. One such company, the Canadian Arctic Gas Pipeline Ltd, made up of oil companies including Shell, Exxon and TransCanada Pipelines Ltd, put in a proposal with the federal government to build a route from Alaska's Prudhoe Bay through to the Mackenzie valley- home also to wide array of some of Canada's magnificent biodiversity resources. ${ }^{65}$ Citizens' response, as far as the construction of the oil and gas pipeline is concerned, have evolved from outright opposition to a begrudging admission of the need for some level of industrial development. The readiness of the federal government to reach out to the residents of the area in the management of region's natural resources does in many ways account for this gradual change of heart. Arrangements that allow this federal government and residents of the region to enter into formal agreements specifying their rights, powers and obligations with reference to the management and allocation of resources, have subsequently been put in place. A good case in point is Mackenzie Valley Review Board (MVERB), a management committee with 50/50 government and Aboriginal participant representation charged with undertaking environmental assessment and environmental review in the region.

While the MVERB, in general terms, may be conceived of as an advisory body, it has some authority over assessments and review processes for development proposals in the region. This is exemplified by the fact that it is the Board and not the federal government that has the final word on whether or not a development proposal should undergo an environmental review and assessment, including a full-scale public review. It must be

\footnotetext{
${ }^{65}$ It is home to woodland and barren ground caribou, wolves, lynx, grizzly bears, moose and huge populations of migratory ducks, geese, swans, shorebirds, raptors and loons.
} 
pointed out, however, that none of these strategies has as yet been institutionalized. Reasons for this vary. There is, for instance, resistance on the part of some policy elites to initiate 'open-ended citizen engagement exercises' mainly because of the perceived difficulties in controlling the agendas and outcomes of such meetings (Turnbull and Aucoin, 2006: 31). Nevertheless, the above case studies are important to this study in as much as it attests to the importance that is being placed (at least in Canada) within the public sector on experimenting with participatory approaches to problem-solving and devising strategies or techniques for involving and empowering citizens. Also what makes the Canadian examples remarkable is the existence of a history and culture of political activism which provide a counterbalance to official bureaucracy. Citizens do not wait to be consulted. They are able to compel governing elites to embrace participatory processes, open up spaces for consultation and deliberation, and, by so doing, bring about some measure of accountability and transparency to the decision-making process. This clearly stands in contrast to the case of Ghana where there has been much 'talk' about engaging civil society participation, but with very little concrete examples to show.

Much of the 'talk' about opening up public spaces and embracing participatory processes, it must be noted, has been initiated by the international elite who continue to hold a lot of influence of Ghana's governing elites. For instance, the World Bank as earlier noted, continues to promote its good governance agenda for Ghana which claims to, among other things, have a great degree of cultural awareness and appropriateness. In the Bank's discourse, civil society emerges as the link between economic liberalization and democratization. Essentially, the good governance agenda argues for a "systematic efforts 
to build a pluralistic institutional structure in which intermediary organizations would have an exceptionally important role to play in the dual processes of economic and political liberalization. Civil society groupings can "bring a broader spectrum of ideas and values to bear on policy making" (World Bank, 1989: 61). Intermediate nongovernmental organizations are also expected to put pressure on public officials for better performance and greater accountability. In short, it is believed that by deliberately supporting the development of plural institutional structures, these external agencies can help create an environment that will end the abuse of political power. Ironically, it is this very discourse - ideologically driven and Western in orientation - that has eclipsed traditional notions of participation, the result of which is the further alienation of the civil society. For example, one problem which is taken lightly relates to ownership of the development process. When external agencies dominate, it implies that the development process including the much cherished democratic process is not locally owned. It further implies that the people are no longer sovereign, but outsiders.

What has become rather obvious is that, there has been in Ghana, a significant alienation of popular groups and social movements who, in theory, are projected as the ones capable of championing the democratization process (and by implication foster better governance.). Ironically, forums in which governments consult civil society on the general directions of policies and decisions still remain scarce. Best evidence of this, is in the environmental sector, which, in spite of the far reaching and wide-spread nature of its problems, has comparatively low levels of civic participation and engagement. The following section explains how organizations and associations in Ghana are excluded 
from meaningful participation in public affairs including environmental management in Ghana. It is argued that the exclusion of these organizations and other traditional institutions continues to undermine effectiveness in environmental management.

\subsection{Civic Engagement and Participation and Environmental Protection in Ghana}

\section{Civil Society Groups and Organizations}

Civil Society organizations (CSOs), Non-Governmental Organizations (NGOs), voluntary and private associations, faith-based organizations and community based organizations - by their very nature all stand to play a crucial role in natural resource management and environmental protection. This stems mostly from their position within society that allows them to work more closely with the local populations within their respective communities. However, as this study shows, while some CSOs in Ghana are actively engaged in the delivery of certain important services within the environmental sector, their influence or impact on relevant environmental policy and programmes is rather negligible, to say the least. In reality, their involvement in important decisions, is nothing more than a 'mere window washing' or symbolic exercise ${ }^{66}$ embarked upon by government officials who want to be seen as being 'open' and democratic. Indeed, as official documents from the Ministry of Environment, Science and Technology and the Environmental Protection Agency (EPA) suggest, CSOs (at least the more visible ones) are often 'invited' to participate in agenda setting and policy deliberation processes. This

\footnotetext{
${ }^{66}$ As discussed in chapter 5 , some NGO officials interviewed for this study expressed their dissatisfaction with what they describe as unwillingness on the part of government to reach to non-state actors and incorporate their input into important decision-making.
} 
can be surmised for instance, from the minutes of meetings of the Environmental ministry and the EPA, on issues including climate change, and waste management most of which record the attendance of environmental NGOs and community based environmental organizations.

In reality, civil society is 'called in' mostly for the sole purpose of 'rubber stamping' government decisions, not to be meaningfully, effectively and actively involved. Stemming from the latter is an increasingly antagonistic and suspicious relationship between the state and civil society, the direct result of which, in recent years, has seen CSOs (at least the well-resourced ones) increasingly resorting to the media (among other things) to confront and force the government into taking action on what they consider to be important matters.$^{67}$ It should be noted, however, that the actual number of CSOs that are on the forefront of environmental advocacy and public campaigns is far from adequate. There are currently in Ghana, over 100 indigenous and community based organizations 'engaged' in natural resources management. ${ }^{68}$ But, in spite of the existence of spaces and rules of engagement and the ability to mobilize and garner collective action, environmental advocacy predominantly rests only with a few NGOs including Conservation International, Green Earth Organisation, and Friends of the Earth, Forest Watch Ghana, and the Third World Network. These organizations are based in the

\footnotetext{
${ }^{67}$ A good case in point: in 2009, the Wassa Association of communities affected by Mining (WACAM), a Community Based Organization, embarked on a vigorous media campaign aimed at drawing nation-wide attention to the debilitating effects of mining operations in the Tarkwa and Obuasi townships.

${ }^{68}$ United States Agency for International Development, USAID(2005) "Summary of Environmental Threats and Opportunities Assessment(ETOA) with special focus on Biological Diversity and Tropical Forestry", a report for USAID/Ghana , Accessed online on December , 2008 from http://www.encapafrica.org/documents/biofor/ghana_strategy05a-annex letoa.doc
} 
national capital, Accra, and have some sort of affiliation or support from internationally recognized environmental organizations.

One such NGO, the Third World Network (TWN), has been active particularly in communities adversely impacted by mining activities. Established in 1994, as a nonprofit organization, the TWM has devoted a lot of its time and energy in advocating for reform on existing state mining law and policies and championing community rights in ecologically vulnerable areas. In 2006, the TWN organised and sponsored a National Conference on communities affected by mining which directly led to the establishment of a National Coalition on Mining (NCOM) that has since then embarked on a national campaign to act as a 'voice' for the people. For instance, it launched a national campaign advocating the opening up of the consultation processes leading to the review and passage of a new Minerals and Mining Bill to replace the 20 year old document (TWN, 2008).

The TWN has also closely worked with groups that have 'mushroomed' in the affected communities by providing them with needed resources and organizational support. A good case in point is the Wassa Association of Communities affected by Mining (WACAM) which (unlike other community based organizations) has been visible even at the national level mainly because of continued support and mentorship from the TWN. WACAM, for instance, produced a formal petition ${ }^{69}$ against human rights violations in mining communities with the Commission for Human Rights and Administrative Justice

\footnotetext{
${ }^{69}$ The CHRAJ has investigated the human rights situation in mining communities in Ghana, but has not come out with a final report.
} 
(CHRAJ) and called on the government to implement effective remedies for victims of corporate violence in mining communities and effect punitive measures against the perpetrators of these actions (WACAM, 2001). Also in 2009, WACAM launched a research report that drew nation-wide attention to the debilitating effects of mining companies operations in two major mining communities. ${ }^{70}$ It has also collaborated with the Centre for Public Interest Law (CEPIL) to provide legal support to several mining communities. $^{71}$

The Friends of the Earth (FOE) - Ghana, for its part, has been on the forefront of the battle against desertification and the results of its work are seen particularly in the Northern parts of the country where it has mobilized community members to undertake afforestation and wood lot projects. Best evidence of this is seen in Northern region town of Wulugu where FOE, with the help of funding from the Japan Fund for Global Environment (JFGE), has introduced community self-help projects that has helped to avert a looming desertification crisis (FOE, 2008). By empowering local people to be responsible for the management of their environment, NGOs such as the FOE and TWN are in many ways doing a whole lot more than government does with respect to civic engagement.

\footnotetext{
${ }^{70}$ The "Determination of Heavy Metals in Water Bodies in Tarkwa and Obuasi Mining Areas" report noted that most of the rivers in the Tarkwa and Obuasi Mining areas were polluted with high levels of hazardous chemicals including Arsenic, Manganese, Cadmium, Iron, Copper, Zinc, all of which were by-products of mining operations in the area.

${ }^{71}$ For example, WACAM and CEPIL supported the people of Nkwantakrom when they launched a civil suit against Ghana- Australia Goldfields over the destruction of property including houses, churches and mosques in the Nkwantakrom community.
} 
These examples confirm that CSOs when well-resourced and properly set up are themselves effective and efficient vehicles of helping communities meet and address their developmental challenges. It is not surprising, therefore, that one sees, in recent times, an increasing emphasis on the communitarian model of governance which focuses more on the role of the 'Third Sector'(i.e. non-profit organizations existing outside of the public sector) in the quest for long-lasting and practical solutions to many of societal problems. The argument here is that, where governmental institutions have failed, these non-profit, non-governmental organizations, once 'infused' or inculcated with desirable communitarian values will more or less steer society towards the eventual realization of its ultimate goals. Not surprisingly, the literature on the 'Third Sector' and its relevance to the success of public sector management has burgeoned in recent years. It is true that recurrent instances of state failure and state mismanagement (perceived or real), particularly in developing countries, have made activities of the 'Third Sector' appear more attractive and perhaps more productive in the eyes of many.

On the whole, however, the ability and capacity of the Third Sector to positively impact public sector management might, to a large degree, depend on the level of organization, coordination and cooperation of elements both within it and the external environment, as well as their organizational skills and expertise, horizontal autonomy and cultural dynamism. It is safe to argue, therefore, that it is in cases where elements of the third sector have been able to organize themselves and fully collaborate with one another - and with the governing elite - that considerable and noticeable contributions to the realization of public sector goals have been possible. On the other hand, when the relevant 
associations, groups and organizations have acted in an ad hoc and individualistic manner, their impact might be, to say the least, minimal if not at all absent. The latter seems to be the case in Ghana where the level of coordination and networking between CSOs on one hand and between CSOs and state actors is minimal or sometimes absent. CSOs, it must be pointed out, tend not to be self-autonomous, but rather operate and are affected by conditions in the larger external environment within which they find themselves. These conditions may be cultural, economic, social, and political. This suggests that third sector success, to a large degree, depends on how it is able to deal with and tackle challenges that emanate from the larger environment. This larger environment includes the chieftaincy institution - traditional rulers.

\section{Traditional Authorities: Chieftaincy and environmental protection}

The institution of chieftaincy is one of the universal and oldest institutions in Ghana which unlike modern forms of authority, permeate the social fabric of the Ghanaian society. By its very nature and cultural significance, therefore, the chieftaincy institution forms a very important component of the Ghanaian social structure. Before colonial rule, chiefs were powerful rulers who occupied a single composite office to which were attached real judicial, military, political and religious powers. The chieftaincy institution has, however, been transformed to some extent by modernising forces through purposeful political action as well through its own internal dynamics. Under colonial rule, chiefs were stimulated by colonial officials to become intermediaries between the colonial rulers and the local populations. Their powers were somewhat expanded in scope, but they became dependent on the colonial powers for the exercise of these powers. 
The chiefs were not totally mere tools in the hands of the colonial administration because they had enough latitude and some autonomy to use their new though constrained powers to advance their own economic and political interests. This, in the post-colonial era, made them rather unpopular in the eyes of the ruling modern elites resulting in an antagonistic relationship between the two. An example of this is the protracted struggle by the Nkrumah regime with chiefs over the control of rural areas. As Rathborne (2000) notes, the CPP government's interest in rural order stemmed primarily from the fact that so much of the national wealth was produced in the countryside. ${ }^{72}$ Also, the government saw the absence of rural disorder as a testament of its growing authority and legitimacy.

Most chiefs, on the other hand, sought to maintain independence and control over administrative and legal affairs in their areas. This culminated in a concerted effort by the government to undermine the authority of those chiefs who failed to submit to their exigencies and demands. Best evidence of this is the CPP government reorganization of the Akyem Abuakwa court system that saw the relocation of the native court from $\mathrm{Kyebi}^{73}$ to New Tafo, a town considered to be a CPP stronghold. As a follow up, the government in October, 1957, announced that it had withdrawn its recognition of the Paramount chief (known as the Okyehene) of the Akyem Abuakwa area over allegations of administrative and financial malpractices. It is important to note however that this

\footnotetext{
${ }^{72}$ With cocoa steadily becoming a major foreign exchange earner, the government sought to have control over farmers in the cocoa producing areas of the country.

${ }^{73}$ This was the capital town of the Akyem Abuakwa area
} 
dramatic move by the government was not unrelated to the Okyehene, Nana Ofori Atta II's public declarations of opposition to some of the government's policies. ${ }^{74}$

The political, economic, and judicial bases of chieftaincy powers were further weakened because, as state acquired some lands in the interest of the public, chiefs lost some of the direct access they had to stool revenues as well as some power to administer stool lands. ${ }^{75}$ Becoming a paramount chief or sub-chief was made conditional on being recognized and gazetted by government. By 1966, therefore, the institution of chieftaincy had become a weakened and battered one. It was somewhat revived after $1966^{76}$, although chiefs, for the most part, remained relatively weak even in their immediate communities. The 1992 Republican constitution, for example, prohibits chiefs from taking part actively in party politics. The consequences of this constitutional provision is perhaps best seen at the local level where chiefs are denied any meaningful form of representation in local governance beyond their discretionary participation in District Assemblies' deliberations (they have to be consulted by the president on the appointment of 30 percent of members of the Assemblies). In many ways, therefore, the position of the chief in existing systems of governance at the local, regional and national level is symbolic and not backed by the power to enforce laws and regulations.

\footnotetext{
${ }^{74}$ This included the Okyehene's disagreement with some of the rulings of government-appointed commissions over traditional constitutional affairs.

${ }^{75}$ Stool lands are lands owned by the various chiefs or traditional leaders in their respective areas of operation.

${ }^{76}$ After the overthrow of the Nkrumah government in 1966, the NLC military government embarked on a national programme of reconstruction that among other things focused on the restoration of some of the chiefs' power and influence. By the end of 1966, the military leadership had ordered an investigation into the de-stoolment of chiefs under the Nkrumah regime. But the military's government interest restoring the power and influence of the chiefs was to a great extent overshadowed by its own desire to strengthen its hold on power and extend its stay in power.
} 
These drawbacks notwithstanding, there are chiefs who have made significant gains as far environmental protection is concerned. Here, mention can be made of the current Paramount Chief of the Akyem Abuakwa area, Okyehene Nana Osagyefuo Amoatia Ofori Panin II, who continues to wage a war against deforestation and other forms of environmental degradation not only in his jurisdictional area, but also in other parts of the country as well. In connection with the latter, he set up the Okyeman Environment Foundation in 2000 described in the media as "charitable organisation devoted to conservation and development" which has, since its establishment, been credited with stemming the devastation of the Atewa Forest Range in the Eastern region of Ghana (Aryee, 2007). Evidence suggest that the key to the Okyehene's success in environmental protection is the high level of public engagement. A good case in point: under the auspices of the Okyeman Environment Foundation, Community Environment Protection Brigades (CEPBs) have been established in about one hundred and forty communities in the Akyem Abuakwa area. These CEPBs are made up of members of local communities and are entrusted with the responsibility of protecting the resource endowment of their respective areas(ENS, 2008).

\subsection{Summing Up}

In sum, chapter three makes the case for the opening up of policy/decision-making processes to include citizens who ordinarily are left out of these processes. Drawing on examples from the Canadian case, it shows how efforts are being made by Canada's governing elite to experiment with and embrace within the public sector various models and strategies that aim at effectively engendering and facilitating citizen participation/ 
involvement in environmental management. While concrete results are yet to be documented, it is rather evident that in the Canadian case, the input of the public - at least at some levels of decision-making - count and that public views are actively sought and acted upon. This is an eye-opener for Ghana which like Canada is a resource dependent economy, and is currently facing problems of environmental degradation similar to what resource-rich Canada has had to deal with. Unlike Canada, Ghana's system of governance has a recognized traditional and informal dimension to it which promises immense opportunities for citizen involvement and collaborative partnerships. The latter is evident in the work of local chiefs such as the Okyehene of the Akyem Abuakwa traditional area that has helped to keep in check the rapid rate of resource depletion and environmental degradation. The potential for public participation notwithstanding, non-state actors remain little more than mere onlookers in environmental decision-making processes. This allows for a whole lot more room for improvement on the part of governing elites to embrace similar models to fit the country's specific context. This study delves into finding and examining the rooms for improvement with the view of recommending some possible solutions. The following chapter explains in detail the methodological approach that guided this study. 


\section{CHAPTER FOUR (4): THE METHODOLOGICAL APPROACH}

\subsection{Introductiont}

Chapters two and three chapters discussed the theoretical basis which, in the author's view, informed successive Ghanaian elite coalitions' management of the environment and the implications of citizen participation (or the lack of it) on the latter. This chapter explains in detail, the methodological approach that guided this research with particular emphasis on the research design and the methods employed for the gathering of relevant data. As an exploratory inquiry into the dynamics and complexities of environmental management, this study follows the case study approach that "investigates a contemporary phenomenon within its real-life context" (Yin, 1989, 23). It is informed by the elite analysis approach which is considered appropriate in the Ghanaian context where class consciousness is weak.

As explained earlier, the elite analysis approach is also compatible with group or pluralist theory when it is considered that it is elites that lead or manage the various groups and engage in negotiations in their interests. Qualitative methods - a series of semi-structured interviews, focus groups and participant observation - were used to obtain relevant data. For supplementary purposes, relevant data was also sourced from archival records and current government documents related to environmental management practices and processes during the period under study. Another useful source of data used was national and local newspapers the contents of which were systematically analyzed, using specifically, the content analysis method. The latter was used to help tease out and 
identify the specifics of messages, views, and opinions of political elites as they relate to the environment.

\subsection{Data Collection}

Data for this dissertation was collected from both primary and secondary sources. Primary data is data which the researcher generates and is specific to the study, while secondary data on the other hand is collected by someone else for other purposes. Much of the initial work was done here in Canada, with a focus mainly on secondary sources including reports and publications, journals, newspapers and other relevant literature. Included in the latter were environmental articles from major Ghanaian newspapers such as the Daily Graphic and the Ghanaian Times. Also the author made use of reports on global environmental trends including Global Environmental Outlook (GEO) editions 14, Our Common Future, as well as the United Nations' Agenda 21:Earth Summit : The United Nations Programme of Action from Rio. Others include national reports and publications on Ghana such as the, EPA's State of the Environment in Ghana, National Environmental Action Plan(NEAP) Ghana-Vision 2020 and the Ghana Poverty Reduction Strategy (GPRS) I \& II.

However, as pre-testing in research demands, several interviews were also conducted with Ghanaians living in Canada and of similar backgrounds as those expected to be interviewed in Ghana so as to appraise this researcher of some prevailing ideas and opinions about environmental governance in Ghana and to establish the validity and reliability of the questionnaire instrument. For purposes of collecting primary data, a field trip was made to Ghana, during which interviews were conducted with key actors and 
stakeholders over a four month period from March to July, 2008. While in Ghana, relevant official documents were obtained from different government ministries and agencies. Other reports and publications were sourced from both public and private archival records, and from public and NGO libraries.

\subsection{Primary: Sources}

A primary source, as explained above, is evidence related to the research topic from any contemporary source which the researcher generated directly. Discussed below are the primary sources which the researcher relied upon in the collection of relevant data.

\subsubsection{Interviews}

Interviews are a very important data gathering technique that allows the researcher to establish some rapport with the interviewee. The major advantage of this method is that it gives the researcher a free hand and helps him/her to extract almost all the information from the interviewees - although it is a very time consuming method. By way of preliminary work, the researcher outlined to all potential interviewees the goals behind the interview sessions and also informed them about the ethical aspects of the study. All participants were informed beforehand, about their right to decline or discontinue their participation whenever they felt inclined to do so. Also, all participants were given consent forms ${ }^{77}$ prepared beforehand in Canada under the supervision and approval of Carleton University Ethics committee. No remuneration was provided as incentive for participation in these interviews. However, for the focus groups sessions, refreshment (drinks and snacks) was provided for participants in line with Ghanaian cultural practices

77 A copy is attached in Appendix 1 
where it is common for meetings of any sort, formal or informal, to start or conclude with the sharing of drinks and snacks.

For the formal interviews, the researcher created beforehand a preliminary list of potential participants compiled from both public and non-public sources. Reasons for the selection of the potential participants range from their level of involvement or engagement within the environmental sector to practical ones such as accessibility and economy. ${ }^{78}$ Because of the limited time and resources available to the researcher, an effort was made to limit the pool to participants in parts of the country that could be reached quickly and at less cost- the latter included Greater Accra, Central, and Western Regions. The fact that most government offices and organizations were based in the Greater Accra Region also made the researcher's work much simpler. From the study population, possible participants were systematically selected at random, their details and profiles of which are discussed in the next section and also in chapter five. Attempts were then made to personally contact those selected individuals through their respective ministries, agencies, departments and organizations. With the exception of NGO officials, arrangements to see government officials turned to be rather tedious and required repeated visits to government offices to secure and schedule possible interviews and associated dates. In some cases, interview dates had be rescheduled over and over again with those government officials blaming their unavailability on official duties including meetings, cabinet briefings and parliamentary appearances. Those excuses were difficult to believe, but acceptable.

\footnotetext{
${ }^{78}$ Chapter five gives more details about the interviews conducted.
} 
The envisaged time for each interview was one hour. The focus group discussions ${ }^{79}$, on the other hand, were scheduled to last between two to three hours depending upon circumstances. The researcher's interviews with government officials turned out to be rather shorter than anticipated. There were, however, some few exceptions in which the officials in question were willing to go out on a limb to outline what they perceived to be the underlying causes of the current state of the environment in Ghana. In one particular instance, two separate, but equally informative interview sessions were held with the same interviewee. In contrast with the interviewing of individuals, the length of focus groups discussions lasted an average of 2.5 hours, mainly due to high participation.

For the focus group discussions, the researcher had to ensure at various points during these sessions that discussants stayed right on topic and did not steer into other issues (however interesting) which were not relevant in the context of this study. Unlike the interviews with government officials, focus groups were organized in very informal settings. In one instance, the researcher had participants all sit on mats and stools under a big tree on a community school compound in the suburb of Kwabenya in the Greater Accra Region. The very informality of the setting of the group sessions often also attracted passers-by who, upon seeing their neighbours and friends, came by to find out what was going on. The researcher often had to disrupt ongoing discussions so as to adequately explain to newcomers what the session was all about. Those interested were supplied with information packages, including consent forms, and then invited to join the group. This lengthened considerably the duration of the sessions in question, although additional ideas were also gathered this way.

\footnotetext{
${ }^{79}$ The nature of which will be discussed in detail in the next section
} 
An information letter ${ }^{80}$, which the researcher had prepared beforehand with the supervision and approval of both the thesis supervisor and Ethics Committee here in Carleton University, was used as a formal introductory document. The information letter clearly stated the intents and objective behind the study and provided clear contact information about the thesis supervisor and the Ethics Committee and included, as well, background information about the researcher herself. It also asked for cooperation and assistance from all recipients of the letter. In addition, consent forms which had been prepared in advance were given to each potential participant for approval and signature before the start of the interviews and focus group discussions. With regard to questions for which the disclosure of personal information was required, participants were informed of their right to decline answering any or even all of the questions whenever they felt threatened in any way. Each participant was also apprised about avenues for withdrawing their agreement should they change their mind after completions of sessions. Assurances were also given that all data would be destroyed after they had been analyzed.

\subsubsection{Profile of Interviewees}

Formal interviews were conducted with key government officials including the Ministry of Environment, Science and Technology, Environmental Protection Agency (EPA) and other governmental agencies and departments, as well as officials of several NonGovernmental Organizations (NGOs). Here, the researcher faced several challenges principal among which was the reluctance and suspicion on the part of government officials to be interviewed despite assurances that information would be not be used for

${ }^{80}$ Please see a copy in Appendix 2 
any purposes other than that which had been clearly stated in introductory and consent letter. Interviews were also arranged with several traditional rulers (chiefs) and heads of traditional authorities some of whom eventually proceeded to participate in the actual interviews. To get a better idea of the issues being discussed, the researcher focused on areas most characterised by severe environmental problems. To this effect, chiefs were interviewed in Ghana's Greater Accra, Central and Western Regions of Ghana demonstrated a deep level of awareness and frustration on issues of deforestation, land degradation, waste management, water pollution and coastal and marine pollution. These were common problems they dealt with on a daily basis. To gain access to traditional authorities, (specifically chiefs) lengthy and detailed customary procedures and protocols had to be followed. These included the presentation of drinks through several intermediaries after which possible interview dates were passed onto the researcher.

After the initial contacts were made, however, the snowballing effect was relied upon as other chiefs were willingly recommended by those initially interviewed. This turned to be of tremendous help because it opened up the gateway to traditional rulers in communities in other parts of the country. In one instance when the researcher, upon request from a paramount chief, went over to his palace for the interview, that paramount chief, upon meeting other sub-chiefs who had come to pay homage, seized the opportunity and allowed the researcher to elicit their views and opinions on the subject matter. It must be noted that most of these chiefs, although highly educated (lawyers, PhDs holders, medical doctors), nevertheless sought to use the occasion to highlight the importance of traditions and customs. Subsequently, the interviews were conducted (at the behest of the 
chiefs in question) in local dialects. This researcher's command of several local dialects undoubtedly turned to be a useful and timely asset. To ensure that the questions posed during the interview were relevant to the objectives of this study and to ensure consistency, an interview questionnaire was developed and pretested (see Appendix three). Some of the interview questions were open-ended, giving interviewees the opportunity to extrapolate at length some of concerns and constraints they faced in their different roles (actual and perceived) in environmental management. All interviews were summarized so as to unearth existing generalities, differences, characteristics and issues, for further analysis.

\subsubsection{Focus Groups}

The focus group method turned to be very useful considering that it did not discriminate against individuals who couldn't read or write. It was also very effective in engaging those individulas who, for several reasons, were reluctant to be interviewed alone or were simply inspired and stimulated to participate by the views and comments of others. In simple terms, this method was very interactive and informative in nature, and encouraged participation. Upon identifying potential participants, the researcher asked them individually to attend the group meeting at a pre-determined date and venue. The sizes of these groups ranged from five to twelve people, comprising both men and women ranging in age from 18 to 65 , of different professions, income, and educational backgounds. This was done in order to capture a wide range of views, attitudes and responses on the current state of the environment. It was also intended to elicit or draw out prevailing opinions and perceptions about the governing elite's responses and patterns of actions and inactions towards environmental management. Indeed, it is 
patterns of actions and inactions of elites in authority that constitute policy and, in this case, environmental policy. But focus groups and interviews alone cannot tell the whole story since environmental managemnt has its own historical roots which can be unearthed through available written records or archives both official and unofficial. Content analysis is about what was expressed in such records and to what effect.

\subsection{Content analysis}

Patterns were obtained through content analysis of secondary data from official documents, reports and publications from several environmental NGOs as well as libraries, and archival sources. These included collections from the Environmental Protection Agency, the Ministry of Science and Environment, Acts of Parliament (Gazettes), environmental regulations, and publications on the environment. Websites, radio and television programs were also studied for relevant information. The objective of the researcher was to assess whether or not the environmental problem was perceived as a pressing problem that required immediate and collaborative solutions. Content analysis is the technique most commonly used in the unobtrusive analysis of qualitative data. It is a useful element of the multi-pronged methodological approach, given that it helps bring to the fore what social scientists consider to be the most important process in societal interaction: communication. Berelson defines the latter as "a research technique for the objective, systematic and quantitative description of the manifest content of communication" (1952: 18). Manifest content analysis is concerned with counting the number of times some word or words with similar meanings have been used within a defined space such as paragraphs or pages. However, the number of times words with similar meanings have been used may not necessarily determine to what effect they have 
been used. For this reason another measure of content analysis is latent content analysis which does not depend upon how many times words of similar meanings have been used within defined space, but the degree to which the defined space conveys some idea or ideas. Normally, a combination of both latent and manifest content analysis conveys what is said and to what effect. Content analysis essentially has to do with what communication took place and how effective that communication was. Communication is important in the management of public affairs considering that political leaders spend a considerable amount of their time in transmitting their views, opinions and ideas using various media including public speeches, writings, newspaper publications, reports, and forms of documents. The main purpose here, therefore, was to try and determine from. available records the extent to which actions on the part of policy makers and political leaders were inclusive or participatory in nature with respect to the environment. In other words, contents of relevant documents were analysed to determine the quality of governance pertaining to environmental management. Indeed, this method turned out to be very effective and original, especially in instances where access to key officials (both current and past Ministers of government) were restricted or near to impossible. In such circumstances, available documents constituted the principal data source concerning the positions taken by key government officials and technocrats. Local newspapers including the Daily Graphic, Ghanaian Times, Ghanaian Chronicle and the Weekly Spectator were examined with a view of conducting content analysis on what they debated about environmental management in Ghana. Unfortunately, they published only government policies and did not provide any meaningful debate on the issue. For this reason, the 
intended content analysis of local newspapers was abandoned since they had no additional information to provide.

\subsection{Questionnaires}

To draw out the views and opinions on the central thematic areas of the study, interviews were conducted using questionnaires designed by the researcher with the help of the thesis supervisor. Using data from the Electoral Commission's Voter Register ${ }^{81}$ and the 2000 Population and Housing Census, the researcher purposively sampled the study communities in the Greater Accra, Central and Western Regions ${ }^{82}$, after which a total of 165 people comprising ninety-eight male (59\%) and sixty-seven female (41\%) were randomly selected for questionnaire administration. These randomized ratios did not exactly reflect the microcosmic gender representation of Ghana. ${ }^{83}$ However, since the communities from which respondents were randomly selected were not concentrated in one area, the views gathered from the respondents might approximate those of the entire population. Also the random selection of respondents guaranteed a fair representation of Ghanaians, both male and female, 18 years of age and over with different educational background, ethnicity, or religious affiliations. Questionnaires were administered in person largely due to the given the inconsistencies and inefficiencies in postal services in Ghana and the lack of designated home/ street addresses, all of which render questionnaire administration a tedious and sometimes frustrating exercise. The lack of town planning and the indiscriminate building of houses were recognized as one of the

\footnotetext{
${ }^{81}$ This is a list of all Ghanaians aged 18 years and above who are eligible to vote during elections.

${ }^{82}$ Purposive sampling was used to select the study communities which had most of the characteristics of interest to the researcher- in this case the common characteristic was the level of environmental degradation ${ }^{83}$ Provisional results from the Ghana's 2010 Population Census estimate that men represent about 48.7 percent of the total population with women representing 51.3 percent.
} 
many typical examples of the inefficiencies in existing governance systems in Ghana.

One of the ways in which this challenge was overcome was to identify the respondents and then have them take some time to complete the questionnaires in the presence of the administrator, whenever possible. In addition, administering questionnaires through faceface interviews proved to be useful given the high rate of illiteracy which rendered some respondents unable to read or write. Here, the researcher's fluency in two of the main languages- Akan and Ga- also proved to be a useful tool and made possible the translation of the questionnaires from English without losing the intended meaning. The challenges notwithstanding, there was a rather impressive response rate of about eighty five percent.

Table 3: Demographic characteristics of respondents

\begin{tabular}{|l|l|l|l|}
\hline Category & Variables & Frequency & Percentage \\
\hline Age & $18-24$ & 88 & 53 \\
\cline { 2 - 4 } & $24-34$ & 30 & 18 \\
\cline { 2 - 5 } & $34-44$ & 30 & 18 \\
\cline { 2 - 5 } & $44-65$ & 12 & 8 \\
\cline { 2 - 5 } & 65 and above & 5 & 3 \\
\cline { 2 - 5 } & Total & 165 & 100 \\
\hline Gender & Male & 98 & 59 \\
\cline { 2 - 5 } & Female & 67 & 41 \\
\hline & Total & 165 & 100 \\
\hline
\end{tabular}




\begin{tabular}{|l|l|l|l|}
\hline & Non-formal education & 19 & 12 \\
\cline { 2 - 4 } & Primary education & 27 & 16 \\
\cline { 2 - 4 } & Secondary Education & 60 & 36 \\
\cline { 2 - 4 } & University education & 35 & 21 \\
\hline \multirow{5}{*}{ Occupation } & Post-university education & 12 & 7 \\
\cline { 2 - 4 } & Total & 165 & 100 \\
\hline & Farmer & 9 & 5 \\
\cline { 2 - 5 } & Trader & 10 & 7 \\
\cline { 2 - 4 } & Civil Servant & 12 & 7 \\
\cline { 2 - 4 } & Trades man/woman & 36 & 22 \\
\cline { 2 - 4 } & Service worker & 24 & 14 \\
\cline { 2 - 4 } & Professionals & 44 & 27 \\
\hline & Other & 30 & 18 \\
\hline & Total & 100 \\
\hline
\end{tabular}

Source: Field Survey, 2008

\section{5: Secondary Sources}

In addition to primary data gathering methods as outlined above, the researcher incorporated the study of several secondary sources including books, journals, photographs, and traditional records involving the use of symbols and associated oral accounts. 


\subsection{Ethical considerations}

There are ethical implications involved in social science research which consist of the obligation of the researcher as well as the rights and welfare of subjects of the research. To this effect, ethical codes have been developed to protect the interest and welfare of those being researched. As Zimbardo (1984) explains, ethics represent individual or communal codes of conduct based upon a set of implicit or explicit principles. The researcher observed these codes to ensure that the rights and welfare of respondents were not violated. Also, as Frankfort-Nachmias and Nachmias (1992) argue, there are costs and benefits associated with any research undertaking. The cost and benefit ratio expresses the primary ethical dilemma that, while research is likely to produce benefits including findings that pave the way for advances in theoretical and applied knowledge and while participants are likely to be personally satisfied for having made contributions to this knowledge, there are also costs to participants that may include loss of trust in social relations or self-determination. Also, failure to conduct research may cost to society the potential advantages of new knowledge. To this effect, the researcher balanced the right to conduct research in search of new knowledge with the right of the persons providing the needed information.

\section{Informed Consent}

Considered to be the bedrock of ethical procedure ${ }^{84}$, informed consent as defined by Diener and Crandall (1978) refers to those procedures in which individuals choose

\footnotetext{
${ }^{84}$ See full discussion on this in Diener, E and Crandall, R. (1978) Ethics in Social and Behavioral Research, University of Chicago Press, Chicago
} 
whether to participate in an investigation after being informed of the facts that would likely influence their decisions.

Also as Cohen notes, consent represents the "right of self-determination and places some of the responsibility on the participant, should anything go wrong in the research" ( 2007 : 52 ) Part of this right of self-determination is that the respondent can refuse to take part in the research or choose to withdraw even when it has begun. To this effect, the researcher took care not to force answers from respondents and in cases where she was unable to get an answer out of a potential respondent, quickly moved on to another person. As earlier mentioned, principles of voluntary participation and informed consent were strictly observed which guaranteed that prospective participants took part in the research voluntarily and only upon giving their consent.

\section{Competence}

Competence connotes the fact that mature and healthy individuals, when given the relevant information, might make the right decisions. Consequently, the researcher did not engage individuals incapable of making such decisions due to reasons such as immaturity. For this reason, only healthy individuals 18 years old and above were chosen as part of the study population.

\section{Anonymity and Confidentiality}

Issues of anonymity and confidentiality are important as far as the rights of the respondents are concerned. This is also in accordance with existing research ethical 
requirements. All potential respondents were therefore assured of their anonymity and confidentiality for their participation in the interviews. The researcher took care to ensure the latter by collecting information without the names and other identities of the respondents and, in cases where identities were provided, care was taken to separate the data from the identities of those who provided it. All efforts have subsequently been made to protect their identity and ensure that their safety, personal or job security were not compromised as a result of their participation. Accordingly, all the relevant documentation and tape recordings were destroyed after the extraction of relevant information. The researcher relied on both note-taking and tape recording to record information. It was observed that some interviewees were more comfortable with the researcher taking notes and jotting down observations by hand while others liked both. It, therefore, became common practice to attend the interviews armed with both tape recorder and writing material. This enabled the researcher to rely on either method as and when necessary.

\subsection{Research from an Insider perspective}

Alvesson (2003) points out that, being an insider means that the researcher lives or has lived in the setting and for the purposes of research, employs to his/her advantage the experiences, knowledge and access to empirical material. The researcher considered herself as an insider having been born, and lived in Ghana for most of her life. To this effect, she used to her advantage her knowledge of local culture and customs, particularly with respect to establishing relationships with respondents. Also her knowledge of several of the major Ghanaian local languages meant that the researcher prepared and 
translated the interview guides and questionnaires by herself. Insiders have been accused of built-in biases - having lived in the setting for so long, they are unable to see things that an outsider would perhaps see. But the researcher also had the advantage of having lived outside of the country for many years. Consequently, she was able to make observations from an outsider perspective as well.

\subsection{Challenges}

The field trip in Ghana - which as earlier mentioned, was carried out in an intensive 4 month period from March to July 2008 - was fraught with several challenges, pertaining particularly to problems of red-tape and unnecessary paperwork. Also, the researcher, in many instances, had to go through numerous government officials to secure interviews. She had to break through the ubiquitous thick barrier of suspicion and mistrust within government circles towards independent researchers by giving constant reassurances that the information and data being gathered would not be used for purposes other than what had been indicated in the introductory letter. Needless to say, that access to important official documents and current data was rather difficult. Suffice it to say that the degree of secrecy surrounding the dissemination of official data and information combined presents great challenges to potential researchers.

This is compounded by the lack of a Freedom of Information Bill in Ghana which would otherwise create easy access to information for the general public. Yet another challenge is that information made public by government ministries, in this case the Ministry of 
Environment and Science and the EPA, through their libraries and public relations departments were, for the most part, outdated. Online publications by government departments are also almost non-existent. For example, on the official website of the EPA, one cannot find a single publication of completed Environmental Impact Assessments (EIAs) or annual reports. Considering that Ghana had been under structural adjustment for decades under the auspices of the IFIs who are supposed to take the Environmental Impact Assessment process seriously, this situation is most disappointing. In sharp contrast, the researcher found NGOs engaged in environmental activities to be very helpful as they supplied very useful and current information (mostly collected by independent bodies) on the state of the environment in Ghana.

\subsection{Limitations of Stwdy}

There are several limitations of this study that need to be discussed. First and foremost, because of its exploratory nature, the findings of the author's research may be limited in their application to cases beyond Ghana. But the information gathered from this research may, however, serve to guide the development of further research that examine the nature of elite governance in countries in the sub-Saharan region and developing countries elsewhere and the impact of the latter on policy outcomes including but not limited to environmental ones. Secondly, budgetary and time constraints made it impractical to collect relevant data on a nation-wide basis. Thus, as earlier noted, data collection was limited to study populations in Greater Accra, Central and Western regions of Ghana. However, all of these areas were, chosen because they present many of the environmental problems central to the thematic focus of this study. Another study limitation had to do with the researcher's difficulty in obtaining reliable statistical data from official sources. 
This mainly resulted from the mistrust within government circles towards independent researchers. But this problem was reduced to some extent by the researcher's reliance on primary as well as secondary data from non-official sources particularly the NGOs.

\subsection{Summing $T p$}

In sum, this chapter has explained in further detail the methodological approach employed in the study. In undertaking this research, data from primary sources was collected during a four month field trip to Ghana during which the researcher used various methods including semi-structured interviews, focus group discussions and questionnaires, as well as participant observation. Also data from secondary sources was used. Ethical issues were considered in which the researcher took steps to ensure an appropriate balance between her right to unearth new knowledge and the right of selfdetermination of the participants involved in the study. The study goes on in the next chapter to analyse the data collected and present the patterns observed and the findings. 


\section{CHAPTER FIVE (5): DATA ANALYSIS AND INTERPRETATION}

\subsection{Dominant Patterns and Themes}

The previous chapter described in detail the methodological approach employed in this study. In this chapter, patterns and themes that emerged from the data collection are analyzed, interpreted and presented. It is a combination or fusion of what was found in primary data, and content analysis of secondary data including official documents. This fusion is considered appropriate given that the data collected are mutually complimentary. In the process, some relevant concepts which are considered necessary for understanding the research findings are explained.

\subsection{Centralization and Formalization in Environmental Decision-making}

In theory, political legitimacy requires, among other things, that public decisions be made in an open and participatory manner. However, as surmised from the data collected on Ghana's environmental management practices, decision-making continues to be elitist centralized, formalized and exclusionary in nature. Examples of this abound in Ghana's management of the deforestation problem.

Ghana's battle with Deforestation: Who does what?

Timber, one of the many resources that Ghana is endowed with, ranks very high as a foreign exchange earner and a major source of livelihood. Equally important are the 
medicinal plants, fuel wood, meat and other natural forest products all of which make important contributions to the ultimate welfare of Ghanaians. But, as mentioned in chapter one, Ghana has seen a rapid depletion of its total forest cover. To assess the performance of successive coalitions of elites with regard to the management of the country's deforestation problem, the researcher conducted a series of semi-structured interviews with key officials and traditional rulers, elicited information from focus groups and examined available official documents and existing archival records including Gazettes and environmental publications.

\section{Interview and Focus group Analysis and findings}

On the issue of deforestation, a total of ten (10) interviews were held with government officials of relevant ministries and agencies in the Greater Accra region alone, with four (4). of these officials at the EPA, two (2) at the Ministry of Environment, Science and Technology, two (2) from the Forestry Commission and one (1) from the Ministry of Lands and Forestry. In addition to the latter was one (1) official from the Centre for Remote Sensing and Geographical Information. In the Central and Western Regions areas which like the Greater Accra region are characterised by the problem of deforestation, two (2) officials of the Regional Coordinating Council (RCC) were interviewed in their respective regions. Also, traditional rulers of six (6) traditional areas were interviewed. Still on the issue of deforestation, four(4) focus groups were organized in the Sefwi -Wiawso district of the Western region, with one(1) and two(2) in the Greater Accra region and the Central region respectively. Participants in the focus group 
ranged from community leaders, women, farmers, migrant workers as well as village elders.

The interviews and focus group discussions revealed a pervasive lack of public engagement in the ongoing fight against deforestation in Ghana. Particularly telling was the conceptualization by the local people of their relationship with government forestry officials in authoritarian or paternalistic terms. The latter was viewed as being out of sync with local needs and demands. Also telling was the description of district forestry officials as 'policemen' whose sole preoccupation was to patrol forest plantations and reserves with the sole aim of keeping the local people out.

As one discussant put it:

I am over sixty years old now and $I$ have lived in this village all my life. I have seen successive governments come and go. I have ten children, five males and five females whose future is very dear to me. Protection of the environment to serve later generations is very important to me, my family and my extended family that I love very dearly. I am prepared to cooperate with any government in this respect. Our fore-fathers handed to us certain values about the environment which, when combined with the efforts of the successive governments I have seen coming and going, could have yielded much fruit. I am convinced that the traditional values and knowledge that have been passed down to people like myself bring a lot to the table and will serve the whole community for the ultimate benefit of all. Unfortunately, this 
kind of cooperation between government and the local population has been a dream at best. We have done our best to reach out to the successive governments of Ghana, but those governments have invariably turned a deaf ear to us. Government officials treat us like thieves in our own villages. They are always telling us not to cut down this tree or that tree, and have banned us from collecting firewood in the reserves or even to go hunting... and yet never sit down with us to discuss what role we can play in protecting our resources.... During elections, the politicians come to court us for our votes and make all sorts of promises. We always take advantage of these rare encounters to voice out our grievances and to emphasize the extent to which we feel marginalized from vital decision-making processes concerning the management of our environment. Yet, they forget all about us once they are voted into power. It is therefore not surprising to me at all that we continue to face these environmental problems all of which, in my view, are preventable. In the old days, none of these problems existed because members of our communities, leaders and ordinary people alike relied strongly on each other to manage our natural resources and preserve them for the upcoming generations (Focus Group Discussion - Central Region, 2008).

Another added:

As an energetic and upcoming young person of this community, it saddens me to see the extent to which our valuable environmental resources are being 
depleted. Judging from the actions and utterances of politicians and government officials, there is no doubt in my mind that policy makers and government officials see the local population as being the root cause of these problems. What else is their justification for banning us from going into our own forests to gather firewood and find food for our families? Why else would they erect barriers around our forests and pay people to police them day and night? Despite their supposed actions in the interest of the environment, we are all witnesses to the rampant depletion of our trees by big timber contractors who, on daily basis, continue to come in and cut down our trees? Who gives them the permission? Isn't it these same government officials who single us out as being the root cause of deforestation? Timber contracts and concessions continue to be allocated unabated every year to these companies who have no regrets whatsoever about the deleterious impacts of their activities on our very existence. It is even much sadder when it is considered that we never see any of the money these timber contractors pay to the government being invested back into our local communities. Where this money goes is anybody's guess.......... (Focus Group discussion, Western Region, 2008).

Indeed, the words of one of the discussants seemed to capture the frustration felt by the people about the seeming lack of empathy and understanding demonstrated consistently by government forestry officials as far as forestry protection was concerned 
I am a middle-aged female subsistence farmer. Like many women of my age and as long as I can remember, I played a vital role in crop and animal production to meet both my family needs as well as the needs of the wider community as a whole. We have been responsible for vital activities such as weeding, transplanting, preparing the land for cultivation and also for food storage and marketing activities. This is why our communities have continued to thrive up until now. We have nowhere else to go and nothing else to live on... This is the life we have known all our lives... We will continue to do what our forefathers did to put food on the table... We are not about to be cowered into submission to these government officials who do not understand our traditional ways of life and are bent on making us bow to their wishes and demands. For me, politicians and government officials have so far been part of the problem and never part of the solution. If they want to be part of the solution now, they must first recognize the part they play in the destruction of the environment, take appropriate action to address their own shortcomings, then, and only then can they be our allies in protecting and managing the environment. As the situation is at the present, while we strive to manage the environment, their policies and alliances with the timer contractors undermine our efforts. We are not the problem, they are. (Focus Group discussion, Western Region, 2008)

The input of a very old person in a village during one of the focus group sessions was very insightful. He said: 
I am about 90 years old. I love my country and I love our people. It really pains me that governments from the colonial time to the present have paid lip service to the preservation of the forests of this country. When I was young, the forest stretched for miles into the horizon. Today that beautiful forest is no more. When we were on our own, we preserved the forest and left it almost the same as we inherited it. Then the government came in with its concessions to timber contractors and the forest slowly vanished. We were told that for every forest tree felled, the timber contractors would plant at least one in its place. The timber contractors failed to live to that promise and no government ever saw to it that the timber contractors complied. Indeed, the government officials were allies of the timber contractors who provided them with kickbacks to the licences they allocated to the contractors. In this way, the timber contractors so captured the government officials that there was no control from above. Within forty years, the thick forest was gone. Look at the small size of this village! Are we capable of destroying a forest of hundreds of square miles in forty years? Even if we wanted to do so, do we have the equipment? See how poor the villagers are! Did we really gain anything for the destruction of our beautiful forest? Who are those who gained? They are the timber contractors and their allies, the government officials. It is they who ride in the luxurious cars and live in big mansions in the cities. We had no say in the destruction of our beautiful forest. We were powerless spectators! If any government wants to resurrect 
the forest they destroyed, let them begin the replanting now. It is that simple (Focus Group discussion, Western Region, 2008).

\section{Analysis and Inference}

Common themes arising from the Focus Group Discussions (FGDs) were as follows:

Perception of the environmental problem:

Participants decried what to them was a lack of a sense of urgency or commitment on the part of government towards the deforestation problem, in particular and environmental degradation in general. To the participants, government's perception of the environmental problem was that it could be put off without any immediate or apparent repercussions on societal well-being. Neither was environmental degradation - the problem of deforestation included - considered to be a major threat to their positions of power. This, to the participants, explained why politicians hardly ever campaigned on environmental issues. It also explained the lack of urgency as characterized by government actions and initiatives towards attaining environmental goals. As they pointed, no politician to their knowledge had as yet been 'booted' out of office on the basis on non-action or lack of results as far as the environment was concerned. While recognizing their own rights and 
responsibilities towards environmental problem solving, the overwhelming view of the participants was that real progress would remain nothing, but a pipe dream, until the environmental problem was taken to be a 'pressing one' by those in power.

\section{Lack of collaboration or engagement:}

FGD participants also raised serious concerns about government's inability to effectively engage and involve communities affected by environmental problems in the decisionmaking and problem-solving processes. This, to a large extent was due to the disproportionate allocation of power in favour of the government which foments a relationship that is characterised by miscommunication and mistrust. As evidence of the latter, participants noted the tendency of government officials to 'talk at them' and not 'with them' when it came to finding solutions to protecting the environment. In other words, rather than establishing open-ended communication channels that would allow meaningful dialogue and information sharing, governing elites preferred to adopt a 'one policy fit all' approach that yields very little results. In relation to the latter, concerns were also raised about the prevailing view within government that the local populations or communities themselves were the underlying cause of the problem of deforestation. This view, to the participants, not only drew attention away from the exploitative activities of big timber companies, but even more importantly precluded what would otherwise be very useful contributions on the part of the local people towards environmental problem solving. In short, participants expressed deep frustration about their inability to own and manage their own forests and by so doing, improve their livelihood. 
The role of timber contractors:

While recognizing the economic value of forest products, particularly timber, participants were also quick to highlight the fact that forest also presented recreational, medicinal, emotional benefits not only for surrounding communities, but for the country as a whole. They, therefore, expressed serious concerns about the adverse impact of commercial logging on the remaining forest cover. The dominant view expressed was that the activities of big timber companies and contractors if left unchecked would result in the decimation even of the remotest forest areas. Interestingly however, there was very little optimism expressed about the willingness and commitment of government to make and enforce stricter regulations and laws that would deter the unsustainable practices associated with commercial logging. Low concession and license fees as charged to loggers by governments and the unwillingness of timber companies to invest in reforestation projects were also cited as some of the underlying causes of the loss of forests and other biodiversity resources.

\section{Illegal Loggers}

In the focus group discussions, participants also questioned the wisdom of the total government ban $^{85}$ on chainsaw operations ${ }^{86}$ given the sophistication and determination of the operators which allowed them to continue their activities unabated. As indicated by the participants, most of the chainsaw operators were outsiders who would even go as far

\footnotetext{
${ }^{85}$ In 1997 , the government placed a total ban on the activities of chainsaw operations to prevent the indiscriminate felling of timber in forest reserves.

${ }^{86}$ This refers to the use of chainsaws to fell, de-limb and buck trees.
} 
to resorting to the use of firearms during their operations and in some instances collude with the forest guards who were supposed to prevent them from felling trees. In their view, chainsaw operations also continue to thrive, because of the support of big financiers whose only interest was to make huge profits out of the thriving demand for timber and wood products.

\section{Accountability and Transparency}

During the focus group discussions, participants decried the absence of mechanisms or channels through which governing elites could be held accountable for their decisions and actions on the environment. The root of this problem, they noted was the lack of local representation in the formulation and implementation of environmental policies and programs. As they argued, the only way in which local communities could be empowered to take charge of their environmental problems and find context specific solutions, was for governments to encourage open and transparent decision-making and facilitate easy access to information.

\section{Government Officials Interviews}

Interestingly, government forestry officials interviewed identified inadequate resources and funding for policing and monitoring purposes as being their biggest challenge in their fight against deforestation. As an official of the Forestry Commission stated, 
I have been an official of the Forestry Commission for decades. One of the sore problems of the Forestry Commission for all these decades has been inadequate funding. What is most necessary is for more funding to be allocated in the national budget to hire more officers to patrol and monitor our remaining forest reserve boundaries on a routine basis. The more visible we become, the less problems we will have in terms of local population encroaching and decimating the remains of our forest resources. It is important that we encourage our local population to appreciate the vital role these resources play in contributing to the growth of our economies. Timber, for instance is a major foreign exchange earner, and must be protected at all costs (Government Official Interview, Accra, 2008).

The comments of this particular interviewee confirms the fears of the villagers that government officials are so prejudiced against them and blame them as the cause of deforestation. For this high-ranking government official, cutting timber to earn foreign exchange is not part of the problem of deforestation. It is the local people who use wood as a source of energy who must bear the blame. This is very disturbing considering that cutting small trees to serve as wood for firewood or energy purposes does not affect the gigantic forest trees in the same way that large-scale timber harvesting does. Examination of existing timber regulations reveals that logging companies in Ghana operate through 
long-term contracts that do not only grant concessionary harvesting rights, but also require them to undertake forest management activities and reforestation projects. ${ }^{87}$

But, as some government officials admitted in the interviews, government lacked the capacity, manpower and resources to ensure that concessionaires fulfilled their contractual obligations of investing in forest management and reforestation projects. Also concerns were raised, albeit grudgingly by some government officials about the longterm nature of the concessions which ended up providing very few incentives for concessionaires to adopt more sustainable logging methods. ${ }^{88}$ Also governments, whether through non-enforcement of regulations, provision of attractive tax rebates, or low fines to timber companies for breaking forest conservation regulations, continue to provide very attractive incentives for commercial logging and the timber industry as a whole. The absence of independent organizations or bodies with responsibilities of auditing and supervising the allocation and performance of concessions also opens up spaces for collusion between corrupt government officials and timber concessionaires.

Interestingly, in another official interview the interviewee opines:

\footnotetext{
${ }^{87}$ The 1997 Timber Resources Management Act ( Act 547) and the Timber Resources Management Regulation(LI 1649) outline the rights and responsibilities of concessionaries in the Timber Utilization Contracts(TUCs)

${ }^{88}$ Empirical studies including those conducted by Boscolo and Vincent, 2000, Walker and Smith, 1993, show a low growth rate in tropical forests- a fact which encourages concessionaires to quickly exhaust their concessions and then turn their attention to other profit yielding ventures. See Boscolo, M. and Vincent, J. (2000) "Promoting better logging practices in Tropical forests: A simulation analysis of alternative regulations" Land Economics 76(1) and Walker, R. and Smith, T. (1993) "Tropical deforestation and forest management under the system of concession logging: A decision-theoretic analysis" Journal of Regional Science 33(3)
} 
In my long years as a public servant I have come to realize one thing. Encroachers are the main obstacle to forest management. The encroachers notoriously, always and consistently undermine our good plans. It is only by coming down hard on encroachers of our forest reserves and holding them accountable for their destructive and negative actions that we can make any headway in our quest to stem the tide of massive deforestation that we are grappling with today. Members of our local communities must realize that we do this for the good of the country as whole and, in return, give us their utmost cooperation (Governmental Official Interview, Accra, 2008).

\section{Analysis and Inference}

The view as expressed by this respondent requires an explanation of who the encroachers are and how they can be stopped or controlled. For this interviewee the encroachers of the forest include illegal loggers and the local people engaged in charcoal or firewood production. But this bunching together of illegal loggers and the local people is not an accurate representation of the picture. The local people are primarily engaged in farming, but produce charcoal and firewood to supplement their income. As indicated by focus group participants, most illegal loggers do not even belong to the local population and are not engaged in farming locally. Both legal and illegal loggers are only interested in making money by felling trees and selling the logs produced. Some illegal loggers do much damage to the forest reserves in the same manner that the licensed loggers do except that some illegal loggers have no legal concessions in a specific area. Hence, some illegal loggers, as pointed out by focus group discussants, might be legal loggers in 
specific areas but not in others. Given that some of the illegal loggers might have some legal concessions in other areas but not in others, it is difficult to draw a fine line between the two. Moreover, the illegal loggers might have the same equipment as the legal loggers in a particular area for they belong to the same industry. With the EPA (2000) estimating over 90 percent of Ghana's high forests as having been logged, there is no doubt that deforestation remains a grave problem.

What can be surmised from the findings as outlined above is that governmental elites politicians or bureaucrats - have so far failed to appreciate the sheer significance of forest and land resources to the survival of local populations. They consider the local farming populations and the illegal loggers to belong to the same category because both do not pay license fees and provide no kickbacks to government officials in the specific local area of operation. One thing is clear, so long as the traditional approach to forest protection prevails, wherein policing remains the primary and dominant function of the forestry department, local populations will continue to appear apathetic and uncooperative in the fight against deforestation.

\section{Analysis of Official documents}

As far back as the colonial era, the exploitation of timber has always been a challenge, but since the onset of the Economic Recovery Programme (ERP) in 1983, the loss of the country's forest cover has taken on alarming proportions. Indeed, ten years into the ERP programme, by 1990 , the volume of exported lumber had shot up by $500 \%$ with the 
volume of logs rising to $806 \%$ (Ghana Statistical Service, 2000). Official documents indicate that some measures have been put in place to address this problem, and these include the establishment of forest management programmes, tree plantations and agroforestry practices. Also, to coordinate and oversee the activities of public agencies responsible for the management of the country's forest resources, the Forestry Commission (FC) was established through the Forestry Commission Act (Act 57I) in 1999.

Also, in 1994, the government promulgated the Forest and Wildlife policy to ensure the conservation of the nation's wildlife and forest resources. Emerging from the Forest and Wildlife policy was the enactment of the 1997 Timber Resources Management Bill which proposed the introduction of Timber Utilisation Contracts to regulate the harvesting of timber. It is also important to note that the NDC government in 1997 put in place a total ban on the activities of chainsaw operators in an effort to stem the decimation of the country's forest cover. The latter does not by any means suggest inaction on the part of policy-makers. In all of this, however, the emphasis seems to be on what government can do, rather than what the government and other existing non-governmental actors can do together.

Although some efforts have been made in the recent past on the part of successive governments to, as it were, encourage some public input including that of the 'Third 
sector $^{89}$, these efforts, for the most part, almost seem like an after-thought or symbolic exercise. As aptly put by an official of an environmental Non-Governmental Organization:

My long years of experience working in a non-governmental organization convinces me that civil society's contribution to vital decisions and creation of policies is almost non-existent in Ghana. Non-governmental organizations such as mine have seen very little action as far as problem-definition, agendasetting and policy formulation processes are concerned. To say the least, organizations and civil society groups such as mine are brought into these processes at the very last stages of these important processes. What happens in reality is that we are invited to sit on committees and meetings merely to affirm decisions that have already been taken by the Minister and his officials.... Invitations extended to us are meant only to create impressions of the involvement of civil society in the decision making process. In reality, we are prevented from making any effective contribution. We constitute only a convenient historical and political statistic. Our criticisms and objections do not matter or change what had been decided prior to the meeting. I do not remember even one occasion when our views were accepted and incorporated. More often than not, the excuse was given that the Minister and his officials had some pressing issues to attend to and that was used to

\footnotetext{
${ }^{89}$ This is taken in this study to refer to NGOs, CBOs, and other not-for-profit organizations, groups, and individuals whose role is considered to be crucial to the quest for solutions to policy problems including environmental ones.
} 
justify a quick decision, a decision the Minister and his officials would have taken prior to the invitation.

(NGO interviewee, Accra, 2008).

One aspect of forest management that demonstrates that gaps do exist between what nongovernmental actors can do and what they actually do has to do with the allocation of timber rights. As currently stipulated under the Timber Management Resources (Amendment) Act 2003, application for rights to timber must be done through competitive bidding which "shall be conducted through two stages, namely a prequalification process and a bidding for timber rights process" (2003:.2). In order to be considered or an evaluation process carried out by the Timber Rights Evaluation Committee (TREC), all applicants must meet several pre-qualification requirements including evidence of ownership or membership of a registered company relevant to forest ventures and a demonstrated ability to add value to timber products. Quoting from the Act, the TREC as established by the Forest Commission must have as its members:

- the Chief Conservator of Forests of the Forestry Department or his representative who shall not be below the rank of a Deputy Chief Conservator of Forests (any of whom "shall be the chairman of the Committee);

- the Planning Officer of the Forestry Department;

- the Chief Administrator of the Commission;

- the Administrator of Stool Lands; 
- the representative of the Lands Commission on the Forestry Commission;

- a representative of the Ghana Institute of Professional Foresters and

- one person appointed by the Minister. (Quoted from TRMA, 1997; Act 547)

Given the important role the Committee plays in prequalifying and selecting companies and individuals for the bidding process, it would be safe to describe its composition as problematic, to say the least. The obvious problem here is the exclusion of nongovernment actors including civil society groups as well as the local population directly affected by the activities of these prospective bidders. The local people who communally own the land, in essence, do not have a say over who gets awarded timber rights. Secondly the Committee's selection process appears to be shrouded in a cloud of secrecy because of the confidentiality stipulations under the Act that bars public disclosure of a prospective applicant's information.

It must be pointed out at this point, however, that matters relating to the bidding process itself have undergone several revisions. Amendments, for instance, have been made to the stipulations, as they appeared under the Timber Resources Management Act 1997(Act 547), that required the Evaluation Committee(EC) to " submit all evaluation reports together with recommendations to the Commission within forty two (42) days of receipts of the applications"(Act 547, $1997: 4$ ).

These amendments as seen in the Amendment Act 2003 require, first of all, that 
"where the Evaluation Committee considers it appropriate to grant timber rights in an identified area, the Evaluation Committee shall cause to be published in the Lands Concession Bulletin and in at least two national daily newspapers, an advertising inviting pre-qualified applicants to bid for the grant of timber rights in respect of areas specified in the advertisement" $(2003: 6)$

Allowing the general public to witness the awarding of the timber rights to the bidder who offers to pay the highest annual timber fee ${ }^{90}$ may well be described as the most significant change to the original Act. But it still does not obviate the exclusivity associated with the membership composition of the Evaluation Committee itself. It also does little to change the fact that it is the Minister who has the final say over who gets awarded timber rights although the recommendations of the Forestry Commission is said to hold some sway over any such decision. The inclusion of a Social Responsibility Agreement (SRA) clause which highlights the importance of community development by requiring potential bidders of Timber Utilization Contracts(TUCs) to commit to assisting communities and inhabitants of the timber utilization areas with amenities, services or benefits, for all intents and purposes, may be described as the one and most significant provision.

But even this provision, which seemingly champions the welfare of the people, when subjected to closer scrutiny, reveals several shortcomings. For instance, there have been

\footnotetext{
${ }^{90}$ Where there are two or more equal highest bids, the area shall be awarded to the bidder from amongst the equal highest bidders who offers the highest price and in case of continued equal highest bids; the award shall be finally decided by a lottery amongst those highest bids.
} 
documented cases where these companies, upon being granted the contracts, have consistently failed to honour their promises with impunity. A study carried out by Mayers and Vermulen, (2002) in the Central, Brong Ahafo and Ashanti regions, (Diaso, Nkoranza and Offinso respectively) notes wide-spread dissatisfaction of the local people about the benefits accruing from ongoing timber operations in their respective areas. Interestingly, there was a consensus among the locals that "any profits returned to the area... had gone to the stool or elders rather than to ordinary people (Ibid, 2002). Also local people had issues with “....strangers coming to harvest the Non Timber Forest Products (NTFPs) ${ }^{91}$....;. timber contractors paying no compensation to farmers for tree harvesting; and the lack of benefits from tree harvesting ..." (Mayers and Kotey; 1996: 28). Ayine also cites reports of how local people in Omanpe in the Western Region of Ghana, succeeded in subverting the operations of a timber company that reneged on its promise to provide certain amenities as provided in its social responsibility agreement. (Ayine, 2008).

In sum, the failure of companies to honour their corporate social responsibility is well documented. Yet, this researcher was unable to find any data that demonstrates the willingness of government to legally enforce the Timber Utilization contracts by suspending or stopping the operations of the defaulting companies. Nothing is more telling about government's commitment to the fight against deforestation than its abolishment of provisions previously stipulated in the Timber Act of 1997. These

\footnotetext{
${ }^{91}$ These include rattan(cane) fruits, vegetables, meat and other by-products from game animals, microorganisms and plants for medicinal and pharmaceutical purposes
} 
provisions, among other things, required timber companies to implement reforestation plans. ${ }^{92}$ Currently, timber companies are under no legal obligations to replant the trees they cut down. Rather, culpability for the loss of the country's forest and natural resources seems to have been unfairly placed squarely on the shoulders of the local people inhabiting the forest areas and its environs. The latter is clearly evident in policy narratives that attempt to trace the root causes of environmental degradation - in this case deforestation - to local cultivation particularly small-scale farming and fuel wood cutting. With respect to shifting cultivation, for example, the argument is made that as farmers continue to rely on this practice as a main source of their livelihood, fallow periods are becoming shorter. This negatively affects the ability of the soil to regenerate the fertility needed to support forest regeneration. Thus, through such practices, forest regeneration supposedly becomes negatively affected leading to marked increases in deforestation. Interestingly, however, there is very little scientific evidence to back the claim that fallow lengths are indeed on a steady decline. In such situations, local people are portrayed by relevant decision-making authorities as either being ignorant of or being indifferent to the adverse impacts of their livelihood practices on the forests. It is therefore not surprising that solutions are developed and implemented that do not necessarily reflect their interests. It might be unfair to say that these traditional practices are always entirely sustainable, but the importance of a broader and cultural-sensitive assessment of the underlying casual factors of deforestation cannot be wished away.

\footnotetext{
${ }^{92}$ Equally disturbing is the decision by the New Patriotic Party (NPP) government, in 2001, to permit gold exploration (by implication mining) in protected forest reserves.
} 
However, as a close look at available archival documents shows, efforts have been made on the part of past governments to 'modernise' existing traditional farming practices such as shifting cultivation and slash and burn considered as being destructive to the natural environment. This indeed goes as far back as the colonial days. The following are some examples from the reports.

- In 1951, the Gonja Development Corporation (GDC) was created under the Agricultural Development Corporation (ADC) and charged with the responsibility of introducing modern and mechanized farming in the Northern Region of Ghana and to carry out experiments in large-scale farming (Development Progress Report, 1955).

- In 1959, a bigger programme was introduced as part of the Second Development Plan which provided both farm incentives such as improved seeds and subsidized mechanization as well as non-farm incentives including capital and grants and guaranteed prices for selected commodities. In his introductory remarks on the Second Development Plan, Kwame Nkrumah, then Prime Minister, stated

"Although our emphasis is on helping the small Ghanaian farmer, we have also had no difficulty in deciding that it will be helpful to have some sort of large scale modern agrarian projects in this country, partly to demonstrate to the farmers the profitability of new crops and new methods, and partly because this is the quickest way to develop some of the empty spaces in our 
large and under-populated country" (Gold Coast, The Second Development Plan, 1959-1964: 6)

- A similar narrative is presented in more recent development plans including the Ghana Vision 2020 document which cities as prerequisites for increased productivity in agriculture "... major changes in agricultural technology and ...the organization of rural society". The latter, the document notes, will lead to the "creation of a robust, diversified and commercially-based agricultural sector with strong linkages to an efficient technologically-progressive and market oriented industrial sector" (Vision 2020: 1). The Ghana Poverty Reduction Strategy (GPRS) for its part pushes for the "rationalisation and modernisation of Ghana's agriculture and agro-based industry" in pursuance of accelerated growth rates (GPRS, 2006: viii).

\section{Analysis and Inference}

The conceptualization of modes of production(in this case farming) in 'modern' terms finds its root in models of economic development postulated by the likes of Rostow (1960) who in The Stages of Economic Growth describes traditional modes of development as being backward and non-productive in nature. In the case of agriculture, the modern technology was promoted not as a complement, but a replacement to existing modes of production. But it is hypocritical that minimal mention is made in these documents of the potential for wide-spread environmental degradation that is often 
associated with large-scale and mechanized farming. ${ }^{93}$ Again, this demonstrates how notions of economic growth and development are often trumpeted within government circles, at the expense of the environment.

\section{Content Analysis of Local Newspapers}

As explained in chapter four, local newspapers including the Daily Graphic, Ghanaian Times, Ghanaian Chronicle and the Weekly Spectator were examined with a view of conducting content analysis on what government officials and bureaucrats debated about environmental management in Ghana. Unfortunately, they published only government policies and did not provide any meaningful debate on the issue. For this reason, the intended content analysis of local newspapers was abandoned since they had no additional information to provide. However, the researcher's analysis of news stories from these newspapers ${ }^{94}$ - between the 1988 to $1993^{95}$ revealed for the most part, rhetorical and passing references by political leaders and government officials on the seriousness of the environmental problem and the need for practical, sustainable and collaborative environmental management solutions.

\footnotetext{
${ }^{93}$ Elements of agricultural mechanical technology, such as tractors, internal combustion engines, irrigation systems are worthy of mention because they all exert pressure on the environment.

94 These included the Daily Graphic, Ghanaian Times, and the Weekly Spectator.

95 This five year period marked the beginning of the government's agenda on the environment, with the establishment of an Environmental Action Plan (EAP) in 1988which led to the full documentation of Ghana's environmental policy in the National Environmental Action Plan in 1992.
} 
Problems of Land Tenure System and Land Management

The ambiguous nature of Ghana's land law as derived from a complex mixture of customary, statutory and constitutional provisions presents a situation in which land rights is often contested. Constitutional and statutory provisions such as the 1980 Land Commission Act (Act 401) entrust in the state, managerial responsibilities over public land. On the whole, however, eighty percent of land is held under customary law and arrangements where traditional institutions such as stools, skins, clans and families are allowed to hold allodial (absolute ownership) of titles to land on behalf of their people. This makes the outright ownership of land the exception rather than the rule. Instead, people have access to or acquire land through 'derived rights' emanating mostly from lineage, inheritance, marriage or contractual arrangements. This places a disproportionate amount of power in the hands of the governing elites - that only serves to alienate and disempower . their non-elite counterparts. As this study gathered, there is ample evidence of this in the Western region of Ghana which faces peculiar environmental challenges mostly in respect to deforestation.

Endowed with about fifty one per cent of Ghana's forest resources, the region is home to several timber companies, all of whom have secured access to huge tracts of land through various arrangements with the original land title holders. It is also a major cocoa producing area. The situation obviously presents a myriad of problems with respect to land availability and security of tenure. This is amply demonstrated in the case of local communities and migrant farmers who mostly derive their land rights from contractual 
and tenancy arrangements with the original land title owners. Some small cocoa farmers interviewed complained about the verbal nature of contract arrangements which leaves a lot of room for manipulation and exploitation by land lords. One farmer insisted:

I am a Ghanaian, but a migrant farmer in my own country just because I come from a different area of the country. There are some strangers from other countries who are also migrant farmers like me, but I am no stranger. I am a Ghanaian. I am a hardworking man responsible not only for the upkeep of my immediate family, but also for my extended family as well. I come from a long line of farmers that have tilled the land to put food on the table. But migrant farmers, like me, are at the mercy of the communal landowners of this area... The lack of tenure is not good for us and denies us the right to even care for the land that feeds us and our families. Eventually, when the land loses its quality we lose for the landlords living in the cities have other sources of income, but we do not ... We migrant farmers do all the work and then have to share it equally with the landlord...Sometimes the landowners change the rules or promises to their advantage and we are powerless against that, for the agreement is only verbal. If we demand a written agreement, the landlords might replace us with other migrant farmers willing to live by the verbal agreement. Since we cannot afford to lose our livelihood and starve our families, we are always at the mercy of the communal ownership group. Formerly, the migrant farmers received twothirds of the product, now we receive only half. Who knows when they will 
demand to have two-thirds and us only one-third? (Focus Group Discussion, Western Region, 2008).

Another farmer clarifies the issue:

I have been farming in this village for decades, but just because I was not born in this town nor have any blood relationship here, I do not belong to the land ownership group of this area and never shall I be. From my rich experience as a farmer, I know how to care for the land and preserve its fertility, but the ignorant landlord rather has the land because he belongs to the land ownership group and I do not. Before I can farm here, I have to enter into some agreement with the leaders of the land ownership group of this area. I am only to farm and not to engage in questions about land ownership, land care or land qualities which are the concerns of the landlord only. Unfortunately, such agreements are also not committed to paper. The landlords are clever enough to reject the idea of written agreement outright. It is a situation of take our word or leave our land. But we cannot leave because we must live. Apart from farming, we have no other skills. The landlords can alter the verbal agreements at any time. Formerly we had more than half of the harvest. Now it is down to half and that is also in danger of being reduced further. In fact, when the harvest is ready, some landowners refuse to let us have half of the proceeds of the harvest as originally agreed in the agreement we had with them... but there is very little we can do about that... We cannot take them to court, because nothing was 
written or signed as per the agreement. The landlords are aware that we do not even have adequate resources to take them to court .... (Focus Group Discussion, Western Region, 2008).

As another put it:

While we work on the farms, the landlords are engaged in other businesses which earn them lucrative income. They call themselves absentee farmers though they are not farmers, but landlords. They do not consider that farming is our only source of income. It seems it is in their interest to keep us poor and landless so that they have power over us to keep on farming for them. They consider only their interests and not ours. For this reason, the shares landlords take for doing nothing are too high, and yet we do all the work... this has to stop..., but who will fight for us? Because of the contributions the landlords make to finance the political parties, they have influence over both politicians and government officials. It is no wonder that successive governments have so far failed to come to our aid. In fact, they have turned a deaf ear to our plight. That is why the land owners have been emboldened to treat us the way they do and deny us our rightful shares to the fruits of our hard work. This situation is, however, counter-productive when it comes to caring for the land. Moreover, we have no say in caring for the land and the landlord are more interested in the proceeds from the farm than caring for the land. How can we care for land which we do not own 
especially when we can be thrown out of that land any time the landlord so wishes? (Focus Group Discussion, Western Region, 2008).

\section{Land Tenure and Environmental Sustainability}

It is clear from the above discussion that the contested nature of land rights does present difficulties in terms of security particularly for the vulnerable and rural poor. This is the case, given that the inherent lack of ownership to a large degree inhibits, rather than fosters self-regulation and self-development. More importantly, the inability of local communities to negotiate easy access to land has adverse implications for the environment. Thus, insecure land tenure to a large extent can be linked to land use which, in turn, leads to environmental degradation. The lack of clear rights provides very little incentive to local communities to adopt practical and sustainable resource management and protection measures. For instance, tenant farmers who have short-term and temporary rights to land use may choose not to invest their time and energy in reforestation, and soil protection exercises, to the detriment of the environment. The lack of alternative means of livelihood, other than farming also gives very little room for local communities to adopt sustainable land use practices that can enhance the environment. As one discussant noted:

We will readily sign up for other jobs if the government makes them available - of course we would have to be trained considering that most of us migrant farmers lack the basic skills needed for other jobs. But I can see 
myself being a carpenter or even a mason- so long as it puts food on the table and clothing on our back.....But with the current situation being what it is now, I can tell you that we are really frustrated because we are being left with very little options and we are being forced to encroach on whatever is left of our forest reserves... whose fault it that? (Focus Group Discussion, Western Region, 2008).

\subsection{The Case of Waste management}

Ghana's solid and liquid waste is currently being managed in an untenable manner and this leaves a lot of room for concern. Indeed as Asante Duah notes "an uncontrolled waste disposal practice can be ... perceived as a potential source of serious health and environmental problems and a disbenefit to any region..." (1993: .8) This is particularly the case in the Greater Accra region of Ghana, where communities such as Nima and Ashaiman have over the years become 'renowned' for overcrowded housing and poor sanitary conditions. To home in on the issues underlying the waste management problem, the researcher sampled the views and opinions of residents in Nima and Ashiaman through interviews, surveys and focus group discussions. Also interviewed were seven (7) officials of the Accra Metropolitan Authority (AMA), which is the organization, charged with oversight and managerial responsibilities in the area of waste management. 


\section{Nima}

A migrant-dominant community made up mostly of people from the three Northern regions of Ghana, the population of Nima, located in the Greater Accra region of Ghana has grown from 29, 797 in 1960 to 52,270 in 1970 to 69,004 in 2000 (Ghana Statistical Service, 2002). Currently, Nima is grappling with all the serious problems facing rapidly growing areas dominant among which are poor drainage systems and an abysmal lack of waste management facilities. This researcher observed, on a consistent basis, the unattractive heaps of garbage overflowing in containers, dirty drains filled with garbage, ghastly smell of human faeces, livestock feeding on exposed garbage, and the littering of house compounds with waste.

Residents of Nima interviewed revealed an implicit awareness of the implications of the filthy conditions they lived in, but complained about the failure of successive governments to provide more than the basic physical infrastructure for sanitation and waste management.

Of the total of 60 respondents, an overwhelming eighty six percent $(86 \%)$ of respondents indicated that they practiced open storage of garbage in their own backyards, using anything from sacks, old buckets, plastic containers and bags with the remaining fourteen percent $(14 \%)$ saying they used waste containers provided by the municipality authority.

As one respondent said, 
I have lived in Nima for forty years at least. Never has any government provided enough receptacles for waste storage in Nima or any of its surrounding area. The efforts of the authorities are cosmetic at best. For a community as huge as Nima, only two or three small waste receptacles have been provided, and they are always overflowing... that is why we are forced to store the garbage in our backyards ...I challenge any official, newsmen or any curious person to visit Nima and see things for himself or herself. In addition, public places of convenience are almost nonexistent. With the exception of some few places of convenience dating back to the colonial days, very few have been constructed. Meanwhile the population keeps on growing at an alarming rate. We pay our property and other taxes, but we do not know how our contributions are used. Instead, we see government officials riding in luxurious cars and acquiring very expensive homes. There is also talk about ex-gratia for parliamentarians, but we do not hear any talk about provision of adequate receptacles to contain the filth or talk about facilities for garbage collection. This is shameful. Are the authorities serious about sanitation and hygiene at all? (Interviewee, Nima 2008).

About ninety eight percent $(98 \%)$ of respondents indicated that they had no toilet facilities in their homes- only two percent $(2 \%)$ of the respondents had water closet facilities. This clearly puts pressure on available pay-per-use public toilets commonly referred to in local parlance as Kumasi Ventilated Improved Pits (KVIPs). This often 
leads to the overuse and temporary closure of the KVIPs. Some respondents admitted to open defecation into drains and other open areas within the community. As one respondent explained,

Does it make sense at all to pay to attend nature's call? The poverty of a person does not deny him or her the right and dignity to be a human being. If a person has no money, does it mean that he or she should not attend nature's call? The queues at the KVIPs are notoriously long especially in the mornings... besides we need to pay to use them. I try to be a good citizen and use the KVIP whenever I can, but on the mornings when I am in a hurry, I have to look elsewhere to do my thing... besides it is not every day that I have money to pay the toilet attendant. When I have stomach upset necessitating that I ease myself quickly, I have no time to queue and disgrace myself publicly by soiling myself in the line (Interviewee, Nima, 2008).

\section{Ashaiman}

Listed as one of the fasted growing in Ghana, Ashaiman is a major squatter settlement located in the Tema district of the Greater Accra region, which beginning in the 1950s became home to the thousands of construction labourers working on the Tema port. Its population has grown faster than the national average: 2624 in 1960 to 22, 549 in 1970 to 150,312 in 2000 (Ghana Statistical Service, 2002). The growing population notwithstanding, very little has been done by successive governments in providing the necessary physical infrastructure and waste management facilities. It is common in 
Ashaiman, as this researcher observed, for people to defecate in the open and dispose of refuse in any open space or gutter.

There is no doubt that there needs to be an attitudinal change on the part of the residents themselves if problems of sanitation and poor waste management are to be solved. But there is very little attempt on the part of relevant government authorities to engage local populations in overcoming problems of sanitation and waste management. It is interesting that residents of Nima who were interviewed had very little knowledge about the role of District Assembly (DA)/ District Environmental Management Committees (DEMCs) in the waste management problem. People in Nima were unable to name any member of their DEMC or say anything about the nature of their task. Ashaiman residents also complained that interventions of the DEMCs could at best be described as inconsistent and incoherent. Government officials blame residents for the filth and poor sanitation standards in their areas. Residents, in turn, blame the authorities and the cycle of blame goes on.

As one focus group participant observed:

The crux of the problem, in my opinion, is that successive governments have so far failed when it comes to sanitation planning for communities such as ours. To my knowledge, no sites have been allocated for waste disposal and we the residents are forced to dump our household waste in our own backyards. We would love to live in a community that is free of filth and stench, but what other choices do we have? We the members of the 
community have tried on several occasions to allocate specific areas in our communities where waste can be dumped, but this has been met with fierce resistance from home owners in these vicinities most of whom have pointed out to us that having a waste site in their backyards will have dire implications for the health and welfare of members of their households.... But we cannot blame them; I think it is up to the authorities, particularly the Town and Country Planning Department to allocate specific areas that can be used for the disposal of both liquid and solid waste. Until they do that, we are not going anywhere with this waste problem... (Focus Group Discussion, Ashiaman, 2008)

Another added:

Politicians do not prioritise the environment; they have so far failed to push the issue of the environment on the agenda. This is a real shame considering that our populations continue to grow and the demographic changes. All of this requires that proper planning is done as far as the sanitation of the community is concerned. The truth of the matter is that, people are not aware of exactly who is in charge of what. For instance, enforcement of laws on sanitation have been woefully inadequate- I do not see any work being done by our District Assemblies and other authorities in charge and to make matters worse, few civil society groups have been involved so far.... (Focus Group Discussion, Ashiaman, 2008). 
In the words of another participant:

As a young member of the community, I am always willing to lend my time and effort to cleaning up our neighbourhoods and ridding ourselves of the filth that engulfs us. I have always taken part in those clean-up campaigns organized from time to time in this community. But such campaigns are far from enough. What we need for growing communities such as mine are sustainable local programs that engage both young and old, leaders and ordinary people, chiefs and government officials and bring everybody together to make our environment a clean one... My suggestion is that governments should also significantly increase the budgetary allocations to local authorities to help the latter invest more resources into managing the environment... (Focus Group Discussion, Ashiaman, 2008).

In addition to the open-ended questions discussed during the focus groups, the researcher sought out the views of respondents on several central thematic areas including the level of collaboration or participation in environmental decision-making and the perception of the environmental problem within governing circles.

Of the thirty-five (35) respondents randomly sampled in the Nima community as to whether the words "unsatisfactory", "meets expectation", and "exceeds expectation" can be used to describe, government's performance on waste management, twenty-nine 
(29) representing $(82.8 \%)$ perceived government's approach as "unsatisfactory", five(5) representing ( $14.2 \%$ ) responded "meets expectation". Only one person representing (3.6 \%) described the government's approach as "exceeds expectation".

Table 4 : Respondents' perception of government performance on waste management-Nima

\begin{tabular}{|l|l|l|}
\hline Perception & Frequency & Percentage (\%) \\
\hline Unsatisfactory & 29 & 82.8 \\
\hline Meets expectation & 5 & 14.2 \\
\hline Exceeds expectation & 1 & 3.6 \\
\hline Total & $\mathbf{3 5}$ & $\mathbf{1 0 0}$ \\
\hline
\end{tabular}

Field Survey, 2008, Nima

Figure 5: Respondents' perception of government performance on waste management-Nima

\section{Respondents' perception of government performance on waste management-Nima}

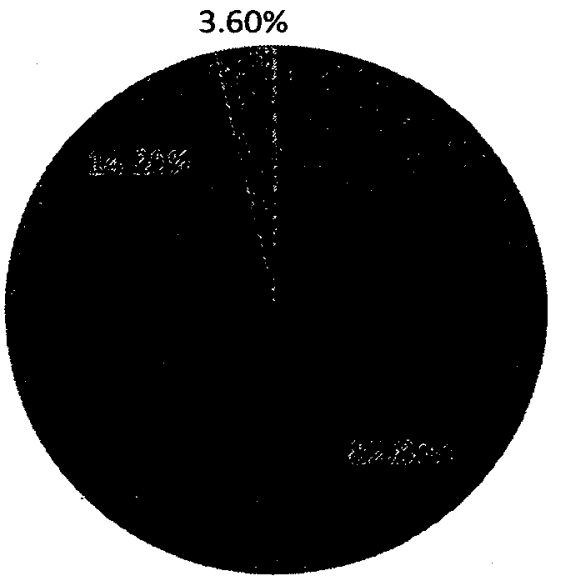

- Unsatisfactory

Meets expectation

Exceeds expectation

Source: Field Survey, 2008, Nima 
When the same number of respondents were asked whether the level of public engagement or involvement in policy making and implementation regarding the waste management problem could be described in the words, "non-inclusive", "somewhat inclusive" or "inclusive", twenty-five (25) representing (71.2\%) believed that the public engagement in decision-making processes was "non-inclusive", six (6) representing $(17.1 \%)$ described the level of public participation as "somewhat inclusive", with the remaining 4 representing (11.4\%) percent describing participation as being "inclusive".

Table 5: Respondents' perception of level of public participation in policy making regarding waste management -Nima

\begin{tabular}{|l|l|l|}
\hline Perception & Frequency & Percentage (\%) \\
\hline Non-inclusive & 25 & 71.2 \\
\hline Some-what inclusive & 6 & 17.1 \\
\hline Inclusive & 4 & 11.4 \\
\hline Total & 35 & $\mathbf{1 0 0}$ \\
\hline
\end{tabular}

Source: Field Survey, 2008, Nima 
Figure 6: Respondents' perception of level of public participation in policy making regarding waste management -Nima

\section{Respondents' percetion of level of public participation in polic making regarding waste management-Nima}

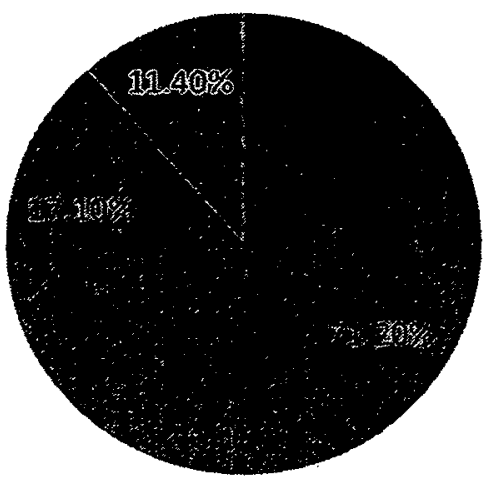

Non-inclusive

- Somewhat -inclusive

Inclusive

Source: Field Survey, 2008, Nima

When the same number of respondents in the Nima community were asked whether the words "unsatisfactory", "meets expectation ", and "exceeds expectation" can be used to describe on an overall basis, government's performance on the environment so far, twenty-four (24) representing (68.5\%) perceived government's approach as "unsatisfactory", seven(7) representing (20\%) responded "meets expectation", two(2) representing ( $5.7 \%$ ) saw the government's approach as "exceeds expectation", while the remaining two(2) representing $(5.7 \%)$ indicated that they did not have an opinion on the issue.

Table 6: Respondents' perception of overall government performance on the environment -Nima

\begin{tabular}{|l|l|l|}
\hline Perception & Frequency & Percentage (\%) \\
\hline
\end{tabular}




\begin{tabular}{|l|l|l|}
\hline Unsatisfactory & 24 & 68.5 \\
\hline Meets expectation & 7 & 20 \\
\hline Exceeds expectation & 2 & 5.7 \\
\hline No Opinion & 2 & 5.7 \\
\hline Total & 35 & 100 \\
\hline
\end{tabular}

Source: Field Survey, 2008, Nima

Figure 7: Respondents' perception of overall government performance on the environment- Nima

\section{Respondents' perception of overall government performance on the environment-Nima}

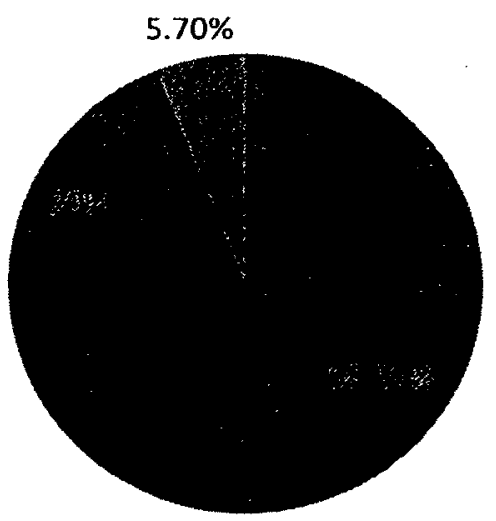

Unsatisfactory

Meets expectation

Exceeds expectation

Source: Field Survey, 2008, Nima

When sixty(60) respondents in Ashiaman and its environs were asked whether the level of public engagement or involvement in policy making and implementation regarding the waste management problem could be described in the words, "non-inclusive", "somewhat inclusive" or "inclusive", forty-eight(48) representing ( $80 \%$ ) believed that 
the public engagement in decision-making processes was "non-inclusive", eight(8) representing (13.3\%) described the level of public participation as "somewhat inclusive", with the remaining four (4) representing (6.7) percent describing participation as being “inclusive".

Table 7: Respondents' perception of level of public participation in policy making and implementation regarding waste management Ashiaman

\begin{tabular}{|l|l|l|}
\hline Perception & Frequency & Percentage (\%) \\
\hline Non-inclusive & 48 & 80 \\
\hline Somewhat inclusive & 8 & 13.3 \\
\hline Inclusive & 4 & 6.7 \\
\hline Total & 60 & 100 \\
\hline
\end{tabular}

Source: Field Survey, 2008, Ashiaman 
Figure 8: Respondents' perception of level of public participation in policy making and implementation regarding waste management Ashiaman

\section{Respondents' perception of public partcipation in policy making and implementation regading waste management- Ashiaman}

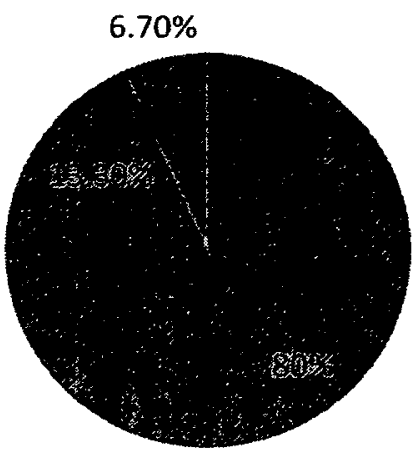

Non-inclusive Somewhat inclusive Inclusive

Source: Field Survey, 2008, Ashiaman

Still in Ashiaman, respondents were also asked to respond "yes", "no" or "no comment" to the question as to whether the government saw the waste problem - and in general the environmental problem - as a national priority that demanded urgent attention. Of the sixty (60) respondents, a total of forty-nine(49) representing (81.6\%) said "no", eight( 8 ) representing (13.3\%) said "yes", with the remaining three(3) representing (5\%) saying “no comment." 
Table 8: Respondents' response as to whether the environmental problem was perceived as a national priority by government -Ashiaman

\begin{tabular}{|l|l|l|}
\hline Response & Frequency & Percentage (\%) \\
\hline No & 49 & 81.6 \\
\hline Yes & 8 & 13.3 \\
\hline No comment & 3 & 5 \\
\hline Total & $\mathbf{6 0}$ & $\mathbf{1 0 0}$ \\
\hline
\end{tabular}

Source: Field Survey, 2008, Ashiaman

Figure 9: Respondents' response as to whether the environmental problem was perceived as a national priority by government- Ashiaman

\section{Respondents's reponses as to whether the environmental problem was percieved as a national priority}

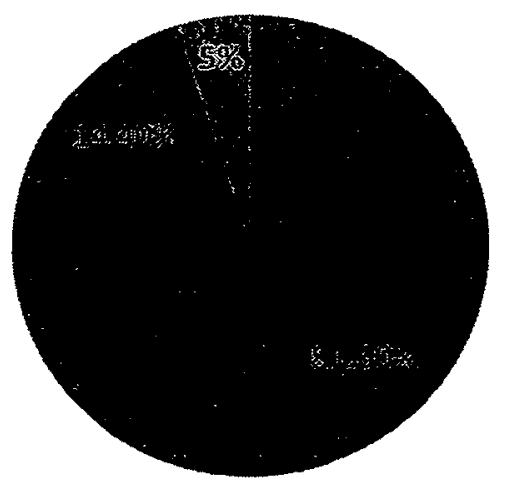

Source: Field Survey, 2008, Ashiaman 
Interestingly, officials of the Accra Metropolitan Authority (AMA) interviewed overwhelmingly placed the blame squarely at the door of "uncooperative and uncivilized residents in overpopulated areas such as Nima who relished living in filth."

As one official complained:

The roots of filth in the cities and especially Accra may be traced to lack of education and specifically in sanitation and hygiene. I must admit that due to lack of adequate resources and social marketing, our efforts to draw awareness of the population to sanitation and hygiene related communicable diseases such as cholera is rather weak. The majority of the people in the filthy areas are ignorant. We have poured a lot of resources into acquiring modern waste receptacles which have been placed at vantage points in the Nima community and yet these people choose to litter and dispose their waste indiscriminately... This to me defies logical explanation except in their complete ignorance of the consequences of filth on their own health. I think the time has now come for us to send a strong message to the people. Mass sanitation and hygiene education organized in the past seemed not to have sent the proper message. Under such circumstances appropriate sanctions to control the situation and prevent health hazards are justified. What we need to do is to strongly enforce existing by-laws on waste disposal and punish those who are caught to be breaking such laws. It is the only way we can 
make any headway in our fight against the growing accumulation of filth and waste in Ghanaian communities such as Nima and save the larger population from outbreak of sanitation related epidemics (Field Interview, Accra, 2008).

\section{Analysis and Inference}

One of the key themes identified had to do with the need for increased collaboration to bring government and non-governmental actors together to find practical and long-lasting solutions to environmental problems. Another issue of concern raised, was the perceived lackadaisical approach of the government towards environmental policy making and implementation. This state of affairs stemmed from the perception within government circles that the environmental problem was not one which deserved immediate and urgent attention. To this effect, government's performance in terms of formulating, implementing and enforcing policies and regulations was described as one that needed more improvement and commitment.

\subsection{Environmental (Mis.) Communication in Ghana: the role of elites}

The wide-spread and pervasive nature of Ghana's environmental problems demand that governmental actors reach out to other actors whose input and contributions can make a difference to the quest for sustainable and practical solutions to these problems. One method for achieving the latter is through effective and meaningful communication, the key indicators of which are taken in this study to include the style and /or approach as well as its relevance. In terms of style or approach, environmental communication in Ghana is conducted in a top-down and centralized manner with the disclosure or sharing of important information on and about the environment mostly emanating from central 
government organizations, particularly the Ministry of Environment and its implementing body, the Environmental Protection Agency (EPA). Shown in the table below (Table 9) are the major sources of environmental data.

\section{Table 9: Sources of Environmental data in Ghana}

\begin{tabular}{|l|l|}
\hline General Sources. Examples include: & $\begin{array}{l}\text { Ministry of Environment, Science and } \\
\text { Technology, Environmental Protection Agency, } \\
\text { Ministry of Local Government and Rural } \\
\text { Development, Volta River Authority, Ministry } \\
\text { of Health, Centre for Remote Sensing and } \\
\text { Geographical Information. Ghana Tourist } \\
\text { Board, Survey Department, Meteorological } \\
\text { Services Department }\end{array}$ \\
\hline Sector Specific Sources: Examples include: & $\begin{array}{l}\text { Forest Commission, Forest Services Division, } \\
\text { Wildlife Division, Energy Commission, } \\
\text { Ministry of Energy, Minerals Commission, } \\
\text { Water Resources Commission, Water Research } \\
\text { Institute, Ghana Water Company, Community } \\
\text { Water and Sanitation Agency, Soil Research } \\
\text { Institute }\end{array}$ \\
\hline
\end{tabular}

Source: EPA (2002)

In terms of relevance, evidence points to the fact that Ghana's environmental problems are presented as a set of 'technical problems' that can be best solved by experts. One of the implications of scientific intervention in policy development is that policy is often conceptualized in technical terms that are not easily absorbed or comprehensible to the 
lay person. For example, the following is an excerpt from a governmental report by the Water Resources Commission, describing the incidence of ground water in Ghana.

\author{
The occurrence of groundwater in Ghana is associated with 3 main \\ geological formations. There are the basement complex, comprising \\ crystalline igneous metamorphic rocks, the consolidated sedimentary \\ formations underlying the Volta basin...and the Mesozoic and cenozoic \\ sedimentary rocks... Groundwater occurrences in the basement complex are \\ associated with the development of secondary porosity as a result of shearing, \\ fracturing and weathering... (Water Resources Commission, www.wrc- \\ gh.org/ghanawaterresources.html).
}

Implications: The framing of environmental problems in scientific terms - as the example above connotes - is rather problematic because it presents a situation in which government officials end up merely filling information gaps as and when they think necessary and handing out information considered beneficial to the public's appreciation of environmental problems. Related to the fore-mentioned, is a tendency of government officials to withhold information that should otherwise be made public. This stems mostly from fear of what information might be used for. Public servants, particularly high ranking officials, possess the power to classify some information as being exempt from public consumption. In Ghana, this problem is exacerbated by the absence of a Freedom of information law and this situation effectively prevents individuals from accessing and requesting certain official documents and information. 
This brings to the fore the importance of freedom of information legislation commonly referred to in the literature as 'sunshine laws'. The latter are important because they help in protecting the rights and interests of the people, and also importantly help to ensure that those who hold the reins of power and make the decisions are held accountable for their actions and inactions. Information in Ghana is not easily accessible to public except for what government chooses to make available. But, even when this happens, there appears to be very little effort devoted towards the decentralization of the dissemination of relevant information. There is also a lot to be said about the medium or language of communication. Language and literacy are crucial to the retrieval of information. In the Ghanaian case however, information is disseminated via the print or written media which therefore means that the illiterate poor are unable to access and understand the necessary information which is predominantly presented in the official language - English. In addition to the above-mentioned problems, government officials interviewed cited as a key obstacle to effective communication, the lack of institutional coordination. This suggests inherent difficulties in information sharing and open dialogue even within governmental departments and agencies.

This is a cause for concern, given that a persistent lack of information or difficulties in understanding information leaves a lot of room for misperceptions within the public for whom it is be intended. This, in turn, leads to the public's non-confidence in the government. For instance, as earlier shown, the government of Ghana in 1991 took a step further in its battle against environmental degradation with the introduction of a National Environmental Action Plan (NEAP). 
The main rationale behind the plan is to identify areas of environmental concern to the government and people of Ghana and, by so doing, help in prioritising the key areas for action. To this effect, the plan reiterates the importance of community and women's involvement in decisions about the use of environmental resources (NEAP, 1992). Yet, as shown in the figure below, when asked to identify any of the existing governmental programmes or policies on the environment, only twenty-eight (28) of the one hundred and sixty-five (165) respondents representing (17\%) demonstrated some knowledge or awareness of environmental programs and policies. The remaining one hundred and thirty-seven (137) representing ( $83 \%$ ) could not name a single initiative, policy or program introduced by the government towards environmental management over the years.

Figure 10: Respondents' knowledge or awareness about governmental policies or programs on the environment

\section{Respondents' awareness or knowledge about governmental policies and programs on the environment}

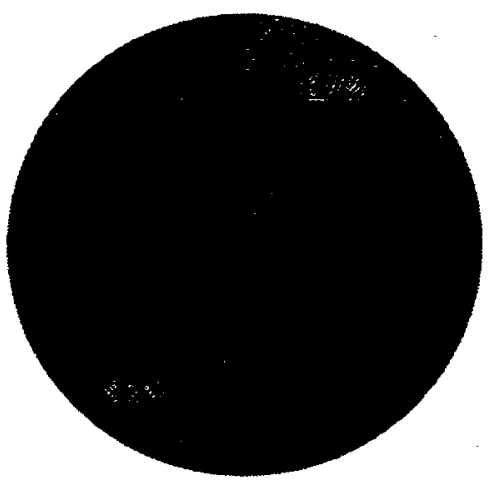

Knowledge

- No knowledge

Source: Field Survey, 2008 
It is interesting to note that of the twenty-eight(28) respondents who identified existing policies, only eight(8) described existing environmental documents as being easily digestible or understandable. The remaining twenty (20) found the information to be rather technical in nature. Also respondents expressed discontent with the websites of the environmental ministry and its supporting agencies and departments and reported having difficulties with finding the information they needed. Others noted that most of the information on government portals was quite outdated.

As explained earlier in the content analysis of local newspapers, news stories revealed for the most part, rhetorical and passing references by political leaders and government officials on the seriousness of the environmental problem and the need for practical, sustainable and collaborative environmental management solutions. The researcher's observation of television and news programmes also highlighted the failure of government to take full advantage of the media to communicate their environmental message and its underpinning concepts to the general public. A good case in point was the fact that the state-owned television station, Ghana Broadcasting Corporation (GBC), did not have a single programme dedicated to environmental management issues. Equally telling was the glaring absence of environmental programmes on the state radio, GBC Radio - a medium which could otherwise have been used to effectively disseminate the environmental message given that programs are run nation-wide in English and Ghanaian vernaculars. 


\section{Analysis and Inference}

The lack of knowledge or awareness about existing environmental programmes given that at least half of the respondents had some form of formal education - albeit at different levels, shows the failure of government to effectively communicate to the general public what its message on the environment was all about.

\subsection{The Case of Water Pollution}

Although Ghana is no stranger to environmental disasters, there is still a lot of work to be done particularly in terms government's anticipation of impending disasters and how it collaborates with non-state actors towards finding sustainable solutions. Best evidence of this has to do with the problem of water pollution. For instance, the Korle Lagoon located in the very center of the capital city; Accra in the Greater Accra Region of Ghana has, since colonial days, but more importantly in recent years earned the most unfortunate reputation of being one of the most polluted places on earth. As a result of constant pollution, this water body, once vibrant before the colonial day, has become a receptacle of domestic and industrial waste as well as raw sewage. This state of affairs, however, did not happen overnight. Rather, the siltation of the lagoon - a direct effect of which is a reduction of flood carrying capacity - was a gradual one and there is documented official proof pointing to persistent problems of flooding dating as far back as the colonial days to 1963 , then in 1973 and 1986 . While not exonerating local population from the blame, it is also difficult to overlook what appears to be a persistent inability on the part of successive governments to effectively energise them into protecting and managing what would otherwise be a dependable source of livelihood and a first-rate tourist attraction for the country as a whole. 
The frequent occurrence of cyanide spillages which have adverse effects on surrounding communities is yet another ample demonstration of the mismanagement of environmental disasters.

In June of 1996 cyanide spillage from the Teberebie Gold Ltd(TGL)mines estimated to be about thirty six million litres seeped into one of the tributaries of the Bonsa river ${ }^{96}$,the Angonaben stream and in the process killed numerous species of fish and destroyed large areas of cocoa farmlands. There were also some health repercussions as local residents of surrounding communities complained of various skin infections and respiratory tract diseases (WACAM, 2001).

In October 2001, a botched mine operation sent several thousand cubic meters of mine waste water laced with cyanide and heavy metal into the Asuman River in the Wassa West District of the Western region of Ghana. This resulted in the loss of drinking water for surrounding communities of Abekoase, Huniso and other small villages which also negatively impacted the health of the people. Also residents of the affected communities reported seeing large amounts of fish stock and other aquatic life floating dead in the river). In June 2003, water from an abandoned mine again seeped into the Asuman River with similar devastating results (WACAM, 2004)

In June 2006, Bogoso Gold Ltd announced that it had accidentally released about 40 drums of mill tailings into the external environment. This accident resulted in the

\footnotetext{
${ }^{96}$ This river is found is in the Western Region of Ghana
} 
contamination and extermination of aquatic life in the nearby Ajoo stream. In the aftermath of this incident, residents of the Dumasi ${ }^{97}$ and other surrounding communities also made numerous reports of respiratory tract and water borne illnesses (Anane M., Environmental News Services, and July 2006).

\section{Analysis and inference}

A greater part of this problem stems from the non-existence of mining law provisions that would not only allow independent and external auditing of environmental performance of mining companies, but also require that the audit reports are made public. In 2003 , the EPA, the main implementing agency for environmental programs, in collaboration with the World Bank, introduced a program that aimed at providing information about the environmental performance of industries for public consumption (EPA, 2005). The intent was to assess compliance levels with environmental standards and compliance with existing environmental laws in Ghana. Standards to be assessed were developed and agreed upon by implementing agencies. For example, the performance of the participants was to be colour rated with the best earning 'gold' and then green, blue and so on. Ironically, the designers of this initiative limited their scope of activity only to surface mining and other activities that resulted in discharging of effluents and particulate matters. Attention was not directed at the big mining and manufacturing companies, who, as the above examples illustrate, are the most likely culprits. Neither is there any evidence pointing to the willingness and commitment on the part of the designers of this project to use it as an effective communication and monitoring tool.

\footnotetext{
${ }^{97}$ This is also in the Western Region of Ghana.
} 
An examination of official documents, particularly the EPA's current annual reports, came up with no information about performance compliance of mining companies regarding the said initiative and most of the officials questioned about it seemed to have very little information about it. While recognizing the importance of information dissemination and persuasion, it is also important that people for whom these messages are produced are heard as well. This calls for a multi-dimensional communication strategy which fosters and facilitates exchanges between stakeholders to arrive at possible solutions for existing problems. The latter approach is significant in as much as it increases opportunities for identifying possible partnerships, resources, knowledge and skills needed to solve a peculiar problem. Open-dialogues allows for all stakeholders to listen to each other and this ultimately helps in avoiding one-policy-fits all situations in which solutions are imposed from above regardless of the peculiarities of the context in which these problems occur.

\section{6: Shared Capacity}

The concept of shared capacity as used in the literature refers to the ability of all relevant stakeholders to effectively introduce and successfully execute the necessary interventions towards the attainment of specific policy goals without intervention from a higher authority. To illustrate this further, the researcher took an in-depth look at the nature of relationship between formal and traditional authorities involved or responsible for town and country planning specifically in the Greater Accra region of Ghana. Traditional authorities while not a part of the formal political system, for their part, command a lot of respect in their respective communities mainly because of their role as cultural custodians of the land. But as earlier mentioned, while the traditional elite in Ghana- chiefs in 
particular - by virtue of their position, wield considerable influence over other stakeholders, they do not necessarily possess the "combined measure of resources and legal authority and the capacity to access and mobilize these resources ... for the formulation and implementation of existing policy "(Ondee et al, 2008; 783).

Comparisons were made based on evidence drawn from interview data and official documents and the following observations were arrived at:

- Under existing constitutional provisions such as 1994 National Development Planning System Act, Act 480, legal and regulatory authority for the planning of settlements and developments is vested mainly in central government institutions including, but not limited to the Town and Country Department (which falls under the Ministry of Environment). Others include the Ministry of Local Government and Rural Development, and the Survey Department, Land Title Registration, Land Commission and the Office of the Administrator of Stool Lands. Chiefs by virtue of their role as custodians of the land also have a say over the allocation and distribution of land. However, evidence gathered appears to suggest a pervasive lack of synergy between these governmental bodies on one side and the traditional authorities as headed by chiefs on the other side. 
Available records for instance point to legislations ${ }^{98}$ that allow the state to acquire and hold land in public interest or for public purposes. Eighty percent of land, on the other hand is under customary law which allow chiefs to hold allodial (absolute ownership) of titles to land on behalf of their people. This state of affairs which on one hand gives the state managerial and oversight responsibilities over public land, and at the same time gives land ownership to chiefs in reality makes for tensions and difficulties.

- For example, though land is under the control of the traditional rulers, their input is often not sought in the exercise of town planning. The resulting tension is reflected in the often non-compliance with the town planning directives by the local communities. Thus, in the Greater Accra Metropolitan Area (GAMA) of Ghana, this tension has undermined water distribution projects, and houses have been built within proposed roads leading to much congestion. Other problems include unplanned expansions and unauthorized development, all of which impact negatively on sound environmental practices. Such confusion is indicative of lack of effective leadership. It also sends the message that the articulation between the traditional elite and the modern elite leaves much to be desired including discipline on both sides of the parallel.

\footnotetext{
${ }^{98}$ An example is the 1962 Administration of Land Act which gives power to the state to grant stool-related concessions and also empower the President to intervene in land litigation cases.
} 
Chiefs interviewed complained about being left out of the formal planning processes aimed at the sustainable and practical use of land. This, to them poses serious challenges, as far as planning of development is concerned.

Although backed by legislation, relevant governmental institutions pointedly have failed to communicate to the public in a clear and persuasive manner, that there is need to adhere to sound land use practices. As this researcher gathered from our interviews with members of the general public, part of this problem stems from the negatively widespread public perception about the readiness and commitment or ability of government officials to enforce existing laws and regulations on proper land use. This is not far from the truth. As surmised from interviews with several government officials, a combination of problems including inadequate logistics, lack of base maps, obsolete technologies and operating procedures, low staff morale remain that continue to impact their implementation and enforcement capabilities, leading a flagrant abuse of these laws. (Government officials Interviews, Accra, 2008).

- Particular mention was made of the introduction of $L U P M I S^{99}$, a decision- support tool for land-use planning which, at the time of the interview, was still in its draft stages and had only been introduced on a pilot basis in a few communities nationwide.

It is interesting to note that that some residents of Accra continue to construct houses in both natural and designated water pathways which ultimately results in wide-spread flooding in several parts of the city. The Accra Metropolitan Authority was compelled in 2010 to demolish a lot of houses in the flooding areas

\footnotetext{
${ }^{99}$ This is the Information System for Land Use Planning established by the Land Use Planning and Management Project (LUPMIS) at the Town and Country Planning Department of Ghana
} 
of the Kpeshie Lagoon located between Teshie and La. The Tema Municipality was similarly compelled to destroy many houses at Klagon that stood in the flooding areas of the Tema Sakumo Lagoon. The avoidable costs of these demolitions were enormous to those whose buildings were demolished.

- As earlier mentioned, chiefs are not legally mandated to execute and enforce existing laws. In reality, chiefs are constrained largely, in part, as a result of the lack of support and recognition by the relevant government authorities. This is amply demonstrated at the local level where successive governments have failed to institutionalize the representation of chiefs in existing local government structures such as the District Assemblies. There may be existing constitutional provisions that require that traditional authorities and other stakeholders be consulted on the appointment of $30 \%$ of non-elected members of district assemblies. Ironically, this same constitution bars chiefs from engaging in partisan politics. This perhaps explains why successive governments have failed to formulate a clear and comprehensive policy that facilitates or formalises the participation of chiefs in existing local governance systems.

- It is also important to point out that the capacity and mobilization powers of the chiefs are to some extent also hindered by in-fighting and divisions among themselves. Chieftaincy disputes in the Greater Accra Region of Ghana are rampant. In the researcher's interview with chiefs, the point was made to the effect that these disputes were mostly results of contestation over land ownership as well as land sale. The lack of unity among these chiefs and the inability of traditional (supervisory) councils to amicably resolve these disputes have helped 
create an unfavourable climate for the sustainable use of land in the Greater Accra area.

There are other non-state actors such as NGOs and CBOs who, through various activities including advocacy and public awareness campaigns, endeavour to make a meaningful impact in the area of land use planning. The CBOs by virtue of the position they occupy within society are, in many ways, better placed than government officials to identify with the needs and demands of local populations. However, as noted during the researcher's interview with several key members, the CBOs themselves lacked the legal authority and, by default have to rely on formal state institutions for the necessary backing. Their mobilization capacities are also to a large extent hindered by problems of inadequate funding, professional staff and expertise. This leads to the next major theme observed: questionable lack of autonomy of actors.

\subsection{Lack of Autonomy of Actors}

As scholars, researchers, policy-makers strive towards the search for ideas and answers on issues and problems pertaining to the environment, there seems an increasing emphasis on the significance of participatory approaches or models for environmental policy and management. As gathered during interviews and focus group discussions, individuals, communities and other important stakeholders have as yet to retain or gain influence and control over local and non-local decisions that affect them.

\section{Traditional rulers}

Traditional rulers in Ghana - chiefs in particular - command a lot of respect and high esteem in their respective communities. This for all intents and purposes connotes an 
inherent ability and potential on the part of these rulers to act as effective guardians and managers of the environment. For instance, chiefs interviewed for this research demonstrated a deep understanding of the long-term implications of the environmental problems as indicated above, as well as a willingness and commitment to address the root causes of these problems.

As one Paramount Chief interviewed put it:

It is common knowledge to even the youngest child in Ghana, that we chiefs by virtue of the position we occupy, wield a tremendous amount of influence in society and are better placed to initiate and oversee the effective management of our environmental resources, including our forests, water bodies, coastal resources and land. But, the truth of the matter is that, we have been rendered mere onlookers in the ongoing efforts at managing our environment. We continue to look on helplessly as successive governments, often in cohorts with foreign organizations and officials, make important decision-making processes, without bothering to ask for any input whatsoever from us. Of course, once these decisions are made, we are expected to spread the message of the government in our communities, but sadly enough we are not empowered to enforce them. Any person summoned into my presence for flouting an environmental bye-law knows very well that there is very little I can do, aside from issue a verbal warning. So, let's face it, we chiefs are nothing more than toothless bulldogs with very little or no bite (Field Interview, Western Region, 2008). 
This was the view of another chief:

Chiefs govern through service, Chiefs govern by obedience, and Chiefs are priests and the opinion leaders in the community. The face of the Chief is to represent truth at all times, that is why we wear gold. But we do not have any power, Chiefs are powerless. The role of Chiefs has changed: now Chiefs belong to the State after he is installed, and merely exist for symbolic means. One thing is clear, and this is the need for wide-spread reform into the existing local governance systems (Field Interview, Western Region, 2008).

Indeed, in many of these areas, it was the chiefs who had themselves initiated community self-help programs such as street cleaning and tree planting exercises and also introduced education and public awareness campaigns. But as this researcher gathered from interviews, despite being custodians of culture and commanding respect and obedience from local population, chiefs are not able to hold people responsible for their actions. Indeed, all of the chiefs interviewed expressed dissatisfaction with their inherent lack of enforcing power. This rests solely in the hands of government officials who are too far removed from their reality on the ground and, hence, are unable to enforce the laws as needed. It is safe to conclude then that the inability to engage civic responsibility on environmental matters on the part of chiefs and traditional authorities stems largely from their inability to punish those who break existing laws and regulations on the environment.

As one chief of a coastal fishing community pointed out 
Fishing communities such as mine, continue to face problems such as the defecation of our beaches, water pollution, and the accumulation of waste in our backyards. My elders and I are ready to cooperate with the government authorities to enforce the numerous bye-laws on the environment, but it does seem to be the case that our politicians are unwilling to enforce laws for fear of losing their jobs via the ballot box.. (Field Interview, Central Region, 2008).

\section{Analysis and Inference}

Unless existing arrangements of governance, particularly at the local level are reformed to extend a much more meaningful role to chiefs, their impact on the ongoing quest for sustainable environmental management will continue to be peripheral in nature.

Successive governments speak about inclusion of all citizens in the decision making processes as part of democratization, but invariably and amazingly pay lip service to it when it comes to chiefs.

\section{Citizens and Civil Society organizations}

One of the criteria for sustainable development, as identified in the United Nations Commission's Brundtland report is "a political system that secures effective citizen participation in decision-making" (Brundtland, 1987: 65). The African Union also makes similar calls in its Charter on Human and Peoples' rights which categorically states that all individuals have a right to a clean environment. ${ }^{100}$ Such calls for a movement away from an exclusionist model of environmental decision-making, (reiterated as well in numerous international Conventions and Declarations ) together set the stage for the

\footnotetext{
${ }^{100}$ See Article 3 of the Constitutive Act of the African Union(CAAU)adopted by the $36^{\text {th }}$ session of the Assembly of Heads of State and Government, July $11^{\text {th }}, 2000$, Lome, Togo, which reiterates the Union's commitment at "promoting and protecting the human and people's rights.
} 
creation of a system of governance within which the rights of citizens to participate in environmental policy making are guaranteed. Environmental rights, one could argue, are particularly significant for developing countries where the impacts of environmental degradation are far-reaching and wide-spread. The table below for example, describes the magnitude of environmental problems experienced by inhabitants of Accra-Tema industrial area located in the Greater Accra Region of Ghana

Table 10: Environmental effects of major factories in the industrial area of Accra-Tema

\begin{tabular}{|l|l|l|}
\hline Type of Factory & Pollutant & \\
& Roise & Recipient \\
\hline Textiles & Biochemical Oxygen & Water bodies \\
\hline Breweries & Demand(BOD) & \\
\hline Cement & Cement dust, noise & Operatives, air \\
\hline Aluminum smelting & Alumina dust, Fluorides, noise & Air, vegetation, operatives \\
\hline Sawmills & Wood dust, shavings, noise & Factory premises, air, \\
\hline Food Processing & & surrounding water bodies \\
\hline Soaps and Detergents & BOD, Agro industrial waste & Water bodies \\
\hline Steelworks & Iron oxides, solid waste(slag) & Air, factory premises and \\
& & surroundings \\
\hline & Iron oxides, solid waste(slag) & Air, factory premises and \\
\hline
\end{tabular}

Source: Environmental Protection Agency (EPA) 
Evidence collected for this study point to some attempts made in Ghana, particularly in the post $1992^{101}$ period towards the guarantee and protection of environmental rights relating to decision-making. There are existing regulations that require manufacturing and extractive industries to involve citizens in the making of relevant decisions through various mechanisms such as Environmental Impact Assessment (EIAs). For example, under the 1999 Environmental Assessment Regulations Act, proposed projects owners are required to submit scoping reports and environmental management plans at the various project phases for review. Also importantly, the public is supposed to be notified and engaged in the impact assessment process. Introduced in the United States, after the passage of the National Environmental Protection Act (NEPA), impact assessment of environmental projects has since been adopted by over 100 countries worldwide (Dorais, 1996; World Bank, 2001). The rationale behind the implementation of Ghana's EIA procedures includes assurance of the active participation of the general public in the evaluation of the feasibility or otherwise of proposed projects. The figure below shows a flow sheet of the EIA process.

101 The National Environmental Action Plan was first introduced in 1992 


\section{Figure 11: Generalised process flow sheet of the EIA process}

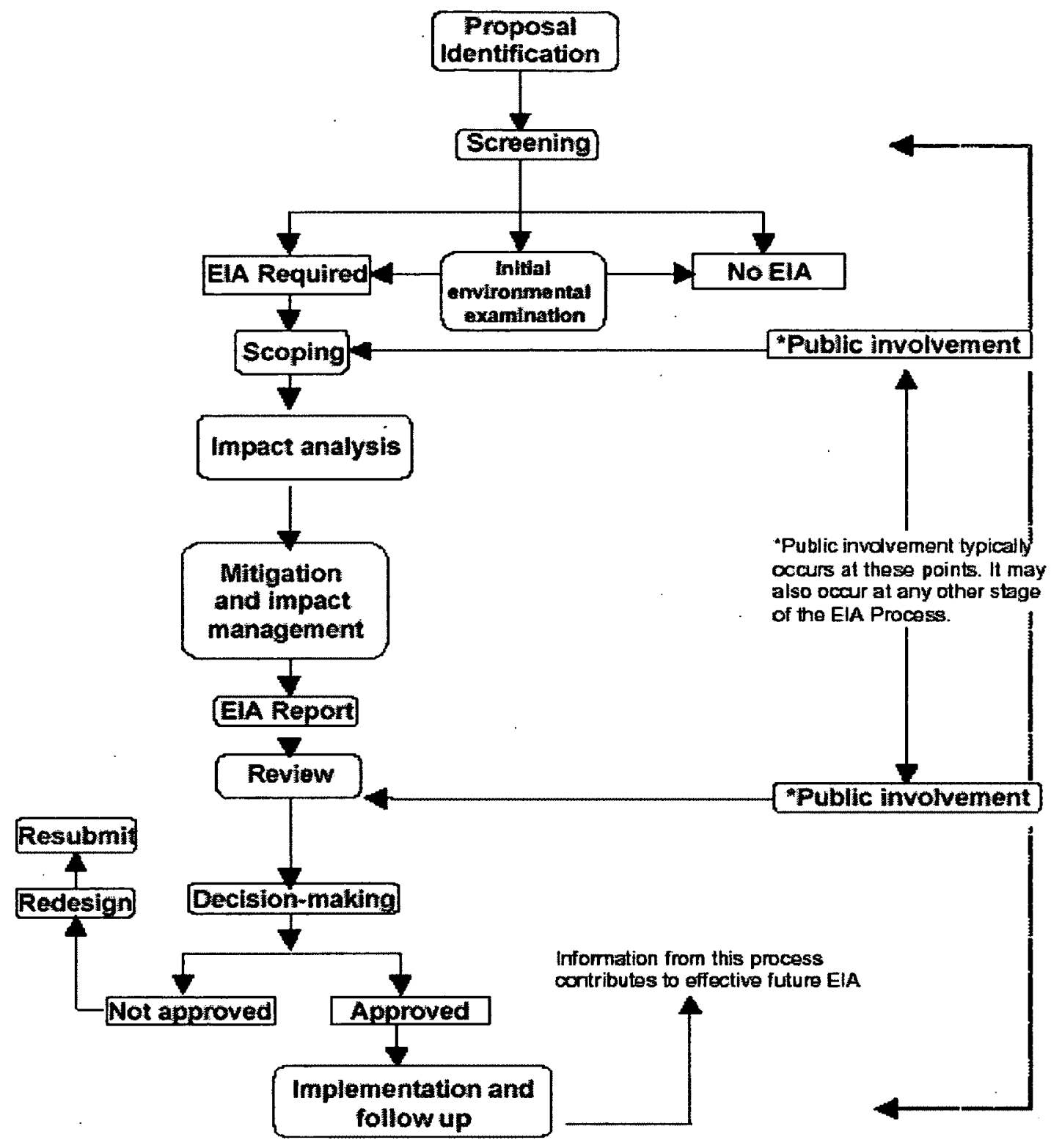

Source: United Nations Environment Programme(2002) "The manual in perspective, EIA Training Resource manual", UNEP

Ghana's history of development is replete with instances where major projects such as the Akosombo Hydro dam were undertaken with very little attention paid to their 
potential environmental impacts and what could be done to mitigate adverse environmental impacts. To this effect, the introduction of EIAs in Ghana in 1999, for all intents and purposes, was a step in the right direction. As stipulated under EPA Act 490, comments from affected parties might be acquired through the publication of Environmental Impact Statements (EISs) in newspaper advertisements. The Act also stipulates for public hearings to be held in those instances in which EIS publications elicit strong concerns about the potential impacts of particular proposed project.

As indicated by government officials during interviews, public hearings are useful given that they present a public forum for owners of proposed projects to inform communities of the outcome of proposed undertakings and also provide an opportunity for the accuracy of EIA findings to be verified in relation to the actual situation on the ground. Also public hearings help to confirm that all the affected stakeholders have not only been adequately consulted, but have also been included in the decision-making processes at all stages. It was also noted that such hearings brought all affected parties and stakeholders together on one platform to express their opinions on any outstanding issues and helped promote effective public participation and public confidence in the EIA process as a whole.

Interestingly, focus group participants in a community in the immediate vicinity of a proposed sanitary landfill project at Kwabenya ${ }^{102}$ in the Greater Accra region expressed dissatisfaction at the government for granting a project permit without any consultation

\footnotetext{
${ }^{102}$ In 1999, Kwabenya was identified as a potential landfill site as part of the second phase of the Greater Accra Urban Environmental Sanitation Project (UESP II)
} 
with the residents. Questioning the rationale or justification behind the siting of the project in their community, participants wondered why such a project with grave environmental impacts would be built in their backyards when a similar project located in the Mallam area of Greater Accra had to be closed down because of vigorous protests and daily complaints by the residents of that area. As one participant noted

If government is aware of the adverse impacts of such a project and has closed down the Mallam landfill, why are they bringing it here? Why did they not seek our opinions before finalizing plans for this landfill? How are we going to stand the odours from the decomposed waste, and who will pay our bills when we fall sick from the stench? We were excluded from the planning of this project, and we will follow the oaths of our brothers and sisters in Mallam and fight against this project (Focus Group Discussion, 2008).

In the words of another,

Look around, everyday new houses are being built. We saved for years to be able to buy land and construct our houses..... We paid for the land and we can't go anywhere else...we will never move and we will not allow the government to take our land from us. The whole community is united on this issue and we will resist this project through any means necessary (Focus Group Discussion, 2008). 
It was also the view of participants that very little had been done by the government in terms of assessing the long-term impacts of the project on surrounding communities.

In the words of a community leader:

There are several alternatives to landfills including waste recycling, and yet the government seems to be in a haste to dump all of the city's waste in our neighbourhood. Landfills are not environmentally friendly and pose serious health risks to children in particular. Despite existing landfill guidelines that require the creation of an appropriate buffer zone, this project was sited within the immediate environs of a school. Given the track record of the government and the metropolitan authorities in waste management and the filth that engulfs the city of Accra, we are not convinced that this landfill would be properly managed- hence our concern.

(Field Interview, 2008).

In a related issue, some residents of the area who were interviewed objected to the project which would deprive them of access to stone quarries which they described as their main source of livelihoods. Interestingly, respondents demonstrated lack of awareness about the adverse impacts of stone quarrying activities ${ }^{103}$ on the environment and instead

\footnotetext{
${ }^{103}$ There is currently a huge local demand in Ghana for quarried chippings which is the core raw material for numerous infrastructural projects including schools, roads, dams and houses. But stone quarrying is also known to have adverse impacts on the environment - these include water pollution, soil erosion and land degradation and loss of wildlife habitats.
} 
described it as a lucrative business venture. The latter, to the researcher, is yet another indicator of existing flaws in the government's environmental communication approach.

Although government officials interviewed could not provide comprehensive and up- todate data on the EIA process in Ghana or reasons for the low level of public participation in the process, one official recognized the need for improvement, noting, for instance, that only eight out of the seventy two EISs conducted in the two year period from 19951997 were selected subsequently for public hearings. It was, however, revealed during these interviews that plans were being formulated to boost public participation. This included the translation of EISs into local languages that can be easily understood by the local populace - although the observation was made that national newspapers in which EISs appear are only published in English and are also not easily accessible to many communities, particularly those in the rural parts of the country

The existence of Environmental Assessment Regulations Act notwithstanding, it is interesting to note that the EPA, in many cases, had gone ahead to issue permits for proposed projects despite objections from stakeholders. A very recent example of this is the EPA granting of a permit to Newmont Ghana Limited and Adamus Resources to mine gold in the Ajenua Bepo Forest (Eastern Region) and Teleku-Bokazo (Western Region) in 2009 even in the face of vigorous objections from CSOs including the National Coalition of Mining (NCOM). Expressing their displeasure at the EPA's decision and demanding the withdrawal of the permits in question, the NCOM at a press conference in March 2009, argued that "surface mining as in the Ajenua Bepo Forest Reserve will 
cause.irreparable damage to the forest, including native tree populations, life forms and soil structure, all of which would have adverse consequences on social, economic and scientific development." (NCOM, 2009).

Also, the proposal phase of a project of a much bigger scale, the West African Gas Pipeline (WAGP) was carried out with very little input from the general public. As an official of an environmental NGO noted, "public consultation and information about the WAGP has been inadequate...affected Ghanaians have not received detailed information about resettlement plans while the WAGP only provided vague and unconvincing answers when questioned about them" (NGO Interviewee, 2008).

In another interview, one official of an environmental NGO raised concerns about the growing number of projects going ahead without any public hearing sessions and cited as possible reasons for the low level of public participation in EIA processes, the voluminous and technical nature of the relevant EIA documents and reports, as well as the inability of government officials to release the documents on time. Making reference to the public hearing sessions on the Tarkwa Gold Mining project in the Western region of Ghana, during which an important stakeholder group - tenants- was excluded from the deliberations, the official expressed deep frustration at the low level of public engagement that characterised most public hearings and highlighted the need for the government to pay more attention to this problem. She noted: 
Questions remain about the representative nature of these public hearings they are scarce, and when they do take place, the input of local communities who stand to be affected by the proposed projects is easily lost or glossed over. We, as environmental NGOs by virtue of what we do, have a much wider representation at these hearings, but the truth be told .... NGOs, whatever their good intentions, are organizations that may not be directly affected by the proposed projects and, hence, cannot truly represent the voice of the communities in question. It is therefore important that the people themselves are present at these hearings to make their voices felt and to influence decision-making....... (NGO Interviewee, 2008).

\section{Analysis and Inference}

Identifiable themes arising from focus group discussions, interviews and the review of relevant documents include the following:

- Lack of synergy within governing elites - chiefs and other traditional authorities, by virtue of being the opinion leaders and cultural custodians of their respective communities, hold a lot of sway and influence and yet, have become symbolic appendages within existing governance arrangements.

- Inadequate public consultation or deliberations: although regulations and laws exist that require public participation and consultation during environmental assessment processes, the opinions and concerns of communities who stand to be most affected by 
environmental projects are not adequately sought and incorporated into formal decisionmaking.

-Lack of urgency or commitment towards sound environmental project planning and management: while many developmental projects have portentous and far-reaching effects on the environment, not enough action is being taken by government to enforce the adoption of measures that will eradicate or mitigate these effects.

\subsection{Citizen attitudes and responses to environmental problems}

In an attempt to paint a bigger and clearer picture of the attitudes and responses of citizens towards prevailing environmental problems, a random sampling method based on key demographics such as age, occupation and educational level was used to select and interview 150 respondents. The study population was chosen from the Greater Accra Region which presents most of the environmental problems examined in the study. The opinions and views of the interviewees were sampled with respect to the following: (1) Knowledge of and concern for environmental problems and more importantly; (2) Citizen responsibility and commitment to finding solutions for these problems.

As shown in the figure below, forty-two (42) representing $28 \%$ of the respondents expressed knowledge of and ranked as being their biggest concern, the problem of waste management. Forty (40) representing $26.6 \%$, had concerns about water pollution, particularly with respect to its implications for health. This problem, according to respondents, was linked to that of waste management. They noted that the accumulation 
of waste, and its poor management had resulted in the use of existing water bodies as waste receptacles. Thirty (30) respondents representing $20 \%$ identified air pollution as the biggest problem with nineteen (19) representing $13 \%$ naming the problem of deforestation the one that deserved the most attention by decision-makers. Eleven (11) respondents representing $7 \%$ expressed deep concern about the problems of desertification and land degradation, four (4) representing $3 \%$ listed the loss of wildlife and biodiversity as the top environmental problem, with four(4) representing $3 \%$ referring to climate change as Ghana's most serious environmental problem. The remaining two (2) representing $1 \%$ were most concerned about noise pollution.

\section{Table 11: Citizens' ranking of environmental problems in Ghana}

\begin{tabular}{|l|l|l|}
\hline Environmental Issues & Frequency & Percentage \\
\hline Waste management & 42 & 28 \\
\hline Water pollution & 40 & 26 \\
\hline Air pollution & 30 & 20 \\
\hline Deforestation & 19 & 12 \\
\hline Desertification and land degradation & 11 & 7 \\
\hline Wildlife \& Biodiversity loss & 4 & 3 \\
\hline Climate Change & 4 & 3 \\
\hline Noise pollution & 2 & 1 \\
\hline Total & 150 & 100 \\
\hline
\end{tabular}

Source: Field Survey, 2008

Other problems identified during the survey included 
-Water quality issues stemming from constant pollution mainly through the dumping of household waste and sewage into the sea

-Accumulation of marine debris;

-Indiscriminate sitting of houses and development along the coast leading to constant flooding.

The level of environmental consciousness demonstrated during the survey, although encouraging was not altogether surprising, given the wide-spread and pervasive nature of these environmental problems. As shown in the figure below, an overwhelming $88 \%$ of respondents perceived the environmental problem as a national one which deserved urgent and immediate action.

Figure 12: Respondents' perception of the environmental problem

\section{Respondents' perception of the environmental problem}

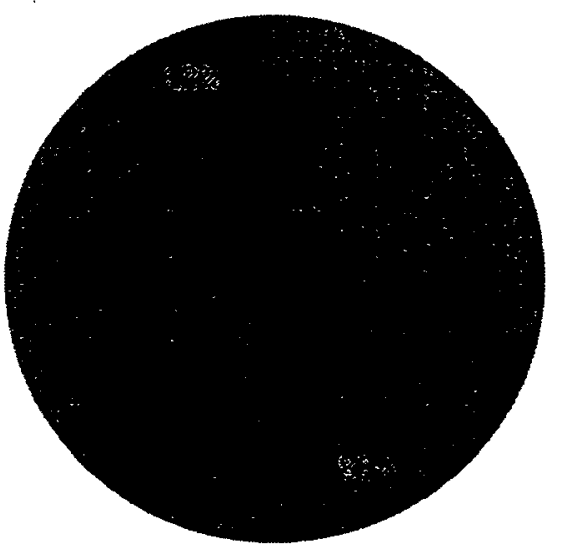

- National Priority

Not a national priority

Source: Field Survey, 2008

However, a majority (78\%) of the respondents perceived the management of environmental problems as being the sole responsibility of the government. Only (12\%) 
indicated their readiness to take up ownership of environmental problems such as waste management, deforestation and water pollution, rather than looking up to government to take appropriate action.

Figure 13: Respondents' responsibility and commitment to finding solutions for these problems.

\section{Respondents' responsibility and commitment to finding solutions to environmental problems}

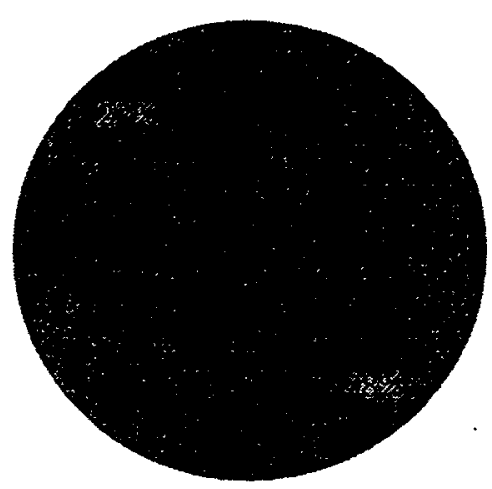

Environmental management as sole responsibility of government

Environmental problem as a problem to be tackled by all

Source: Field Survey, 2008

\section{Analysis and inference}

Despite an appreciable level of environmental awareness among Ghanaians, there is at the same time, a lack of ownership of environmental problems among Ghanaians irrespective of their age, income, educational status, or residency. This is an indictment of the inability on the part of government to engage citizens and make them own their problems. What seems to be lacking is a sense of urgency and creativity on the part of 
government officials and politicians to evoke civic consciousness and responsibility on environmental stewardship on the one hand and cultivation, on the other hand, of an atmosphere conducive enough for the productive use of existing spaces for active citizen involvement. This stands in sharp contrast to ability of political leaders to 'whip' up partisan sentiments among ordinary citizens especially during electoral campaigns, the consequences of which sometimes turn out to be deadly. ${ }^{104}$

Based on the evidence presented, the argument could be made that civic engagement and involvement - at least as far as the environment is concerned - amounts to nothing more than symbolic gestures and overtures usually blown out of proportions under the full glare of the media, but with very little substance or significant impact. A good case in point is the annual commemoration of the World Environment Day (WED) ${ }^{105}$ in Ghana which, for all intents and purposes, appears to be a public relations exercise that paints a beautiful, but misleading picture of unity and strong collaboration between state and nonstate actors in the fight against problems of the environment. Originally set aside by the United Nations Environmental Programme (UNEP) as a day to motivate environmental awareness and political action, the celebration of the day is meant to underscore the commitment of all governments worldwide to some tenets of environmental management including:

\footnotetext{
${ }^{104}$ In the immediate period leading up to the December 2009 presidential and parliamentary elections in Ghana, there were many reported cases of electoral-related violence. In Northern Ghana, for example preelection violence resulted in the death of three people and injuries to many others.

${ }^{105}$ Beginning in 1972, June 5 has been set aside the United Nations Environmental Programme as a day to celebrate global environmental action.
} 
- Humanise the environmental problem

- Empower ordinary people to become active agents of sustainable and equitable development Promote an understanding that communities are pivotal changing attitudes towards the environment

- Advocate and develop partnerships which will ensure that all people enjoy a safer and more prosperous (UNEP, 2008)

It is important to note that the above tenets presuppose the existence of an ongoing meaningful dialogue between citizens and officials of government and a two way communication channel where all relevant stakeholders speak to and understand their respective responsibilities to combating problems of the environment. This, unfortunately, is far from the case in Ghana, where the planning and preparatory processes associated with the day is confined to the purview of a 'national' committee made up only of a handful of representatives from the environment ministry and other implementing agencies and departments. Government officials interviewed, described the WED as an important day in the environmental events calendar and indicated that a great amount of time, effort and resources were dedicated to ensure the successful celebration of the day each year. They, however, acknowledged that the public is 'brought' into the picture in the immediate weeks leading up to the event itself-during which time residents of the venue for the day's celebration are called upon and encouraged to embark on some tree-planting and street cleaning exercises under the supervision of the traditional authorities. 
Analysis and inference

Instead of being a culmination of collaborative partnerships between government and citizens on environmental protection, WEDs in Ghana are, in reality, mere public relations campaigns and one-stop events during which government officials engage their audience whose needs and expectations they do not really know or understand. The lack of civic engagement in environmental management in Ghana, given the larger political context, is a cause for concern. This of course stands in contrast to Canadian cases as earlier discussed where government and public officials have actively engaged the public in the search for practical solutions. It is true that CSOs and NGOs have, in recent years, become more active within affected communities. The reality, however, is that environmental problems have prevailed and persisted over long periods of time. This may be attributed largely to lack of commitment or will on the part of successive governments to involve citizens in a meaningful and productive manner. There is, indeed, ample evidence of this in Ghana's mining sector.

\subsection{Mining Degradation in Ghana}

Based on available data from the period of intense Structural Adjustment, 1985-9, it is clear that Ghana's economic growth was largely resource-intensive in nature. For instance, cocoa production, which has traditionally been a major source of export earnings, rose to $\$ 495$ million in 1987 from $\$ 425$ million in the previous year. Even more significant was the steady rise in export earnings from the mineral sector which, in the same period, rose through 1985 and peaking at some 48 percent of national income in 
1994 (Ndulu, 2008). In the particular case of the mining sector, the fore-mentioned gains can be attributed largely to the implementation of market-driven reforms which saw increases in foreign direct investment especially in mining.

Given the huge increases in large-scale mining activities, mining pollution, particularly in this period became a wide-spread phenomenon. Rampant cases of cyanide mismanagement have led to serious pollution of freshwater sources that affected people, fish populations and crops. The 1996 contamination of the Bonsa River with about 36, 000 cubic meters of cyanide-laced solutions from the Teberebie Goldfields Ltd resulted in loss of crop and animal life. As Akabzaa and Darimani(2001) note, food and cash crops destroyed by the TGL spill included cocoa, cassava, plantain, pineapple, cocoyam, tomatoes, okra and beans. It is just one the many examples. Of equal concern also is the impact of mining activities on forests. The government in Ghana, on the whole, awards companies 150 -square-kilometer land plots for 30 years. To date, therefore, an estimated two million acres of virgin-forested land is lost annually to mining (Drillbits and Tailings, 2000). As an official at an Environmental NGO laments:

We can prosper as a nation without having to raze down our forest reserves for mining. ... I do not think that the mining companies should be allowed to operate surface mines in the reserves. ... Just look at this country's forest estate. We had about 8.3 million hectares now we're left with only 1.2 million hectares, and we still want to give out more for mining when we know very 
well that after the mining there will be no forests" (NGO Interviewee, Accra 2008).

Ironically, the commoditization of land has had unintended consequences which do not bode well for environmental protection. Of particular interest is the upsurge of illegal mining otherwise referred to as galamsey which offers far more benefits to local residents than does the Government of Ghana's disbursement of mining royalties or employment opportunities offered by the large-scale mines. The timing of the upsurge in these illegal activities, particularly in Tarkwa, Prestea, Obuasi, Kenyasi, beginning in the early 1980s was by no means coincidental. The reality is that adjustment programs inadvertently leash untold hardships mostly on the vulnerable and poor in society.

To deal with this problem, in 1989, the PNDC government passed the Small-Scale Gold Mining Law as parts of its efforts to regulate erstwhile illegal mining operations and promote artisanal mining activities. On the whole, however, small-scale mining operations - legal or otherwise - remain basically unsophisticated in nature. This, not surprisingly has resulted in common environmental problems such as the widening of river banks and loosening of soils; contamination of rivers during the beneficiation process; erosion of river banks by large work gangs and the removal of vegetation and crops. The deleterious effects of galamsey operations may to some extent be attributed to the persistent lack of technical assistance and expertise. As members of a galamsey group in Tarwka in the Western Region of Ghana pointed out: 
"It is no secret that we galamsey operators are on a continuous basis are being denied full participation in government- sponsored educational, financial and technical services. We are told that to be able to fully benefit from these programs, we must be duly licensed, yet there are so many obstacles we face during the licensing process. For instance, potential licensees are required to pay for the first year, something in the area of about 2000 Ghana cedi (1900 USD) - an amount most of us cannot afford and then we have to wait anywhere between six to twelve months for licenses to be issued. To my knowledge many galamsey operators would prefer to be trained for instance on how to effective use mercury for gold extraction, but are not getting the needed assistance because of these financial and procedural obstacles. Those government officials sitting in their big offices in Accra are quick to judge us and criminalise our activities, but they are not making any effort to find out form us what our needs are and how we can work together towards finding solutions to ongoing problems..." (Focus Group Discussion, Central Region, 2008)

A greater part of this problem however stems the highly antagonistic stance adopted by the government which further alienates and disengages local galamsey operators from any meaningful form of collaboration. As one government official put it: 
"Illegal mining is a menace to society and must not be encouraged or excused on any level. That is why policies have been put in place to ensure that all galamsey operators are duly licensed and registered. These licenses do not only allow us to equip them with the necessary expertise and know-how on best mining practices, but they also provide us with the means of keeping track of their activities and holding them to existing standards on mining. This is how the environment can be protected... As for the stubborn ones that refuse to come out of the woodwork, we will do all in our power to flush them out and make them pay severely for their actions...

\section{Analysis and Inference}

There appears to be very little commitment on the part of the governing elites to create spaces for engagement in which illegal miners could make their voices heard. Rather than criminalizing these small scale miners and looking upon them as unequal partners, the relevant government authorities could make significant headway by working with them and making an effort to understand and appreciate their needs. It is only by doing this that an atmosphere of mutual respect and recognition can be created that will allow for meaningful environmental outcomes. Also, one could infer from the above-mentioned case that economic reforms have failed to move Ghana onto a path of development that is sustainable, at least in the environmental sense. 


\subsection{0: Perception of environmental issues vis-à-vis issues of economic development.}

Analysis of available information point to attempts by government to reach a sustainable balance between economic growth and sound environmental stewardship. For instance, in 1992, Ghana together with 153 countries endorsed the Polluter Pays Principle (PPP), during the United Nations Conference on Environment and Development (UNCED). ${ }^{106}$ Subsequently, the PPP has been adopted in Ghana's environmental policy. In broad terms, this concept which aims for equity in the distribution of environmental cost, calls for polluters to be held liable for pollution costs through the use of economic instruments such as pollution charges, taxes and permits. For instance, the government of Ghana, in an attempt to address the rising spate of air pollution, established a system of taxes and charges to discourage the import of old cars. Technically, the penalty is a tax paid by the importers of cars of various specifications which exceed a specified age from the date of manufacture to the time of arrival in Ghana. For example, data from the Ghana Customs Excise and Preventive Service (CEPS) indicate that luxury cars between 5 and 10 years are levied charges that fall anywhere between US $\$ 800$ and $\$ 2000 .{ }^{107}$ However, this penalty has serious limitations given the skewed nature of the taxation policy which makes it cheaper to import an old car than buy a car which is less than 5 years old locally and also exempts imported scrap engines from tax. As a member of the Ghana Used Car Importers Association pointed out, it costs more to import a 2000 Hyundai than a 1997 edition of the same model; a fact which he noted encouraged the importation of older

\footnotetext{
${ }^{106}$ EPA Annual report(1994)

${ }^{107}$ Interview with Ghana Customs Excise and Preventative Service Official
} 
models of vehicles which have a more serious toll on the environment. ${ }^{108}$ In addition to difficulties and challenges associated with calculating the right rate for environmental charges, an official of a government ministry, during an interview, cited other problems with the environmental taxation system such as ease of introduction, monitoring and enforcement, predictability and acceptability.

In the words of the official:

Acceptability of environmental taxes in a developing country such as Ghana is a serious problem. People with low income are less likely or willing to pay for environmental improvements and amenities. Also tax revenues in Ghana are constrained by the narrow tax base of low incomes which also limits tax collection capacity - which are principal reasons for the country's budget deficits. It is therefore difficult to add the environmental administrative costs to the national budget. When a development project - for example construction of a dam- and environmental protection are in conflict, the probability of choosing the development project over environmental protection is quite high (Field Interview, Accra, 2008).

${ }^{108}$ New vehicles release less carbon dioxide into the atmosphere than older ones. 
A review of existing regulations and laws suggest little commitment on the part of successive governments in Ghana towards the integration of environmental use into economic management decisions and policies. Best evidence of this is in extractive industrial sector where mining and oil companies continue to operate in the absence of enforceable and binding standards that would otherwise make them liable for the environmental and social costs of their operations. For example, the PNDC Law 153 of 1986 was amended to 2006 Mining and Mineral Law, Act 703 to reflect current exigencies and yet it fails to set any precise standards to this effect and to hold mining companies liable for the adverse impact of their operations on the environment. As an official of an environmental NGO opined:

There is an urgent need for laws which, once enforced, will see mining companies pay for clean-up costs of cyanide spillages and so on...Also rather than politicising this issue, it is time for government to demonstrate great commitment towards upholding the Polluter Pays Principle to ensure the sound protection of our environment. This is the only way forward (NGO Interviewee, 2008).

Similarly, Ghanaian manufacturing industries are associated with adverse environmental impacts including industrial solid and liquid waste and yet fail to bear the full costs of environmental damage. The Accra Metropolitan Authority (2008) estimates, for instance, that the plastic industry which has in recent years seen a recent spurt in growth ${ }^{109}$ generates, on an annual basis, 270 tonnes of non- biodegradable plastic waste in the city

${ }^{109}$ Plastic is a cheaper substitute to other means of storage such as glass, metal. 
of Accra alone. But, the failure of plastic manufacturing companies to invest in efficient disposal systems and recycling facilities has helped contribute to the current state of affairs where plastic collects and stays in gutters, dumps, beaches, etc.

\section{Analysis}

Environmental charges and taxes can play a more important role as part of an integrated bundle of measures to attain environmental sustainability. But it is important not to expect too much from the use of economic instruments by themselves given that challenges such as enforceability still remain and continue to render the larger political climate not conducive for their use. In addition, the very low levels of income of the majority of the population, especially in the rural areas, make it politically and socially difficult to insist on implementing the Polluter Pays Principle on a comprehensive basis. Yet another major issue of concern is the inability of developing countries such as Ghana to pass on environmental costs incurred in the production of exports into product prices on the international market. On a broad level, it could be argued that internalization of costs is possible only in cases when export- producing countries possess a large share in the international commodity market and also have low dependence on income accrued from the export of particular commodities. Under these conditions, one can see how environmental costs can be passed onto to external clients. This unfortunately is not the case in Ghana, a country with huge dependence on exports such as cocoa and gold which are basically price-sensitive in nature. 


\subsection{Summing $U_{p}$}

As this chapter has shown, there is still a great degree of centralization and formalization in decision-making and practices in the environmental sector in Ghana. This stems from the failure of government to reach out to other non-governmental actors when formulating decisions and policies on the environment. To this effect, traditional rulers in Ghana, who for instance, command a lot of respect and high esteem in their respective communities, have become mere symbolic appendages in existing environmental governance arrangements. At the same time, the lack of collaboration and engagement has also helped to alienate the very communities, groups and individuals who are directly affected by problems of environmental degradation, making them mere onlookers in the ongoing quest to 'battle' the environmental crisis. For their part, NGOS and CBOs, despite their deep appreciation and understanding of localised problems, continue to remain on the fringes of decision-making and are unable to make an impact where it matters most.

That governmental elites, on their own, have not fared very well, is demonstrated, among other things, by the lack of clear leadership on communicating their message on the environment - a fact which has led to guess work, apathy and ignorance among the wider public in so far as issues of the environment are concerned. But even more importantly, governmental elites have not shown enough commitment and good will towards the promotion of environmental protection goals in tandem with those of economic growth. With these challenges characterising environmental management processes and practices in Ghana, it is not surprising that very few gains have been made 
towards achieving long-lasting and practical solutions. The next chapter summarizes the research findings and advances recommendations on bridging the existing gaps. 


\section{CHAPTER SIX (6) SUMMARY, CONCLUSION S AND RECOMMENDATIONS}

\section{0: Conclusion}

The preceding chapter 5 analyzed the data or information collected and from the patterns observed interpreted the data or information and drew inferences or findings. This chapter brings the research to its conclusion. In conclusion, it is emphasized that Ghana continues to grapple with problems of environmental degradation including the loss of forest cover and wildlife, pollution of water bodies, indiscriminate disposal of solid and liquid waste. This raises questions about the efficacy of structures, systems and actors traditionally associated with environmental management and protection. Consequently, this study directed towards this objective, involves an examination of the direct (intended) and indirect (unintended) impacts of environmental management efforts on the part of key actors and stakeholders. Specifically, it examined the role of the governing elites who, by virtue of the positions they occupy and the influence they wield, are supposed to be vested with the power needed to demonstrate transformational leadership and, by so doing, define opportunities and issues, build social capital and mobilize necessary resources in ways that lead to effective action on environmental policy problems. It is emphasized that, through good and effective leadership, the governing elite can mobilize and direct stakeholders to achieve intended goals and objectives. To this effect, the study focused on assessing the efficacy of existing governance arrangements mainly by examining and unearthing the dynamics, complexities and challenges of elite rule within the specific context of Ghana. This chapter further 
summarizes the findings of the research. It begins with a restatement of the main argument of the dissertation and related research questions, establishes that the thesis or main argument has been confirmed and that the research questions have been answered. It discusses the major themes, advances recommendations and highlights its contribution to the literature on elite governance.

\subsection{Restatement of Thesis and Research Questions}

This study examined environmental management policy and decision-making processes from a political perspective. The main argument or thesis of the study is that the current state of the environment, in Ghana as characterised by problems including deforestation, water pollution, and waste mismanagement, signals, a gross failure on the part of those who have been in charge of the environment - the political elites - to effectively engage all affected stakeholders to achieve practical and sustainable environmental goals.

\section{Confirmation of the Thesis}

In this dissertation, I have emphasized how the wide-spread and encompassing nature of Ghana's environmental problems demand an all-inclusive, collaborative and 'all hands on deck' approach towards finding appropriate and lasting solutions. To this regard, I have shown that in the context of the Ghanaian society, it is the political elites, who wield power and make important decisions and policies. This is by virtue of the positions they occupy and the influence they wield, which imbues them with the power needed to define opportunities and issues, build social capital and mobilize necessary resources in ways that lead to effective action on policy problems. To a large extent therefore, it will be 
right to attribute to Ghana's political elites (who form part of a two-tier or parallel elite system - traditional and modern elites) great potential in terms of effective and transformational leadership which, for all intents and purposes, is a precursor to meaningful and long-lasting changes to the status quo. I have argued that effective and transformational leaders are those who are able, as it were, to stand their ground and rally those around them to meet challenges when things go wrong. In relation to the latter, attention was drawn to the fact that existing environmental policy initiatives and interventions have exclusively been at the behest of the country's political elites - with the not so tacit input of international elites. To this effect mention was made of the fact that it was in 1991 that the PNDC government introduced the National Environmental Policy (NEP) which, for all intents and purposes, marked the beginning of efforts to prioritise environmental issues and create national awareness about the need for environmental protection (EPA, 1994). Ironically, however, it is the very lack of effective and transformational leadership on the part of the political elites that has translated into an inability on their part to effectively engage all affected stakeholders in the quest for sustainable environmental management.

That there is a pervasive lack of engagement between the governing elites and other nonstate actors is evident, as highlighted in this study, by the disarticulation and lack of synergy between the political elites and their traditional counterparts. With respect to the latter, I have shown how traditional elites - chiefs in particular - in spite of the influence they wield in their respective jurisdictional areas, are for the most part sidelined when it comes to making and implementing important decisions and polices on the environment. 
This has resulted in a state of affairs where chiefs, who would otherwise have a lot to offer by way of sustainable environmental solutions, have more or less been rendered mere onlookers in the country's battle against environmental degradation. Other non-state stakeholders whose contributions are as yet to be fully harnessed by political elites include local and national NGOs, who by virtue of their positions within the communities in which they operate, have the potential to contribute positively towards sustainable environmental management goals. That some of these NGOS - in spite of the paucity of spaces for active collaboration and engagement - have managed considerable significant gains (particularly with respect to environmental advocacy) is testament of their tenacity and commitment to change the status quo. Yet another dimension to the problem, as has been established in this study, has to do with the inability of political elites to adequately involve local populations when it comes to important decision-making. The latter is evident, for example, in how the governing elites communicate the environmental message to the general public. As earlier discussed, it does appear to be the norm that, government in its environmental communication approach tends to focus more on 'talking to' and not on 'talking with' local populations who are most affected by environmental problems. The latter would partly explain why tangible, meaningful and productive collaboration or partnerships between governing elites and the governed are far and between. Whatever relationships exist, one could say, is characterised by mistrust on the part of the governing elites and fear and apathy on the part of the governed. It is against this background, that one can draw an answer to this research project's overarching question. 


\section{Research Question}

How have the actions (or inactions) of political elites, who are leaders of the Ghanaian society, shaped or determined the realization of sound environmental management goals?

\section{Answer}

While significant barriers to addressing environmental problems such as poverty, illiteracy still exist and need not be underemphasised, it is also true that the inactions or lack of effective or transformational leadership on the part of Ghana's political elites has negatively impacted the realization of sound environmental management goals. This study has shown for instance how important environmental decision-making processes and practices remain centralized and statist in nature. What this means is that non-state actors such as chiefs, community groups and citizens all of whom are affected by environmental problems and all of whom stand to contribute meaningfully towards positive environmental outcomes, are in reality denied the opportunity to do so. It is to this effect that this study makes the following conclusion: Ghana's response to its debilitating environmental problems has over the years amounted to management without leadership. What the country has been lacking so far is an enabling environment that fosters and enhances the capacity of non-state actors so as to enable them play a meaningful role towards positive policy formulation, implementation and outcomes. This 
failure of the governing elites to provide the needed direction and leadership has helped to bring about a gap between envisaged goals and actual outcomes.

Following up on the main research question, the following sub-questions were posed.

\section{Research Sub-question (1)}

Has there been a national environmental decline over the years?

\section{$\underline{\text { Answer }}$}

As has been shown in this study, environmental degradation in Ghana, particularly beginning in the 1980s has reached unprecedented heights. A good case in point: Ghana's forest cover which, at the turn of the $20^{\text {th }}$ century, was estimated to be about 8.2 million hectares, had been drastically reduced to 2.1 million hectares by the end of the $1980 \mathrm{~s}$ (EPA, 2004). Equally at risk are the country's fresh and groundwater water resources which have been increasingly exposed to pollution from industrial and domestic sources. Today, the Korle Lagoon in the Greater Accra Region of Ghana, and many other river bodies in other parts of the country, due to heavy and unabated pollution, no longer offer the commercial and recreation benefits once associated with them. The problem of solid waste management, already an untenable one, has in recent years been aggravated by unsustainable consumption patterns and lack of disposal facilities for household and industrial waste including 'sachet water bags' resulting in the indiscriminate littering of towns and cities, waterways and river blockages, and choking of soil and animals. Other noticeable trends include high rates of land degradation, coastal erosion, biodiversity loss 
and desertification in many parts of the country. These problems have as yet to be tackled in a sustainable and long-lasting manner and appear to be on the ascendency.

\section{Research Sub-question (2)}

To what extent can we attribute this decline to the nature and dynamics of the elite leadership within the specified time frame?

\section{Answer}

It must be emphasized that Ghana, in its battle against environmental decline or degradation, is presented with significant barriers such as poverty and illiteracy which cannot be ignored. But it is also true that Ghana's political elites continue to demonstrate through their actions and inactions, a lack of transformative leadership which would otherwise have allowed them to identify opportunities, mobilise the needed resources and galvanise other stakeholders towards positive environmental outcomes. For example, this study has emphasized that non-state actors such as traditional rulers wield a significant amount of influence within their respective communities, and yet are not active participants within existing governance arrangements. Partnerships between the political elites and their traditional counterparts or other non-state actors, may not be entirely lacking within the Ghanaian case, but the latter are most often characterised by paternalism and mistrust on the part of the political elites who for instance perceive local populations as part of the problem and not the solution. Ample demonstration of this, as shown in the study is the propensity of state authorities to lean towards an aggressive and 
punitive policing stance rather than a supportive one in areas affected by deforestation. At the same time, such partnerships are perceived by non-state actors such as NGOs as being symbolic or figurative in nature. As this study notes, ineffective elite leadership has translated into challenges such as ineffective communication, the result of which has been the creation of attitudes of apathy, disinterest and mistrust on the part of the majority of non-state actors. It is to this effect that this study argues that the inactions or lack of effective or transformational leadership on the part of the country's political elites has negatively impacted the realization of sound environmental management goals.

\section{Research Sub-question (3)}

What has been the level of political commitment towards the protection and management of the environment vis-à-vis economic development goals - has environmental management been a priority for the political leaders and what is the level of priority given to these issues of the environment?

\section{Answer}

As shown in chapter one, environmental problems currently lack immediate priority in comparison to economic development goals. This, I have argued stems the perception of the environmental problem, within governing circles, as that policy problem which can be 'overlooked' without incurring the displeasure or losing the favour of the people. Evidence of this is found, not only in current national development plans such as the Ghana Vision 2020, but also in the party platforms and manifestos of ruling governments or governments-in-waiting that give very little attention to cutting issues of the environment. In the face of the low level of prioritisation being afforded to issues of the 
environment within the entire spectrum of national affairs management, several inferences can be drawn, one of which is that the governing elites, although aware of the gravity and severity of environmental issues, are yet to demonstrate the required level of commitment needed to achieve sustainable outcomes.

\section{Research Sub-question (4)}

What is the level of public participation or civic engagement in environmental policy and decision-making processes in Ghana?

\section{Answer}

Evidence gathered in support of this study suggests that, in so far as the environment is concerned, Ghana's governing elite are yet to come up with new ways of reaching out to and fully harnessing the know-how and capacity of non-state actors including traditional rulers, NGOs, CBOs, and ordinary citizens towards finding appropriate solutions to existing problems including deforestation, water pollution, waste management. What this means is that civic engagement or public participation in environmental policy and decision-making processes in Ghana remain on the low side. This is a major cause for concern, especially when one considers the fact that the country's environmental problems (not unlike environmental problems elsewhere) are wide-spread and encompassing in nature and, therefore, require all hands to be on deck.

This is a demonstration of a persistent inability or unwillingness on the part of the Ghanaian political elite to break through the status quo and bring about the necessary transformational change. That environmental problems currently lack immediate priority 
in the management of national affairs might itself be an answer to the question as to whether the governing elites are committed to achieving sustainable outcomes for environmental problems. The reality of the matter is that environmental problems including deforestation, waste management and water pollution are on the ascendency and continue to defy practical and long-lasting solutions.

\section{Research Sub-question (5)}

To what extent are ordinary citizens encouraged or allowed to take ownership of the environmental problems that plague the communities in which they live and do these people feel a sense of engagement in environmental decision-making processes?

\section{Answer}

One of the conclusions drawn from this study is that environmental management processes and practices are overwhelmingly dominated by governing elites. To this effect, decision-making and policy development are centralized at the national level and ordinary citizens are allowed very little input when it comes to shaping or determining sound environmental goals. In some instances they are allowed to have a say in decisionmaking processes, but those in charge always have their way, when all is said and done. The lack of inclusion or participation is rather unfortunate. For one thing, it results in a situation where ordinary citizens are made to feel as if they are part of the problem and not the solution. The latter, in turn, fosters an attitude of mistrust, fear and, most importantly, apathy among the general public towards those in power. Not surprisingly, citizens, on their part, are increasingly disengaging themselves from governing elites and pushing the onus of responsibility for solving even their local environmental problems 
squarely on the shoulders of the governing elites. It is common to hear people say in local Ghanaian parlance "eye aban adjuma' meaning 'this is the government's responsibility'. Clearly, a lot more work needs to be done on the part of the governing elites to reach out to those they govern and effect an attitudinal change that might foster civic responsibility and a sense of duty towards prevailing environmental problems.

\subsection{Summary of Significant Findings}

Discussed below are the major findings of the study specifically about the dictatorship of the modernizing elites, the power of the bureaucratic elite, the state as the dominant actor in environmental governance arrangements, and the disengagement of non-state actors.

\subsubsection{The Dictatorship of the modernizing elites}

Ghana prides itself as being one of the first countries in the Sub-Saharan region to attain political independence from its former colonial master, Britain. This presupposes some level of political 'maturity' and 'development' especially in terms of the institutionalization of the formal aspects of its political system. ${ }^{110}$ A direct result is the unfortunate tendency to locate political power only within the formal aspects of the political system (all of which are legacies of colonization). These include the legislature, judiciary, executive, government agencies and departments. That is what makes the country an interesting focus of study. As this study has shown, in Ghana, political, military and bureaucratic elites (with the not-so tacit support of international elite) are those that essentially 'run the show'. This is a great cause of concern, given the apparent dictatorship of the modernizing elite. Under constitutional rule, the Cabinet is the

\footnotetext{
${ }^{110}$ The political development thesis as advanced by the likes of Huntington posits that the level of a political development of any society can be determined by the level of institutionalization of its existing political structures.
} 
political executive that formulates government policies, programs and priorities. Accordingly, Article 76(1) and 78(1) of the 1992 Constitution of Ghana stipulates that the Cabinet shall comprise the President, the Vice-President and at least 10 Ministers of State, the majority of whom shall be appointed by the president from among Members of Parliament with the prior approval of Parliament.

Formed and led by the President, the powers or control of the Cabinet is overwhelmingly substantial and this stems from the fact that it is responsible not only for the execution and administration of government policies, but also for the finances of the government. The fledging and often partisan nature of the country's legislature has also, over the years, helped the Executive - the President and his Cabinet - exert undue influence over the other arms of government and the rest of Ghanaian society. This most often reduces Parliament, the Judiciary and the rest of society into mere spectators who watch on powerlessly as government pushes through its agenda with very little or no resistance.

Also worthy of mention, as explained earlier in this study, is the military elites who, over allegations and claims of political, economic and social mismanagement, have periodically overthrown democratically elected governments and taken over the reins of government. Indeed, it is often claimed that the military are best suited for corruption clean up (on a short term) and for preserving or revitalizing economic development (Bienen, 2009). Ironically, these same military leaders unwittingly found themselves deeply involved in the very situations they accused their predecessors of, and have been implicated in numerous cases of corruption and mismanagement. A good case in point, 
the Colonel and leader of the 1972 military coup d'etat that overthrew the democratically elected government of Prime Minister K.A. Busia, (the later) General I.K Acheampong, was forced to resign in 1978 by his own military colleagues over allegations of corruption, nepotism and mismanagement of state resources. Thus, even Bienen's modest expectation of the military does not seem to apply in the Ghanaian context.

\subsubsection{The Power of the Bureatrcratic Elite}

Elitism in the bureaucracy, on the other hand takes several forms. Politicians, as explained above, might have the final say in policy making, but it is also true that bureaucrats interpret and translate policies into action or activities and do exercise a lot of discretionary powers when it comes to policy implementation. Indeed, they are the ones whose actions are reflected in policy outcomes. In the forestry sector, for example, a great deal of responsibility for the coordination, regulation, management and utilization of Ghana's forest and wildlife resources is placed in the hands of the Forest Commission. Bureaucratic power is also on the rise given that lawmakers and the executive neither have the time, resources or even the expertise to go over all the details of policy-making. The framing of ideas and the interpretation of the scientific and technical aspects of policies are increasingly being done by scientists and bureaucrats.

As this study found, Ghana's environmental problems are presented as a set of 'technical problems' that can only be solved by experts. One of the implications of scientific intervention in policy development is that policy is more often than not conceptualized in technical terms that are not easily absorbed by or comprehensible to the lay person. It is also true that the President and his Cabinet are in charge of running the day to day affairs 
of the country, but the number of political appointees are far outnumbered and, in most cases, outlasted by the large number of bureaucrats. This gives bureaucrats considerable leverage in influencing policy outcomes. It must be pointed, however, that a multiplicity of factors including low morale, weak motivation, poor personnel policies have prevented the bureaucracy from being an effective instrument for the successful realization of public policy goals.

\subsubsection{The State as the dominant actor in environmental governance arrangements}

This study has argued that the capacity needed to bring about societal change within any society does not necessarily have to emanate only from formal political arrangements, structures or actors. Rather it is possible to identify informal sources of capacity (some of which trace their roots to pre-colonial times) which, in addition to the formal ones, can serve as useful basis upon which suitable governance initiatives can be developed to effectively tackle environmental problems. The dictatorship of the Ghana's modern elite, for a country described by many as a success story in good governance practices and democratic reforms, is therefore a cause for concern. As earlier noted, the debate about African politics has, in recent times, been centered mainly on the trend and patterns of democratization that has 'hit' the continent beginning in the 1990s. A case in point is the good governance discourse for sub-Saharan Africa in which liberal democracy emerges as the necessary political framework for the attainment of national developmental and societal goals. As advocates of the good governance discourse have pointed out, authoritarian and totalitarian governments are grossly inefficient and, as such, are unable to execute the national agenda as effectively as democratic governments. The latter 
assertion, as noted in this discussion, helps bring to the fore, issues pertaining to elite rule, regime type and its associated mode of governance and outcomes.

As the literature reveals, the criteria for classifying regimes types ranges broadly from policy orientation, ideology, right through to leadership styles and the degrees of competition, participation and control. On the whole, however, and at least as far as subSaharan Africa is concerned, the conceptual emphasis has been either on the style of leadership associated with a particular regime or the degree to which regimes either control or foster participation or competition.

Placed on one extreme end of the continuum, are regimes that are associated with autocratic and coercive style of leadership and are underpinned by a culture of control and exclusivity. On the other extreme are those regimes that are mobilizing and conciliatory in nature in terms of leadership and also, for that matter, foster competition and participation. By casting regime types in positive or negative terms, the case is then made for political renewal and regime change which, as advocates are quick to point out, is attainable through political liberalization and democratization. To be democratized is to move towards a more egalitarian society which is devoid of "autocratic authority structures" (Keller, 1996: 204). It is based on the latter assertion, that liberal democratic regimes are touted as the ideal form of democracy with emphasis placed on principles of rule of law, free and fair elections and popular participation in political processes. The underlying assumption here is that democratization engenders and facilitates a 
fundamental change in existing modes of governance. This connotes, among other issues, significant improvements in existing processes of policy formulation and implementation.

But as this study has argued, environmental decision-making continues to be centralized and top-down in nature. There is evidence of this in the environmental management setup/structure under which environmental protection responsibilities are limited to government agencies and departments most of whom operate at the national level. For example, most of the activities and operations of the EPA which is the main implementing agency in Ghana's environmental sector are carried out in its national office, while its regional and district offices are left to handle mostly with administrative and other mundane issues. Another dimension to the problem is that the country's local governance system of which District Assemblies form a major part of, which is widely perceived as the means through which the functions of the central government can be limited, have so far offered very few and meaningful opportunities for participation and empowerment of local populations mainly as a result of elite capture. Best evidence of this is the fact that District Chief Executives- the heads of the District Assemblies, together with 30 percent of the total membership - are in fact political appointees of the President all of whom will look to the centre for direction as to how to run affairs at the local level. In this sense, participation by other non-state actors in Ghana's environmental policy and decision-making processes can at best be described as transient and peripheral. The latter assertion is buttressed by the interviewees' claim that they are either sidelined in the decision making process or government cares little about the local people. Clearly, the dominant actor in governance is the state. It is, therefore, not 
surprising then that the management of the environment has been hijacked by successive governments who have so far been found lacking in terms of effective leadership as well as the political will needed to tackle the country`s environmental problems. The significant linkages between the environment and the economy notwithstanding, it is rather clear that the environmental problem in the case of Ghana is yet to be taken as a pressing one. This is evident in major development plans such as the ERP that failed to adequately address the environmental effects of economic activities as well as the failure of political parties to inspire positive change in the area of environmental management or protection.

\subsubsection{The disengagement of Non-state Actors}

As discussed in this study, non-state actors, although vocal and active on the environmental front, have failed to bring significant and lasting influence to bear on crucial decision making and implementation. Something is being done on the part of the latter with respect to environmental protection, but, as is often the case, it is those interventions that transcend or originate from beyond national borders that make some meaningful impact. As case in point, the introduction of standardization in the export of Ghanaian timber was undertaken at the behest of international NGOs such as CARE in collaboration with European Union. Thus, in reality, what local actors have to say brings very little to bear on decisions taken by the modern elites in consonance with the international elites. For instance, traditional rulers in Ghana - chiefs in particular command a lot of respect and high esteem in their respective communities. Indeed, most Ghanaians owe allegiance to their chiefs and not to the appointed or elected public 
officials. This, for all intents and purposes, connotes an inherent ability and potential on the part of traditional rulers to act as effective guardians, managers and leaders in caring for and administering the environment. But, in reality, chiefs are seen as mere appendages to the governance system, with emphasis placed most often on their symbolic role. Thus, in practice, the lack of support and recognition they receive from relevant state authorities constrain the capacity of traditional rulers in mobilizing the citizenry for effective and sustainable use of the environment. For instance, traditional rulers are not legally mandated to execute and enforce existing laws. This is amply demonstrated at the local level where successive governments made no effort to institutionalize the representation of chiefs in local government structures such as district assemblies.

There are existing constitutional provisions that require that traditional authorities and other stakeholders be consulted on the appointment of $30 \%$ of non-elected members of district assemblies. Ironically, there are other constitutional provisions which bar the same chiefs from engaging in partisan politics. This contradiction perhaps explains why successive governments have failed to formulate a clear and comprehensive policy that facilitates or formalizes the participation of chiefs in existing local governance systems. This is ironic, considering that during colonization, colonizers recognized the efficiency, effectiveness and economy of the traditional rule system headed by chiefs, effectively relied on it and made it the focal point of their indirect rule system. On the contrary, in Ghanaian governance since independence, the modern elites have so far demonstrated sheer lack of appreciation of the inherent transformational powers of chiefs. Unlike colonial rule, constructive articulation between the traditional elite and the modern elite is 
lacking. Thus, while traditional authorities in Ghana continue to wield considerable cultural, economic and quasi-political powers over the people, their potential for transformational leadership remain grossly under-exercised. Unfortunately, such will remain the case until more efforts are put in place to bring about a closer degree of cooperation or articulation within the existing two- tier parallel system. At the same time, this lack of articulation has both enabled and encouraged the international elite to take advantage of the situation to try and exercise alarming and total domination over the modern elites. This control predominantly expresses itself in the increasing tendency of modern elites to draw heavily on foreign technical resources and expertise in advancing national objectives and goals. Also the international sphere has and continues to serve as the principal source of policy formulation as national elites look beyond their borders for normative, evaluative and prescriptive ideas pertaining to environmental protection.

Other notable non-state actors include Non-Governmental Organizations (NGOs) and Community Based Organizations (CBOs), who, through activities including advocacy and public awareness campaigns, endeavour to make meaningful impact on environmental management in Ghana. NGOs and CBOs possess capacities which allow them to identify with, and relate to the needs of the people. Hence, in some cases, they do much a better job than government officials (who on their part are seen as being remote from the people) in persuading the public on the need to observe existing laws and regulations. It must be said, however, that problems of inadequate funding, professional staff and expertise hinder their mobilization capacities to a large extent. In addition to the latter, NGOs also (like traditional rulers), lack the legal authority to execute necessary 
action. As such, they rely on formal state institutions for the necessary backing. Also, as surmised from supporting evidence presented in this study, citizen involvement amounts to nothing more than symbolic gestures and overtures. At the risk of generalising, there appears to be a persistent lack of commitment and innovation on the part of successive governments to evoke civic consciousness and responsibility on environmental stewardship on one hand, and to cultivate an atmosphere conducive enough for the productive use of existing spaces for effective citizen participation on the other hand. Yet, citizens and local communities are the ones who not only know and understand their problems well, but also better placed to contribute effectively towards solving them.

The lack of environmental stewardship, means for example, that citizens are less compelled to organise themselves to meet certain environmental goals. Given that a spirit of communalism and an innate predilection to social initiatives, including, but not limited to environmental protection, have traditionally characterised local communities and groups, this state of affairs, for all intents and purposes, should be cause for concern. So while traditional communities have, in the past, ensured the conservation and protection of natural resources by holding members of the community individually and collectively responsible for their adherence to traditional rules and regulations, this is hardly the case anymore. ${ }^{111}$ Examples of such changes have been demonstrated in the decimation of sacred forest groves and the pollution of river bodies hitherto considered sacred. It is

\footnotetext{
${ }^{11}$ Under customary law for example, certain pieces of land were designated as 'sacred groves' that could not be touched by anyone, and the control of which was given over to the traditional authority, i.e. the chief or fetish priest. Regulations or taboos commonly used in the governing of these groves included the prohibition of all form of use including farming, hunting or even the collection of plants of medicinal value. See Brown J., Mitchell, N.J., and Beresford M., (eds) (2005) The protected landscape approach: linking nature, culture and community, IUCN for a detailed analysis.
} 
pointed out, however, that there are a few of Ghana's natural resources that have weathered the storm and withstood the ever-increasing pressure on them. Good cases in point are the Boabeng Fiema Monkey Sanctuary and the Bofie sacred grove in the Northern transitional zone (Fargey, 1991; Ntiamoa-Baidu, 1995). Falconer (1992) also makes mention of the Numafoa sacred grove in the Nanhini village Southern Ghana which remains highly revered among the surrounding local communities.

All of the above, in effect, have left in place a style of governance (conceptualized in this study as processes of decision-making and implementation) that is top-down, elitist and exclusionary in nature. It has been shown that within the context of Ghanaian politics, where political and bureaucratic elites (with the not-so tacit support of international elite) essentially 'run the show', governance is elitist in nature and not democratic as some would like to believe. This implies, for example, that public affairs (in this case environmental ones) are managed without adequate input and participation of a wider section of the Ghanaian populace. It is, therefore, not surprising that the quest for sustainable and practical solutions have so far come up with very little results. This factor has served as a major constraint on the attainment of goals as they relate to the protection and management of the environment. It is recognized that, there are other factors, including economic ones that can be linked in some way to the current state of the environment. But as argued above, there has been also a persistent lack of commitment and will on the part of successive governments to promote environmental protection goals in tandem with those of economic growth. This connotes governance failure, especially considering the debilitating nature of prevailing environmental problems 
which, by themselves, also threaten the very livelihood of ordinary citizens. Governance should be based on holistic and broad-based participation, yet, as evidence suggests, it is the central state officials who still remain the most dominant face of governance as far as environmental management is concerned.

6.4 Recommendations: Bridging the Gap for Sustainable Environmental Management

Based on the findings as discussed above, the following recommendations are proposed. These recommendations about transparency, accountability, effective communication, citizen empowerment, and research and development when implemented, might contribute effectively to environmental management in Ghana.

\subsubsection{Transparency}

Bridging the gap between the existing status quo and the desired state of affairs might go a long way to improve environmental situation in Ghana. It is therefore important that key state actors work together on engendering and fostering participatory problem solving processes and practices - effective participatory democracy. Ensuring that these arrangements are maintained and constantly reviewed to guarantee the much needed sustainability in environmental management cannot be overemphasized or ignored. This might be achieved through enhanced transparency, accountability, effective communication and citizen empowerment. All of the latter can be described as both necessary and sufficient conditions for effective, sound and transformational leadership. Transparency is relevant here in as much as it 
"Develops trust as a building block of workable partnerships....facilitates open exchange of accurate information and strengthens linkages among varying parties in the governance process... and enhances opportunities for evolving the forms and models of partnerships from reactive and accommodative to proactive, cooperative and interdependence models..." (Farazmand, 2004: 97).

In Ghana, the government is the largest repository of data and information. The latter includes, but is not limited to Commission/Committee, or Administrative Reports, Annual Reports and Statistical Publications. Yet, successive governments have not been favourably disposed towards giving out information. Contributing to the latter are concerns about privacy, security and copyright laws which clearly act as barriers to public accessibility of government data. The best way forward is to create incentives and remove disincentives to information sharing. In this regard, efforts by the current New Democratic Convention (NDC) government to speed up the passage of the Freedom of Information Bill, is most welcome. ${ }^{112}$ Indeed, this might go a long way to removing the veil of secrecy that has surrounded the activities of government. Transparency also ensures that information is made available that might subsequently be used to measure the performance of government officials and elected leaders. It might guard against mismanagement and temptation of abuse of the power delegated to the representatives of the people. Transparency serves to ensure and achieve accountability by serving as a preventative mechanism through which governments are held continuously responsible for their actions.

112 See article, "Freedom of Information Act in Ghana, NDC Action Imperative Now", Ghana Web, General news of Sunday, January $20^{\text {th }}, 2011$ :

http://www.ghanaweb.com/GhanaHomePage/NewsArchive/artikel.php?ID=202204 


\subsubsection{Accountabilitv}

Indeed, accountability in governance is considered to be an important cornerstone in democracies. It ensures that public officials are subject to oversight to guarantee that government initiatives meet their stated objectives and respond to the need of the community. But the key means of ensuring accountability involve governance structures and processes. Thus, it is important that lasting changes at different levels within the system are effected for optimal results. The key precondition here is a fully decentralized and coordinated political and administrative system from the national level right through to the local level. This calls for the organization of free and fair elections not only at the national level, but also at the local level to ensure that the actions of government officials are directly or indirectly monitored. It involves fostering dialogue, sharing of relevant information, meaningful consultations and building of consensus. In addition, efforts to tailor accountability processes to the peculiarities of the system itself are necessary. Consequently, in the particular case of Ghana where Chiefs remain strong pillars in society and are considered, in part, to be the custodians of the land, it is pertinent that traditional methods for holding authorities accountable, which have in the past been considered effective, are successfully integrated into existing environmental management practices and principles. 
Accountability is interwoven with responsibility and, by itself, might open up spaces for transformational leaders to engender constructively radical changes that translate into meaningful results in environmental management in Ghana. The Polluter Pays Principle which requires that the cost of pollution be borne by those who cause it may be adapted and customised for use especially by the traditional authorities. In the area of mining, it might allow the Chiefs and people of resource-rich areas such as Tarkwa, Obuasi, Akwatia, to hold companies accountable for their actions and, when necessary, determine how the costs of pollution can be allocated to the responsible parties. This might reduce the current spate of resource exploitation in the resource-rich areas of the country. Thus, Chiefs might be held accountable for their responsibilities towards their areas and subjects and, in turn, hold polluters in their areas accountable for their actions.

\subsubsection{Communication and Empowerment}

Neither transparency nor accountability, it must be noted at this point, can be attained without effective communication. Ensuring meaningful and productive flow of information among all stakeholders entails the adoption of a multi-dimensional communication strategy which fosters and facilitates exchanges among stakeholders to arrive at possible solutions for existing problems. The latter approach is significant in as much as it increases opportunities for identifying possible partnerships, materials, and knowledge required to solve a peculiar problem. Encouraging dialogue allows for stakeholders to listen to each and that ultimately helps in avoiding one-policy fits all situation imposed from above to address recurrent problems regardless of the 
peculiarities of the context in which these problems occur. It is also important that the potential of hitherto disadvantaged stakeholders be appropriately cultivated towards the attainment of their local goals and needs. One way is through the promotion of inclusive decision-making initiatives that place emphasis on increased recognition and respect for the views of local people. Conferring autonomy through relevant capacity building initiatives and devolving power to those who previously have been unable to decide matters for themselves or to influence decision-making is an important step towards realizing sound policy outcomes in the environmental sector. Moreover, effective governance that incorporates community building, enhancement of social capital and personal networks should be encouraged. Unlike the conventional perspective that projects policy as necessarily driven or determined through rational means from above, it might be constructive to see it as an outcome or product of power relations between various social and political actors. Consequently, the policy path from policy formulation to policy outcomes should ideally pass along many links and, at different stages, enjoy the input and contributions of affected parties - the stakeholders.

Applying the principles of transparency, accountability and communication implies, among other things, that all relevant stakeholders are sufficiently empowered to take the necessary actions to improve their well-being. Empowerment simply put, is really all about "creating the right conditions conducive to enhancing the motivation to perform" (Gergis, 1999: 7). But more importantly, there must be effective governance at all levels of government. This calls for more collaboration between national authorities and those at the regional and local level. Leveraging regional and local resources and analyzing 
each area's competitive advantage might also go a long way in optimising long-term and practical solutions to environmental problems. Citizen engagement must also be encouraged and sustained by wèlcoming new voices, especially the under-represented individuals and youths in the communities. For Ghana to achieve an acceptable level of efficacy in its environmental management efforts it is crucial, therefore, that citizens are adequately empowered to unleash their creative and innovative energies to help solve the many environmental problems that currently besiege the country. One of the ways to achieve this is for leaders to strive at envisioning a different future in which effective systems for engaging and sustaining wide-spread participation encompasses both the bottom and the top.

\subsubsection{Research and Development}

Efforts towards sustainability in Ghana's environmental management processes, in addition to the above-mention principles, should also adopt a comprehensive research and development approach. This means that the modernizing elite must engage the support of the relevant stakeholders, to move beyond the current emphasis on developing modern energy and resource-saving technologies towards funding innovative and context-specific research geared at improving a better understanding of traditional natural resource management practices. The latter is relevant, given the paucity of research and information pertaining to traditional beliefs, taboos, rules and regulations that have been in the past effective in natural resource management. There is also a need for the creation of an enabling environment capable of providing the needed incentives and support for the existing research community in Ghana including universities, think tanks and other research organizations. 


\subsection{Contribution to Knowledge}

Elite theory is one of the major theories that aim at analysing and explaining the structure of power as well as power relations. Elites are important actors in processes and initiatives aimed at societal progress and political development and peace building efforts. Scholars of democratization for instance identify compromise or consensus between competing elites as a necessary condition for successful transition to democracy. Linz and Stepan (1996) argue that elite consensus on distribution of power among institutions is a critical factor for democratic stability for countries in transitions. To this end, the literature abounds with themes relating to integration and differentiation, elite attitude, network and modes of interaction. For the most part, however, there appears to be continual references, in the literature to a modern elite system without mention or recognition of the fact that there is indeed a penetration, in some cases and especially in developing countries, by aspects of the indigenous political structure and practices. Thus, the elite analysis approach ignores the existence of more than one type of elites, the traditional, the local modern and the international elites whose appropriate articulation is essential for effective governance. As has been noted in this study, preferring the modern elites over the traditional elites is part of the problem of ineffective governance.

There are different modes of articulation. One mode is for the two to have little to do with the other with each party doing whatever it pleases and developing free from the influence of the other. Because of interdependence, this type of articulation is, in practice, very rare. A second type is when the parties interact, but power asymmetry exists leading to unproductive tension between the two. It happens when one party dominates and 
ignores the other to the extent of suffocating the other party into ineffectiveness. A third mode is for the two to be harmoniously and respectfully integrated as equals with dignity. This leads to mutual reinforcement and cooperation with little tension between the two. Unfortunately, as this study has explained, it is the second mode of articulation which exists in Ghana. The latter is a consequence of the departing colonial powers leaving power entirely in the hands of the modern elite. On their part, the modern elite, because of historical indirect rule, perceived the traditional elites as puppets of the departing colonial powers and desired to have little to do with them. This attitude is at the roots of the ineffective articulation between the two parallels and requires addressing for the sake of constructive, proactive and productive elite governance.

As explained earlier, what pertains locally in Ghana essentially is a two-tier and parallel elite system comprising modern and traditional elites. The common threads of Ghana's traditional structure include traditional rulers being custodians of ancestral and community land. Others include their being custodians of culture, customary laws, traditional history and initiators and champions of development activities in their respective areas of jurisdiction. Again, as explained earlier, modern elites, are those who, in modern times, emerged out of the struggle for pre-eminence concerning wealth, status, authority and control over the means of directing human activities or wills, and decisions about who gets what and when.

On a general basis, elite theory was used in this study to examine and explain the systematic mismanagement of the environment in Ghana. But, while this study has 
presented a rather negative account of the two-tier elite system in the specific case of Ghana, there are, indeed, several key factors for making the two-tier system work. Traditional authorities express and exemplify values and norms including consensusbuilding, inclusion, reciprocity, all of which foster and encourage options for local selfhelp and development initiatives. Given that the indigenous political system and its associated practices cannot be wished away, it might be imperative for the modern elites to recognise and respect the undeniable, constructive and productive values in traditional rule. This might serve as a basis upon which increased social cohesion and societal progress can be realized. As explained above, the major problem with the two-tier elite system in Ghana, however, is the lack of articulation or cooperation between the modern and traditional elites.

Interestingly, Chiefs, for their part, have been demanding a more active role in mainstream governance, but a lot of their requests have so far fallen on deaf ears. This is a cause for concern, given that failure to bring the existence of such tension under control might rather spell the demise of a ruling elite coalition. For example, though land is under the control of the traditional rulers, their input is often not sought in the exercise of town planning. The resulting tension is reflected in the often non-compliance with the town planning directives by the local communities. Thus, as this study found in the Greater Accra Region, this tension has undermined water distribution projects and houses have been built within proposed roads leading to much congestion. It should not be forgotten that the neo-colonial structure of Ghana's economic and political spheres implies that these successive coalition of elites often include the international power elite with whom 
some of the modern elite of Ghana (the compradors) may be aligned, making the tension more complex.

Compounding this problem is the overt interference of the international elite. The international power elite has for the past century or so played a dominant role in the politics of the Third World. A case in point was when, in the early 1980 s, the World Bank, in response to the ever-worsening balance of payment problems in sub-Saharan countries including Ghana, began to devote a lot of attention to program aid. International organizations such as the World Bank assumed responsibility in the planning and preparation of what were considered to be relevant programs to combat sub-Sahara Africa`s environmental problems. The traditional nature of African society and how such programs impacted it were not adequately considered.

In accordance with Weber's model of traditionalism, Ghanaian society, for all intents and purposes, may be considered traditional. Indeed as Twumasi rightly points out "...the social organization of the people revolves around kinship: it is an elder-oriented society in which the head of the lineage occupies an important place" (Twumasi, 1979: 1). The traditional nature of Ghanaian society is reflected in the 2000 National Housing and Population census which placed over 70 percent of the Ghanaian population in predominantly rural areas (Ghana Statistical Service, 2002). The rural areas are undeniably within the province of traditional rule. The modern elites' underestimation or denial of the inherent transformational potential of the traditional elite is, thus, a cause for concern. It represents, on a much broader note, a subtle movement away from traditional 
norms such as consensus-building, reciprocity, inclusion towards more rationally acceptable ones such as efficiency, effectiveness and competitiveness.

Thus, the efficiency of indirect rule is denied. It also represents a rejection of indigenous relations for more formal and modern ones. But, it is wise as Osabu-Kle (2000) argues that systems of elite governance are more capable of attaining their desired objectives when devised in a manner compatible with a society's political, social and cultural traditions. In other words, culture and context matter and have to be fathomed and factored in conceptualizing elite governance systems capable of attaining policy objectives and national goals. This is even more desirable in Ghana where the majority of the populace owe allegiance to the traditional rulers first and the state second. Constructive articulation between the modern elites and the traditional elite in the management of the environment cannot therefore be overemphasized. It is an important gap, which as this study has recommended can be filled by transparency, accountability, empowerment and effective communication. 


\section{BIBLIOGRAPHY}

Aalberts, T., E., (2004) “The Future of Sovereignty in Multilevel Governance”, Journal of Common Market Studies, Vol. 42, No.1

Abernach J., and Rockman B., (2000) In the Web of Politics: three decades of the US federal Executive, Brookings Institute Press, Washington, D.C.

Adejumobi S., (1995) "Adjustment Reforms and its Impact on the Economy and society" in S Adejumobi and A. Momoh (eds), The Political Economy of Nigeria under Military rule: 1984-1993 SAPES books, Harare

Ake, C., (1996) Democracy and Development in Africa, Brookings Institute, Washington, D.C

Akabzaa, T. and Darimani, A., (2001) "Impact of mining sector investment in Ghana: A study of the Tarkwa mining region" Paper presented at the Second National Forum in Accra, Ghana, May 7-9, 2001. Accessed online on August, 2008 from http://www.saprin.org.ghana/research/gha_miningpdf

Alvesson, M., (2003) "Methodology for close-up studies- Struggling with closeness and closure", Higher Educational, Vol. 46, No. 2.

Allen., C., (1995) "Understanding African Politics" Review of African Political Economy, Vol. 22. No.65

Amanor, K.S., (2004) "Natural and Cultural Assets and Participatory Forest Management in West Africa", Political Economy Research Institute (PERI) Working Paper Series No.75, University of Massachusetts, Amherst

Amanor, K.S., (2001) "The Symbolism of Tree Planting and Hegemonic

Environmentalism" Paper presented at a workshop on changing perspectives of Forests:

Ecology, People, Science/policy processes in West Africa and the Caribbean, IDS, University of Sussex

Anane M., (2006) "Lethal Cyanide spill in Ghana outrages Gold Mining communities, "Environmental Services News, Accra, Ghana

Appiah-Opoku S., and Mulamoottil G., (1997) Indigenous Institutions and Environmental Assessment: The Case of Ghana, Environmental Management, Vol. 21, No. 2

Arce, A., and Long N., (eds) (1999) Anthropology, development and modernities: exploring discourses, counter-tendencies and violence, Routledge, New York

Arnstein, S. R., (1969) “ A Ladder of Citizen participation” Journal of American Institute of Planners, Vol. 35, No. 4 
Aryittey, E. and Boateng-Baah W., (2007) "Growth, Investment and Employment in Ghana”, Working Paper, No. 80. Policy Integration Department, International Labour Organisation (ILO), Geneva

Asuobonteng K., and Agyeman W., (2010) "Traffic-driven modelling of vehicular Emission using COPERT III in Ghana: a Case study of Kumasi, American Journal of Scientific and Industrial Research, Vol. 1, No. 1.

Aryee, J.R.A., (2000) Decentralisation and Good Governance in Ghana, unpublished paper of May 2000, prepared for the Canadian High Commission, Accra

Aryee., J.R.A., (2007) "Traditional Leadership and Local Governance in Africa: The Ghanaian Experience" Paper presented at the Fourth Annual Local Government Conference on the theme " Traditional Leadership and Local Governance in a Democratic South Africa: Quo Vadis, held from 30-31 July, at the Southern Sun, Elangeni, Durban, South Africa, Unpublished, Accessed online on December, 22, 2008 from http://www.ddp.org.za/programme-events

Bailey, K.D., (1994) Methods of Social Research, Free press, New York Barker, R., (1990) Political Legitimacy and the State, Clarendon Press, Oxford, UK Barrow C., (2005) Environmental Management and Development, Routledge, New York

Barrow C., (2006) Environmental Management for Sustainable Development, Routledge, New York

Barzelay, M., (1992) Breaking through Bureaucracy, University of California Press; Berkeley

Baumgartner F., and Jones, B., (1991) "Agenda Dynamics and Policy Sub-Systems, Journal of Politics, Vol. 53, No.4

Berelson, B., (1952) Content Analysis in Communication Research, Free Press, New York

Bienen H., (Ed) (1971) The Military and Modernisation, Aldine, Atherton

Bill C-27 (2001)" An Act respecting the long-term management of nuclear waste fuel, Parliament of Canada, Ottawa

Binder, L., (1971) Crises and Sequences in political development, Princeton University Press, N.J, Princeton 
Block F., (1984) "The Ruling Class does not rule: Notes on the Marxist Theory of the State", in Boafo-Arthur, K., (2007) Ghana: one decade of the liberal state, Zed Books, New York

Bond, P., (ed) (2002), Fanon's Warning! A Civil Society Reader on the New Partnership for Africa's Development, Africa World Press, Trenton, N.J

Bond, P., (2002) "Thabo Mbeki, New Partnership for Africa's development: breaking or shining the chains of global Apartheid? The Progressive Response, Vol. 6, No. 9

Boon E., K., and Hens L., ( 1997), (ed) Environmental management in West Africa, Human Ecology Department, VUB, Brussels, Belgium

Boon E., K., and Hens L., ( 1999) "Institutional, Legal and Economic Instruments in Ghana's Environmental policy," Environmental Management, Vol 24, No.3

Bascule, M. and Vincent, J., (2000) "Promoting better logging practices in Tropical forests: A simulation analysis of alternative regulations" Land Economics Vo1.76, No.1

Boston J., (2000) "Organizing for Service Delivery: Criteria and Opportunities", in Governance in the Twentieth Century: Revitalizing the Public Service, (eds) Peters G and Savoie D. J, Mcgill-Queen University Press, Montreal

Bratton, M., (1994) "Civil Society and Political Transitions in Africa" in Harbeson, J.W, Rothchild, D., \& Chazan, N., (eds) Civil Society and the State in Africa, Lynne Rienner Publishers, Boulder

Bratton M. and van de Walle N., (1997) Democratic Experiments in Africa, Cambridge University Press, New York

Bruntland G., (1987) Our Common Future, World Commission on Environment and Development

Brown J., Mitchell, N.J., and Beresford M., (eds) (2005) The protected landscape approach: linking nature, culture and community, IUCN World Commission, Switzerland

Burns, J.M., (1978) Leadership, Harper \& Row, New York

Busia, K. A., (1958) The position of the chief in the modern political system of Ashanti: a study of the influence of contemporary social changes on Ashanti political institutions, Oxford University Press, London

Canadian Energy Research Institute (2008) "The Canadian Nuclear Industry: Contributions to the Canadian Economy", Paper prepared for the Canadian Nuclear Association, CERI, Ottawa 
Cartwright, J., (1983) Political Leadership in Africa, St Martin's Press, New York

Cobb, R., W., and Rochefort, D. A., (1994) (ed), The Politics of Problem Definition: Shaping the Policy Agenda, University Press of Kansas, Lawrence

Cohen L., and Manion. L., (1994) Research Methods in Education, Routledge, London

Conference Board of Canada, (2011) "Greenhouse Gas mitigation in Canada" Paper published by the Conference Board of Ghana, Ottawa, Accessed online on September, 22, 2011 from http://www.conferenceboard.ca/hcp/Details/Environment/greenhouse-gasemissions.aspx

Cort, C. (1991) "Voices from the margin: nongovernmental organization participation in the Tropical Forest Action Plan", WRI Working Paper, Washington, D.C.

Coser, L., (1977) Masters of Sociological Thought: ideas in historical and social context, Harcourt Brace Jovanovich, New York

Crick, B., (1962) In Defense of politics, Weidenfield and Nicolson, London

Creswell, J.W., (2003) Research Design, Qualitative, Quantitative \& Mixed Approaches, Sage Publications, Thousand Oaks.

Dahl, R., (1971) Polyarchy: Participation and Opposition, Yale University Press, New Haven

Dahl, R., (1984) "Polyarchy, Pluralism and Scale", Scandinavian Political Studies, Vol.7, No.4.

Dahl, R., (1986) "Rethinking Who Governs" in R.J. Waste, Community Power:

Directions for Future Research, Sage, and Newbury Park

Dahl, R, (1961) Who governs Democracy and Power in an American city, Yale University Press, New Haven

Davidson B., (1992) The Black Man's Burden: Africa and the curse of the nation-state, Curry, London

Desario, J. and Langton, S., (eds) (1987) "Citizen Participation in public decisionmaking" Journal of Planning Literature, Vol.11, No.3

Devarajan, S., Dollar, D., and Holmgren T., (2001) Aid Reform in Africa, World Bank, Washington D.C

Dewey J., (1946) The Public and its Problems, Gateway, Chicago 
Diamond, L., (1987) Class formation in the Swollen African State, The Journal of Modern African Studies, Vol. 25, No. 4

Diamond, L.,(ed)(1994) Political Culture and Democracy in Developing countries, Lynne Rienner, Boulder

Diamond, L., (1999) Developing Democracy towards consolidation, John Hopkins University Press, Baltimore

Diener E. and Crandall R., (1978) Ethics in Social \& Behavioural Research, University of Chicago Press, Chicago

Dilulio, J., (ed). (1994) Deregulating the Public Service : Can Government be Improved? The Brookings Institute, Washington, D.C

Dixon, F. N., (1976) On the Psychology of Military Incompetence, Cape, London

Doe K. B and Peprah P., (1988) "Problems of Waste Management in the Urban Areas of Ghana", Paper prepared for the Town and Country Planning Division (TCPD), Accra, Ghana

Dogbevi E., (2009) "Desertification devastates Ghana economies, Ghana loses $5 \%$ of Agricultural GDP", Ghana Business News, June, 21, 2009, Accra, Ghana

Domfeh, K., A., (2004) "Managing the environment in a decade of administrative reforms in Ghana", International Journal of Public Sector Management, Vol. 17, No.7

Dorais M., (1996) "Preface" in Sadler B, (editor) "International study of the effectiveness of environmental assessment" , International Association for Impact Assessment and Canadian Environmental Assessment Agency, Ministry of Supply and Services

Dorsey, A.H.J., and Macdaniels, T., (2001) "Great Expectations, Mixed Results: Trends in Citizen Involvement in Canadian Environmental Guidance", in Parsons, E. A., Governing the Environment: persistent Challenges, Uncertain Innovations, Toronto University Press, Toronto

Dror, Y., (2001) The Capacity to Govern: A Report to the Club of Rome, Fran Cass, and London

Drillbits and Tailings (2000) "Gold Mining in Ghana destroys Livelihoods, Health and the Environment" Drillbits and Tailings Vol. 15, No.2. Accessed online on December 1, 2008 from www.moles.org/ProjectUnderground/drillbits $/ 5$ 19/4.html.

Dunn Williám N, (2004) Public Policy Analysis, An Introduction, Prentice Hall, Upper Saddle River, NJ 
Dye, T., and Zeigler, H., (2003) The Irony of Democracy: an uncommon introduction to American politics, Cole Publishing, Pacific Grove

Barbier, E., (ed) (1998) The Economics of Environment and Development: Selected Essays, Edward Elgar

Easton, D., (1953) The Political System: an inquiry into the state of political science, Knopf; New York

Easton, D., (1965) A Systems Analysis of Political life, Wiley, New York

Engmann, E.Y. S., (1990) Urban Management Programme: Case Study of Accra Metropolitan Area, A report for the Government of Ghana and the UNDP, Accra, Ghana

Environmental Protection Council (1989) Ghana National Environmental Action Plan, Vol 1\& II, Accra, Ghana

Environmental Protection Agency, (1994-2004) Annual Reports, Accra, Ghana

Environmental Protection Agency (EPA) (2005) Ghana's State of Environment Report, 2004, Accra, Ghana

Environmental Protection Agency (EPA), (2002), Ghana Landfills Guidelines, Accra, Ghana

Etzioni, A., (1968) The Active Society, The Free Press, New York

Fairhead J., and Leach, M., (1996) Misreading the African Landscape, Society and Ecology in a Forest-Savannah Mosaic, Cambridge University Press, Cambridge

Fairhead J., and Leach, M., (2003) Science, Society and Power: Environmental Knowledge and Policy in West Africa and the Caribbean, Cambridge University Press, New York

Falconer, J., (1992) "Non-Timber Forest Products in Ghana" ODA Main Report

Fargey P.J. (1991) "Assessment of the conservation status of the Boabeng Fiema Monkey Sanctuary, Report submitted to the Flaura and Fauna Society

Farazmund, A., (2004) Sound Governance, Policy and Administrative Innovations, Prager, Westport, CT

Ferguson, T., and Rogers, J., (eds) (1984) The Political Economy, M.E. Sharpe, New York 
Finer H., (1941) "Administrative Responsibility in Democratic Government" Public Administration Review, Vol 1, No. 2

Fischer F., (2000) Citizens, Experts and the Environment: The role of Local Knowledge, Duke University Press, London

Frankfort-Nacmias C., and Nachmias D., (1992) Research methods in Social Science, Edward Arnold, London

Freeman III, A. M., Haveman R. H. and Kneese A. V., (1973) The Economics of Environmental Policy, John Wiley and Sons, New York

Geddes B., (1995) "Challenging the Conventional Wisdom", in Larry Diamond and Marc Plattner, (eds) Economic Reform and Democracy, John Hopkins, Baltimore,

Ghana Statistical Service (2002) 2000 Population and Housing Census Report, Accra, Ghana

Ghana Statistical Service (2009) Ghana at a Glance 2009, Accra, Ghana, Accessed on June $2010 \mathrm{from} \mathrm{http://www.statsghana.gov.gh/docfiles/news/gh} \mathrm{at} \mathrm{a} \mathrm{glance.pdf}$

Ghana Statistical Service (2005) Ghana Living Standards Survey, Accra, Ghana

Girmay, Y., (2006) Assessing the Environmental Impacts of a Hydroelectric power project: The Case of Akosombo/Kpong dams in Ghana, Unpublished MSc Thesis, Stockholm, Sweden

Gold Coast (1959) The Second Development Plan, 1959-1964, Government Printer, Accra, Ghana

Gould J., and Szomolanyi S., (1997) Slovakia: Problems of Democratic Consolidation and the Struggles for the Rules of the Game, Columbia International Affairs Online, New York

Government of Canada, (2002) Nuclear Fuel Waste Act, Ottawa, Canada

Government of Ghana (1955) Development Progress Report, Accra, Ghana

Government of Ghana (1962) Administration of Land Act, Act 123, Accra Ghana

Government of Ghana (1980) Lands Commission Act, Act 401, Accra, Ghana

Government of Ghana (1993) Constitution of the Republic of Ghana (last amended 1996), Accra, Ghana 
Government of Ghana (1993) Local Government Act, Act 462 Accra, Ghana

Government of Ghana (1994) Environmental Protection Act, Act 490, Accra, Ghana

Government of Ghana (1994) National Development Planning System Act, Act 480, Accra, Ghana

Government of Ghana (1994), Forest and Wildlife Policy, Accra, Ghana

Government of Ghana (1997) Ghana-Vision 2020, Accra, Ghana

Government of Ghana (1999) Forestry Commission Act, Act 571, Accra, Ghana

Government of Ghana (2003) Ghana Poverty Reduction Strategy (GPRS I) 2003-2006, Accra, Ghana

Government of Ghana (2006) Ghana Poverty Reduction Strategy (GPRS II) 2006-2009, Accra, Ghana

Government of Ghana (1997) The Timber Resources Management Act, Accra, Ghana

Government of Ghana (1999) The Forest Commission Act, Act 571, Accra, Ghana

Government of Ghana (2003) The Timber Resources Management (Amendment)

Regulations, Accra, Ghana

Government of Ghana (1994) Office of the Administrator of Stool Lands, Act 481, Accra, Ghana

Gow, J.I., (1994) Learning from Others: Administrative Innovations among Canadian Governments. Toronto: The Institute of Public Administration of Canada and Ottawa: Canadian Centre for Management Development.

Gyimah-Boadi, E., (2004) Democratic reform in Africa: the quality of progress, Lynne Reiner Publishers, Boulder, Colorado

Habermas, J., (1979) Communication and the evolution of society, Beacon Press, Boston Haggard S., and Kauffman, R., (1992) The Political economy of Democratic transitions, Princeton University Press, N.J

Hardin G., (1968) "The Tragedy of the Commons", Science Vol. 162, No.3858

Harmon, Michael M., and Mayer Richard T., (1986) Organization Theory for Public Administration, Little Brown, Boston 
Heady F., (2001) Public Administration: A Comparative Perspective, Marcel Dekker, New York

Heclo H., (1978) "Issues Network and Executive Establishment," in The New American Political System, (Ed), Anthony King, American Enterprise Institute, Washington D.C

Heeger, G., A., (1973) "Bureaucracy, Political Parties and Political Development, World Politics, Vol. 25, No. 4

Hens, L., and Boon, E. K. (1999) Institutional, Legal and Economic Instruments in Ghana's.Environmental Policy, Environmental Management, Vol. 24, No. 3

Higgot, R. A. (1983) Political Development Theory: the contemporary debate, Croom Helm, London

Hill L., (1974) "Institutionalization, Ombudsman and Bureaucracy", The American Political Science Review, Vol 68, No.3.

Hirschman Albert O., (1963) Journeys towards Progress, studies of economic policy making in Latin America, Twentieth Century Fund, and New York

Hirschman Albert O., (1981) "The Rise and Decline of Development Economics", In Essays in Trespassing, 1-24, Cambridge University Press, Cambridge

Huntington S., (1968) "Political Order and Decay" in Huntington, S., (1968) Political Order in Changing Societies, Yale University Press, new Haven

Ilchman, W. F. and Uphoff, N. T., (1969) The Political Economy of Change, University of California Press, Berkely

Iris Marion Young, (1993) "Justice and communicative democracy," in Roger S. Gottlieb (ed.) (1993), Radical Philosophy: Tradition, Counter-Tradition, Politics Temple University Press, Philadelphia; Iris Marion Young (1995) "Communication and the other: beyond deliberative democracy," in Margaret Wilson and Anna Yeatman (eds.), (1995) Justice and Identity: Antipodean Practices, Allen \& Unwin, Sydney

Institute of Statistical Study and Economic Research (ISSER) (2000) The State of the Ghanaian Economy, Accra, Ghana

Janicke, M., (1997) “The Political System's capacity for Environmental Policy” in Janicke and Weidner (eds) National Environmental Policies: A Comparative Study of Capacity Building, Springer, Berlin

Jackson T., (ed) (1993) Clean Production Strategies, Developing Preventing Environmental Management in the Industrial Economy, Lewis, Boca Raton 
Karikari A., Y, Asante, K. A., and Biney, C. A., (1999) "Water Quality Characteristics of the Estuary of the Korle Lagoon in Ghana", Paper prepared for the Water Research Institute, CSIR-, Accra, Ghana

Kamieniecki, S., (1993) (ed). Environmental Politics in the International Arena: Movements, Parties, Organizations and Policy. State University of New York Press

Kaufman, D., Kraay, A., and Zoido-Lobaton, P (2002), “Governance Matters", World Bank Policy Research Working Paper No. 2772

Kaufman, H., (1956) "Emerging Doctrines of Public Administration" American Political Science Review, Vol.50, No.4.

Keeley J., and Scoones, I., (2003) Understanding Environmental Policy Processes: Cases from Africa, Earthscan Publications

Keller, E., J., (1996) "Structure, Agency and Political Liberalisation in Africa, African Journal of Political Science, Vol. 1, No.2

Kernaghan, K., (1992) "Empowerment and Public Administration: Revolutionary Advance or Passing fancy? Canadian Public Administration, Vol.35, No.2

Kooiman, J., (ed), (1993) Modern Governance: New Government-Society Interactions, Sage Publications; London

Kuper A. and Kipper J., (1989) The Social Science Encyclopaedia, Routledge, London

Laing E., (1994) (ed) Technical Papers by Six Working Groups, Ghana's

Environmental Action Plan, (Volume 2), The Environmental Protection Council, Accra, Ghana

Lasswell D., (1966) The Analysis of Political behaviour: an empirical approach, Archon Books; Hamden

Lindbloom, C. E., (1965) Intelligence of democracy, Free Press, New York

Linz, J and Stephan A., (1996) Problems of Democratic Transition and Consolidation: Southern Europe, South America and Post-Communist Europe, John Hopkins University Press, Baltimore

Locke, E., (1991) The Essence of leadership, Lexington Books

Lowery, D., and Gray, V. (2004) "A Neo-pluralist perspective on Research on Organized Interests", Political Research Quarterly, Vol. 57, Nol 
Madison, J. (1940) The Federalist No. 10, The Federalist Modern Library, New York

Mahoney, J. \& Snyder, R. (1999) "Rethinking Agency and Structure in the study of Regime Change" Studies in Comparative International Development, Vol. 34, No.2

Marcussen, S., H., (2003) "National Environmental Planning in the Third World:

Sustaining the Myths? The Journal of Transdisciplinary Environmental Studies, Vol. 2 No. 1

Mckevitt, D. \& Lawton A., (1994) Public Sector management, Theory, Critique and Practice, Sage Publications Ltd, Thousand Oaks

Michels R. (1962) Political Parties: a sociological study of the oligarchical tendencies of modern Democracy, Collier Books, New York

Michels R. (1964) "The Iron Law of Oligarchy", in Roy, C. Macridis and Bernard C. Brown, (eds) Comparative Politics, Notes and Readings, Dorsey Press, Homewood

Migdal J., (1977) "Urbanization and Political Change: The Impact of Foreign Rule", Comparative Studies in Society and History, Vol. 19, No. 3

Millennium Assessment Report (2005) Ecosystems and Human Well-being: Synthesis, Island Press, Washington, D.C

Mills C. W., (1956) The power elite; Oxford University Press, New York

Ministry of Environment, Science and Technology, (1998-2005) Annual Reports, Accra, Ghana

Ministry of Works and Housing (1998) Ghana's Water Resources Management Challenges and Opportunities, Unpublished Study, Accra, Ghana

Molebatsi, C.O., (1994) "Towards understanding policy-practice disjunction in urban planning, The Case of Kenya, Botswana, Unpublished PhD Dissertation, University of Newcastle

Morgan M., (2007) "Annual Cost of Environmental Degradation to Ghana: \$1.2 Billion" Ghanaian Statesman, Accra, January $25^{\text {th }}, 2007$

Mosca, G., (1939), The Ruling Class, ( $1^{\text {st }}$ edition) McGraw -Hill, London

Mosher F. C., (1968) Democracy and the Public Service, Oxford University Press, New York 
Nagel, J., (1976) The Descriptive Analysis of Power, Yale University Press, New Haven, Connecticut

National Coalition of Mining (NCOM) (2009) "Ghanaians present complaints of human abuses", Memorandum to the Minister of Defence from NCOM, March, 2009, Accessed online on August, 20, 2008 from

http://www.minesandcommunities.org/Action/press1466htm

NEPAD Secretariat (2001) The New Partnership for Africa's Development, NEPAD, Abuja

Neuman, W. L., (2003) Social Research Methods: Qualitative and Quantitative approaches, Allyn and Bacon, Toronto

Nkrumah, S.A., (2000) 'Decentralisation for Good Governance and Development: The Ghanaian Experience' Regional Development Dialogue, Vol. 21. No.1

Noor, D., (2009) "NCOM faults EPA on Newmont Akyem Project... calls for withdrawal of permit" Ghanaian Chronicle, March 13, 2009 Accra

Nordlinger, E., (1981) On the autonomy of the democratic state, Harvard University Press, Cambridge,

NDPC (2005) "The Coordinated Programme for the Economic and Social Development of Ghana, 2000-2009”, Ghana and Poverty Reduction Strategy (GPRS II) Final Draft, Government of Ghana

Nsiah-Gyaboah, K., (1994) Environmental Degradation and Desertification in Ghana, Ashgate Publishing Ltd, London

Ntiamoah-Baidu, Y., (1995) "Indigenous vs. Introduced Biodiversity Conservation Strategies: The case of protected area systems in Ghana", African Biodiversity Series, No.1, Washington

Nuclear Waste Management Organization, (2005) "Choosing a Way forward: the Future of Canada's used Nuclear Fuel" Draft Study Report, NWMO, Toronto, Canada, Accessed online on December 2008 from http://www.nwmo.ca/uploads managed/.../1436 nwmo draft study report e.pdf

Nuclear Waste Management Organization (2009) "Moving Forward Together", Annual Report, NWMO, Toronto

O'Leary, R., Gazley,. B. McGuire, M., \& Bingham, L.B. (2009) "Public Managers in collaboration", in Bingham, L.B. \& O' Leary R. (eds) The Collaborative Public Manager, Georgetown University Press, Washington, D.C. 
Oakeshott M., "Rationality" in Mckevitt, D. and Lawton, A. (1994) Public Sector Management: Theory, Critique and Practice, Sage Publications, Newbury Park, C.A

Organisation for Economic Cooperation and Development (OECD) (2001), "Engaging Citizens in Policy-Making: Information, Consultation and Public Participation", $\boldsymbol{O E C D}$ Public Management Policy Brief, No. 10. Paris Accessed online on June $3^{\text {rd }}, 2009$ from http://www.oecd.org/LongAbstract/0.3425,en $2649 \quad 33735 \quad 2384034$ 1 111 1 1 1.00.html

Ofei- Aboagye, E., (2000) "Promoting the participation of women in Local Governance and development: the case of Ghana" (ECDPM Discussion Paper 18), Maastricht, European Centre for Development Policy Management, Accessed online on June, $2^{\text {nd }}$ 2009 from

http://www.ecdpm.org/web ecdpm/web/content/content.nsf/vwPrint/37934F6BC08133B 8C1256C6F006053B9?Opendocument

Oppenheim, A.N., (1992) Questionnaire Design, Interviewing and Attitude Measurement, Pinter Publishers Ltd, London

Oquaye, M., (1980) Politics in Ghana, Tornado Publications, Christiansburg, Accra Organski, A. F. K., (1965), The Stages of Political Development, Knopf, New York Osabu-Kle, D., (2000) Compatible Cultural Democracy: the key to African development, Broadview Press, Peterborough, Ontario

Osabu-Kle, D., (2000) "The Politics of One-Sided Adjustment" Journal of Black Studies, Vol.30, No.4

Osborne D., (1993) Reinventing Government: How the Entrepreneurial Spirit is transforming the Public Sector, Plume, and New York

Osborne, D. and Plastrik, P., (1997) Banishing Bureaucracy, Addison-Wesley Reading

Convery, F.J., and Tutu K.A., (1990) "Evaluating the Environmental Cost of Environmental Degradation in Ghana", A Report prepared for the Environmental Protection Council, Accra

Owakah, E. F., and Aswani, R. D., (2009) "Technocracy and Democracy: The Challenges to Development in Africa" Thought and Practice, Vol. 1 No. 1

Owusu Boadi K., and Kuitunen M., (2002) "Urban Waste Pollution in the Korle Lagoon, Accra, Ghana", The Environmentalist, Vol. 22, No. 4 
Owusu-Koranteng E. (2001) "Presentation on Human Rights Issues in Mining" CHRAJ Public Forum, Accra

Owusu-Koranteng, E., (2004) "Statement by WACAM on the cyanide spillage by Bogoso Gold Ltd", Accra

Pal, L., (2006) Beyond Policy Analysis: Public issues management in turbulent times, , Nelson Publications, Toronto

Pareto V. (1935) Mind and Society: a treatise on general sociology, Dover Publications, New York

Pareto V., (1968) The rise and fall of the elites: an application of theoretical sociology, Bedminster Press, Totowa, N.J

Pareto V., (1950) The Ruling Class in Italy before 1900, H. Fertig, New York

Parry, G., (1969) Political Elites, and Praeger, New York

Peters, B.G. (2001) The Future of Governing, University of Kansas Press, Kansas

Stavins R.N., Pearce, D., Atkinson, G., Mourato, S., (2006) Cost benefit Analysis and the Environment: Recent Development, Organisation for Economic Cooperation and Development (OECD), and Paris

Pierre J, "Externalities and Relationships : Rethinking the Boundaries of the Public Service" Governance in the Twentieth Century: Revitalizing the Public Service, (eds) Peters G and Savoie D. J, Mcgill-Queen University Press, Montreal

Pinkney, R., (1997) Democracy and Dictatorship in Ghana and Tanzania, Macmillan Basingstoke

Pollitt, C. and Bouckaert, G., (2000) Public Management Reform: A Comparative Analysis Oxford University Press, Oxford.

Professor Bekoe A., (2007) "The Role of Traditional Authorities in the Ghanaian Society" The Ghanaian Chronicle, Accra, Ghana

Przeworski A., (1991) Democracy and the market: political and economic reforms in Eastern Europe and Latin America, Cambridge University Press, Cambridge

Putnam R., (1993) Making Democracy Work: civic traditions in modern Italy, Princeton University Press, Princeton

Rathbone, R., (2000) Nkrumah and the Chiefs: the Politics of Chieftaincy in Ghana, 1951-60, Villiers Publication, and London 
Repetto R., (1988) Public Policies and the Misuse of forest resources, Cambridge University Press, Cambridge

Repetto R., (1988) "Overview" in Repetto R and Gills M (Eds) Public Policies and Misuse of Forest Resources, Cambridge University Press, New York

Rhodes, R.A.W., (1997) Understanding Governance: Policy Networks, Governance, Reflexivity and Accountability, Open University Press, Buckingham

Ribot, J. C., (2001) Local Actors, Powers and Accountability in African

Decentralisation: A Review of Issues, Unpublished paper prepared for International Development Research Center, Canada

Rodney, W., (1972) How Europe Underdeveloped Africa, Bogle L'Ouverture, London

Rondinelli, D. A., Nellis, J., \& Chema, S. (1983) "Decentralisation in developing countries: A review of recent experience, World Bank Staff Working papers, No. 581 World Bank, Washington, D.C.

Rosamond, B., (2000) Theories of European Integration, Palgrave Macmillan, Basingstoke

Rostow, W. W., (1960) The Stages of Growth: A Non-Communist manifesto, Cambridge University Press, Cambridge

Savoie, D.J., (1995) "What is wrong with the New Public Management?", Canadian Public Administration, No. 38, No.1

Savan, B. Gore C. and Morgan A. J., (2004) "Shifts in environmental governance in Canada: How are citizen environment groups to respond?", Government and Policy, Vol. 22 No. 4

Saris, A. and Shames, H., (1991) Ghana under Structural Adjustment: The Impact of Agriculture and the Rural Poor, New York University Press, New York

Seidman H., and Gilmour R., (1986) Politics, Position and Power: from positive to the regulatory state, Oxford University Press, New York

Shafik N., and Bandyopadhyay S., (1992) in "Economic Growth and Environmental Quality: Time Series and Cross Country Evidence”, Policy Research Working Paper, No.WPS 904, World Bank, Washington, D.C.

Shils, E., (1962) "The Military in the Political Development of New States," John J. Johnson, (editor)The Role of the Military in Underdeveloped Countries, Princeton University Press, Princeton, N.J 
Silverman, D., (1993) Interpreting Qualitative Data, Sage Publication, London

Smith, B., C., (2003) Understanding Third World Politics: theories of political change and development, Indiana University Press, Bloomington

Speirs, M., and Marcussen, H., S., (1998) "Environmental Planning in Africa- action or words?” Journal of Geography, Special Issue, No. 2

Stagl. S. (1999) "Delinking Economic growth from Environmental Degradation? A Literature survey of the Environmental Kuznets Curve Hypothesis" Working Papers, Vienna University of Economcs and B.A Research Group. Accessed online on March, $1^{\text {st }}$ 2010 from http://www.ideas.repec.org/p/wiw/wiwgee/geewp06.html

Stavins, R. N. and Whitehead, B. W., (1997) "Crafting the Next Generation of MarketBased Environmental Tools", Environment, Vol. 39, No. 4

Stoker, G., "Governance as Theory: Five propositions", International Social Science Journal, Vol. 50 , No. 1

Subramanian, V., (ed) (1990) Public Administration in the Third World, An International handbook, Greenwood Press, New York

Taylor I and Nel P., (2002) "New Africa, Globalisation and the confines of Elite Reformism: Getting the Rhetoric right, Getting the Strategy Wrong" Third World Quarterly, No. 23 Vol.1

Tetteh, K., (1997) Environmental Charges and Taxation as Economic Instruments for Environmental Management in Ghana, in Boon E., K., and Hens L (1997), (ed) Environmental management in West Africa, Human Ecology Department, VUB, Brussels, Belgium

The Nuclear Waste Management Organization (2009) "Moving Forward Together", NWMO Annual Report, Accessed online on March, $1^{\text {st }} 2010$, from http://www.nwmo.ca/uploads managed/.../1439 nwmoannualreport2009.pdf

Throup, D., (1993) "Elections and Political Legitimacy in Kenya" Africa, Vol.63, No. 3.

Throup, D.W., and Hornsby C., (1998) Multi-Party Politics in Kenya: the Kenyatta \& Moi States \& the Triumph of the System in the 1992 Election. J. Currey, Oxford

Tordoff, W., (1997) ( $3^{\text {rd }}$ ed) Government and Politics in Africa, Indiana University Press, Indiana

Torfing, J., (2005) "Governance network theory: towards a second Generation" European Political Science, Vol. 4, No. 3 
Truman, D., (1951) The governmental process: political interests and public opinion, Knopf, New York

Tsikata , I.,E., (1997) Communication Strategies for Effective Environmental Management, A Case Study of the Mining Sector, in Boon E., K., and Hens L ( 1997), (ed) Environmental management in West Africa, Human Ecology Department, VUB, Brussels, Belgium

Tunstall D., (1993) 1993 Directory of Country Environmental Studies: An Annotated Bibliography of Environmental Assessments, WRI, USA

Turnbull L and Aucoin P., "Fostering Canadians' Role in Public Policy: A Strategy for Institutionalizing Public Policy" Canadian Policy Research Network

Twumasi, P.A., (1979) "History of Pluralistic Medical Systems: A Sociological analysis of the Ghanaian Case" Journal of Opinion, Vol 9, No.3

UNDP (2005) "Public Sector Management, Governance and Sustainable Human Development, UN Department of Public Affairs", Discussion Paper 1, UNDP, New York

UNEP (1992) United Nations Framework on Climate Change, United Nations, New York

UNEP (1993) Agenda 21: Earth Summit, The United Nations Programme of Action from Rio, United Nations, New York

UNEP (2007) (4 ${ }^{\text {rd }}$ edition) Global Environment Outlook, Progress Press Limited UNEP (1997) Kyoto Protocol to the United Nations Framework Convention on Climate Change, United Nations, New York

Van de Walle, N., (2001) African economies and the politics of perpetual crisis, 19791999, Cambridge University Press, New York

Vig, N. and Kraft, M., (1990) Environmental Policies in the 1990s, CQ Press, Washington

von Weizsacker, E., Lovins, B. , Lovins H., (1997) Factor Four: Doubling wealth, halving resource use, Earthscan, London

WACAM(2001) "Presentation by Daniel Owusu Kwarteng at the Public Forum of CHRAJ on Human Rights Issues in Mining Area" Accessed online on March 24, 2007, from http://www.wacamghana.com/app/webroot/img/documents/4af43a1912d4c.pdf 
Walker, R. and Smith, T. (1993) "Tropical deforestation and forest management under the system of concession logging: A decision-theoretic analysis" Journal of Regional Science 33(3)

Walters, J., (1992) Reinventing government, managing the politics of change, Governing, Vol. 6, No.3

Waternburg, T. E., (1992) Rethinking Power, SUNY Press, Albany

West African Civil Society (WACS) (2005) Civil Society Statement on the West African Gas Pipeline, Third World Network Africa, Mining and Environment Agenda, Bulletin, No. 14 Accessed online on August $28^{\text {th }}, 2008$ from http://twnafrica.org/mining/mining \& environment agenda/Mining Issue14rtf

World Commission on Environment and Development (WCED), (1987) Our Common Future, Oxford University Press, London

White, W. \& Watson D., (1996) "Natural Resources based Communities in Canada: An Analysis based on the 1996 Census, Canadian Forest Service, and Unpublished

Wilson, J. Q., (1989) Bureaucracy: What Government Agencies Do and Why They Do It, Free Press; New York

Winterbottom, R., (1990) "Taking Stock, the Tropical Action Plan after five years", Rapport, Washington, D.C.

World Bank (1989) Sub-Sahara Africa: From Crisis to Sustainable Development, World Bank, Washington D.C.

World Bank (1991) Managing Development: The Governance Dimension, Discussion Paper, 25, Washington, D.C.

World Bank (1994) Governance: The World Bank Experience, Washington, D.C.

World Bank (1994) Governance: The World Bank Experience, Washington, D.C

World Bank (1992) Governance and Development, World Bank, Washington, D.C.

World Bank (1994) Governance: The World Bank Experience, Washington, D.C.

World Bank (1996a), Effectiveness of Environmental Assessment and National Environmental Action Plans- a process study, Report15385, Operations Evaluation Department, (OED) World Bank, and Washington, D.C. 
World Bank, (1996b),Towards Environmentally Sustainable Development in subSaharan Africa-a World Bank Agenda, Development in Practice Series, World Bank, Washington, D.C.

World Commission on Environment and Development (WCED), 1987, Our Common Future, Oxford University Press, New York

World Health Organization (2002), Reducing Risks, Promoting Healthy Life, World Health Report, Geneva

Yin, R., (1989) Case Study research: design and methods, Sage Publications, Newbury park, California

Young, C., (1999) "The Third wave of Democratisation in Africa" in Joseph, R. (ed)

State, Conflict and Democracy in Africa, Lynne Reiner, Boulder

Zimbardo P.G.,(1984) "On the ethics of interaction in human psychological research with specific reference to the 'Stanford Prison Experiment' in Murphy J, John M., and Brown, H. (eds) (1984) Dialogue \& Debates in Social Psychology, Lawrence Erlbaum Associates Ltd, London

\section{Ghanaian Websites and Newspapers}

Ghana Environmental Protection Agency, www.epa.gov.gh

Ghana Ministry of Environment, Science and Technology, www.mest.gov.gh

Ghana Council for Scientific and Industrial Research, www.csir.org.gh

Ghana Town \& Country Planning, www.tcpghana.gov.gh

Ghana National Development Planning Commission, www.ndpc.gov.gh

Ghana Forest Commission, www.fcghana.com

Environmental News Today- Ghana, www.environment. einnews.com

Ghanaian Times: various publications between 1988 - 1985

Daily Graphic: various publications between 1988- 1995

Ghanaian Chronicle: various publications between 1988- 1995

Weekly Spectator: various publications between 1988- 1995 


\section{LIST OF ABBREVIATIONS}

ADC- Agricultural Development Corporation

AMA- Accra Metropolitan Authority

CBD- Convention on Biodiversity

CBO- Community Based Organization

CEMC- Community Environmental Management Committee

CEPS- Customs Excise and Preventive Service

CEPB - Community Environment Protection Brigade

CEW- Citizen's Environmental Watch

CSO- Civil Society Organization

DA - District Assemblies

DCE- District Chief Executive

DEMC- District Environmental Management Committee

EIA- Environmental Impact Assessment

EIS- Environmental Impact Statement

ERP-Economic Recovery Program

EPA- Environmental Protection Agency

EPA- Environmental Protection Agency

EPC- Environmental Protection Council

EU - European Union

FAO- Food and Agricultural Organization

FC- Forestry Commission

FOE- Friends of the Earth 
FSD- Forest Services Division

GAMA- Greater Accra Metropolitan Area

GBC- Ghana Broadcasting Corporation

GDC- Gonja Development Corporation

GDP- Gross Domestic Product

GEO - Global Environmental Outlook

IFI- International Financial Institution

IMF- International Monetary Fund

JFGE- Japan Fund for Global Environment

KVIP- Kumasi Ventilated Improved Pits

MOE-Ontario Ministry of Environment

MVERB- Mackenzie Valley Review Board

NCOM- National Coalition on Mining

NDC- National Democratic Convention

NDC- National Desertification Committee

NDPA- National Development Planning Act

NDPC- National Development Planning Commission

NEAP- National Environmental Action Plan

NEP- National Environment Policy

NEPAD- New Partnership for Africa's Development

NGO- Non Governmental Organization

NPA- National Program of Action

NPM-New Public Management 
NPP- New Patriotic Party

NTFP-Non Timber Forest Product

NWMO- Nuclear Waste Management Organization

NWT-North West Territories

OECD- Organizations for Economic Cooperation and Development

OPEC- Organization of Petroleum Exporting Countries

REMC- Regional Environmental Management Committee

RCC-Regional Coordination Council

SAP- Structural Adjustment Plan

SEA- Strategic Environmental Assessment

SRA- Social Responsibility Act

TNC- Transnational Corporation

TQM- Total Quality Management

TRCA-Toronto Region Conservation Authority

TREC-Timber Rights Evaluation Committee

TUC-Timber Utilization Contract

TWN- Third World Network

UESP- Urban Environmental Sanitation Project

UN- United Nations

UNCCD- United Nations Convention to Combat Desertification

UNCED- United Nations Conference on Environment and Development

UNEP -United Nations Environmental Plan

UNFCC- United Nations Framework on Climate Change 
WACAM- Wassa Association of Communities Affected by Mining

WAGAP-West African Gas Pipeline

WCED- World Commission on Environment and Development

WED- World Environment Day

WMD- Waste Management Division

WHO- World Health Organization 


\section{APPENDIX 1: Sample of Letter of Consent}

As a PhD student, working on my dissertation entitled The Politics of Environmental Policy and Management: A Case Study of Ghana, I am currently acquiring data that will subsequently be collated, analyzed and documented.

This study sets out to explore how political distribution of power shapes policy processes - in this case those which pertain to the protection of the environment.

The main objective of this study is to assess the influence of the dominant power force in the Ghanaian society, i.e. the modern and traditional elites and examine their influence on the environmental policy process.

\section{Procedures}

When you do decide to participate in this study, you will be required to do all or some of the following:

1. Completion of questionnaires that have been designed to elicit information on issues ranging from the current state of the environment in Ghana, the perceived root causes of prevailing problems, as well as the possible solutions that will help to 'nip these problems in the bud'.

2. Participate in audio-taped interviews on a group or individual basis, the main objective of which is to provide an appropriate medium for participants to offer their opinions, views and knowledge of how power distribution shapes environmental practices and policy processes.

\section{Potential Risks or Discomfort}

There are no known risks to participating in this research. 


\section{Potential Benefits}

You will not personally benefit by participating in this research. However the information you offer will serve as useful input for this study, which upon completion will be disseminated through diverse medium such as journals, books and at conferences, all towards the further advancement of knowledge.

\section{Compensation}

This research project being a purely academic exercise will not offer any compensation for participants.

\section{Anonymity and Confidentiality}

The interviews will be audiotape recorded, but recorded by notes upon your request. What you say on the tape will be typed out. As the sole researcher for this project, I will be the only person, who will listen to the tapes - to protect your identity, your name or any other relevant source of identity will not be included in the transcripts of the tapes and all the recordings will be destroyed upon completion of this research.

\section{Voluntary participation}

Participation in this study is voluntary. You may refuse to participate, refuse to answer any questions, or withdraw from the study at any time by informing the researcher. If you do withdraw from the study, any information that you have provided may still be used in the research findings. This letter is for your personal records

This research project has undergone a review and subsequently received clearance from the Carleton University Research Ethics Committee. If you have any questions about your rights as a research participant or the conduct of the study you may contact: 
Prof. Antonio Gualtieri, Chair

Carleton University Research Ethics Committee

Carleton University

1125 Colonel By Drive

Ottawa, Ontario, K1S 5B6

Tel: 613-520-2517

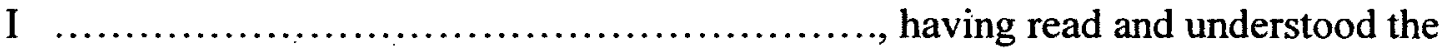
above information about the proposed research project, voluntarily offer my consent to participate in this study.

Signature of Consent by

Participant.

Signature of Researcher

Date 


\section{APPENDIX 2: Sample of Letter of Information}

Research for PhD dissertation on the Politics of Environmental Policy and Management: A Case Study of Ghana

Principal (Sole) Researcher: Vivienne Antwi-Agyei, $\mathrm{PhD}$ Candidate

Department of Political Science

Carleton University, 1125 Colonel By Drive

Ottawa, Ontario, K1S 5B6

613-

vaagyei@connect.carleton.ca

Thesis Supervisor

Daniel T Osabu-Kle, PhD

Associate Professor

Department of Political Science

Carleton University, 1125 Colonel By Drive

Ottawa, Ontario, K1S 5B6

613-520-2600 ext. 2568

\section{Description of Research Project}

This is a study entitled The Politics of Environmental Policy and Management: $\mathbf{A}$ Case Study of Ghana, which sets out to explore how political distribution of power shapes policy processes - in this case those which pertain to the protection of the environment.

The main objective of this study is to assess the influence of the dominant power force in the Ghanaian society, i.e. the modern and traditional elites and examine their influence on the environmental policy process.

\section{Procedures}

When you do decide to participate in this study, you will be required to do all or some of the following:

1. Completion of questionnaires that have been designed to elicit information on issues ranging from the current state of the environment 
in Ghana, the perceived root causes of prevailing problems, as well as the possible solutions that will help to 'nip these problems in the bud'.

2. Participate in audio-taped interviews on a group or individual basis, the main objective of which is to provide an appropriate medium for participants to offer their opinions, views and knowledge of how power distribution shapes environmental practices and policy processes.

\section{Potential Risks or Discomfort}

There are no known risks to participating in this research.

\section{Potential Benefits}

You will not personally benefit by participating in this research. However the information you offer will serve as useful input for this study, which upon completion will be disseminated through diverse medium such as journals, books and at conferences, all towards the further advancement of knowledge.

\section{Compensation}

This research project being a purely academic exercise will not offer any compensation for participants.

\section{Anonymity and Confidentiality}

The interviews will be audiotape recorded, but recorded by notes upon your request. What you say on the tape will be typed out. As the sole researcher for this project, I will be the only person, who will listen to the tapes - to protect your identity, your name or any other relevant source of identity will not be included in the transcripts of the tapes and all the recordings will be destroyed upon completion of this research.

\section{Voluntary participation}

Participation in this study is voluntary. You may refuse to participate, refuse to answer any questions, or withdraw from the study at any time by informing the researcher. If you do withdraw from the study, any information that you have provided may still be used in the research findings. This letter is for your personal records 
This research project has undergone a review and subsequently received clearance from the Carleton University Research Ethics Committee. If you have any questions about your rights as a research participant or the conduct of the study you may contact:

Prof. Antonio Gualtieri, Chair

Carleton University Research Ethics Committee

Carleton University

1125 Colonel By Drive

Ottawa, Ontario, K1S 5B6

Tel: $613-520-2517$

Signed

Vivienne Antwi-Agyei 


\section{APPENDIX 3: Questionnaire Sample}

\section{Politics of Environmental Policy and Management: The Case Study of Ghana:}

Kindly be informed that questions 11-13 are strictly optional and do not have to be filled in by the participant.

1. Indicate your level of awareness of environmental problems in Ghana by assigning a value between 0 and 10

2. Assess the environmental problem below according to their level of severity by assigning values of 0 to 10

a. Water pollution

b. Land degradation d. Deforestation e. Loss of biodiversity c. Waste management g. Air pollution h. Climate change f. Land tenure issues i. Noise pollution

3. By assigning a value of 0 to 10 , indicate the extent to which you consider that successive governments since the 1980s are responsible for the prevalence of environmental problems

4. By assigning a value of 0 to 10 , indicate the extent to which the following questions are relevant
a. Political elites are not committed to environmental policies and its management
b. Appointed officials are to blame for the poor state of the environment
c. Lack of resources is to blame

5. By assigning a value of 0 to 10 , indicate the extent to which you consider that the people of Ghana are responsible for the persistence of the environmental problem

6. Indicate to what extent the following are applicable to the people of Ghana in contributing to the environmental problem by assigning values of 0 to 10
a. Indifferent behaviour
b. Ignorance
c. Poverty
d. Illiteracy
e. Lack of alternative livelihoods 
7. By assigning a value of 0 to 10 , indicate the extent to which you consider that traditional rulers are key to the solving the environmental problem

8. By assigning a value of 0 to 10 , indicate the extent to which you consider that traditional rulers are responsible for the persistence of the environmental problem

9. Indicate by assigning a value of 0 to 10 , the extent to which you consider the following to be applicable to traditional rulers in environmental management

a. Inappropriate allocation of land

b. Disrespect of government regulations

c. Failure of government to involve them in environmental planning processes

d. Erosion of their legitimacy

e. Collusion with political elite

f. Indifference to environmental issues.

10. Approximate year of birth

11. Occupation

12. Circle your level of education

a. No-education

b. Non-formal education

c. Primary

d. Secondary

e. University/Polytechnic

f. Post-University

Please answer the following questions in the space provided

13 Name/identify any national guideline/policy/program on the environment 
14 What do you think are some of the appropriate solutions to the environmental problem in Ghana?

15 Who in your opinion should bear responsibility for solving the environmental problems of Ghana? Explain

16 In your opinion, should environmental management be among the top national priorities, given the current economic situation of Ghana? Explain 


\section{APPENDIX 4: Interview and Focus Group Discussion Guide}

The following Interview/Focus Group Discussion guide was employed by the researcher to collect data on central thematic areas of interest to the study. Prior to the use of the interview guide, interviewees were asked to provide information such as age and occupation.

\section{Interview Guide}

\section{Politicians/ Bureaucrats}

a. What is your assessment of the state of the environment so far?

b. Would you say the state of the environment has improved or deteriorated over the past $10-15$ years?

c. What in your view are the salient environmental challenges

d. What are the underpinning causal factors of these problems?

e. How would you describe the country's current approach to environmental management particularly in terms of participation?

f. Is there/is there not an overconcentration of power/responsibilities on the government?

g. In your view, based on your experiences, what is the degree of involvement of the public - NGOs, CBOs and other groups and individuals - in environmental management or governance? 
h. What are some of the existing guidelines of participation for environmental management?

i. How are these guidelines operationalized?

j. Who is involved in important decision-making?

k. How are they involved? At what stages are they involved?

1. Is the current level of public participation in your view, an adequate reflection of the views, concerns of all affected stakeholders?

m. If yes, what are some of the existing indicators?

n. If no, what has impeded / prevented a broad level of participation

o. What efforts are being put in place to encourage broad-based participation?

p. What are some of your concerns as far as environmental management is concerned?

q. What, in your view is the way forward?

\section{NGOs/CBOs}

a. What is your assessment of the state of the environment so far?

b. Would you say the state of the environment has improved or deteriorated over the past $10-15$ years?

c. What in your view are the salient environmental challenges 
d. What are the underpinning causal factors of these problems?

e. How would you describe the country's current approach to environmental management particularly in terms of participation?

f. Is there/is there not an overconcentration of power/responsibilities on the government?

g. What in your view is the best approach(s) to environmental management in Ghana?

h. Where should the onus of environmental management lie?

i. Where is it now?

j. In your view, based on your experiences, what is the degree of involvement of NGOs or CBOs such as yours in environmental management or governance?

k. What can you tell me about the mission, activities and challenges of your $\mathrm{NGO} / \mathrm{CBO}$ ?

1. Has it made any meaningful headway as far as environmental management is concerned

m. What are the main concerns of your organization?

n. What in your view is the way forward?

\section{Community members, Individuals}


a. What is your assessment of the state of the environment so far?

b. Would you say the state of the environment has improved or deteriorated over the past $10-15$ years?

c. What in your view are the salient environmental challenges

d. What are the underpinning causal factors of these problems?

e. How would you describe the country's current approach to environmental management particularly in terms of participation?

f. Is there/is there not an overconcentration of power/responsibilities on the government?

g. How would you describe the overall performance of the government as far as environmental management is concerned?

h. In your view, based on your experiences, what is the degree of involvement of the general public in environmental management or governance?

i. What are some of your concerns as far as environmental management is concerned?

j. What, in your view is the way forward? 